\title{
IntechOpen
}

\section{Globalization and Responsibility}

\author{
Edited by Zlatan Delić
}





\section{GLOBALIZATION AND RESPONSIBILITY}

Edited by Zlatan Delić 
Globalization and Responsibility

http://dx.doi.org/10.5772/2598

Edited by Zlatan Delic

\section{Contributors}

Samuel Adams, Daniel Sakyi, Khuram Shahzad Bukhari, M.Ishaq Bhatti, Hayat Muhammad Awan, Amna Wahid, Jaime Jimenez, Maura Striano, Miguel Marquez, Blanca Munster, Antoine Lutumba Ntetu, Marc Jean, Joao Dias, José Rodrigues Coura, Zlatan Delic

\section{(c) The Editor(s) and the Author(s) 2012}

The moral rights of the and the author(s) have been asserted.

All rights to the book as a whole are reserved by INTECH. The book as a whole (compilation) cannot be reproduced, distributed or used for commercial or non-commercial purposes without INTECH's written permission. Enquiries concerning the use of the book should be directed to INTECH rights and permissions department (permissions@intechopen.com).

Violations are liable to prosecution under the governing Copyright Law.

\section{(cc) BY}

Individual chapters of this publication are distributed under the terms of the Creative Commons Attribution 3.0 Unported License which permits commercial use, distribution and reproduction of the individual chapters, provided the original author(s) and source publication are appropriately acknowledged. If so indicated, certain images may not be included under the Creative Commons license. In such cases users will need to obtain permission from the license holder to reproduce the material. More details and guidelines concerning content reuse and adaptation can be foundat http://www.intechopen.com/copyright-policy.html.

\section{Notice}

Statements and opinions expressed in the chapters are these of the individual contributors and not necessarily those of the editors or publisher. No responsibility is accepted for the accuracy of information contained in the published chapters. The publisher assumes no responsibility for any damage or injury to persons or property arising out of the use of any materials, instructions, methods or ideas contained in the book.

First published in Croatia, 2012 by INTECH d.o.o.

eBook (PDF) Published by IN TECH d.o.o.

Place and year of publication of eBook (PDF): Rijeka, 2019.

IntechOpen is the global imprint of IN TECH d.o.o.

Printed in Croatia

Legal deposit, Croatia: National and University Library in Zagreb

Additional hard and PDF copies can be obtained from orders@intechopen.com

Globalization and Responsibility

Edited by Zlatan Delic

p. cm.

ISBN 978-953-51-0655-5

eBook (PDF) ISBN 978-953-51-5132-6 


\section{We are IntechOpen, \\ the world's leading publisher of Open Access books}

Built by scientists, for scientists

\section{$4,100+$}

Open access books available

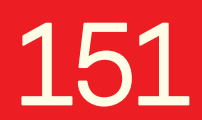

Countries delivered to
$116,000+$

International authors and editors
$120 \mathrm{M}+$

Downloads

Our authors are among the

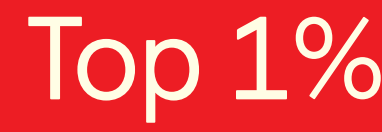

most cited scientists

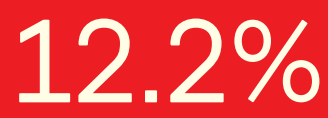

Contributors from top 500 universities

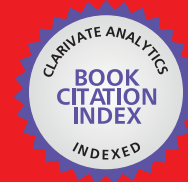

WEB OF SCIENCE ${ }^{\mathrm{TM}}$

Selection of our books indexed in the Book Citation Index in Web of Science ${ }^{\mathrm{TM}}$ Core Collection (BKCI)

Interested in publishing with us?

Contact book.department@intechopen.com

Numbers displayed above are based on latest data collected.

For more information visit www.intechopen.com

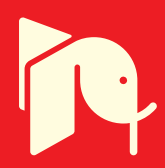





\section{Meet the editor}

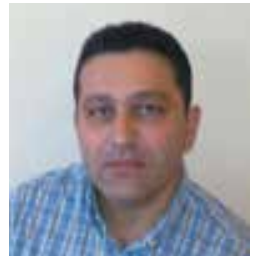

Zlatan Delić is an Assistant Professor currently working at the University of Tuzla, Bosnia and Herzegovina. He has received his MA in Modern Philosophy and his PhD in Social Science. He has published two books, several articles in the field of humanities and social sciences and he has participated in international research projects. He teaches economic sociology, globalization theory, social research methodology, sociology of law and sociology of Bosnian society. Subjects of scientific interest include: sociology of knowledge, methodologies, critical discourse analysis, critical studies of science, technology and ideology, globalization, glocalization, multicultural and social epistemology, sociology of Bosnian society, sociology of sustainable communities, bioethics, social and deep ecology, postcolonial studies and local and regional development. 



\section{Contents}

\section{Preface XI}

Chapter 1 The Consequences of Globalization and Responsibilities: Challenges of Sustaining Development 1 Zlatan Delić

Chapter 2 Developing Educational Practices in the Globalized World 47

Maura Striano

Chapter 3 Strengthening the 'Social' in Sustainable Development: Finding the Impact of Social Sustainability in Business Performance of Hospitality Sector of Pakistan 71 Khuram Shehzad Bukhari, M. Ishaq Bhati, Hayat Muhammad Awan and Amna Wahid

Chapter 4 Globalization and Human Development:

The Experience of Cuba 91

Miguel Márquez, Blanca Munster Infante and Camilo Márquez Cerezo

Chapter 5 How Third World Countries Can Take Advantage of Globalization A Mexican Experience in Learning and Research 113 Jaime Jiménez

Chapter 6 The Stakes of Globalization in the Field of Health: The Tolerance in Self-Regulatory Ethics Perspective, a Solution for Health Professionals for the Management of All Differences 127 Antoine L. Ntetu and Marc Jean

Chapter 7 Globalization, Democracy, and Government Spending in Sub-Saharan Africa: Evidence from Panel Data 137 Samuel Adams and Daniel Sakyi

Chapter 8 Globalization and Chagas Disease 153 João Carlos Pinto Dias and José Rodrigues Coura 



\section{Preface}

Globalization is perhaps only another name to replace the lacking one for what is happening to (with) us humans in the name of techno-bureaucratic, commercial, violent, amusing, consumerist process of creating a so-called global society of knowledge and skills. "Globalization offers both a theory of everything and an explanation of nothing" - suggests J. Annesley in Fictions of Globalization (2006). However, daily deaths of children as a result of hunger, disease and malnutrition on a massive scale in Africa, and elsewhere, is not fiction.

"Being is, and not being also is" - those are the words of a French sociologist, philosopher, and forensic media communication theorist, Jean Baudrillard - which he used to describe what is happening before our eyes. Globalization threatens to undo the last remnants of humanity in us, and it's not just a matter of semantics or importance of humanity.

This book is the result of good intellectual energies. It gives a contribution to ongoing debates about the negative consequences of globalization. In different ways, it implies that the experience of globalization is not identical but different. Many critics have already indicated that it is necessary to expand further the socio-epistemological critique of the following: linguist essentialism, the culture of commercialization, consumerism, seduction and market fundamentalism. The concept of the so-called knowledge economy, as well as the overall process of commercialization of knowledge, is not scientifically legitimate for many scientists. Mostly, because it is closely associated with social dominance, with the symbolic and actual violence, or with the ruling, seductive, and often misleading discourse on the creation of global knowledge society and skills.

Major parts of modern science, with the new knowledge and success based economy on head, have become overly commercialized. Many commercial projects of the socalled development are often irresponsible to people, nations, regions and indigenous communities who would like to live peacefully in their own country and work their own land. We do not believe that there is only one model of economy and technology based on the knowledge upon which it would be possible to easily apply the global knowledge society in all the regions and at all sites. 
Therefore, in future research it is necessary to encourage emancipative, de-centered and socially responsible discourses and trans-disciplinary scientific research that includes scientists of different directions, orientations and preoccupations. It is necessary to encourage new opportunities for responsible methodical doubt on all dogmatic, privileged, aggressive, colonizing conceptions of knowledge. It takes dehierarchized, anti-hegemonic, sentimental, therapeutic, local and regional stories. It takes "microhistory" (Luis Gonzalez) that undermines and brings into question the master language (e.g. in the form of new knowledge economy.) A recent historian, Stephen Greenblatt, argued that the original crime of the "new world" was committed in the name of the language (Stephen Grenblatt, Learing to Curse: Essays in Early Modern Culture (New York and London: Routledge, 1992, 16-39).

The chapters in this book offer a decentered and dynamic terminology. They show that globalization consists of not only an objective process, but also of a lot of statements that define, describe and analyze the different experiences of the process. The chapters are written by authors and researchers from different academic disciplines, cultures and social contexts, therefore different experiences and scientific analyses on the consequences of globalization have been unified, starting from the multicultural and social epistemology to ethics of responsibility.

An open, pluralistic, trans-cultural and interdisciplinary approach to focal problems of today has been tried out. Therefore, both qualitative and quantitative methodologies have been combined, both the positivist and post-positivist, and also postcolonial. In various ways it is shown that our knowledge is socially conditioned and inscribed into the body of language. The list of researched and analyzed problems can be read in a different order, and the same applies for chapters themselves.

Each chapter can be read separately, but in a complex, interconnected global universe of intertextuality of our world. The increase in social inequality, structural and chronic poverty, long-term unemployment, sustainable development, education, health, social responsibility, the deficit of democracy, etc. - are just some of the globally significant and far-reaching issues that the authors of this book have touched upon. To all of them, I owe enormous gratitude.

I give my thanks to InTech for a very good and open cooperation. I owe special thanks to Anja Filipovic. As a Publishing Process Manager, she has helped in the process of making this book.

Zlatan Delić

University of Tuzla

Bosnia and Herzegovina 


\title{
The Consequences of Globalization and Responsibilities: Challenges of Sustaining Development
}

\author{
Zlatan Delić \\ University in Tuzla, \\ Bosnia and Herzegovina
}

\section{Introduction}

Anachronistic simultaneity and 'multiple temporalities' that we live, can easily produce confusion and we already have too much of that, in our so-called global knowledge society. Therefore, we could start with some principal observations. The leading approaches to globalization are those approaches that come from the language and buzzwords of the dominant streams of economic science. Dividing globalization on different dimensions, aspects, lawmakers, opponents, and so on - is also marked by a determined, almost inevitable economic discursive order. Research programs, reconstructions of knowledge systems, liberating perceptions and critical insight of the various researchers - can be expanded or adjusted, especially if we managed to have a balanced relations with epistemological, ontological, ethical and environmental issues but also with other emancipated issues (which were neglected in the 'new knowledge economy'). It is the same situation regarding the social consequences of hegemonic economic discourse of globalization. It is useful to go through the trans-disciplinary approaches and take into account the dangers of 'advanced' recursive, tautological, positivist, linear, reductionist methods that we have been presented with. These methods are very often put forward by dogmatically privileged economists and as such usually don't reflect its own, social or cultural rootedness. However, the crisis of globalization which has deepened over the last decade does not leave much time or space but, in spite of this feverish production of words, "we can hardly move in the consolidation of the concepts, methods and records that would identify and assess globalization" (Jan Aart Scholte, 2005) - the consequences of globalization. We must recognize disparate human experiences of globalization. We tend to focus on the negative consequences of globalization, the ones that upset most people. Globalization is also a symbolic and socially constructed power of appointing, identifying, perceiving, selecting, explaining, and experiencing the world. Its power manifests itself as it presents itself (to act) as a historical inevitability, like some natural force, like gravity. Therefore, globalization is easily converted into globalism - the ideology. According to some social and political thinkers, globalism has become a "strong discourse" - the one that is terribly hard to resist and very hard to dismiss. It's hard, because it has powerful social forces on its side that have already chosen what counts as "real" and therefore they shape 
the world accordingly. Constant repetition and public recitation of the key claims of globalism has the ability to produce exactly what they are appointing (Steger, 2003). Globalization means, first and foremost, global change of language patterns that are in use. Its impact on biodiversity of human language, the discursive order, systems of signification and representation - it is greater from what we are able to see or express at this moment. Positivist approaches to globalization are mainly engaged in various dimensions and aspects of globalization, by encouraging formal classification, uncritical attitude and tabular models of thinking that can easily turn into a dangerous dogmatism. Globalization is certainly multidimensional, but what does it mean? German sociologist, U. Beck drew attention to the fact that "the literature on globalization permeates fundamental controversy." He believes that the answer to the question "what drives globalization forward" has two contradictory responses (that have been divided many times). The first group of authors emphasizes the existence of a dominant "logic", while other authors are working on theories that explain complex, multi-causal logic of globalization. Incidentally, the central theoretical controversy exceeds the horizon of meaning of the word "globalization", because it is often associated with conflicting meanings. At the same time it repeats the historical controversy between Marx and Weber, economic dominance and theoretical pluralism of the economic and socio-cultural approach to the thematic field of globalization sociology. Attempting to push one of the logics into the centre, excludes an important dimension of globalization. Pairing them together (seemingly) and excluding the mutual logic of globalization leads us to the point where various, partial logics of globalization compete with one another. Firstly - we are to talk about the approaches which manage to keep a special dimension and the logic of globalization central. The key authors whom we shall mention here as a common starting point, are the following: Wallerstein, Rosenaua, Gilp, Held, Robertson, Appadurai and Giddens as a common starting point." (Beck, Ulrich: 1999). Privileged economic approaches have imposed their own discursive order and their cognitive assumptions to many other fields of study. These approaches are not sufficient for understanding one of the most important consequences of globalization and that is widening the gap between the rich and the poor. Economic reductionism seriously interferes with, or even prevents, objective study of long-term poverty, structural unemployment, social exclusion and structural irrelevance of certain regions. Key international agencies, such as, the United Nations (UN), World Bank (WB), International Monetary Fund (IMF), Organization for Economic Cooperation and Development (OECD) and World Trade Organization (WTO) - have made many declarations. Such international organizations believe that in this way they will prove dedication to the fight for global justice and solidarity, and that they are against global inequality, poverty, exclusion, etc. Social sciences have the task to demonstrate that such declarations often do not pay enough attention to the cognitive, epistemological-methodological and cultural assumptions. It is on the ground of these assumptions that developed and undeveloped world is put together in the abstract correlation. The economic development criteria, as well as classical and neoclassical measure of poverty, contain significant limitations. These standards have become the subject of dispute among economists such as Karl Polanyi, Joseph E. Stiglitz, Jeffrey D. Sachs, Michel Chossudovsky and many others. The development strategies and policy development is often viewed through the administrative-bureaucratic language, without clear scientific criteria. Development is a complex category. It can mean different 
things to different people. The phenomenon of development, or existence of chronic state of underdevelopment, is not simply a question of economics, nor is it even one of the quantitative measures of income, employment and inequality (Todaro, M. P \& Smith, C. S, 2006). Development is a process that encompasses every aspect of society, putting all the efforts into operation: markets, governments, NGO's, cooperatives and non-profit institutions (Stiglitz). In that sense, generally speaking, it is required to have a better cooperation among economists and other scientists, governments, NGOs, trade unions and public sector. Cooperation is needed in order to avoid economist and reductionist approaches to these problems. However, only when we try and do achieve something like that, we encounter the most difficult theoretical and epistemological dilemmas. One of the tasks that the social science has faced is a critical 'deconstruction' of the wrong approach to the social consequences of globalization. About 80 percent of the world's population lives in developing countries, which are characterized by the low incomes and widespread poverty, high unemployment and low education. Even, the so-called developed countries have perceived their own development problems differently, over the recent years. Economists tend to ignore the social basis of economic activities and rather focus on studying the questions that they themselves benefit from the most. On the contrary, the scientists, generally, have a great responsibility in determining the priorities and objectives of the research they are engaged in. The economists have often pushed increasing social inequality, poverty on the increase, and unemployment in the background, believing that these problems do not concern them. It is similar with other problems, such as environmental degradation, soil pollution, air pollution, water pollution, etc. The critics have warned that these are not problems that are not related to the economy, but quite the contrary. They are deeply connected with the destructive logic of the new global economy. Discourses on globalization from the 90-ies of the 20th century, haven't had any of the implications that it has faced in 2000 and 2001. Over the recent years, confidence in the scientific solidity of neo-liberal economic globalization has dramatically declined and continues to erode. It is undisputed that since the 70ies, and explicitly since the 90ies, the mainstream social sciences began to take the shape of a unique discursive order of globalization, which came into the hands of market fundamentalism, one of the most dangerous ideologies, whose consequences we still continue to suffer. This order is inextricably linked to the institutionalization of what we might call the global politics of knowledge. What we consider by that name, was firstly presented under the signifier of a so-called new knowledge economy. The story of the construction of the so-called new world order and the popularization of various conspiracy theories, arising over the last twenty years, was just a reaction to the cognitive dissonance that arose between beautified language of globalization - and the spiritual and actual misery that has fallen on humanity. The consequences of globalization should be analyzed on the basis of normative requirements for the epistemological unity of knowledge (Masudul Alam Choudhury and Lubna Sarwath Mohammad: 2011) and the principle of accountability which has been neglected for a long time. However, the unity of knowledge is more easily achieved in meta-theoretical discussions rather than in reality. The recent studies have shown that the negative effects of globalization occurred long time ago and that they are primarily associated with the 'rise of capitalism catastrophe' (Klein, 2008), but also with the increasing gap between the rich and the poor. Poverty is a global and regional problem. Poverty is a problem of many communities. The world risk society (Beck, 
Ulrich, 2007) and the crisis of the Western paradigm of the global knowledge society are concerned about the poverty. Poverty cannot be scientifically analyzed, unless we approach it independently and exclude other problems associated with the crisis of 'knowledge society'. The crisis of the knowledge society, tends to destabilize our frame of reference, undermines all stable systems of knowledge, but opens up new research opportunities. The list of problems is long: the crisis of orientation, the lack of public discourse on human responsibilities (in relation to the story about all sort of rights), the commercialization of knowledge, education and research, the growth of social inequality, unemployment, social exclusion, property rights, the right to work, lack of justice, the environment, lack of solidarity, corporate crime, marketing crime, abuse of religion, strengthening the killer identity, violence, lack of corporate social responsibility. The predominance of quantitative techniques in the new knowledge economy requires paying more attention to qualitative methodology and discourse analysis (Sheila C. Dow: 2003) Analyze, for the moment, the very concept of globalization. "The pure concept of globalization," or globalization itself (that what is "transcendentally signified") which we cannot have.

The concept of globalization cannot be included in a scientific theory of globalization. In reality, for instance, we own, or possess, any of the territories. We may appoint it as our property - such property and possession may be in the domain of property rights. But globalization, as such, cannot be possessed. Starting from the logical or philosophical analysis, the concept of globalization cannot be approached from the outside. We humans cannot see it until the end, as if it was from a bird's perspective. Our mind cannot approach it with some divine sight. We need different types of analysis, different epistemologies and different methodologies of globalization. Discursive analysis of globalization can be a useful methodological procedure, if combined with other qualitative and quantitative methods. It is a form of a meta-theoretical, mostly textual analysis, which examines and analyzes the existing approaches, definitions and descriptions of globalization. Discourse analysts and other scientists agree that we need new methods and new literature on methodology $(\mathrm{M}$. Castells: 2000; Norman G. Finkelstein, 2001; Iver B. Neumann, 2001; A. Sen, 2006; U. Beck, 2007.). How was it possible, that a discursive order could produce that what - in the mainstream science - and beyond that, is most often referred to as globalization, and occasionally "colonialism" or "occupation"? Inability to deliver "clean" concept of globalization may be best presented by examples of the inability of non-violent establishment of "pure" culture. Specifically, the idea of a so-called "pure culture" (Zigmunt Bauman) - whenever there was an attempt to implement it somewhere - in reality, has always been associated with the symbolic and actual violence - with the excessive use of force. In this sense, discourse analysis is important because it draws attention that there is no such thing as a pure concept of globalization. Also, we must accept the uncertainty that lies in the issue of a difference between reality which has been understood as a physically given reality and the reality perceived as a social representation (Iver B. Neumann, 2001). After "consuming" the neoliberal form of globalization for twenty years, people everywhere are coming to a conclusion that what is considered to be a globalization is not a good thing. Analysts of discourse seem to suggest that what they said was never sufficiently based on knowledge about what is actually happening in the name of globalization. Discursive analysis that has not given up on the most important tasks of philosophy, such as - the truth, justice and meaning of human existence - would have much to say about the negative 
consequences of irresponsible use of the discourse of globalization. By discourse we mean several things: the language or mode of argumentation, discursive practices, socio-cultural practices and other similar things. However, the critique of the economic discourse, which is not very developed, has just begun to acquire a number of additional, sometimes unexpected meanings. Among discourse analysts, as well as among other groups, the struggle about the necessity of pluralism is never ending. If the notion of a discourse is so narrow that it can only mean one thing, then violence is carried out over a range of other fields of use (Iver B. Neumann, 2001). As we were taught in the Critique of Judgment (1790) by Kant, philosophy does not serve to set infinite expansion, but to set the determination of those limits within which they must firstly reject the prejudices, misconceptions and deviations in order to create some room for understanding the truth as it is. Globalization synonymously indicates a world without borders, and the way we perceive it and believe in that truth will actually prove whether we are able to get rid of our prejudices and misconceptions. In this sense, it is reasonable to assert that there is not such a thing as a conflict-free, referential frame of knowledge about globalization. However, there is a need to try to find the biggest failures and delusions of globalization. The most common misconception of globalization is associated with neoliberalism, or in other words, with the disastrous impact of the neoliberal discourse on economics and globalization in general. But a retrospective critique of the neoliberal discourse about globalization does not mean that we have entered into a post-global time. Unless we rely on a pseudo-logical capitalist trick and the current stage of the overall global crisis and call it a "post capitalist society"- like Drucker (Drucker, Peter: 1993). In one, perhaps crucial sense, the era in which we live is no longer possible to simply designate. We could appropriately call it the age of the anachronistic simultaneity (Derrida). The dilemma on whether the discourse of globalization has too much of the social and too little of the textual or it is the other way around is not just a theoretical dilemma. The fact that the discourse of globalization cannot be separated from what we are talking about - is a sign that it is necessary to draw attention to the consequences of globalization, and not only on what we can or cannot say regarding them. Therefore, discourse analysis, as a very fruitful postpositivist method, is primarily based on the analysis of the irresponsible use of the globalization discourse. There is an enormous amount of literature, texts, programs, proclamations, slogans, pamphlets, flyers, and various movements around the world - they all have something to do with globalization. But the very concept of globalization has become inert. People think too little about each other's social or spiritual connection. Moreover, what we think about globalization and what we say or "conceal" (Wittgenstein) has become more complex. The concept of globalization, which could be socially useful in the 21st century, is not possible to impose as if it was a certain decree. The ruling conceptions of society are mainly based on some kind of discursive imposition of terms. The monopolization of terms has a lot to do with a misuse of terms. However, critical sciences, and global social theories, cannot impose terms that are to be used in each and every society. Instead, the critical science deconstructed those discursive regimes that have a monopoly on knowledge about knowledge, including knowledge of the alleged globalization. Great thinkers, preoccupied with first (or last) metaphysical issues, have an insight into the limits of the human mind, at least in terms of its use. Some have concluded that there is no heaven for concepts (Deleuze \& Guattari), and that all concepts are processed in people's hearts and minds. Thus, the definitions and concepts change over time and space. The terms may be 
used for different things. For instance, a few things - related to marketing - can function well without words. Marketing, for instance, can function well on its own without the discursive analysis of the final effects of their own functioning. But marketing cannot function well without the analysis of financial statements. Criticism of the discourse of globalization cannot separate the effects of the social philosophy and the social effects of advertising discourse in advance. What discourse analysts can do is to warn that it is necessary to constantly keep paying attention to the discursive strategies of speech on globalization. Also, critics of discourse may indicate the need to build some alternative pedagogy of concepts which we use to talk about the consequences of globalization. The philosophical analysis of concepts is very rigorous, "The concept is therefore used as a cover-up of certain, and hence countable items. To perceive it means to have something in your "hand" or a grasp of mind. If philosophy can be defined as conceptual analysis, it would seem to follow that "we have" a sense of the term, or (as strange as it may sound) farm of a farm property. If you cannot provide any conceptual content to the metaphorical characterization of "thinking like properties", then it becomes doubtful, to even say, that anyone has the right to insist that philosophy is the equivalent of a single instrument, namely to the conceptual analysis (Stanley Rosen, 1980). It is also true that the use of "term" globalization is the social problem. We cannot understand the problem of its use only in terms of endless disagreement over the meaning. "People just talk about globalization," as Wallerstein once noticed. The critique of the "empty talk", has suggested that globalization is, above all, concerned with the responsibility for the consequences of what we do. First of all, we could say, for instance, that the post-structuralism, 'deconstruction', new knowledge economy, marketing, feminist theology etc - if we treat such discourses as separate research areas - are not sufficient to radically deal with the problem of the negative consequences of globalization. The critics of the theory of economic development have observed and noticed that science, government and marketing is based on the system of knowledge about man, society and nature, for which they claim to be valid everywhere and for everyone. Since knowledge has successfully removed all traces of their own origin, time and environment, it does not belong anywhere, and therefore can penetrate everywhere. In a sense, (1) mechanical causality, (2) bureaucratic rationality and (3) the law of supply and demand are the rules that have been cleared of any attachment to a particular society or culture. No wonder that, throughout the history, we encountered subversive movements that have advocated a simple lifestyle and asceticism. The rich society today represents a threat to the survival of the planet, and their material wealth is actually an indicator of their cognitive misery. From its earliest impressions of the 60 -ies of the $20^{\text {th }}$ century the notion of "globalization" is used in both popular and scientific literature to describe the process, state, system, power and time. Due to these conflicting marks and the different meanings that they imply, their uncritical use is often vague and misleading. For instance, combining the process and the state encourages the creation of circular definitions which explains very little (Steger, 2003). Concluded from the previously mentioned, it is possible to conclude that the uncritical use of globalization causes confusion. Also, it suggests that scientists should turn to criticism. Criticism is an important element that makes the science function. Criticism could eliminate, or at least minimize confusion about globalization, which contributes to the increasing presence of essentialist, uncritical literature. The term essentialism implies a form of discursive order which cannot review the social implications of their own functioning. In the 90ies, neo- 
liberalism has successfully presented itself as a force that helps the process of modernization and dynamism, accusing the labour movement, left wing and labour union for conservatism and hostility towards technological advancement. At the same time, the faith in progress and development started to shake. The period from 1992 - 1995, was marked by a so-called "humane resettlement of people" plan in the name of the implementation of the so-called "clean and pure cultures of ethnic territories" (in the government of Serbia during the Milosevic regime, and then in the government of Croatia, during the regime of Franjo Tudjman). The plan was founded in the Serbian Academy of Arts and Sciences in Belgrade. What came next was the misuse of religious officials and the church, with the homogenization in the background as well as mobilization, and organizing for the purposes of an aggressive war. The implementation of the previously planned forced displacement of population, ethnic cleansing, deportation (genocide) happened on the territory of the multicultural and internationally recognized state of Bosnia and Herzegovina. Since the end of the WW2 in 1945, it was stated all over the Europe that genocide is never to happen again to anyone, anywhere. (This statement probably meant that it cannot happen again - but it did). After that, an act of plundering occurred in the name of free markets and democracy mainly through privatization. It was a rough ethnic privatization of the assets of the working class, which was created in the long decades of hard work. The negative consequences of neoliberal globalization, and the social effects of free markets and privatization, have been more salient than positive ever since. Firstly, the power and influence of individual countries (or even entire regions), particularly of the developing countries, are getting weaker. Secondly, the risk of instability in financial markets are getting higher (as seen in the 1995 Mexican crisis, the 1997 Asian crisis, crisis in Turkey and Argentina in 2001 and crisis in Greece, Italy, Spain, Portugal and many other countries). The global financial crisis is related to a whole network of others: global, regional and local geoeconomic, geopolitical, trans-cultural and orientation-related crisis. The crisis has been associated primarily with the cognitive and social-epistemological crisis of the very idea of knowledge society, with a crisis of economic, political and trans-cultural identity of the EU, but also with the encouragement of the Balkan neo-fascist genocidal fundamentalism. The most obvious example of the crisis of democracy is the negation of the idea of cosmopolitan living together on the ground of the European continent. At this point we have an institutionalized racism, created by an international mistake (or with an intention), such as: geopolitical act of installing a genocidal formation of Republika Srpska in the heart of Europe. It happened on the ground of Bosnia and Herzegovina, an internationally recognized state. Institutional reward of ethnic cleansing is in favor of the monstrous idea of achieving the so called "pure culture", as was formulated by Z. Bauman. World financial crisis is intertwined with the unintended consequences of market fundamentalism, and takes the form of international geo-political and geo-economic crisis which threaten to undermine peace in the world. The fact that capitalism has become a global system makes it also sharper and a lot more unbridled (Kagarlitsky, 1999). The theory of globalization has suffered some criticism over the recent years. The major objections were related to the fact that the neoliberal globalization of the world of life entailed excessive dominance of epistemological fundamentalism (an example is the predominance of commercially motivated actions such as "Quantifying Quality" even in the areas of education, or human health). In general, with the help of the new knowledge economy, neoliberal globalization contributed 
to the spread of essentialist, monistic and internist methods and procedures of knowledge. The economic dimension of globalization, determines all the other dimensions, especially by emphasizing the commercial picture of globalization. Such a picture mostly suited multinational companies, or interests of a handful of individuals. They get (and use) an opportunity to usurp and almost infinitely expand its social, cultural and political power. Commercial picture of globalization is, in essence, one-dimensional and reductional. It encourages consumerism, infantilism and social irresponsibility, and enables the formation and cultural reproduction of one-dimensional structure of personality. Therefore, commercialization, in all aspects, especially in the terms of commercialization of knowledge, has long-term negative consequences for the wider interests of the public good of a huge number of people. The new knowledge economy is not value neutral, but on the contrary, it is completely imbued with the capitalist strategy of commercializing the idea of knowledge. In this sense, it is (or can be) cognitively very limited. In fact, the stylization of the economic ideas of knowledge is characterized by the absence of reflexive, spiritual, emancipated multicultural, critical, pluralist, and post-colonial experiences of what we call a global reality. In contrast to the reductionist conception of the idea of knowledge, which is promoted, expanded, and distributed and upon which they impose commercial discourses and institutions, there are many sets of critical approaches to knowledge. These approaches do not belong to the mainstream science and are not rooted in privileged institutions of knowledge and power. They are characterized by being open towards different experiences of globalization, pluri-perspectivism, and multi-cultural epistemology. Also, insisting on a higher principle of social responsibility of science is not uncommon for the critical approach. The critical approaches are based on differently perceived holistic philosophy of knowledge. Such approaches represent the unity of science and universal environmental ethic. The results are reached in equal communication, which can consist of completely different and even disparate experiences of imposing neo-liberal concept of globalization. The critical approaches to globalization are not even nearly unambiguous. The differences come from there because such approaches include deepening of the main currents of post-positivist emancipated, hermeneutic, phenomenological, feminist, deep-ecological, and post-normal research, practice and experience. Without attempting to impose definitive conclusions, all of these critical approaches have something in common and that is that they recognize the value of open and dialogical forms of knowledge which can be put in the service of the common good and the welfare of most people. Analysis of the discourse of globalization, as a post-positivist method of knowledge, consists in the fact that we pay attention to the archeology (Foucault) of the language of globalization. Also, again and again the less visible, the underlying assumptions and metaphors are being analyzed which contribute to building a particular argument. Language of globalization is not seen as an unproblematic, conflictfree system of concepts that refer directly to things and phenomena. It would be right to say that the focus is on the construction of social meaning, and that language is analyzed as a discursive order (specific socio-semiotics spheres) and it is a part of the overall social system. This order has its own rules and its own logic that dictates, and reproduced again and again the reality that we are talking about. In this sense, critical discourse analysis of globalization reveals a remarkable power and consequences of the appointment, because the way we name things, dictates the meaning that we are to ascribe to phenomena and how we evaluate them. The symbolic and the real impact of globalization on people and nature, is 
huge. Thanks to M. Foucault, we know that knowledge and power are connected. Nowhere is this more evident than in the symbiosis of the so-called "new economy of knowledge" and the politics of knowledge in the dominant trends of economic science in the West. The new knowledge economy, from the 1990s, based on the ideology of market fundamentalism and the technological determinism, was linked with the global political economy of power.

The new knowledge economy has solved a fundamental epistemological problem of establishing knowledge - or its own foundation, in other words - by declaring itself to be a knowledge-based economy. Knowledge is very simply defined as an IT collection of useful information. The whole field of ontology or metaphysics of knowledge, new knowledgebased economy, has reduced it to "information." The rare warning that knowledge cannot be reduced to information, has not met with the approval of the mainstream economics. For the new knowledge economy to avoid being placed in an air-free space, it was necessary to view society as if it was permeated with knowledge and that explains the quick change of the title into an information society of knowledge (and skills.) Relationship between "knowledge" and "skills" were able to be set up completely free, since society is reduced to the market, and all social relations could be established on the model of market relations. The critical expression of "market fundamentalism", which started to be used after some time, and which wanted to warn that society cannot be reduced to the market - came too late. The only fundamentalism, which the global public is constantly "being bombarded with," is another form of fundamentalism - Islamic fundamentalism. As formulated by Eriksen - on 11th September in 2001, the world was hit with one stone and thrown into an uncomfortable and paranoid time, in a war without front lines, a conflict, without limitation, with a clear beginning, but with an uncertain end. Cues for the globalization of the 90ies were the openness, freedom of flight, the Internet and the aircraft traffic on the increase. Cues for the following ten years of globalization are AIDS, threats, controls and the police state. We could cite various examples of long multiple-decade effects of U.S. foreign policy but it has already been done and nothing is accomplished. It is therefore worth quoting Eriksen when who says: "All the intellectuals who do not want to be idiots when it comes to a scenario of a conflict between" the West "and" Islam ", must focus their main priority on the strategy, which reduces the mutual enemy forces, now" (Thomas Hylland Eriksen: 2002). If we are to understand suicide terrorism, we must carefully examine the wider socio-political context in which it occurs. If we are to mention a quote that explains the spiritual poverty of companies, when it becomes trapped in fundamentalism, then here is one: "We live in a fundamentalist world because the fundamentalists have such a strong impact on so many of our institutions - religious, political and economic. I am not saying that there is a global conspiracy of fundamentalisms. Fundamentalists of one area are not necessarily in agreement with the fundamentalists of another - and so that can often lead to a turbulent, mutual disagreement. What is particularly evident in the field of religion is that Christian fundamentalists reject the claims of Islamic fundamentalists and vice versa. Each side claims that they are the only ones who "know the truth," which was discovered only, solely and exclusively to their prophet. There is no disagreement in this part of their faith. The definition is that monotheism cannot stand the rivalry... Religious fundamentalism is exclusive by nature - either you are within the circle of devoted believers, or you're against them (S. Sim, 2004). It is more or less the same when it comes to market fundamentalism, when it mastered the world's economic, political and educational institutions - as it 
happened after 1989. Market fundamentalism is a thoroughly documented phenomenon in world civilization (the term was made up by George Soros). Some commentators find the International Monetary Fund and World Bank to be a threat to the world peace and harmony. According to Sim's observation, an Islamic scholar Akbar S. Ahmed was one of the first to draw attention to the negative effects of the policy of the IMF and World Bank toward the Third World countries. However, it is not particularly important who among the scientists drew attention to that what many other people noticed as well. Today, there are many who will speak of market fundamentalism as a dangerous catalyst of other fundamentalisms. It is possible to specify a number of examples of the negative consequences of market fundamentalism (Africa, Russia, Southeast Asia, Argentina and so on). They all witness to what can happen when the free market economy (it turned out that not even some of the most developed countries followed the rules of the very policy that they themselves imposed), is imposed, without any alternatives, on the countries that lack the necessary social and political structures that could enable this program to be implemented. The fact that in the circles of media, political, scientific and other public discourses, we can talk about a variety of different fundamentalisms often remains unnoticed since there is a tendency of selecting our perceptions. The recent American philosophy text, for instance, is a good example of how it is possible to work on a symbolic extension of the social conditions for the creation of a global liberal democracy with the use of ironic critique of "methodological essentialism". There would be a minimized possibility of humiliation, glorifying violence or a violent attitude of people towards one another (Rorty, 1989), in such a society. It is true that the best way to get the people to suffer constant pain is to humiliate them, display the things that they value the most as useless, superfluous and without force. 'Imagine', says Rorty, 'what happens when the child's precious things things which help the child to create fantasies and also things that differentiate that child from other children - to be re-described as "rubbish" and "rejected". Or what happens when you make fun of such things, in relation to other things, that are in the possession of a wealthier child. Something like that is probably happening in a primitive culture when it gets occupied by another, which is more advanced. Occasionally, the same thing happens to illiterate people in the presence of the intellectuals (R. Rorty, 1989). The comparative study of various types of fundamentalisms is a sign that the central problems of globalization and the global knowledge-based society deeply imbued with pragmatic and socioepistemological issues. (A. Sen, 2007; T. Coady and M. O 'Keefe, 2002; E. Hobsbawm, 2007; Monbiot, 2004.) Here we come up with a series of paradoxes. The central paradox is that the new knowledge-based economy, which is basically a part of a global knowledge society, is deliberately getting rid of its own self-reference, while developing its advanced vocabulary. In fact, it does not call for an epistemological tradition of philosophy of knowledge, but it builds its own philosophy (the so-called business philosophy) and its own ethics (so-called business ethics). Is business ethics as a discipline, meant to be in the service of corporate interests and to what extent? Is it meant to be a servant to a new knowledge based economy? Professors of business ethics have recognized it and stated that: "Teaching on the course of business ethics can be a difficult and demanding task. Many students come to study business economy in order to become rich or to at least try to make a good living. They believe that the capitalist business world is some kind of a jungle where only those with best skills (and most competitive ones) manage to survive. In the view of this light and 
regarding the business, ethics is far more than just the moral action in other parts of a human life. According to one of the American, "Business ethics is the ethics of poker," Bluffing and cheating is allowed in poker. (Norman Bowie, 2007). After 2011 years, the discourse of globalization is still inherently controversial and completely at the service of the power that it determines. The radical power produces its own impotence because it causes even more powerful one - a radical opposition to power. The greatest power of globalization is placed in its very discourse, the discursive order and its institutions of knowledge. Power is therefore connected with the knowledge and has always been rooted in the policy of nomination of that what we build a world of meaning on or even knowledge itself. Only the name you give determines what a thing is or what it may become the future. Each policy of appointment also means the demonstration of certain power. However, in its ultimate effects, which are manifested in the impossibility of reaching transcendental signifier - the politics of appointment reveals its own impotence. At the end - what we learn from poststructuralism and deconstruction is that - the name never refers to the thing itself. The politics of appointments fully identifies words and things, and therefore invokes its own discursive failure. After twenty years of fruitless debate over globalization, we have entered a new era of dogma (S. Sim, 2004), which is more destructive than the previous one we had. Preferential flow of the Western science claim that the world is making a progress and it is developing, as a whole. It has been constantly pointed at the fact that we live in a free and democratic society of both creative and equal opportunities. We have been told that we live in the era where science, technology, innovation and creativity rule and we live in a global knowledge society. It is true for those who have access to all of this, but it is a lie for the biggest number of people living on the planet. Many people suffer from the consequences of poverty and have been humiliated. We live in a world of fear, in a destructive world of unwarranted violence against man and nature. We are trapped in the nets that we ourselves have forged. The future causes us to tremble. We flounder in our own self-deception and forget "the oblivion of Being" (Heidegger). We are in the networks of a meaningless production of fear of another man and of a continuous media production of mortal enemies. Civilization has reached a critical stage when what is called a civilization turns out to be the greatest enemy of civilization itself. The responsible scientists have warned that we have entered the era of dangerous fundamentalist ideas and ideologies - the world risk society (Beck, 2007). We live in an irresponsible, dissolute, consumerist, foolish, barbaric society. The society which has been described by pessimistic authors as a controlled society, society of surveillance, violence, mistrust, manipulation, and organized corporate and media control over the body, mind and emotions. We are exposed to strong biases, stereotypes and unseen - an almost unprecedented violence. Many authors assume that something has gone wrong. That, what the world history perceived as wrong, is linked to the modernist, colonialist, imperialist and neo-imperialist strategies in many ways, as well as with the current global policies of a well-known spreading of ignorance. The colonialist strategies of developing and advancing the notion in the past, was recognized through the grandiose metaphysical systems (so-called absolute knowledge) from the arsenal of great philosophies in the West, for instance, in objectively idealistic strategy of constructing a so-called scientific "views on objectivity" (Hegel). What seems to be the problem and the biggest misunderstanding in different discourses on globalization? Global politics of appointments carried out in the signifier of the globalization discourse, wants to impose a black-and-white, 
bipolar, murderous global perspective on the identity of the world, everywhere. Maalouf, for instance, speaks of the "murderous identities" precisely in the context of globalization and the need for belonging. A serious misunderstanding of religions - if such a thing exists is also affected by this deadly logic, resulting in a global turmoil in our hearts and minds: "Such turmoil can be expressed in the following way: Is globalization just another word for Americanization? Will not its main effect be to impose a single language throughout the whole wide world, as well as the same economic, political and social system, the same lifestyle, same scale of values that they have in the United States? (Maalouf). Indeed, it is worth thinking about the deeper, epistemological, social and other reasons why, the view that the totality of the phenomenon of globalization is a deception, is expanding more. Yes it is a "dust thrown in people's eyes" (Wallerstein, 2003); The domination hidden in Trojan horse, or is it that the globalization has opened a representation of the impossible, yet possible, strategically guided special war being waged between the different, complementary in essence, competing, self-injurious, and therefore false fundamentalism causing immense damage to all of us. Discursive order of the privileged image of globalization tends to get organized and selected through the exclusionary categories, such as: "we" - "they", "our" - "their", "good" - "evil", etc. After a series of an "impossible / possible" event - which happened - after 2000 - a new army of experts emerged out and imprinted new, beautiful words in a receptive canvas of our post-traumatic consciousness: the "clash of civilizations"- they wrote:"axis of evil", "Islamofascism", "Homeland security"(Klein, 2007). We encounter a difficulty by trying to explain the history of the ideological crusade that reached its maximum through the radical privatization of war and disaster. This difficulty, as Naomi Klein explained, is about ideology: an ideology changes its shape - and changes the name and identity forever. Friedman, for instance, called himself a "liberal", while his American followers - associating liberals with taxes and hippies identified themselves as "conservatives", "classical economists", "supporters of free markets" and, later, fans of "Reaganomics" or laissez-faire economics. In most parts of the world their beliefs are called "neo-liberalism", but also the "free trade" or simply put, "globalization". Only during the second half of the 90ies, did the intellectual movement, led by the leadership of brain trust, which Friedman has linked with, - Heritage Foundation, Cato Institute and American Institute for Entrepreneurship - proclaimed to be "neoconservative", thus presenting a worldview that is in the service of corporate plans, he clamped down all the strength of the U.S. war machine. All these incarnations have affection programmatic trinity in common: (1) removal of the public sphere, (2) full liberalization of the corporation, and (3) radical cuts in public spending. The only problem is that none of the names of various ideologies sound appropriate enough (Klein, 2007). Globalization can act on the behalf of more than one name. All of these names feel free to fluctuate in different discursive fields and gray zones of questioning of knowledge economy, power and useable information. Perhaps the biggest fallacy of the popular (supportive) globalization image is the shallow faith in the alleged clash of civilizations. In his book How Soccer Explains the World: An Unlikely Theory of Globalization, Franklin Foer puts it very nicely that some people "are experiencing football deeper than religion." Of course, this is referring to the fans. What do the fans do? They are cheering. Supporting whom? The answer is "ours". They are against the opposite team, against "their team". It's always "us" and "them", "we" against "them" - "them" against "us." It is a very simple logic. However, it is completely wrong, as 
well as a pamphlet on the Clash of Civilizations. Starting from the game - through the war to the fight that will last until the Judgment Day or Death? The power of militant pamphlets lies in the fact that it is primarily addressed to the masses, mental "fans" (who believe in them) and not thinkers or analysts of discourse. The world is not the same to someone who reads certain authors such as, for example, Derrida and Chomsky, compared to someone who does not read them and still believes that violence in stadiums or around the stadium is justified. In violence, or even wars between fans, such as Arkan's (Franklin Foer wrote about him) it is required to have the highest sense of one's individual existence. The media are in the service of interests of powerful men. The media does not educate people that selling sport players is a postmodernist version of the colonial "slave trade", or selling out the football matches so the sport betting could profit on the present global, regional and local levels. Excited, loud voice of sports commentators (with too much shouting) never makes it known to fans that their cheering support is hopeless in such situations where the result has been pre-set: They do not say that their cheering is pointless and humiliating. Supporters see the ball and not the game that is being played. Fans are the ones cheering and not the ones thinking. The first sentence by D. Mabot written in his ethics is: the man has a responsibility to think. Of course, opinions cannot be prescribed by a decree - such as Bologna. This global collective "we", that universal, indispensable deputy is present whenever we talk about universal human rights or duties, something that we will discuss later in the text. In some contexts, globalization can mobilize the masses to the level of arising fans' passions and emotions: as a particular flag, motto, or song. It can be a common buzzword, a rhetorical tool for something else. Today's mass media - often with the help of marketing, systematically distorts our view of any of the really important issues such as global democracy, justice, solidarity and survival of a mankind. That, what is specifically done in the name of globalization, can therefore take any name or form: civilization, culture, freedom, democracy, free markets, technology, new economy, information, knowledge society, the informal market, informal economy, and even so-called war against terrorism: "When the market goes too far in dominating over the social and political outcomes, opportunities and benefits of globalization are spread unevenly, concentrating power and wealth among a selected group of people, regions and corporations at the expense of the majority" (Steger, 2003). In a very concessive way, it is possible to distinguish between the three basic views on globalization - neo-liberal, reformist and radical:

1. Neo-liberalism in the market recognizes "the fundamental strength of a human benefit, freedom, democracy and peace." That's why the state border should not and must not be an obstacle "to an efficient allocation of resources in the world economy", and in the same way a state must not intervene in the economic sphere - the "Control of globalization" should be left to the global markets, which should work without any formal restrictions. Neo-liberalism as the dominant conceptual and policy framework should encourage governments and multilateral institutions (IMF, WTO). Multilateral institutions advocate privatization as a measure to reduce state ownership of productive resources and they suggest that states work on reduction of expenditure, guaranteeing social well-being, thus opening up the possibility of market mechanisms in pension and health care policy as well as in other areas of social security.

2. A reformist approach generally accepts globalization and its driving forces (capitalism and modern technology in an attempt of proclaiming the global social democracy, rational application of knowledge, market ...), but it also requires some corrections, and 
is committed to the implementation of global social democracy. The foundations of this approach can be seen in Keynesian economics, New Deal, Great society in the U.S. and Western European welfare state. Reformism recognizes the strong drivers of social welfare in capitalism, but believes that the public policy plays an important role in achieving positive results. On the one hand, wild capitalism produces personal, social and environmental injustice, and, on the other hand, the global market can fail. Therefore, it is necessary to introduce corrections in the form of political intervention of public institutions. The reformers, therefore, do not believe in "immaculate" nature of capitalism, but instead they advocate the measures to promote its positive and suppress its negative potentials (e.g. antitrust measures to limit the power of corporations). Some believe that the national strategy is not an appropriate tool of managing global capitalism and therefore advocate for the global public policy in which supranational institutions would play an important role (rules of conduct of global companies, global environmental regulations ...). Thus, as some authors noticed, the IMF should create a mechanism for the establishment of greater stability and fairness in global financial markets and global institutions should pursue programs that would improve the state of the global economy of the disenfranchised.

3. A radical approach advocates reversal of globalization, or its continuation, but in a different structural basis. It is possible to distinguish between two types of radicalism: a) a reactive traditionalism and b) proactive radicalism. The first one is in favour of preventing globalization and going back to the idyllic, autarkic pre-global state, because it seems that de-globalization is the only way to restore economic security, ecological balance, cultural integrity and democracy. These and similar ideas are usually represented by environmental radicals, but also by economic nationalists and groups that support going back to religion. Proactive radicals accept the continuation of globalization, but want to see it on different grounds. A wide range of diverse actors and movements such as worldly movements of workers, women, the oppressed by postmodernist critics of contemporary society belongs to this group. Considering that radical approach to globalization failed to achieve a stronger influence on the official institutions, and neoliberal reformist approach, they still continue to fight for total domination, outlining an old controversy about the extent to which states (in terms of nation-states) may interfere with the functioning of markets. Here we should point out that the last three decades - and the level of international relations - was marked by a significant predominance of the neoliberal approach. Among the different concepts of globalization, there are those that oppose her and have other tendencies and processes which are equally strong and far-reaching (Kalanj, 2001; in Marija Geiger Zeman and Zdenko Zeman, 2011).

For instance, Benjamin R. Barber recognizes not one, but "two-axle principle of our time": "globalism" and "tribalism." According to the interpretation of Roland Robertson, Barber represents the notion of globalization as a sharp opposition to the world of the local, but Roland Robertson rejects this approach. Instead, he advocates the concept of globalization, which includes a "simultaneity and interpenetration of what is conventionally called the global and local" (Robertson, 1995). To emphasize this close relationship and interaction between global and local further, Robertson reaches for the concept of glocalization, which was made up, according to the Oxford Dictionary of New Words (1991), in order to combine global and local mix in a way that will allow them mutually beneficial intermingling. 
According to another dictionary (Oxford Dictionary of Sociology), the concept of glocalization means "global localization" or "the process through which global processes, such as the activities of transnational companies, result in the preparation of local, specific goods" and "Communicating specific information back into the global system" (Scott \& Marshall, 2005). According to the Oxford Dictionary of New Words, the idea of glocalization emerged from the Japanese term dochakuka (derived from dochaku "live in their own country"), which originally signified agricultural principle of adapting one's farming techniques to local conditions, so that the Japanese business practices would take them and reinterpreted it as a global localization and global approach adapted to local conditions (Robertson, 1995). Robertson states that global is not opposed to the local, but on the contrary, states that "what is often meant by the local, is included within the global" Discursive form of globalization, which tends to provide absolute power for itself only causes a radical resistance. The very existence of globalization - no matter what you meant by this opaque name - will depend on its radical transformation. Globalization does not recognize who her true friends or true enemies are. If we could imagine philosophy to be a friend of the concepts, then globalization, as an absolute discursive order can easily become an enemy in terms of freedom and opinions. Driven by commercial and corporate interests, marketing seems to be the only heir (prematurely discarded) of philosophical wisdom in the Western world today. Connecting the spiritual sense of philosophy and the consuming interests of marketing is logically impossible. The movement for global justice has developed thousands of websites, magazines, videos, pamphlets and books, which may serve as competing sources of information on many global issues. Marketing is a recent invention, an innovation. It is the manifest of the absence of thought - and a pure negation of philosophy. Marketing is a privileged place for the control of our mind, body and emotions; a holiday of seduction: an organized deception, lie, deceit, illusion, delusion. Marketing has declared itself to be a science. The manifesto, that they have agreed on, could be interpreted as a symptom of profound crisis of identity in Western science, but also as the sign of the great issues of free thinking and responsibility at all. Marketing itself has twisted and subverted science, metaphysics, ontology, epistemology, hermeneutics, aesthetics, ethics, ontotheology and so on. Marketing has used its big lies and illusions, from all sides, to occupy the language of the new knowledge economy. Marketing has turned time into money, space into the market, the man into the consumer and the service user (e.g. patient = client, or student = 'satisfied' customers), and the thinking into a lucrative calculation. Human beings are turned into "human resources" - the means for achieving goals created by the marketing, capital logics, and corporation. For instance, in some schools in the Balkans it is now evident that they have introduced a subject called consumer rights. That way they teach children from an early age, about consumerist mentality. They encourage the consumption, wastefulness, branding, stereotypes and irresponsibility. They only superficially speak about the rights, needs and desires of consumers (e.g. The Universal Declaration of Human Responsibilities / die Allgemeine Erklärung der Menschenpflichten/ is not mentioned). An act of discrimination is present, since the children are forced to differ mutually. In some schools, children are even physically separated into different classes (a so called phenomenon of "Two schools under one roof "), sometimes just because they have a differently written or pronounced name or surname that a child accidentally inherits (from someone else) in their first or last name. Under the influence of right-wing Cetnik's politics 
in Serbia, some politicians in certain parts of Bosnia and Herzegovina from 1992-1995 committed a large 'ethnic cleansing' of non-Serb population. Today, with the great help of the international community, they represent a globally dangerous idea that co-existence of people of different ethnic or national origins is not possible in reality. International support of such ideas can inspire new genocidal plans and projects, and lead to new ventures and new ethnic cleansing genocides.

The responsibility of intellectuals, journalists, media, citizens and world democratic era of globalization is vast. The commercial media has been filled with emotional and social intelligence of children and adults as well as frequent advertisements which are constantly displaying quick and moveable images. Commercials can be effectively advanced and they can improve the processes and the minds of children, and sometimes completely eliminate the need for complex cognitive processes of personality learning and maturing. Advertisements are not limited by the boundaries of time and space. Advertisements urge people to desire what other people want them to desire. They ignore the deeper-based natural cycles of day and night. They ignore the harmony of life and social world. For instance, large illuminated advertisements in cities affect the living beings, because they amplify light pollution of the environment. Globalization of the media, as well as the use of new media, can result in unpredictable consequences. Therefore, it is generally wrong to speak about globalization only in terms of positivist, advanced categories, or in only negative terms. Almost everything that comes in the name of globalization, comes along with something else, in the name of something else - the discursive order of the new economy of knowledge occurs, for instance, as strategic management, the manipulation of resources: time, space, identity, or career. The new knowledge economy is becoming a political economy of a signifier. It is a deeply politicized discursive and visual production and consumption of signs, pictures and information. And what we, at some point, generally can address as a piece of information or knowledge appears to be something else, at another point. The very discourse of globalization has turned into a very important item intended for public consumption (Stegar, 2003). Globalization was supposed to mark a single borderless world but the reality proved it to be more seductive than capitalism and communism. Globalization has linked the goals and means, and it is often that means determine goals. There is battle against the negative consequences of globalization because the man has become a mere tool of corporate interests and goals of capitalist globalization. The statement on the inevitability of globalization depoliticizes public discourse on globalization. The ideologues of globalization (intellectual advocates of globalization) are those people who deny or minimize the negative consequences of neoliberal forms of globalization (globalism). They argue that globalization is an inevitable force of nature like time or gravity. They claim that people only meet the principles of the world market, and that alone these laws require the elimination of any regulation or control of globalization trends. Thus, the ideologues of globalization of the 90ies could convince a large part of the public that the state has become a surplus. It has been written that our concept of society is no longer useful, because there is globalization to replace it. Justin Rosenberg was among the first who has used an immanent analysis to show that this view is contradictory and untenable. The invisible hand is not so invisible. Every progress of science leads to new, hidden dangers. Let us consider how scientists have assured the public that genetically 
modified crops is actually safer than the cultures obtained by traditional methods. It was assumed that scientists can alter the genes responsible for desirable traits, and leave everything else intact. Although many scientists have believed in that story, it turned out not to be true. Firstly, the insertion and activation of new genes significantly interferes with the entire genetic system of an organism. Nobody knows what the inadvertent damage will be caused to the genome. Fish that have been modified to grow faster were deformed and died before their time. Genetically modified maize contained allergens and regularly polluted crops of other varieties of corn. When the researchers in Germany have tried to reduce the percentage of sugar and increase the percentage of starch in the potatoes (by using genes from yeast and bacteria), they have actually reduced the percentage of starch. These and many other examples show the ignorance of the potential harmful effects of genetic technologiesThus, the paradigm of world risk society draws attention to the many things we do not know and we cannot know that our safety, as individuals, societies, species and environment, will be threatened. It is interesting to see just with the progress of socalled global knowledge society, that we live beyond the normal, at the time post-normality. Post-normal science started to realize that we need a new form of science. The old idea of science, where empirical data lead to true conclusions, and scientific reasoning lead to the correct policy is no longer convincing. The way forward must take the form of dialogue that is based on the recognition that there is uncertainty and ignorance. Such a conclusion also strikes at the heart of the governing narrative that the "new knowledge-based economy" is actually based on the epistemological unity of knowledge and responsibility for the results of technological discovery. Also the definitive scientific diagnosis of global capitalism contained in tautological new management buzzword, is that we live in a global society of knowledge (and skills). The combination of ignorance and uncertainty on one hand and political change in science - including its financing, commercialization, complex security issues and new ways of knowledge production, on the other hand - means that science cannot function in "normal" way. Post-normal science type of analysis that occurs at the point between science and politics can include anything - starting from the scientific study of politics to public dialogue about the quality of these studies (Z. Sardar \& Borin Van Loon, 2001). Sustainable development of global, regional and local communities is not possible if you are in the mainstream of economic science teaching uncritical recycling of "cloned textbooks" (Ritzer, 1996) of management of humanity that resemble the egg as an egg. Accounting of the 21st century must not only be creative but if we want it to be sustainable, at the level of school education of accountants, it must be accompanied by normative, environmental and ethical principles. Environmental and ethical literacy prohibits the abuse, falsification (hairdressing) of accounting reports in its principles. Econometric measurement of progress, growth and development - whether of the local, regional or national community - should not be based on pseudo-logical basics of self-delusion. Selfdeception is defined as (1) activity to avoid recognition of self unpleasant reality and (2) a mental condition that results in ignorance, false beliefs, unjust attitudes and emotional distortion. You can lie to yourself and to the systematic use of (unconscious or partially conscious) tactics such as denial, repression, rationalization, conversion (to oneself or others), selective attention to evidence that suggests what we want to believe and selective ignorance of contrary evidence. Such tactics help us to explain the complicated thinking of highly intelligent managers who either try to apologize or attempt to justify their own 
crimes behind the white collar ("Nobody is really hurt"), production of harmful products ("If we did not do it, someone else would"); exploitation of employees ("Business is business") sexual harassment ("They were free to reject my offer"), racism ("they are all like that"), sexism ("I got the job only because of affirmative action"); An act of ignorance towards yourself and your family ("I'm a workaholic, just committed") and the neglect of the environment ("just doing my job to increase my profits"). Sustainable development in the broadest sense, involves environmental sustainability and intergenerational solidarity. This means that future generations that come after us are not deprived of the possibility to live a life that is worthy. The environmentally-conscious concepts of a GDP (Gross Domestic Product), is also appointed for an instrument that reflects the economic fundamentalism. It measures the wrong things, which lead to erroneous conclusions and faulty economic and world politics. The fundamental objection is that the first version of the GDP made during the Great Depression and it was used by Keynes's economic managers. It came very close to its present form during the WW2, when great efforts were made to maintain high production. Kaynes' associates could not even dream of that production - the very notion of production - soon to be altered. This is not just about consumption, in accordance with the consumerist post-industrial capitalism, became more important than production (G. Debord, P. Bruckner, J. Baudrillard, D. Harwey, F. Featherstone, M. Castells, H. Hromadžić). The destruction of families and communities, and devastation of nature and natural resources in the formal vocabulary of the new knowledge economy, is called a soothing term - externalities. Therefore, GDP reflects not only the crisis of the time, but also narrowminded assumptions of economists. Some critically oriented economists state that the use of GDP as a measure of the "progress", "growth" and "development" - is not only outdated but also perverse. The GDP not only conceals the breakdown of families and communities, and depletion of the natural environment but, in fact, it seems that these breakdowns - which are reflected in such things as car accidents, divorces, and the construction of new prisons appears to be an economic profit. Jeremy Rifkin argues that the mode of GDP as such is that it does not manifest items related to the quality or the quality of life (such as a greater amount of leisure time), health, decent and non-violent education and life in the communities of a safer and environmentally cleaner environment. The definition of quality of life depends on a set of non-material aspects of life such as health, social relationships and quality of the natural environment. There are no better indicators of well-being of a certain society than the public health and safety. Before Obama's health sector reform in the United States, Rifkin noted that the sad fact is that the United States and South Africa are the only two countries in the world that do not provide health care to its citizens. More than 2 million Americans were in a prison back then - a quarter of the total prison population in the world. The American dream is increasingly becoming a sobering wake-up for impoverished American citizens (or it is a shy announcement of a global democracy that is about to come) and the European dream - which nurtured in the lap of beautiful hopes - they both fought for supremacy on the issues of health, leisure, welfare, safety, risks of global warming, the risks of consuming genetically modified organisms, the quality of education, health care, human dignity, healthy interpersonal relationships and life in harmony with nature. If we want a sustainable global society, it is important that programmatic policy-makers at all levels of development incorporate some form of environmental accounting in their decisions. For instance, according to some proposals, the preservation or loss of valuable 
environmental resources should be included in the estimates of economic growth and welfare of men. We are looking for a suitable alternative to GDP: The Index of Sustainable Economic Welfare (ISEW); the Genuine Progress Indicator (GPI); the Fordham Index of Social Health (FISH); the UN's Human Development Index (HDI); the Index of Economic Well-Being (IEWB), are among the most popular indicators. Each of them sought to determine the "real" improvement of human welfare. People are becoming aware that the so-called new knowledge economy, in addition to positive contributions to developing the vocabulary, discursive strategies and the effects of the ideology of free markets, produces and plays an aggressive, technicized and unifying culture. It is, in fact, a hyper culture and a culture of materialism, selfishness and infantilism - or briefly - the culture of death. For the first time in history, the basic unit of economic activity is not the subject, whether it be the individual (such as the entrepreneur or entrepreneurial family) or the whole collective (such as the capitalist class, the corporation or the state), but it is the system units. This leads to the dominant cultural forms in organizations of informationalism of "corporate ethos accumulating" and "the renewed appeal of consumerism" (M. Castells, 2000). We are witnessing the violent realization and promotion of commercial culture in which there is no public space, but there is only market space. In the 1970ies, the idea of neo-liberal theorists is, thanks to their direct impact on the number of politicians and governments, given the opportunity for its practical application, with the increased economic stagflation of the time which Friedman and the way of fighting against it anticipated through the criticism of Keynes' theory. Military dictatorships in South America - Chile, Argentina, Bolivia and Uruguay - directly supported by the United States, led to overthrow democratically elected socialist government in these countries and the introduction of neoliberal-capitalist, economic and political reforms. All of this corresponds to the arrival of Roland Reagan at the head of America and the beginning of the open practice of neoliberal policies $(\mathrm{H}$. Hromadžić, 2008). The scientists no longer believe in a linear economic development based on the principles of neoliberal policies and market fundamentalism. Neo-liberal, universal, mono-cultural concept of development - after all that happened in the name of free markets and the so-called democracy - reminded us of the "black box" of our advanced civilization. From the standpoint of the global ontology of uncertainty, according to the American dream, the world can no longer serve as a model of social progress. The European vision of the future - as utopian and paradoxical as it can be - had a chance to overshadow the American dream. Once so cherished, the American dream is now increasingly causing ridicule, irony and cynicism (J. Rifkin, 2004). Such recognitions when coming from the Western authors have a great weight. When Rifkin says that our lifestyle does not inspire, but is considered to be overcome or, worse, a daunting one, or even causing disgust - then it should be taken seriously and not just as a thought of a lonely scientist. The key issues of global survival assume the possibility of pluralistic education of global human identity and, in this connection, the search for ways of reducing and eliminating violence against humans and violence against nature. Single, monolithic identity is an ideological construction. It is an identity that often functions as a belligerent, murderous identity (A. Maalouf, 1998 G. Haller, 2002). It is necessary to take into account our multiple identities and thus opt for the relative importance of our various connections and relationships in all contexts. Hope for harmony in the contemporary world lies in understanding the diversity of human identity. The socalled developed societies produce too much noise and cause our senses to be numb. Such 
societies are obsessed with conformity and irresponsibility for the fate of others because they are composed of individuals who are proud of their origin, but are governed by the behavior of others. Expressing visible contempt for others and frantically seeking their approval is the evidence of the pathology of a modern man - a consumer of the spectacle of society and an irresponsible seeker who want to purchase satisfactions. Elevated to an absolute standard, the principles of pleasure in all its pathological and degenerate forms (for example: "Enjoy your nation as well as in yourself") weakens our emotional intelligence directed towards others - and is collapsing into mediocrity and hedonism, stupidity and fatalism. The economic science and economic activity in general, are in tension with the ecology and environmental problems. Economics is, at the same time, tense towards other relationships - the politics, culture, art, etc. These relations are complicated because of the negative consequences of neoliberal "globalization of robbers" (M. Castells, 2000). But bear in mind that globalization has not simply fallen from the sky. It is a social phenomenon that, in essence, has social causes and consequences. In order for it to become so widespread and so active, it was necessary to meet a number of symbolic, cultural, political, social and institutional conditions. In fact, in the social, epistemological and institutional sense - it is possible only when, in the name of the global knowledge society, the economy began to speak as a global knowledge economy does. It is possible only when people and corporations, who had an interest in believing in it, have imposed their own interests as well as global interests. It is possible only when those who possess economic, political, institutional and scientific power, get a unique historical opportunity to impose its beliefs on those who believed them, or those who have not adequately confronted them. With the progress of the economic dimension of globalization, economic and environmental problems have become incalculable. The global economy found itself in conflict with the state, society (especially in the light of recent social movements and "civil society"), as well as the public sphere in general. Insisting that it is possible to have the absolute truth about globalization, has always been a threat as it could turn into some kind of a dangerous ideology or dogmatism. Dogmatism, by itself, is not a problem: the problem is what it makes people do. Therefore, it is important not to give up on a critique of an ideology. The ideology of neoliberal globalization of the world, on the basis of epistemological and market fundamentalism has shown a series of negative consequences because it sought to be even in those areas of life and work (such as for example, education) that can be neither understood nor preserved if we use only the econometric parameters ('efficacy', 'effectiveness', etc.) and models of thinking. To prove this, it would be responsible enough to consider only one problem: the global, regional and local water shortages. What is water? Vandana Shiva, an Indian physicist has shown that at every level of ecosystems (such as air, physical geography, vegetation, geolog ...), modern humanity is abusing the earth and its ability to receive water it absorbs and stores. Shiva is associated with the clash of cultures, the war paradigm. Shiva believes that there is a huge misunderstanding between two cultures: the culture where the water is seen as something sacred, and approaches its supplies as a duty to preserve life and culture that looks at water as a commodity, and interprets its possession and trading as the basic corporate law. The global water crisis is the most present, the most serious and invisible dimensions of ecological devastation of the country. Shiva called this devastation of the earth a corporate terrorism. According to the market paradigm the water shortage crisis occurred because the water is not traded. If, according to the proponents of 
the paradigm, the water could be transported and distributed freely on the open market, and if it could be brought to the deprived areas, higher prices would lead to conservation (efficiency, effectiveness, etc). This is the law of the market, market fundamentalists said, and the water for them is no exception. Market assumptions, may be completely blind to the environmental limitations, set by the water cycle, as well as to the economic constraints posed by poverty. Excessive exploitation of water and disturbance of the water cycle create utter scarcity which the market cannot replace by any other consumer goods. Reasoning used by the market paradigm refuses to see one of the most important moments: when the water runs out - there is no alternative. Therefore, the ecological paradigm should confront the market paradigm. However, in order to end the crisis of water - which is listed here only as an example - it is necessary to change global consciousness of the majority of people, and begin to apply an ecological democracy. Globalized economy of knowledge (and skills) moves the definition of water from the level of joint ownership to the level of (privatized) goods, which, according to the laws of free market can and should be exploited and sold. The global water crisis - mentioned here only in short lines - is a paradigm of the global crisis of the knowledge-based economy. It is also a paradigm of the so-called crisis of the global knowledge society (all the main streams of science see a role model in it, not just those in the West) and, finally, it is the paradigm of global, bioethical and ecological crisis, which is now in a radical social and epistemological conflict with the new knowledge economy. In this sense it is worth repeating that the causes of water crisis are business related, but without marketing solutions. We support the bioethical ecological paradigm in the context of recontextualization of sustainable development but also in the context of aspiration towards holistic ontology of knowledge, education and human health. Bioethical ecological paradigm is necessary to apply to other areas of critical analysis of the negative consequences of economic globalization. The reason is very simple: It takes only one step or less from abstract requirements for market deregulation to the dubious corporate law for the privatization of water, air, and the whole country. It is wrong to measure the size of this step through the econometric criteria. Therefore, what is necessary is an alternative interpretation of Reality. It is also necessary to have different ways of thinking and more humane and equitable criteria for measuring quality of life. There is a talk about indicators for measuring the very quality of the indicators of economic (and social) development. The quality - that is the very notion of quality - reduces the quantity and qualifies that way. Quantitatively defined indicators for measuring the quality (used only for measuring quantity indicators) cannot be indicators for measuring the quality - the very concept of quality. That is because people themselves who are affected, let's say, by the devastation of their life or cultural habitat - or live in permanent fear of hunger or fear of (the war against) terror - have plenty to say about the quality of their lives, or the negative consequences of neoliberal globalization. The social and health consequences of the global economy (which claims to be knowledge-based), are best explained by the reality. Keepers of the present order promote a simple thesis that globalization benefits all. This is only superficially true. Who are we? Who proved that globalization benefits all? Globalization benefits the minority so they could exploit the majority because the majority allows them to do so. This means that globalization does not benefit everyone, but only a small number of people. A total of $1 \%$ of demonstrators is in front of the Wall Street. The gap in income inequality in the United States is increasing. The financial wealth of the richest $1 \%$ of U.S. households exceeds $95 \%$ of 
the total wealth of households, reflecting a significant increase in the last 20 years (Stegar, 2003). The group of scientists in the U.S. recently warned that economic globalization could be the biggest threat to prevent the spread of parasitic diseases in sub-Saharan Africa. They pointed out that pharmaceutical companies with headquarters in the United States stopped producing many of the anti-parasitic drugs because developing countries cannot afford to have them. Assets of the three wealthiest world billionaires, is more than the total national product of all the least developed countries and their 600 million inhabitants (Steger, 2003). This is called a knowledge society. "Knowledge society" can only negate the cost to self harm - ironically says Konrad Liessmann, the author of Theory of lack of education - errors of the knowledge society. From the point of knowledge-based economy, quantitatively expressed "life expectancy" for each country of South Africa is: Angola (Men 37, 4 years of age; Women 39, 9 years of age), Zambia (Men 37,1 years of age; Women 37, 5 years of age), Malawi (Men 36, 6 years of age; Women 37, 6 years of age) Mozambique (Men 37, 3 years of age; Women 35, 6 years of age), Namibia (Men 36, 8 years of age; Women 37, 5 years of age), Botswana (Men 36, 8 years of age; Women 37, 5 years of age), Zimbabwe (Men 38, 5 years of age; Women 35, 7 years of age), South Africa (Men 47, 6 years of age; Women 48, 6 years of age), Lesotho (Men 48, 0 years of age; Women 49, 7 years of age.) Swaziland (Men 37, 9 years of age; Women 39, 4 years of age), Madagascar (Men 53, 1 years of age; Women, 57, 7 years of age) Mauritius (Men 67, 3 years of age; Women 75, 3 years of age) Comoros (Men 58, 2 years of age; Women 62, 7 years of age). The common goal of a series of social movements that support global responsibility of a science and corporations towards the people and the earth is to establish a sustainable development of regional and local communities on the principles of planetary awareness, solidarity and global civil democracy. If we look at the intellectual history of mankind, the chronology of ideas, then we can see that ecology has almost never been seen as a key issue for survival of man. Since the beginning of recorded history, until recent times, economic ideas, in addition to various theological, political, and sometimes philosophical ideas, occupy a very important place in human life. In contrast, with some exceptions, the story about ecology is mainly of the recent date. There are, for instance, comprehensive intellectual history books of Europe, where we can find a display of very different traditions of thought, from the Judeo-Christian and Greek and Roman traditions, to post-structuralism and postmodernism, but they almost completely ignore the environmental problems of humanity (see: Marvin Perry, Intellectual History of Modern Europe, Houghton Mifflin, 1993). In addition to this, some authors who deal with the history of economic and political ideas treat ecology as an ideology (the ideology of the environmental protection or environmentalism (See Andrew Heywood, Politics, Originally published by Palgrave Macmillan, 1997, 2002). If ecology is treated merely as a form of ideology among other ideologies, then we are at risk. We forget that we are referring to the quality of the water we drink, the quality of air we breathe, the quality of the food we eat and, more broadly, the overall sense of social and natural conditioned communication that we achieve. Only the recent theories on economic development which have been occurring in the recent years, began to analyze the relationship between economy and ecology, focusing on environmental problems and environmental pollution (see, Michael P. Todaro and Stephen C. Smith, Economic Development, 2006). Complementary studies with a common basis in economic, environmental and development related issues reveal serious shortcomings of conventional knowledge-based economy. The problem is that economists' 
openness towards the environmental problems, is often done blurry and in a sign of the econometric concept of sustainable development. The strategic coalitions are often made for development planning, which correspond only to a privileged group of several powerful people (see, Amy Goodman and David Goodman, 2004.), whereas the responsible consideration of sustainability implies a global change of consciousness and sustainability for people and communities. (For a comparative analysis of the previous definition of sustainable development take a look at: Sharachandra A. Lale, "Sustainable development: A Critical Review," World development 19 (1991): pp. 607-621, and Lance Taylor, "Sustainable development: An Introduction," World development 24 (1996), pp. 215-225.). To sum it up, people who deal with the problem of environmental sustainability as a term used to describe the desired balance between economic growth and environmental preservation. Although there are many definitions, sustainability generally refers to "meeting the needs of present generations without compromising the needs of future generations" (World Commission on Environment and Development, Our Common Future (New York: Oxford University Press, 1987): p. 4.). The implicit fact in these statements is that the future growth and overall quality of life depends on the quality of the environment. The basis of country's natural resources and air quality, water and soil are the common heritage for all generations. However, conventional theories of sustainable development do not pay enough attention to post-colonial and alternative theories of development. They do not pay enough attention to different traditions and environmentally-conscious culture of life. In countries like India the opinion that has been traditionally circling around is that space, air, water and energy are excluded from ownership. In Islamic tradition, the right to water is basically based on Sharia law, which originally quoted "path to water". In the United States, there were those who advocated water as a common good. "The water is moving, wandering, and it is necessary that according to the law of nature it remains everybody's," wrote William Blackstone, "so I can have only temporary and transient, as the enjoyer."With the globalization and privatization of water resources midst, a new effort to completely undermine the rights of people and collective ownership of resources replace corporate control. In that race it is often forgotten that in addition to the state and market, there are alive (and life-threatening) communities of real people with real needs. (V. Shiva, 2002.) Private interest groups and large corporations, in an endless race for profits, even go so far as to systematically ignore the option of joint control over the water. After twenty years of "shocking" (N. Klein) and doctrinal ignorance of the actual social and human consequences of unfettered global capitalism, the president of the World Bank came to the conclusion that for most of the world's population, the word "globalization" includes "fear and uncertainty," and not "opportunity and inclusion "(International Herald Tribune, 02 October 2000, page 13). Even Alan Greenspan and Treasury Secretary Larry Summers agreed that "antipathy towards globalization is so profound" that the "withdrawal from the market-oriented strategy and return to protectionism" are the real opportunities (E. Hobsbawm, 2008). Real people and their primary human needs, their health and educational needs - are ignored under the influence of fundamentalisms which compete with one another and people - regardless of their differences - are seen as a means of achieving some other goals (S. N. Eisenstadt, 1999; K, Kienzler, 2001., Z. Sardar, 2002., S. Sim, 2004). Negative effects of the dominant ideology of market fundamentalism (and its inherent corporate terrorism) cannot be eliminated without prior social-epistemological, multicultural, trans-disciplinary and anti-capitalist critique of 
social, institutional, and (privatization) abuse of the very idea of knowledge. It is also not possible without a radical critique or 'deconstruction' of the corporate structures of universities as the highest institution of knowledge. Universities of knowledge cannot be without serious consequences for the very idea of humanity - reduced to the malls. Future universities of knowledge, "which could happen tomorrow" (Derrida, 2000), should not be organized solely on models of market-oriented factory complex. Universities that are focused on knowledge should not be used exclusively for the promotion of private and fast cost-effective corporate business, not in reality and neither by the definition. Generally, universities in should not be defined solely by criteria of satisfaction (in combination with a higher or lower dose of tabular terror by students or professors). If it is true that we live in a global knowledge society, as stated by the new knowledge economy (something that everyone tends to repeat), the question is, how we get on the edge of a real disaster. Serious programs of reconstruction of a so-called knowledge society cannot be sustained without the reconstruction of the university. This has been pointed out in a variety of programs beyond the reconstruction of our systems of knowledge (Giddens, 1996; Ritzer, 1996; Derrida, 2000; Rorty, 1989; Wallerstein, 2001; Beck; 2007; Pachura, 2011). Corporate Research permeates everything. Knowledge acquisition is now collecting data, and data collection is the processing of changes that occur over time. Such a linguistic metamorphosis opened the door to the new interpretation of being as pure process devoid of any kind of final, unchanging frame of reference (J. Rifkin, 1998). One of the major themes of globalization is education - a dramatic transformation of our institutional systems of knowledge. The crisis of the project of globalization is associated with the deconstruction of our systems of knowledge. This deconstruction cannot be represented in a character or a key. Comparison between the state of education in the developed parts of the world, such as the U.S. or Europe, reveals some very interesting facts. Developing countries have their own problems in all the areas, including the area of education. Very little is known about these problems in developed countries. Nowadays, developed countries are facing a difficulty, where instead of true knowledge and education, they have been dealing with autistic administrative protocol exegesis of performative effects of Bologna, for many years. The university that we could have tomorrow - is a university with the right questions being installed and questioned, a university where "nothing is secure before a question. This is connected with the analysis of what is happening today, "on the world stage and, combining confession, repentance, atonement and asking for forgiveness in one general process" (Derrida, 2000). Global society of knowledge and skills is the ultimate result of the universalization of the universal economic language. Who would ever go against the global knowledge-based society? Who could be against freedom of the global linguistic exchanges that take place (i) in the name of knowledge itself (ii) in the name of freedom itself? Who could be against the free market in which there is a free trade of knowledge - where we can freely exchange words and things, things and words, people and things? Derrida also writes the following: "The event is detected on the basis of one that might not be aligned with the possible, but the impossible. Its power is therefore irreducible to the strength or power of the performative, and if such strength eventually gives her opportunity and efficiency to its performative, it is called the performative force" (Derrida, 2003). This distinction, the distinction between performative speech acts and the constant ones was one of the major events of the last century - and it is, says Derrida, the first one that was an academic event. It 
happened at the university and in a way social sciences are the ones that encouraged and examined its sources. It happened within the social sciences through the social sciences, and has far-reaching consequences (Derrida, 2000). Instead of thinking, the new economy based on knowledge, in order to educate the global knowledge society recommends, suggests, provides excellence, quality and satisfaction, and who would be so narrow-minded to refuse this generous offer. Luhmann's critique of techno-science has shown that the ability to design technical devices are not really all based on a better understanding of nature and the "implementation" of its "laws", but the growing ability of decomposition and recombination of Sciences. Technological advances were achieved without any prior scientific knowledge in many cases. It is not known that a major scientific discovery happened because of favorable intellectual climate that was produced by "Bologna". "Technology is the kind of observation that takes some consideration from the standpoint that it can break down," and based on many empirical analysis of today, the conception that technology is "applied science" can be considered to be defeated. On one hand, technology development cannot be understood as a kind of turning science from its own interests, or on the other hand, as restriction of its autonomy. Can technology be socially and politically acceptable and economically used, is another question to be decided outside of science. Providing a usable technology is the result of science, not its function. It may be that the science is appreciated and financed or even criticized because of such results ... No matter how you define the conditions of action, there can be no question of separation of science and scientists from the company (N. Luhmann, 1991). Similarly, the 'Bologna process' (with its obscene combination of excessive use of "satisfaction" and tables of terror), cuts the very essence of the importance of establishing a global knowledge society on the basis of new economy based on knowledge. The central contradiction of the Bologna educational policy concept of knowledge is in (the key corporate) assumption that there is not a qualitative difference between technological process of goods production and services, and educational and pedagogical process of education and the formation of personality and neither there should be. Bologna might result in the widespread wealth and prosperity one day, if they managed to bring corporate governance to prevail (be dominant) over the public good and private interests. In order to make the motive of profit lead to the best possible education, three requirements must be met. Students must know what they really need to be able in order to evaluate possible alternatives and make reliable decisions. Finally, their wishes must suit the needs of society, as one of the important roles of education is to prepare people to effectively contribute to the common good (Derek Bok, 2003). Stiglitz has explained in detail how "modern economics has shown that social welfare is not maximized if corporations are solely focused on maximizing their own profits" (Stiglitz, 2007). N. Klein has deconstructed a 'scientific' role of Milton Friedman, wrote 'The Shock Doctrine', and elaborated in detail the causes and consequences of the rise of disaster capitalism. André Gunder Frank accused Milton Friedman of "economic genocide". Klein defined catastrophe capitalism as a planned raiding of the public sphere after catastrophe, combined with the notion of tragedy as exciting market opportunities (N. Klein, 2008). Everyone who is preoccupied with the future, not only the future of global capitalism but also a future of sustainable humanity, is not always sure where to direct analytical view of the research: "The extreme right wing talks about the problems of globalization and mondialisation, and then focuses on the problem of migrants, who themselves are the victims of globalization, rather than its cause. Dissatisfaction should 
be re-directed to the real causes of the problem: large companies and mere search for profits, a behavior that destroys human communities everywhere in the world creates instability (Colin Crouch, 2003). It has been pointed at the fact that a man is in a situation where the global human survival is threatened. Man is exposed to major risks due to changes in the environment that he himself produced by creating nuclear weapons and ballistic missiles. "Our power to kill gained a universal character which led to a radically new situation where, if we want to survive, we are required to adopt radically different attitudes towards the provision and imposition of advice and also towards the interpersonal and international relations" - says Senator J. William Fulbright in book, The Arrogance of Power. According to Brzezinski, the power of America is based on four elements: (1) global military power, (2) global economic impact, (3) global cultural and ideological influence, and (4) global political influence. Although America, according to the insights of the nineties, does not have a worthy competitor, the position of global leadership is highly unstable because it is deeply caught in the "paradox of global power." It has a military impact and will have a major military impact for a long time. Economically, its impact is questionable because there are new world regions with great economic potential. Of all the global powers, the most contentious one is cultural and ideological. Brzezinski pointed to twenty deficiencies that question America's leadership role in the world. These short comings are debt, trade deficits, low savings rates and investment rate, industry uncompetitiveness, low rate of productivity growth, inadequate healthcare, poor high school education, poor social infrastructure and the decline of cities, greedy wealthy upper strata, parasitic obsession with litigation, deepening racial problems and poverty, crime on the increase, the use of drugs, instilling hopelessness, the spread of sexual freedom, the spread of moral depravity through the mass media, the weakening of civic consciousness, the emergence of divided multiculturalism, the collapse of the political system and increased sense of spiritual emptiness (Brzezinski, Zbigniew 1997; 2004). Another defect to add to the list, probably the greatest one (for which out of the irreversibility of social events in reality there is no adequate substitute), which has been detected only now, is a democracy deficit. For the first time in the history, American citizens are confronted with a "deficit of democracy", in a country that for many people around the world represents a model of free, democratic, liberal society. In fact, it happened only recently that America began to deal with its own myths, in a far-reaching significance. It is presumed that the libertarian protests of Americans against injustice, hypocrisy, greed, banks and many other things will take a more important place now than before. But there is also a danger that America could postpone the great historic opportunity of responsibly dealing with their own myths - for some unspecified time - in order to focus on internal democratization of their society. A critical expression of "market fundamentalism" seems to have come too late. This phrase 'too late', wanted to warn that society cannot be reduced to the market or a global "labeled" (H. Becker) religion - any religion. The only fundamentalism, which the global public is constantly "informed" of, through the media, is another form of fundamentalism - Islamic fundamentalism. The problem, which also attracts the attention of the global democratic publicity is in the domain of uncontrolled use of science and technology in economic conditions dictated by the logic of market fundamentalism. Private corporations, which have enormous power, apart from the democratic public control, make decisions that affect us all, even in terms of our chances of survival. Engaged intellectuals point to the social responsibility of corporations and they 
propose a kind of revival of active citizenship, a broad public debate about the consequences of irresponsible corporate governance (see, Letica, Slaven, 2009) where they question the foundations of anonymous logic of market relations. Markets are generally imposed as a neutral fact, but it ia quite contrary. Slavoj Zizek reminds us that, none other than George Soros, the embodiment of financial speculation, came to a conclusion that unlimited role of the market represents a greater threat of communist totalitarianism, and therefore should be limited by certain socio-political measures. However, is this view is sufficient regarding the scale of financial, political and moral crisis that we are in? The problem is that none of those who so convincingly describe the deadly vortex that we have been drawn into by the so-called process of globalization, does not have a anything defined on how we can get rid of capitalism (S. Zizek, 2004). Instead, the relevant parts of the former totalitarian regimes of knowledge are still at the scene of misreading wrongly formulated dilemmas of what was worse: Nazism or communism? New theoretical directions which propose various measures to overcome the "undefeated traumatic past," are in the process of developing in the sign of differently motivated cultures of memories (Helmut Dubiel \& Gabriel Motzkin, 2004). Postmodern theorists have gained considerable fame on the thesis that the search for truth is a thing of the past, and that in today's "post capitalist world" (Drucker, 1993) we are doomed to endless recycling of the large number of small, mutually competent stories which we will never see as as a true again. The reason why is that we are, apparently, no longer able to find some solid support out of the language which we could consider to represent the true reality itself. The new knowledge economy responded to the challenges of postmodern social theory, in an original way. It has skillfully privatized only the name of knowledge and combined the concept of knowledge with the new economy - and made a brand of all brands. Knowledge as such has provided itself, its own symbolic and business needs - with the very idea of knowledge. The difference between a postmodern philosophy of free symbolic exchange and the new global economy based on knowledge, which is in the essence of a global knowledge society, that we admire, could be explained only by a radical anti-capitalist theory. This theory, if it was possible, should be able to offer a rational alternative to global capitalism. And such an alternative does has not been created yet. It does not exist because capitalism - in the name of creating the global knowledge society - already declared itself to be a "post capitalist society" and therefore every reason (request) to go beyond capitalism has been meaningless and a surplus in advance. Nevertheless, global capitalism (regarding its consequences), is rather a part of the problem of globalization and not the opposite - its solution. However, the new knowledge economy, in its privileged sense, can be understood as a misunderstanding and misused phrase, which tried to build its power and prestige solely on the absence of epistemological and ontological understanding of the importance of knowledge, whose comprehensiveness is (still) in the mainstream economics in the West. So, what does it mean today to repeat or uncritically assert that we live in a knowledge society? Or, from the reverse perspective, is it possible, and if so, how can we start doubting the idea of a knowledge society without harming ourselves at the same time? At the very level of symbolic appointment, while choosing an appropriate name for the era in which we live, we encounter the paradoxes. If we say that we live in a knowledge society (because knowledge is officially the most important resource), we automatically switch off the field of ignorance. Firstly, we now know that science rarely solves the problem neatly and in an organized way - there are always some elements that are not and cannot be resolved, as in the case of 
radioactive waste generated from nuclear power. These awkward, "unresolved" elements of the problem are usually ignored until suddenly they start to pose a risk in all respects. The problem is that knowledge and ignorance have always been deeply and inherently connected. The new knowledge economy seems to forget or ignore that link, their deeper connection. One of the definitions of scientific knowledge is that science is the art of that what can be solved. Limiting science to the "solveable" has far reaching consequences for our understanding of knowledge and the world. Specifically, that means to completely remove ignorance from the view. Conceptually, it does not seem to be there for us. According to theorists of postcolonial studies of science, ignorance cannot be solved by conventional research. Recognizing ignorance is highly important for a very practical problem of science: priorities and decisions. Because whenever a proposed project is appointed a low priority, its implementation will never happen. Therefore, we lose the chance of gaining new knowledge, and in that sense we remain in ignorance. It is possible to specify a number of examples. If our society is relatively little interested in - sayOccupational or alternative sources of energy, compared to the technologically and commercially developed medicine and nuclear power, we will stay in the dark about these alternatives. Or, if they who finance - for instance - Development Research are totally uninterested in fundamental research in the field of social and multicultural epistemology and, instead, strongly privilege only commercial strategy development, then we remain in ignorance regarding the contribution from possibly critical areas that could be significant for long-term problem solving. What we "know" depends, therefore, on the decisions taken in accordance with those priorities. Therefore, a critical study of science assume that it is necessary to speak of a "deficit of Science" and "accountability deficit" or epistemological lack of knowledge or ignorance of the ontological, epistemological, political, social terms. Transdisciplinary analysis of the tacit assumptions on which today's dominant currents of social science in the West have developed - can be implemented as a critique of the privileged discourse. Considering the negative consequences of globalization it can be a very useful heuristic programmatic work on the critical 'deconstruction' of the ruling "meta-narrative" about the new global knowledge economy and knowledge society. Since Plato's time until Descartes, philosophers have understood the ignorance about ignorance as a separate category. Socrates' goal was to be aware of his own ignorance. Ignorance was an important concept in Islamic, Indian and Chinese science and philosophy. Renaissance authors claimed double ignorance as the worst intellectual failure. The breakthrough came with Galileo and Descartes, who believed that human knowledge is unlimited in the range and perfectibility. Ignorance is, since that time, which was officially the beginning of modern science in the West, taken as a void to be filled as soon as possible. Progressive journey of modern science was really fascinating on many fronts. From the period of collapse of the welfare state the world has not become any more stable or more just, not even more liberal, considering that the conversion of domestic norm of social life, reduced civil liberties (Kagarlitsky, 1999). In Latin America and the United States relationship between formal and informal economy is more or less obvious. People who work in the informal sector ("gray economy") are unemployed and marginalized. In the former Soviet Union, this relationship fell apart, so that the same people ended up working in both sectors (Kagarlitsky, 1999). U. S. and Nicaraguan authors, Roger Burbach and Orlando Núnez, see the only alternative to neo-liberalism in spontaneously occurring movements that require the satisfaction of basic 
needs. New, more just society "will have to appear as a mixture of different national, ethnic, and cultural movements in the world" (R. Burbach, O. Nanez, and B. Kagarlitsky, 1997).

Globalization can be understood as a socio-economic process of the complex dynamics of the structural contradictions and particularly strong and weak points, but for some countries it is understood as an invasion force, which at some point takes clear strategic contours. Scientific and technological changes undoubtedly play a central role in stimulating or blocking the process of global democratization. Internal epistemology of scientific knowledge is not eligible to explain the historians and philosophers how science works and what is even worse, they can easily be dangerous to human life, the environment and a maximum of democratic social relations. Harding believes that it is a suitable moment to grab and use the resources by post-colonial and feminist standpoint grab and that we can try and influence the outcome of this new reevaluation. Slave trade and industry based on slave labour were the crucial labour force of British and French industrialization (C. L. R. James, The Black Jacobins: Toussaint L'Ouverture and the San Domingo Revolution, New York, Vintage 1963; Eric Williams, Capitalism and Slavery, Chapel Hill: University of North Carolina Press, 1994). Different interpretations of globalization will lie in the thesis that the world is becoming more informed and standardized through the technological, commercial and cultural synchronization which seems to be dictated by the West. As a result, globalization is quite frequently perceived as essentially Western "project" - as westernization or "westernization of non-western" part of the plan. However, not even this interpretation can pass by without a strong challenge. Not only is there disagreement over the meaning of global connection to the modern world, but this disagreement is threatening to humans, as rational beings, to become completely unable to actively perceive the foundations of interconnection of the world in which we live. Therefore, it is not surprising that philosophers and scientists have explained in different ways that within the roots of the globalization crisis is a crisis of modernity project - that is the very concept of a crisis of Western rationality (Bidet, Jacques, 1999). Neoliberal capitalism, with the help of the idea of the knowledge society, adopts globalization and at the same time, attempts to suppress any opposition or highlight any alternative to capitalism. Its identification with the natural and normal human condition is the basis for a far-reaching goal: "to turn the entire planet into a giant capitalist enterprise controlled by Wall Street and other world capitalism centers because of only one thing - and that is profit" (B. Berberoglu, 2003; 2010). Criticism (in the knowledge society) becomes an empty symbolic gesture. Instead of having something changed, it only reinforces further the order whose defects it reveals. Such an opinion, which stands up against the system, is drawn into the same logic that lies in the basis of its reproduction. Nevertheless, many structural problems of neoliberal capitalism were uncovered. After protests in Seattle in 1999, the radical left-wing movements have returned in the form of "alter-globalism". New emancipated movements showed up and managed to draw attention to the dangerous mistakes of the system. However, capitalism has largely failed to discredit the idea of socialism. Many actually believe that socialism, rather than market fundamentalism, is the greatest evil in history. Even today, when someone points out the obvious flaws and dire consequences of action of so-called free market, to the majority it sounds as an attack on private property, free enterprise, or basic human rights. It is quite obvious that an effective enterprise cannot automatically result in the efficiency of the whole system. a living system - that is what society is - is not composed only of people 
who are called entrepreneurs. Global capitalism has reached such a level in which maximized economic efficiency (taking into account the technological, environmental, social and cultural issues that arise) leads to undermining the very foundations of society which is in need of balance, in order to survive and evolve. This is not about the bipolar conflict between the concept of economic efficiency and social justice concept, but about the structural contradictions of the capitalist system. Such a system, without epistemological reconstruction of its own cognitive matrix as the ontology of global knowledge society, is unable to reconcile economic and social aspects of their development and reproduction. To sum it up, in reality the company cannot, reduce it the market without its remnant so that people can survive the reduction. Therefore, the authors that can prove that the man is last, remained, unprocessed remnant or it has already become a surplus ("waste") in the global machine of the capitalist self-reproduced capital. The consequences of the global dominance of market fundamentalism are far more complicated than they are presented by media and its protectors of privileged flows of Sciences. The key social problems of people, communities and entire regions need to be simplified as much as possible, but no more than that. Intellectuals of the late twentieth century socialism first began to appear not as an alternative to capitalism, or as a new form of social organization, not even as a political movement, but rather as a set of values. The question that came forward was: 'what kind of values will control the age that is about to come?' It is not necessary to wait for long to get answers to this question, whichever side it was that the answer came from it was hardly a theoretical one. In 1999, after decades of neoliberal hegemony on the world markets and the collapse of economies of East Asia and Russia, a possible global crisis was speculated unless greater control of financial markets could be achieved. Pessimism was a logical consequence of a triumphal illusion of the 90-ies. The current, global financial crisis is intertwined with many other crises. Its roots are deeper than what the narrow-minded economic analysts (apart from a few exceptions) assumed a few years ago. Firstly, it was revealed that there are many myths related to the so-called free market and the so-called deregulation. Apparently, such a thing never existed. Secondly, it is not true that there is no regulation that controls the global "free market". The only way it can work is because of this regulation which allows global financial flows, provides a legal guarantee of loans, determines exchange rates, etc. The national "deregulation" or the end of protectionism, which has enabled globalization, and is now largely reduced to the control of nation states over the domestic economy has a background in various forms of international regulation (Altvater and Mahnkopf, "the World Market Unbound," in: Scot A. (ed.) The Limits of Globalization: Cases and Arguments, Routledge. London, 1997. Humanity today has faced a triple crisis: poverty, social disintegration and environmental degradation. The last century can be called the century of the apparent development. The negative consequences of globalization are associated with a deficit of global social responsibility. It is necessary to analyze the role of international financial institutions and commercial banks, which - guided by their own greed - have contributed and placed the largest number of countries in Latin America and sub-Saharan Africa today in such a desperate state of underdevelopment and poverty. Privatization, liberalization and constant competency struggle in the market are the most important values of neo-liberal ideology incorporated into the foundations of a new model of social development, of a so called Washington Consensus. The new model is to be reduced to a model of controlling the society, which is perceived as a supplement to the market. The 
theory that the victory of private property itself will rapidly create a class of independent entrepreneurs, without an adequate institutional and legal framework, has been proved to be wrong in practice. In fact, privatization did not only fail to help in the process of modernization of economies of Eastern Europe, but it was also closely associated with a reduction in exports. Industrial growth was recorded in the Czech Republic in the period of 1989 - 1997 where privatization is only got simulated (privatized companies have bought state-owned investment banks). Y. Buzdugan, an economist who analyzed the results of liberal reforms said that it appeared in those countries that did not follow instructions of IMF - In China, where the communist regime survived and Belarus, where, after several years of crisis, President Alexander Lukashenko came to power, even though he wasn't favoured in the West. Productivity growth crisis was much greater in sectors in which privatization was only partial. (Y. Buzdugan, "Sotsial-demokratichniy vibir"). Kagarlitsky believes that in 1989 most citizens of communist countries were completely indifferent towards the fate of people in Africa who were dying of starvation or people in Asia who lived in poor conditions. Poverty and instability that have spread like an epidemic across Eastern Europe, is a kind of historical retribution for irresponsible fantasies of consumerism and racist contempt for the rest of the world (Kagarlitsky, 1999). Structural exclusion of Africa from the dominant flow of economic globalization is a loss for the international economic policy and for what the West calls the "new economy of knowledge and skills". Professor Michael P. Todaro, who has lived and taught in Africa for 5 years, tried to incorporate his experiences in the theoretical concepts of Western development. Although he drew attention to the tragic problem of structural underdevelopment and poverty in subSaharan Africa, he still could not completely avoid westernized interpretative strategy while analyzing the reasons for the tragic situation in that region of the world: "The "lost decade of the 1990's", only brought new losses after the previous "lost decade of the 1980's", which mostly hit Latin American countries, and many other developing countries. By 2005, there were no clear signs of reversal. Africa, has recently recorded two successes - Botswana and Mauritius, but they are only rare exceptions... Serious cuts on spending in health and education in the 1980's which were partly caused by credit conditions that were set by the IMF and World Bank - have resulted in a sharp drop in school enrollment and the disturbing rise in malnutrition and maternal and child mortality. For example, by 2003 there were over 200 million severely undernourished people in Africa. The mortality rate of children under 5 years of age in 2002 was the highest in the world, at the level of 174 per thousand inhabitants. Todaro says that "sub-Saharan Africa is facing a difficult period ahead". The positive trend is that many African countries have begun to come out of the process of economic decline in the early years of this century, and some are beginning to show an accelerated economic growth. However, famine spread across South Africa and countries like Ethiopia. If we want global development to be successful, Africa will be the hardest temptation. If it fails, not only will a total of 700 million Africans who live south of the Sahara be sacrificed, but directly or indirectly, the rich countries of the industrialized world will have to bear the huge moral responsibility for this failure, as it will bear the consequences for human health and the environment" (Michael. P Todaro and Stephen C. Smith, 2006). If the 21st century wants to give a promise to less developed countries (LDCs) that have not been able to participate in the fruits of (the so called) global progress, then effective management - in terms of money, finance, environmental issues and the flow of 
resources, labor and technology - will require reform of the international system. Among the most frequently mentioned changes were: (1) The creation of new sources of financing for the LDCs: tax on international financial transactions, such as the so-called Tobin tax to reduce speculative inflows and outflows of foreign capital and (2) reform of the two main existing institutions of global economic growth and stability, the IMF and World Bank. Todaro says, to hear how the poor in their own words explain what it means to be poor is much more distinct than listening to a description of poverty. Therefore, he repeats the voices of the poor:

- When the woman is poor, her voice is not heard, she feels inferior. There is no food but famine in her house, no clothes and no progress in her family (the poor woman from Uganda).

- For a poor man everything is terrible - illness, humiliation, shame. We are disabled; we fear everything and depend on everyone: Nobody wants us, we are like garbage that everyone wants to get rid of (a blind woman from Tiraspol in Moldova).

- Life in this area is so difficult that all the youth and whoever can, must run to other cities or go to the army and on the front to satisfy their hunger which seems to escalates here more (the participants in a trial in rural Ethiopia).

- When food was abundant, relatives would offer to help. In these days of famine, not even relatives are willing to help and give you something to eat (The young man from Nichimishi, Zambia).

- We are forced to stand for hours in line for a little water (the participants in a discussion in the village of Mbwadzula (Mangochi) in Malawi.)

- Poverty means... low wages and unemployment. It also means lack of medicine, food and clothing (the participants in a debate in Brazil).

- $\quad$ Do not ask me what poverty is because you found me in front of my house. Just look at my house and count the holes in it. Look at the appliances and what I'm wearing. Take a good look and take note. What you see here is poverty (the poor in Kenya).

The concept of the idea of humanity is faced with the loss of elemental humanity in us, especially when we say that we live in a global knowledge society. We could therefore speak of a (possibly infinite) difference between what Todaro calls an economy of survival in sub-Saharan Africa and the "new economy of knowledge" in the West. We cannot understand this infinite difference on the basis of a studied 'double hermeneutics'. The words spoken about the recent solidarity in Africa are as cynical as they may sound. In order to understand the pain and humiliation of the poor, we need the emotional rebirth of humanity and epistemological mutation of consciousness - the opening towards the global responsibilities. It is necessary to expand research and methodological procedures of the development economics. What is needed is a holistic social ontology, which, instead of a linear progress and development of science and knowledge, perceived defects of progressive development paradigms, and therefore turns towards ethics, ecology and sustainable development. Criticism of the knowledge society implies a critique of monocultural paradigm of growth and development. The idea of a global knowledge society cannot be based on the privileging of Western theory and practice of progress, growth and development. There is not only one science, just as there is not only one type of rationality. The critical theory of scientific knowledge in action is open towards a concept of sustainable 
development and moves from the starting point of the existence of different regional and local communities, of their interdependence and interconnectedness. Also, it is necessary to take into account the common destiny of all creatures on earth. It often came to the light that while solving global problems it always had to do with the deeper, global interconnection of social and natural world. Science - if it wants to be sustainable - is not possible without the ethics of responsibility towards the other. For the survival of the idea of humanity, which is the basis of international law - it is necessary to obtain a trans-disciplinary understanding on ethics of responsibility towards others, if we want to make sense of living on earth. Influenced by the new knowledge economy, the ideology of market fundamentalism and corporate banking terrorism, the very idea of humanity is in grave danger. The market fundamentalism threatens the diversity of natural and human world, as it is everywhere. From London, to Moyotte, the extreme southeast of the Comoros island - on the metaphysical level, it has turned time into money, space in the market, and opinion in the calculation. On a symbolic level, variously motivated abuses of collective identity also represent a danger. Homogenous, militant actions of religion abuse (Religion fundamentalism) are especially dangerous. So, how come that one tendentious idea of "clash of civilizations," of the 1990's in the 20th century, which is full of errors, could become popular? The answer to this question is connected with a number of other issues. Another question is how human beings understand (construct) or use their own individual and collective identity? Based on what criteria how are human beings classified, ranked and sorted, and how much do they differ, identify, and share? Are human beings characterized by what they do or what they fail to do? And most importantly: how do human beings relate to the pain and suffering of others - and to the violence against others whom they do not know? What is the role of human rights in the regulation of the cruelty that human beings inflict to one another and lastly, can human rights be overestimated in relation to our responsibilities and duties? What are our responsibilities towards other human beings and why do we say that there are sometimes situations where it is justified to commit violence against other people? In the mainstream of commercially focused economics these questions are hardly ever discussed. Critically orientated researchers on different sides were searching for answers to these questions and other related questions. Over the last 10 years, globalization researchers responded to the removal of the conditions of human life itself. Others affect us in a way that we did not choose. Three days after 11th September in 2001 Judith Butler was among the first who argued that the U.S. has internationally tacit and supported legal responsibility for the people of Iraq. The common condition of existence which we share with others is pain - the pain that identifies us as human beings. However, a philosophical problem with which we work is systematically undermined by the conditions under which "those other people" are represented in the dominant Western media, because they are displayed on the infinite distance and through all the manners of moral veils. It takes a certain amount of humility, courage, and above all a global responsibility to function in such a shaken international framework. After 11th September, many have changed course in the American entertainment industry, as the "margin of tolerance" become lower. Now, all the intellectuals, who do not want to be idiots when it comes to the scenario of conflict between "the West" and "Islam" must direct their top priority towards a strategy that reduces the mutual enemy forces (Thomas Hylland Eriksen, 2002). Various artists and authors, who belong to different cognitive, epistemological and 
research orientation, have suggested that any interpretation which claims that religion is a source of conflict not only insufficient, but it is wrong.

There is not such a thing as only one "West", just as there is no a fully monolithic conception of religion. Also, there is not only one America. George W. Bush's America is not the same as America that is coming - America of the ordinary citizens that are being born. The concept of democracy as well as democracy itself, we cannot have as a property. Democracy is always arriving, that is what J. Derrida explains with an utter patience in his Voyous (Deux Essais sur la raison), which deconstructs the dilemma of whether there is only one Rogue state or has more. The point is that globalization is changing the moral world, so that the responsibility extends much further than before. No more space on the planet that is outside our area of responsibility. A Norwegian philosopher argues that politics often creates a greater evil in an attempt to defeat the lesser ones, and "the greatest problem of mankind is not so much excess aggression, but lack of thinking. This deficiency leads humankind to accept and even participate in the most amazing attacks on their neighbors" (Lars Svensen, Ondskapens philosophers, 2001.).

Events that occurred and their geopolitical and geo-economic effects have created a very popular relationship between the U.S. and Europe. People start to look at social problems in Africa, Latin America, and Eastern Europe in a different way. The civil international public follows the democratic protests in front of the Wall Street, as well as protests in London, Paris, Madrid, and Rome in a different way. Economic, political, social, institutional and legal dimensions of globalization are supplemented with others. After World War II, Europeans, as it is formulated by J. Butler, realized that an international set of institutions, identifications, covenants, and engagements, is actually what keeps the prospect of peace in their lives. In discussions of globalization, before the actual research findings and interpretations, the background presumption of conversation should be a philosophy of peace and accountability. In Europe there is a commitment to multilateralism, it is because nationalism is seen as a huge problem, one that feeds and encourages violence. From the standpoint of social expectations, human rights should not remain completely abstract, and should pay attention to how they are implemented. The process of finding meaning that they have, just as in what idioms they can be found in different cultures, is an act of universalization. Here, the question of antagonistic interpretive practice in the interpretation of the universal in universal human rights arises. Unless we want one-dimensionally understood Western culture to impose a universal right on everyone, then we must understand that the "universal" is constantly creating and always articulates and rearticulates, under conditions of cultural translation. Various governmental and nongovernmental organizations are involved in the complex issues of social understanding of human rights. But no one has an absolute monopoly on the interpretation of the meaning of human rights and human duties. However, a major responsibility lies on the developed countries. They have the power to dictate the conditions under which it is possible to allocate money for the development of those countries that do not have that power. We are to be careful regarding cautions on the responsibility of the international financial institutions in the context of the new global economy. Imposing programs of liberalization and deregulation of markets and institutions are coordinated to contribute a certain region sink deeper into despair, poverty, and even ethnic conflict. Africa is a dramatic example of 
structural exclusion from the global information economy. Because of the lack of insight and sense of responsibility and because of the faults of the international financial institutions Africa has been brought to an entirely specific situation. Only a few of the states in the north, which are the demographically closer to Europe, are in a somewhat better position, while the inhabitants of the eastern, central and southern parts of Africa are faced with the existential problem of survival. This is a situation of structural irrelevance, which is worse than the humiliation and worse than depending on others to help. After the oil shock in1979 and an increase in interest rates caused their bankruptcy, most of the African economies came under the direct supervision of policies of international financial institutions. These institutions have imposed liberalization measures allegedly aimed at creating trade and investment. Fragile African economies have failed to resist the shock. While liberalization policies could not attract investments and improve competitiveness, they destroyed large sectors of natural agricultural production. As a result, African countries are left without defense against a bad harvest. When the drought affected Central and East Africa, famine spread (Sahel, Ethiopia, Sudan), which was worsened by the civil war and banditry, which originated in governor's military confrontation between great powers (Ethiopia, Somalia, Angola, Mozambique). Since the state administration, as intermediaries between their own countries and the miserable resources transferred from abroad, were the main source of income, control over the state administration has become a matter of survival. Since the tribal and ethnic networks were the safest bet for winning people's support, the struggle for control of the state administration (often equated with control over the army) was organized around ethnic cleavages. In this way, the centuries-old hatred (which is the Western stereotype to explain the causes of conflict) revived along with biases: genocidal tendencies and widespread banditry in the root of the political economy of African exclusion from the new global economy. However, what we can say about the experience of transferring Africa in the new global economy is that the structural irrelevance (from the point of view of the system), is a condition that is far more dangerous than addiction.

Such a structural irrelevance was found throughout the 1980's when Africa, following example of debt crisis, forced policy adjustments through the application of abstract formulas in unique historical circumstances: under the dominance of free market conditions, international and domestic, the biggest part of Africa ceased to exist as an economic entity capable of life in the information / global economy. According to Castells, the most likely prospects for future development in Africa arose from the potential role that could be played only by the democratic South Africa of the black majority, with strong economic and technological ties with the global economy. Stability and prosperity of South Africa, and its willingness and ability to lead their neighbors as primus inter pares, offers the best chance to avoid a human holocaust that threatens Africa, as well as the chance to feel humanity in all of us through Africa (Castells, 2000). Perhaps the practice of cultural translation, that Butler speaks of, in a number of cases may represent an alternative to the brutal imposition of the dominant culture on those cultures that are (in relation to the dominant) defined as "others." Moral, religious and cultural differences in matters such as abortion or embryo research are very common in different regions of the world. The 20th century - with a few interrupted intrusions - was marked by scientology religion of Western civilization in the limitless possibilities of analytical science, which has made some fascinating results. This belief is still strongly present (which is best evidenced by 
recursively circulation slogan that we live in a society of knowledge) that the occurrence of critical paradigms, such as global risk society (U. Beck) rarely manages to reach out to the mainstream science. Still, over the recent decades, belief that science alone - without the ethics and accountability - cannot find viable solutions to the crucial issue of the world was challenged. Descartes' analytic epistemology to problems in science broke down into sets of simple, but difficult to solve problems. The researchers specialize on them until they narrow their specialization so that "they know everything about nothing". This logic leads to the destruction of the whole system and the destruction of habitat of living beings who maintain a diversified universe of life itself.

Fundamentally critical studies of scientific knowledge which, in various trans-cultural programs developed in recent decades, have much to say about the crisis of the dominant Western paradigm of knowledge. It is about a range of different studies that are based on the holistic paradigm of knowledge, and that the actual analysis of the negative consequences of globalization are trying to connect with the broader ontological, epistemological, social, hermeneutic, feminist, Marxist, postcolonial, and other emancipated research, science and technology. Almost all of these research studies are very heterogeneous and textual practices tend to get legitimized on the ethics of responsibility, or in other words, on the normative invocation of a global society based on accountability attempting to gradually compete with Western knowledge economy and commercial science in general. In her book, 'Is Science Multicultural?' (Post-colonialisms, feminisms and Epistemologies) Sandra Harding has tried to point out the shortcomings of most existing (and still dominant epistemologies and philosophies of science which the ruling economic science in the West, or so-called knowledge-based economy has also adopted for herself). "The world today when considering issues of science and technology, requires courageous research of unexplored territory, and more communication between people who are rarely found at the same institutional locations (Sandra Harding, 2005).

Postcolonial studies do not only use European and world history as evidence, but rather a widespread post-colonial, multicultural, global history. Along with the accumulation of negative consequences of globalization, comparative postcolonial studies the development of underdeveloped regions and continents became more significant; postcolonial histories of individual states, post-colonial history of neglected or missing communities; postcolonial studies of traditional agricultural preindustrial cultures, postcolonial geopolitical and geoeconomic history of countries that have recently fought for independence etc. Postcolonial studies of development which Harding speaks of, get more importance in the light of recent research for sustainable development in the West. The conceptual framework of postcolonial studies of science and technology was organized from the perspective of other, nonEuropean cultures and the great mass of economically and politically world's most endangered population in their struggle to survive. The importance of these post-colonial studies is that they draw attention to how great the tragedy would be if the human race came to the point where there is only one universally valid scientific and technological tradition. Modern epistemological dream of a perfectly coherent interpretation of all natural laws, the interpretation that perfectly matches the order of nature, begins to take on the form of a nightmare, just as it was realized by post-Kuhn, post-positivist and postcolonial studies of science and technology. The so-called knowledge-based economy - and the uncritical use 
of the phrase-based society - is a symptom of a deeper crisis of the dominant streams of science in the West. However, scientists in the West have come to a conclusion that most of the access to knowledge-based economy is characterized by positivist and non-conflicted vision of knowledge and technology that leads to avoiding the social, cultural and ethical contradictions inherent in the knowledge-based economy. A key methodological limitation of access through the knowledge-based economy is that it forgets that the novelty of the current historical conjuncture does not consist in the simple application of knowledge-based economy, but on the contrary, it consists of the fact that the knowledge-based economy is subordinated and bounded by the institutional forms that define accumulation capital (Didier Lebert and Carlo Vercellone, 2002). It could be shown that the critical deconstruction of the language on which the so-called knowledge-based economy is based and it is the key to recognizing the epistemological and social causes of the crisis of cognitive capitalism (Vercellone, 2002) and the project of neoliberal globalization for postcolonial scholars and scientists in the West. It was similarly formulated by another author: because capitalism is primarily a way of exploitation and social domination, and because the concentrated financial capital dominates the most today, it also creates obstacles on the "cognitive" level (François Chesnais, 2002). For example, in March of 1990, Namibia won independence. However, hardly any viewers in Europe or the U.S. could remember the news. The question is whether the Western media (based on global knowledge about globalization) does adequately tell the news. Perhaps, the Western media of the 90 's were preoccupied with the collapse of communism and the celebration of liberal democracy. After the terrorist attacks on New York and Washington and the American decision to militarily invade Afghanistan and Iraq, the neo-liberal theory has reduced their predictions about the epochal transformation of the world. America is back in the geopolitics of international relations, but the return did not lead to interruption of transnational economic and political ties between countries, but it created new opportunities for cooperation and conflict. The new blow to the credibility of neo-liberal perspective of international relations has once again come from America when the first global economic crisis of 21st the century broke out. It is revealing that Washington has not resolved the consequences of crisis in accordance with the principles of free trade (as they explained it to the dominant neo-liberal globalization theory), but instead used the power of government intervention to save the stumbling banks and companies.

There are anthropologists who believe that globalization is just another name for Western aggressive, colonialist policy that has lasted for about 500 years. They argue that the aggressive colonialism of the West missionaries and conquerors completely destroyed and impoverished many regions of the world. Many native people were systematically murdered in their own country. Thanks to advances in technology weapons and other achievements, the rifle barrel has taken place in the world history of progress: "Hunting, fighting and skirmishes with the Indians in the hinterland, stimulated numerous American improvements of rifles" (Daniel J. Boorstin, 1958). In the beginning, this device was quite cumbersome and difficult. It had a long tube. The length increased the precision, but unlike guns it required the use of both hands and one shoulder. Increased length of the pipe lowered force of the recoil on the shoulder of one who is using it, and added length to the inner path that was used for smoother acceleration of grain. With proper use at the field, 
which included adequate calmness, squint on one eye, not blinking or breathing (without trembling hands) rapidly increased precision. All this has enabled the efficient and effective bargaining of any pre-set goals. The gun - in addition to everything that Boorstin said - was used for "civilizing" the wild Indian tribes. Speaking in a modern, back then still an unknown language, it was possible to assume that the persecution (with the aim of closing Indians in the reserve) happened the way it did. Such events did not have an apparent connection with that what came quite a few years later and was called Total Quality Management (TQM) or "Management by Objectives" (Drucker) in economic theory of quality management. Industrial production of individual shooting weapons and weapons of mass destruction during the process of industrial revolution, as well as postindustrial era, has undergone a remarkable progress. Thus, the gun was carefully refined over the time. With the increase of mass industrial production, the training opportunities of its individual parts have been also increased. Its total weight was becoming smaller and precisely guessing pre-selected targets was growing. It was very easy to handle the gun, because its overall performance became increasingly acceptable. With the rise of mass production, offers were growing and prices were falling, while the costs - if we exclude the expenditure for ammunition - were almost zero. Indian bows and arrows, due to the accelerated development of destructive techniques looked like children's toys. With the invention of heavy machine guns, thanks to innovations in the quality of firing mechanism, the slow single shots could be replaced by a fast, efficient and effective automatic firearm. Accuracy in automatic shooting has become somewhat smaller. But the (apparent) lack of precision of the new heavy weapons could have been (due to "compression of time and space") easily replaced. A large number of targets could be achieved in a very short time intervals, from great distances, even at very low or any kind of visibility. These technical innovations, combined with the advancement and improvement of optics and target devices, enabled the representatives of the so-called "civilization" to shoot several thousand grains of lethal fire, in a single stroke of the index finger, for a very short time. The outcome of the modernist, industrial, scientific and technological project of the violent act of "civilizing people without literacy," as we know it was fascinating. Unfortunately, most of the Indians and other tribes, who numbered several million people were brutally killed, or died from the disease. Some researchers consider the whole enterprise of "forced civilizing" to be a genocide. Nearly complete, the social, cultural and civilizational conditioned disappearance of the Indians the extermination of the native population - is evidence of crimes against humanity. The crimes were committed under the (intractable) back of civilization conquest of capitalism where the victims were Indians. Daniel J. Boorstin, in this context, spoke of "black holes in American legal history" (Daniel J. Boorstin, 1958).

Photographs of an Amazonian tribe, surrounded by dense trees, were taken from the plane in the late 11th month of 2011 year, on the border between Brazil and Peru are rare evidence that the indigenous tribes (yet) exist. Such groups of several hundred natives never had contact with the so-called advanced and civilized rest of the world. (The advanced world has been called the first world for a very long time, where the other was called the rest, just as we see in the example of the last remnants of extinct tribes) They are fragile and susceptible to external stimuli and noise. These groups of survivors testify about the "remnants" of a (for anthropologists, linguists and other scholars) precious agricultural culture. They cultivate native plants, live in harmony with their indigenous culture. What 
threatens them is the danger that comes from colonizers, drug traffickers, infections, armed hunters, fishermen, etc. They are in danger of extinction. From their standpoint, they are the center of the world, and they are objectively situated in a hostile environment. This is an example among many other examples that might encourage wider thinking. It is necessary to ask about the historical and civilizational responsibility of those who have the power. The responsibility is always given to those who have the power to divide people between "us" and "them" or "other". Although the majority of us has not yet accepted it, a global identity that is identity of species - has been created at the moment when our ancestors started walking upright. Demagogues who created the state and established empires sought to justify its rule by claiming that people living outside their borders are completely different from those who live inside. Today, indigenous peoples are not so scarce as we often think. According to the United Nations, they make five per cent of the world's population, which is three hundred million people. Anthropologist Darrell Posey said, for example, that the Kayapo Indian tribe in the south of Amazonia developed agricultural system that allows them to survive in places where the growing of crops is extremely difficult. This tribe has grown sweet potato resistant to fire, which takes nutrients from naturally burned stumps, and the main crop, which produces its own pesticide, and weeds out while living in symbiosis with a species of ants. Survival of the tribe depends on subtle understanding of the microclimate and the relationships between animals and plants. Unlike almost all modern farmers in the Amazon, they improve the soil and expand forest cover by planting useful trees in the savannah. Their techniques are coded in their songs and stories and the concepts that are difficult to translate into other languages. Their language and self-worth are threatened, which is one thing that most indigenous peoples share. In this case it is because of the economic globalization, political oppression, and because other Brazilians took over the natural resources. This is not only putting the survival of their traditional agriculture at risk, but also the ecosystems in which they live (George Monbiot, 2003). It is also an example of how diversity and universality are always in conflict. The issue is that this conflict can be solved without having to establish something like a responsible global parliament, which would protect the rights of diversity. Corporations are generally governed by their own greed without limits. They are not primarily interested in universal human rights of different individuals, different communities and even entire regions and continents, unless they can earn more in these areas. The capitalists, by definition, create favorable strategic business opportunities in every inch of the planet. It is realistic to expect that the greedy capitalist corporations, in the name of global prosperity, growth and development, could find excuses to destroy the habitats of many aboriginal cultures and underdeveloped regions, in the future as well unless they are stopped. The objectives are the same everywhere: to impose its own rules, to improve and enhance own business activities, to encourage full privatization and entrepreneurship, expand markets, create a favorable business environment, improve the balance of payments, avoid taxes on international financial transactions, to grab the cheapest resources and so on. Let us go back to the example with the recently recorded Amazon tribes: "What is happening in the world is a crime against nature, various tribes and fauna, and it proves how we, the so-called civilized people, treat the world in which we live", said recently a representative of the Survival International organization, which helps tribal communities around the world. Lots of evidence is pointing to the fact that what is called globalization generally operates as a 
complex, controversial and ambiguous semantic expression. The controversies and wars were fought because of the implications of these meanings. "Coups, wars, and massacres were happening in order to maintain regimes of inclined corporations and have never been considered crimes of capitalism, but have been written off as too much exaggeration of eager dictator" (Klein, 2007). Nicholas Ostler, in his interesting book Empires of the Word, says: "We can already notice that the flourishing of creationist views, and the prophetic interpretation of some ancient Christian texts, comes from the very heart of the richest and most developed countries of the English-speaking world. If the powerful people within the United States, which today represent the most productive source of information and scientific knowledge, at some point decide to exert pressure on its independent intelligence, it is quite possible that some other parts of the world decide to start their scientific knowledge to keep the veil of their own language "(Nicholas Ostler, 2005). Medical sociologists can assist in determining the social basis of many diseases. Along with other scientists, they study the social aspects of health and illness, social functions of health organizations and institutions, relationships between health care system and other social systems, social behavior of health workers and users of health care, and patterns of health services (William Cockerham, 1995. Medical Sociology, Englewood Cliffs, NJ: Prentice-Hall.) As a specialization, medical sociology consists of special knowledge by which health and illness are placed in the social, cultural and behavioral context. The Medical sociology consists of describing, explaining, and theories about the distribution of disease among different population groups, behaviours or activities undertaken by individuals in order to maintain, improve or re-establish health, or to adjust to sickness or disability better; attitudes and beliefs about health, illness, and the providers of medical care and medical organizations, medical professions and the professions of the organization, financing and providing medical services, medicine as a social institution and its relationship to other social institutions, cultural values and social responsibility towards health, illness, disability, and the role of social factors in the etiology of disease, particularly functional and emotional disorders and those that are now called stress-induced diseases (Letica Slaven, Medical Sociology, 2003). Sociology of medicine is dealing with medicine and health care as subsystems (social institutions) of the global social system, for instance the study of basic principles and laws of action and behavior of their participants. On 11th September - as formulated by Eriksen - with one stone, the world has been thrown into an uncomfortable and paranoid time in a war without front lines, a conflict without limitations, with a clear beginning, but with an uncertain end. Cues for the globalization of the 90's were the openness, freedom of flight, internet and aircraft traffic on the increase. Cues for the current ten years of globalization are AIDS, threat, control and the police state. We could cite various examples of decade-long effects of U.S. foreign policy but it has already been done and nothing is accomplished. This policy is reflected in technology superior demonstrations of destructive power of smart bombs, and the global weakness of the human mind to stop this kind of destruction, opposes it. It is therefore worth quoting Eriksen when he writes: "All the intellectuals who do not want to be idiots when it comes to a scenario of conflict between" the West "and" Islam ", must now direct the main priority towards the strategy, which reduces the mutual enemy forces" (Thomas Hylland Eriksen, 2002). If we are to understand suicide terrorism, we must carefully examine the wider socio-political context in which it occurs. A series of social, economic, media and other factors, some are unknown 
and many others are well known, when put together create an environment where suicidal terrorists arise. In his book, through the use of the extensive philosophical literature, Stuart Sim has found a common ground for (1) historic fundamentalism, (2) market fundamentalism, (3) political fundamentalism, (4) religious fundamentalism (5) nationalist fundamentalism and (6) fundamentalism in general (as a quest for purity of thought and deed). The common basis of all these forms of fundamentalism (regardless of whether it is the market or religious fundamentalism) is a fundamentalist mentality. Here is a quote that explains the spiritual poverty of companies, when it becomes trapped by fundamentalism: "We live in a fundamentalist world because fundamentalists have such a strong impact on so many of our institutions - religious, political and economic. I am not saying that there is a global conspiracy of different kinds of fundamentalism. Fundamentalists of one area are not necessarily in agreement with fundamentalists of another area - turbulent, mutual disagreement is often likely to occur. What is particularly evident in the field of religion - is that Christian fundamentalists reject the claims of Islamic fundamentalists and vice versa. Each side claims that only they "posses the truth," which was discovered only, solely and exclusively by their prophet. In this part of faith there is no discord - by definition, monotheism cannot stand the rivalry... Religious fundamentalism is exclusive by nature you are either within the circle of devoted believers, or you're against it" (S. Sim, 2004). It is more or less the same with market fundamentalism when it is in charge of the world's economic, political and educational institutions - as it happened after 1989. Market fundamentalism was a thoroughly documented phenomenon in a world civilization (George Soros invented the term). However, some commentators see the International Monetary Fund and World Bank to be a threat to the world peace and harmony. According to Sim's observation, an Islamic scholar Akbar S. Ahmed was one of the first to draw attention to the negative effects of the policy of the IMF and World Bank toward the Third World countries. However, it is not particularly important who it was among the scientists that drew attention to what many other people noticed themselves. Today there are many who rightly speak of market fundamentalism which appears to be a dangerous catalyst for other fundamentalisms. It is possible to specify a number of examples of the negative consequences of market fundamentalism (Africa, Russia, Southeast Asia, Argentina and so on), which all witness and point at what can happen when the free market economy (which, in the end, has not even been implemented by some of the most developed countries that came up with this policy in the first place and were imposing it on others), without any alternative, is imposing itself to the states which lack the necessary social and political structures that are essential for the implementation of this program.

\section{References}

Appadurai, Arjun (2006) Fear of Small Numbers: An Essay on the Geography of Anger, Duke University Press

Aronowitz, Stanley (1988) Science As Power: Doscourse and ideology in Modern Society, Macmillan Press

Aronowitz, Stanley (2000) The Knowledge Factory, Dismantling the Corporate University and Creating True Higher Learning, Beacon Press

Badiou, Alain (2003) Saint Paul: The Foundation of Universalism, Stanford University Press 
Baudrillard, Jean (2002) L' esprit du terrorisme, Edition, Galilée, Paris

Baudrillard, Jean (2004) La pacte de lucidite ou l'intelligence du mal, Editions, Galilée, Paris

Bauman, Zygmunt (2000) Liquid Modernity, Cambridge Polity Press

Beck, Ulrich (1999) What is Globalization? Cambridge, Polity Press

Beck, Ulrich (2007). Weltrisikogesellschaftt: Auf der Suche nach der verlorenen Sicherheit, Suhrkamp, Verlag, Frankfurt am Main

Berberoglu, Berc (2003) Globalization of Capital and the Nation-State, Lanham, Boulder, Rowman \& Littlefield

Berberoglu, Berc (2010) Globalization in the 21st Century: Lobor, Capital and the State an a World Scale, Palgrave, Macmillan

Bhagwaty, Jagdish (2004) In Defense of Globalization, Oxford University Press, Inc.

Bidet, Jacques (1999) Théorie générale: Theorie du droit, de l'économie et de la politique, Presses Universitaires de France

Boorstin, J. Daniel (1958) The Americans, The Colonial Experience, Random House Publishing Group

Bourdieu, P. (2000). Sur La télévision, suivi de l' emprise du journalisme, ISBN-13: 978ID86288396, Clio, Beograd

Brzezinski, Zbigniew (1997) The Grand Chessboard: American Primacy and Its Geostrategic Imperatives, Basic Books, New York

Brzezinski, Zbigniew (2004) The Choice: Global Domination or Global Leadership, Basic Books, New York

Burbach Roger, Nanez Orlando and Kagarlitsky Boris (1997) Globalization and its Discontens: The Rise of Postmodern Socialism. London and Chicago

Callinicos, A. T. (2009). Against The Third Way: An Anty-Capitalist Critique, ISBN, 953-316064-7, Jesenski i Turk, Zagreb

Castells, M. (2003). The Information Age: Economy, Society and Culture, Volume 3, The End of Millennium, ISBN, 953-212-000-9, Golden marketing, Zagreb

Chesnais, F. (2002). In: Soomes-nous sortis du capitalisme industriel?, (Ed.) Carlo Vercellone, La Dispute, Paris

Chomsky, Noam (2003) Hegemony or Survival: America's Quest for Global Dominance, Published by arrangement with Henry Holt and Company, LLC.

Chossudovsky, M. (2008). The Globalization of Poverty and the New World Order, ISBN, 978-953-6460-83-0, Prometej, Zagreb

Coady Tony and Michael O'Keefe (2002) Terrorism and Justice: Moral Argument in a Threatened World, Melbourne University Press

Common Michael and Stagl Sigrid (2005) Ecological Economisc: An Introduction, Cambridge University Press

Corsani, A. (2002) In: Soomes-nous sortis du capitalisme industriel?, (Ed.) Carlo Vercellone, La Dispute, Paris

Crouch, Colin (2003) Postdemocrazia, Roma-Bari

Deaglio Mario, Giuseppe Monateri, Caffarena Anna (2004) La globalizzatione dimezzata, Guerini e Associati

Debord, Guy (1992) La Société du Spectacle, Éditions Gallimard, Paris

Delić, Zlatan (2011) Brightness and Austerity of the Globalization Theory: The Ideological Foundations of Cognitive Capitalism, in Piotr Pachura, ed. (2011) The Systemic Dimension of Globalization, InTech open Access Publisher 
Derek Bok (2003) Universities in the Marketplace: The Commercialization of Higher Education, Princeton University Press

Derrida, J. (2000) L' avenir de la profesion ou l' université sans condition (grâce aux "Humanités" ce qui pourrait avoir lieu demain)

Derrida, J. (2003) Voyous (Deux essais sur la raison), Editions Galilée, Paris

Drucker, F. Peter (1993) Post-Capitalist Society, by Peter F. Drucker

Dubiel, Helmut \& Motzkin, Gabriel (2004) (eds.) The Lesser Evil - Moral Approaches to Genocide Practices, Routledge, London \& New York

Edvinsson, Leif (2003) Corporate Longitude: Navigating the Knowledge Economy, BookHouse Publishing Sweden AB, of Grevgaten 20 S-114 53 Stockholm, Sweden

Eisenstadt, Shmuel N. (1999) Fundamentalism, Sectarianism, and Revolution: The Jacobin Dimension of Modernity, Cambridge University Press

Featherstone, Mike (2007) Consumer Culture and Postmodernism, Sage, London

Finkelstein, G. Norman (2001) The Holocaust Industry: Reflections on the Exploitation of Jewish Suffering, Verso, London

Foer, Franklin (2005) How Soccer Explains the World: An Unlikely theory of Globalization, HarperCollins Publishers

Fulbright, William (1996) The Arrogance of Power, by J. William Fulbright

Furedi, Frank (2005) Politics of Fear: Beyond Left and Right, Continuum International Publishing Group Ltd., London

Giddens, Anthony (2007) Europe in the Global Age, London

Goodman, Amy and David Goodman (2004) The Exception to the Rulers: Exposing Oily Politicians, War Profiteers, and the Media That Love Them, Published by Hyperion, New York

Guellec, D. (2002) L' émergence d' une économie fondée sur le savoir, in J. -P. Touffut (ed), Institutions et innovation: de la recherche aux sysstèmes sociaux d'innovation, Albin Michel, Paris

Gunjevic, Boris (2009). The virtue of Empire between the capital and terror, in Philosophical research, Vol 29. pp. 63-74. Zagreb

Habermas, Jürgen (2004) Der gespaltene Westen: Kleine Politische Schriften X, Suhrkamp Verlag Frankfurt am Main

Habermas, Jürgen (2008) Ach, Europa: Kleine Politische Schriften XI (Suhrkamp), Frankfurt am Main

Ha-Joon Chang (2002). Kicking Away the Ladder: Development Strategy in Historical Perspective, Anthem Press, London,

Haller, Gret (2002) Die Grenzen der Solidarität: Europa und USA im Umgang mit Staat, Nation und Religion, Aufbau Taschenbuch Verlag, Berlin

Hardt, M. \& Negri, A. (2003). Empire, ISBN, 953-98699-2-7, Multimedijalni institut, Arkzin, Zagreb

Harvey, David (2005) A Brief History of Neoliberalism, Oxford University Press, New York Held, D. and McGrew, A. (2002) Globalization/Anti-Globalization, Polity Press, Cambridge Hobsbawm, Eric (2007) Globalisation, Democracy and Terrorism, Litlle, Brown, London

Howitt, P. (1996) The implications of knowledge-based growth for micro-economic policies, University of Calgary Press, Calgary

Hromadžić, Hajrudin (2008) Consumerism: The Needs, Lifestyle, Ideology, Jesenski i Turk, Zagreb 
Ingrao, Charles \& Emmert, A. Thomas (2009) Confronting the Yugoslav Controversies: A scholars' Initiative, by Purdue University

Ippolito, Roberto (2004) 2014 Il futuro che ci aspetta, Editore Laterza

Jean-Luc Nancy (2002) La création du monde ou la mondialisation, Galilée, Paris

Kagarlitsky, Boris (1999) , New Realism, New Barbarism, first published by Pluto Press, Ltd. London

Kienzler, Klaus (1996) Der religiöse Fundamentalismus: Christentum, Judentum und Islam, München.

Klein, Naomi (2007) The Shock Doctrine, by Klein Lewis Productions, Ltd.

Letica, Bartol (2010) Age of Accontability: Corporate Social Responsibility in a Time of Global Financial Crisis, Mate, Zagreb

Liessmann, K. P. (2008) Theorie der Unbildung: Die Irrtümer der Wissensgesellschaft,

Literature:

Luhmann, Niklas (1991) Die Wissenschaft der Gesellschaft, Suhrkamp Verlag, Frankfurt am Main

Maalouf, Amin (1998) Les Identitès meurtrierès, Éditions Graset \& Fasquelle

Marija Geiger Zeman and Zdenko Zeman (2011) Introduction to Sociology (Sustainable) Communities, Ivo Pilar, Zagreb

Marvin, Perry (1993) Intellectual History of Modern Europe, Houghton Mifflin

Masudul Alam Choudhury and Lubna Sarwath Mohammad (2011) Sustainability by Interrrelating Science, Society and Economy in Embedded Political economy epistemological Approach, in Piotr Pachura (ed. 2011), The Systemic Dimension of Globalization, Published by InTech

McQuillan, Martin (2001-2-28) Textual Activism: Deconstruction After '9/11' (Routlege), ISBN $041593687 X$-EAN 978041593687

Monbiot, George (2004). The Age of Consent: A manifesto for a new world order, by HarperCollins

Mouhoud, M. (2002) In: Soomes-nous sortis du capitalisme industriel?, (Ed.) Carlo Vercellone, La Dispute, Paris

Muller, Jan- Werner (2002) Introduction: the power of memory, the memory of power and the power over memory, in Muller, Jean- Werner ed. (2002), Memory and Power in Post-War Europe - Studies in the Presence of the Past, Cambridge University Press

Negri, Antonio \& Hardt, Michael (2000) Empire, Cambridge, Massachusetts, London

Nelson-Jones, Richard (2004) Cognitive Humanistic Therapy, London, SAGA, Publications

Neumann, I. B. (2009). Mening, materialitet, makt: en innføring i diskursanalize, Alexandria Press

Ohmae, K. (2007). The Next Global stage: Challenges and Opportunities in Our Borderless World, ISBN, 978-953-246-032-2, Mate, Zagreb

Ortayli, Ilber (2009) Different understanding of the Ottomans (Osmanliyi yeniden keşfetmek), Copyright by Connectum, Sarajevo

Ostler, Nicholas (2005) Empires of the World: A Language History of the World, New York, Harper Perennial

Patnam, R. (1993) Making Democracy Work: Civic Traditions in Modern Italy, Princeton University Press

Paulré, B. (2000) De la New Ekonomy au capitalisme cognitif, Multitudes 2, pp. 25-42, Exils Editeur, Paris, 
Rifkin, Jeremy (2004). The European Dream: How Europe's Vision of the Future is Quietly Eclipsing the American Dream, Polity Press, Cambridge. Published by arrangement with Jeremy P. Tarcher, a member of Penguin Group (USA) Inc.

Rifkin, Jeremy (1998) The Biotech Century - Genes are the raw resource for the next century, Jeremy P. Tarcher/Putnam a member of Penguin Putnam Inc., New York

Ritzer, George (1996) The McDonaldization of Society, Sage Publications Company Thousend Oaks, California, USA; Sage publications Ltd. London, United Kingdom

Robertson, R. (1992) Globalisation: Social theory and Global Culture, Sage, London

Rorty, Richard (1989) Contingency, Irony and Solidarity, Cambridge Univesity Press

Rosen, Stenley (1980) The Limits of analysis, New York

Rosenberg, J. (2000) The Follies of Globalisation Theory, Meard Street, London, USA: 180 Varick Street, New York

Sardar, Ziauddin \& Borin, Van Loon (2001) Introducing Science, Cambridge

Sardar, Ziauddin \& Davies Merryl Wyn (2002) Whu do People Hate America? Icon Books, U.K.

Sardar, Ziauddin (2008) Reading the Qur'an: The Contemporary Relevance of the Sacret Text of islam, Oxford University Press

Scholte, Jan Aart (2005). Globalization: A Critical Introduction, Second Edition, Revised and Updated, Palgrave, Macmillan

Semprini, Andrea (1997) Le multiculturalisme, Paris, Presses Universitaires de France

Sen, Amartya Kumar (2006) Identity and Violence: The Illusion of Destiny, W. W. Norton \& Company

Sheila C. Dow (2003) Economic Methodology an Inquiry, Oxford University Press Inc., New York

Shiva, Vandana (2002) Water Wars: Privatisation, Pollution and Profit, Cambridge

Shumar, W. (1997) College for Sale: A Critique of the Commodification of Higher Education, Falmer Press, London

Sim, Stuart (2004) Fundamentalist World: The New Dark Age of Dogma, Publisher, Icon Books

Snower, J. D. (2009). Four mega-dangers international financial markets face, In: The First Global Financial Crisis of the 21th Century, pp. 107-109, ISBN 978-953-6808-17-5, Novum, Zagreb,

Steger, B. Manfred (2003) Globalisation, Oxford University Press Inc., New York

Stiglitz, E. Joseph (2007) Making Globalization Work: The Next Steps to Global Justice, Publisher, Penguin

Swedberg, Richard (2005) New Development in Economic Sociology, Volume I, Published by Edward Elgar

Tabelini, G. (2009) Why did bank supervision fail?, In: Felton, A. \& Reinhart, The First Global Financial Crisis of the 21th Century, pp. 45-48, ISBN 978-953-6808-17-5, Novum, Zagreb,

Todaro, P. Michael \& Smith, C. Stephen (2006) Economic Development - ninth edition

Tonkiss, F. (2006) Contemporary Economic Sociology: Globalisation, Production, Inequality), Routledge, London and New York

Walia, Shelley (2001) Edward Said and the Writing of History, Icon Books, Ltd, Cambridge Wallerstein, Immanuel (2003) The Decline of American Power, The New Press, NewYork London 
Walton, P. \& Young, J. (ed.) (1998) The New Criminology Revisited, Macmillian, Basingstoke

Zimbalist, A. (1999) Unpaid Professionals: Commercialism and Conflict in Big-Time College Sports, Princeton University Press

Zinn, Howard (2003) A people's History of the United States - 1492- Present, New York: Harper Collins

Zizek, Slavoj (2004) Iraq: The Borrowed Kettle, First Published by Verso 2004 


\title{
Developing Educational Practices in the Globalized World
}

\author{
Maura Striano \\ University of Naples Federico II, \\ Italy
}

\section{Introduction}

In the globalized world scenario we can identify new social needs to which new educational needs correspond, with the aid of a matrix focused on individuals, communities and societies and their relationship.

This matrix is particularly useful in making visible -in different cultural and social contextsthe emergence and development of educational demands, which need to be acknowledged and responded to through multiple devices and tools.

We have to cope with the demands of very different kinds of people, from various parts of the world, who are asking to be involved in a common educational journey; these demands are grounded in global educational needs: the need to grow, to develop individual and collective capabilities, to learn lifelong and lifewide and to acquire higher levels of awareness and consciousness.

As far as global educational needs are by-products of global social needs, we are asked to reflect on the emergence and development of social needs on a broad perspective connecting them with the main social issues characterizing the globalized world scenario.

The above mentioned needs concern broad groups of people, who are not localized in a particular cultural or territorial area but are widespread in different countries and are identifiable not for their race, cultural heritage or nationality, but for their sharing of particular conditions of life, experiences, learning, stories and understandings.

In a global framework, it therefore becomes necessary to reflect on the conditions and opportunities which sustain the educational agency as a response to the above mentioned needs and demands; this is necessary in order to understand its role and functions with a pedagogical perspective.

The challenge here is to integrate local and global, contextual and more general perspectives in a mirror game which can help us to have an effective portrait of the complex reality we are asked to deal with.

Global educational needs call for a deep change in educational models, practices and systems, which are required to have a greater sustainability and validity, in order to respond effectively to the requests emerging in the new social scenarios. 
Within this context, it is increasingly necessary to provide specialized educational responses through specific strategies, devices and methodologies, as well as to develop and implement dedicated educational practices, aimed at responding to the multiple educational needs emerging in the globalized scenarios; these practices have to be acknowledged and cultivated as a particular kind of social practice as they exercise and express a specific agency within social structures and have a significant impact on social contexts at a multiple level.

\section{The multi faceted scenarios of the globalized world}

The process of globalization we can observe in contemporary world scenarios has, indeed, its roots in modernity (Giddens 1990). However, it has further developed in the present direction since the end of the nineteenth century according to three big patterns involving different trends over time: the globalization of countries; the globalization of companies; and the globalization of individuals (Friedman, 2000).

While there is, at the moment, an ongoing debate regarding the precise nature of the causal forces behind globalization, there is also a wide agreement on the idea that this process is not to be considered simply as the outcome of international trade and investment drives; therefore, it cannot be explored through an exclusive focus on economic factors, as far as it involves a complex combination of different trends, with significant cultural, political and social implications.

Within this framework, globalization can be considered as a relatively long-term, multipronged process which has been growing more intensively in the recent decades. It is sustained by three different driving forces which manifest themselves in many different arenas of social activity: deterritorialization, interconnectedness, and social acceleration (Scholte, 1996, Kofman \& Scholte, 2000).

This process has involved new forms of interaction and integration between productive forces, governments, institutions and people (Harvey, 1989 1996) through a set of dynamic relationships involving four core units: societies, international systems, individual selves and humankind; these units are deeply interconnected and integrated within different contexts, thus impacting on multiple dimensions of human living (Giddens 1990; Held, McGrew, Goldblatt \& Perraton 1999).

Within this complex and multidimensional framework, economical, political and social dimensions are implied, whose evolution and intersection - in a short as well as a long term perspective -can be studied through a multivariate approach; in this way, it is possible to focus on the developmental trends of new forms of associate living, governance and production, which have a different impact on cultural, economical, political and social development within the different countries (Dreher, Gaston and Martens, 2008).

Each facet of globalization is determined by the above mentioned driving forces and elements, and consists of a complex and relatively autonomous series of empirical developments; these involve a variety of social activities and events, bearing a more or less extensive and strong influence and impact on different local and regional endeavors, irrespective of their geographical location and condition (Ruggie 1993; Tomlinson 1999; Scholte, 1996; Kofman \& Scholte 2000). 
Globalization also implies deep changes in the spatial and temporal contours of individual and collective existence, which modify many essential forms of social agency and social activity in very different ways (Eriksen 2001; Scheuerman 2004); over time, the degree of these occurrences can become predictable and regularized (Held, McGrew, Goldblatt \& Perraton 1999) and these forms may be better understood, in order to orient and manage them in a more sustainable way.

Linking together human activity across regions and continents, as well as adding and expanding crucial links, globalization activates multiple processes of change which underpin a deep transformation in the "organization of human affairs" (Held, McGrew, Goldblatt \& Perraton 1999).

With this perspective, globalization involves processes of societalization, internationalization, individuation, and generalization of consciousness about humankind (Robertson 1991: 215-6; 1992: 27) which determine both the "compression" of the world as well as the "intensification of consciousness of the world as a whole" (Robertson, 1992:8); individuals and communities are therefore asked to define an identity and to assume a position with reference to the emerging global whole (Robertson, 1991: 216; 1992: 29).

This means that, within the global scenario, people are constrained to "care about" the world and to work in order to develop the conditions under which "caring for" global issues can flourish as a direct response to acknowledged and expressed needs, to be monitored according to its results and outcomes (Noddings, 2005).

Within this framework, in order to "care for" the above mentioned social and educational needs, it is necessary first of all that individuals, communities and societies start to "care about" them in order to create the cultural, economical, political and social conditions under which it can be really possible to manage them through dedicated actions, policies and practices.

In these terms, globalization poses a cultural, political and social problem, identifiable as the problem of "globality" which implies the development of a "world culture", denoting the multiple ways of defining the global situation, conceived as a response to this shared predicament (Robertson, 1992: 132).

Capturing "the form in terms of which the world has moved towards unicity" (Robertson, 1992: 175) globalization and globality can help us to define and explore in a different way the issues at stake in contemporary world scenarios; this involves taking into account first of all some universal questions -such as what it means to live and grow in the globalized world, how this world should be organized, how it may be developed - which are basically global in their inner structure and meaning but may receive different answers from individuals and societies, according to different conditions and perspectives.

Social needs and educational needs have to be acknowledged and analyzed according to the paradigm of "globality" in order to be understood in all their complexity, focusing on their interconnectedness and on their impact on social endeavors, considered from a global perspective.

This has a significant educational implication as far as it calls for the development of a global education framework which should promote both the rise of a general global consciousness as 
well as the development of new knowledge structures and new understandings regarding relevant global issues.

Only the propagation and development of a global perspective (including both awareness, consciousness and understanding) can ground the possibility of a multiple and sustainable coexistence in the world, considered as a single place for all and everybody.

\section{The globalization of social needs and trends}

One of the main problems we have to deal with, is the globalization of social issues, which need to be analysed within a global consciousness framework and with reference to a "global culture" (Robertson, 1992).

Social systems may appear very different according to their different continental and national locations, but the problems at stake in contemporary cultural and political scenarios seem to have a common matrix, which helps us to identify them as global issues.

For this reason, it is necessary to take into account the core drives which characterize contemporary scenarios and are strictly interconnected in a global perspective, even if each of them has specific connotations.

These drives can be identified as: social change, social development, social inclusion and human development.

Social change is a common and widespread process determined by a transformation in the social order of a social group or society as well as a modification in social institutions, social behaviors, and social relations which can occur in different ways, times and spaces.

Since societies are driven and sustained by macroscopic and permanent social movements brought about by inner driving forces engaging them in intensive and perpetual selftransformation- we can consider social change as a constantly ongoing process (Etzioni, 1968).

This process is determined both by the interaction of evolving social structures -which have the potential to operate through specific policies and practices- and individual and collective agency (Archer, 1995;Buckley, 1998); agency is shaped by structures, but it can eventually reshape these structures, through action and praxis, in a new and different way (Archer, 1995).

For this reason, the relationship between structures and agency should be understood as a dynamic perspective considering the structuration processes underlying the development of new social patterns (Giddens, 1990) determining social change and social development.

Generally, social change refers to changes that are beneficial to society, but it may result in negative side-effects or consequences that can, for example, undermine or eliminate existing forms of associate life.

Moreover, there could be contradictions, more or less strong, resulting from differential rates of change in various sectors of society, and this may produce internal and external tensions.

There may also be contradictions between structural characteristics and individual and collective aspirations or cultural themes, which can generate different kinds of dialectics (of 
equality; of socialization; of universality) therefore bringing further complexity to the growth and change of human societies (Aron, 1972).

This is particularly true if we consider the phenomenon we are referring to as a global one, even if its manifestations and development may be different within different territorial areas.

Indeed, social change may be driven by cultural, religious, economic, scientific or technological forces, which come to target the underlying causes of critical social problems through different methods (such as for example direct action, protesting, advocacy, community organization, community practice, revolution, and political activism..) having an overall impact on social organization, structuration and development.

It must therefore be understood that social change is not an isolated phenomenon as far as it can be seen as a general drive in the development of world societies. Moreover, even when it occurs in a specific country, social change comes to have an influence and impact also on other social systems, more or less distant, through the circulation of information, ideas, representations and practices.

In this process a significant role is played by new forms of communication, information and interaction through the use of new technologies (such as for example social networks, you tube, skype..) which have impressively contributed to the propagation of images, sounds, texts....as well as to the construction of multiple public spaces of communication, exchange, encounter, debate and reflection.

The basic mechanism driving social change is, at a general level, the increasing awareness and consciousness of social problems by individuals and groups. This results in the search for better opportunities for progress and in the development of new forms of organization and of new structures, which are more able to direct the available social energies, skills and resources towards new actions and practices.

It is therefore extremely important to promote -through different forms of actions, activities and practices- the increasing of the levels of social awareness and consciousness which in practice will determine the activation of a process of social development.

Social development can be acknowledged as a process (natural or planned) pertaining to all societies at all historical periods and may, therefore, be considered as a "global process". As a natural process of development it occurs as the result of the actions, activities and practices of numbers of individuals through which societies achieve new forms of organization without being necessarily conscious of it; as a planned process, it is the result of deliberate conscious initiatives by organizations and institutions to speed up development through dedicated actions, programs and policies.

In any case, this process is characterized by an upwardly ascending movement featuring growing levels of "energy, efficiency, quality, productivity, complexity, comprehension, creativity, mastery, enjoyment, and accomplishment" for all the social systems distributed in the global scenario (Jacobs, Asokan, 1999:152).

As theorists point out, development occurs through different stages (physical, vital and mental) and processes which involve the organization of resources and social forces in an increasingly effective way in order to cope with the challenges imposed by the new world scenarios (Cleveland, Jacobs, 1999): the creation of new institutions which derive from the maturation of organizations into more structured and stable systems; the cultural transmission of 
aspirations, projects and understandings through social organizations (such as families or educational systems) which maintain and sustain the development process as far as its driving forces are human beings and not material factors (also considering that in the mental stage, we observe an increasing power of ideas to change social life).

From this perspective, the main factors determining social development are attitudes, competences, knowledge, skills and values which combine at an individual and collective level, generating new forms of human agency, experience and practice.

In order to produce a real developmental process, these elements must be expressed by all social groups and not by a limited number of individuals or groups.

For this reason, social change and social development are strictly connected, in a circular perspective, to social inclusion which is, indeed, a crucial issue in the globalized world scenario.

In very different social contexts all over the world, it always happens that individuals and even entire communities are systematically blocked from the essential rights, opportunities and resources due to all members of any society, which are the key to social integration; the results are various kinds of deprivation, which exclude individuals and communities from full participation in economic, social, and political life.

EU documents identify social exclusion as "a process whereby certain individuals are pushed to the edge of society and prevented from participating fully by virtue of their poverty, or lack of basic competencies and life long learning opportunities, or as a result of discrimination. This distances them from job, income and education and training opportunities, as well as social and community networks and activities" (European Commission, 2004). This is due to the intersection of multiple factors (economical, cultural, political and social) which have a negative impact on social systems, making them not function as they should.

According to a "capability approach" social exclusion can, indeed, be understood as a limit on individual and collective "functioning" which refers to the states and activities constitutive of a person's or a group's social being (Sen, 1989; 1993).

This is connected to a limitation on the use of different kinds of resources (economical, cultural, social and structural), which causes the deprivation of different forms of capital (financial, human, physical and social) thereby excluding individuals and groups from access to earnings and wealth, educational opportunities, housing, social interactions and political power.

Considered from this perspective social exclusion impacts on all the states and activities embedded in any particular social system and influences the processes of social change and social development.

One determining factor of social exclusion is the presence of cultural and structural barriers to participation -both in the labour market and in society- which are due to a multidimensional process of progressive social rupture, that detaches individuals and groups from institutions and social relations and prevents them from full participation in different types of social activity at multiple levels.

Within this complex scenario, social groups such as children, the disabled, the elderly, immigrants, prisoners, unemployed and women..., have little possibility of being fully 
included in the social systems they belong to due to the strong cultural and structural barriers which constrain the systems in question.

This is connected to what can be described as a "capability deprivation", since depriving someone or some group of one or more capabilities means limiting the range of things that people can do or be in life.

As a consequence, certain individuals and groups who suffer from this kind of deprivation may never reach their full potential in certain kinds of society; these individuals and groups will also be excluded from participating in the labor force, the consumption of goods, wealth accumulation and social functions.

The presence/absence or deprivation of capabilities is, therefore, crucial in promoting social inclusion intended to mean the process of progressive inclusion and participation in a social agency of larger and larger numbers of individuals and groups, on the basis of new opportunities of access to essential goods and resources.

As we have pointed out, social inclusion is essentially based on and driven by an individual and collective capability development. In order to sustain the recovery, maintenance and development of capabilities it is extremely important to support individuals, communities and groups with devices and tools which help them to express fully their own potential on the basis of an increasing level of awareness of their needs, possibilities and rights from a global perspective.

Only if there is a wide consciousness of social needs -which implies a consciousness of social systems, individuals and groups in a global perspective- will it be possible to become aware of one's own educational needs and to connect with other individuals and groups which share the same conditions, even in very distant areas of the world.

According to the "capability approach" we should consider five components in order to be able to assess the presence/deprivation of capabilities within a social system: a) real freedom in the assessment of a person's advantage; b) the valorisation of individual differences in the transformation of resources into valuable activities; c) the presence of multivariate activities aimed at producing and maintaining happiness and well being; d) a balance of materialistic and non materialistic factors in human welfare; and e) a shared concern for the distribution of opportunities within society (Sen, 1989; 1993).

On this basis we can analyse the success or failure of different political systems, as well as the processes of globalization, democratization, development and economic growth, on a world wide perspective.

Global change, global development and global inclusion require, first of all, cultural, political and social conditions which support the overcoming of cultural and structural barriers and, secondly, the enhancement and growth of individual and collective awareness, agency and understanding, acknowledged as the driving forces of the advancement of societies.

As a matter of fact, there cannot be social development without human development. This latter is, indeed, both a condition and a consequence of the former and both are, indeed, deeply interconnected and interwoven.

The concept of human development is better understood if we consider it from a global perspective, since it refers to a global development model that can be applied to any country 
or nation and is grounded on four main pillars: equity, sustainability, production and empowerment, which should be available to any human being in any part of the world (Streeten, 1994; Srinvasan, 1994); this means that each human being has the right to be cared for and educated, to earn a sustainable living, to participate in productive processes and exercise a powerful agency both for his or her own as well as for collective life advancement.

On this basis, we can identify some essential conditions (such as education, environmental sustainability, equality, health and wealth) which are indicated by the United Nations in the millennium goals program (UN, 2009) as well as some specific goals and perspectives (such as creating living environments in which people can develop and express their full potential and lead aware, creative, healthy and productive lives in accordance with their interests, needs, potentialities and resources) leading towards human development.

These goals are strictly connected to the possibility to develop and enlarge human capabilities providing the best conditions for the growth and agency of individuals and groups.

All human beings should have the capability to be healthy, knowledgeable and economically sustained with regard to their needs, and to be in the condition to participate fully in social activities contributing to the choices and decisions of the societies in which they live but also - on a global perspective- to the analysis and management of global issues.

Human development can be measured and monitored with some specific devices which, however, are not capable of providing a description and explanation of the complex processes involved. The United Nations has elaborated the Human Development Index intended as the normalized measure of life expectancy, literacy, education, standard of living, and GDP per capita for every country worldwide which is used as the basis of annual reports for consultation (UN, 1994). These indicators are, indeed, fully representative of the complexity of human development processes but provide only a general overview of the essential conditions and elements involved; for this reason, they are integrated with those provided by the Human Poverty Index which measures the deficiencies in the three indexes of human development (UN, 1997).

Moreover, it must be said that human development is strictly connected to human rights and human freedom, because it can be achieved only if the same rights are provided to all human beings who are acknowledged as individuals who are not constrained in their choices and deliberations within the cultural and social contexts they live in. In this perspective, human development must be considered as a moral, political and social issue to be taken into account in a global framework.

As far as it is one of the driving forces sustaining all the significant advancements in the globalized world human development must be studied together with social change, social development and social inclusion in order to grasp its potentiality and specificity.

These driving forces can be observed and measured from a more general perspective if we consider them as global forces and they should be analysed (according to the "capability approach" which, as we have seen, is particularly useful as a means of focusing on the social conditions facilitating advancement and development on a global perspective) in strict relationship with the social "functionings" in which they are expressed.

One of these "functionings" is, indeed, education, considered not only as one of the primary rights but also as one of the most powerful devices to promote not only human development but social change and development as well. 
The expression of these potentialities is, indeed, not to be taken for granted if we consider that in many countries educational processes are not leading to the achievement of these goals or are simply not successful in terms of reaching educational objectives.

This lack of success depends on a series of elements and factors which weaken the social impact of education and reduce it to an ensemble of policies and practices controlled by outside forces (such as the economy, political power and spiritual power) which it contributes to maintain and strengthen.

These elements and factors are cultural, political and social and represent, indeed, the only real constraints on and oppositions to a full and true global development.

It is therefore extremely important to focus on education from a global perspective concentrating on the educational needs stemming from the social issues at stake in the globalized scenario and indicating the models, strategies, policies and practices that should be developed and implemented in order for education to fulfil its mission and role.

\section{Educational needs in the globalized world}

New educational needs correspond to the social needs previously identified, which require specialized educational responses.

As Nodding points out, the educational needs emerging in the globalized scenario are not mainly focused on knowledge, but instead on a true commitment to well informed choices and on a sound concern for global issues (Noddings, 2005). This means that education should not be conceived as a means of knowledge acquisition and construction, but as a means to sustain different forms of engagement and thinking for an aware and responsible ethical positioning regarding global issues, within a global development perspective.

As we have pointed out, all over the world, development can only be really effective and successful if it is the product of the intersection of four driving forces: social change, social development, social inclusion and human development.

Within this complex scenario, education is therefore called on to contribute to all these processes as they are indeed deeply interwoven.

We acknowledge as an educational need the need to have access to experiences and opportunities for growth intended as an ongoing never ending process directed at no other objective than the expansion of the growing potential of individuals and communities (Dewey, 1926).

Indeed, the need for growth can be understood as a global human need, not strictly connected to any particular historical, cultural or social situation, but it takes different forms within the particular groups and contexts in which this need is reflectively acknowledged and defined as a social problem.

For these reasons, the human need to grow has a particular meaning if it is interpreted within a social change scenario as we move on to focus on the social conditions which, impeding growth and therefore education, limit the possibilities of social change. 
From this perspective we must analyze, for example, the interaction between educational and other social institutions as well as their inner modifications; we must take into account social behaviors and their educational implications; we must study the social relations embedded in educational processes.

If we consider education in relation to social development (intended both as a natural and planned process) we must focus on the actions, activities and practices (not only conscious and intentional but also in some way unconscious and implicit) of individuals and communities as well as on the deliberate and planned institutional and organizational initiatives, policies, programs and strategies which may limit, orient or sustain educational processes.

We can therefore view the emergence of intentions, ends and orientations which may sustain educational processes and practices as they are activated and promoted.

If we focus on education with reference to social inclusion we must consider the conditions that limit the access to educational experiences and opportunities for individual and groups but also look at the exclusive as well as inclusive dimensions deeply embedded in educational processes, with reference to both cultural as well as structural educational barriers; moreover, we must envisage the inclusive potential of education intended as an empowering social device aimed at developing the range of capabilities available for individuals and communities.

Last, but not least, education, if we consider it in relationship with human development, can function as a powerful device as far as it can provide individuals and communities with the cultural and personal resources needed to play an active and responsible role in all the activities characterizing global scenarios.

As we have mentioned above, educational needs concern not only individuals and communities living within a specific social context, but broad groups of people who are widespread in different countries and are recognized for their sharing of particular life conditions and experiences.

A first condition could be the collocation within increasingly deterritorialized, interconnected, and accelerated living contexts, which requires a constant adaptation to new life and work conditions through the acquisition and development of new devices and tools as well as new abilities, competences, knowledge, skills and understandings.

A second condition could be the increasingly intense experience of diversity (of cultures, habits, perspectives, religions and traditions) and of change (of living context, social status and employment...) which requires the development of a new and different understanding of human life.

A third condition could be the shared awareness of the world as a whole and the acknowledgment of global issues which call for the development of a global conscience and a global participatory agency for individuals and communities.

It must be considered, indeed, that the wide-ranging impact of globalization on human existence touches on many social issues (such as immigration, transitions, job changes, ageing, diversity management, environmental protection and the sustainable use of 
resources.....) which are acknowledged as global issues and have a deep moral implication, taking into account the "mental" stage of development which characterizes contemporary social scenarios.

This last condition calls for the development of a global conscience, which is also the basis for an ethical positioning regarding the above mentioned issues, identified as specific problems to be analysed and approached through specific actions and practices.

From a "social development perspective", we are challenged to perform a practical application of ethical ideals to daily social life, which is a powerful educational challenge.

This means that individuals and communities should be involved in educational processes aimed at providing them with tools useful to elaborate pathways of ethical inquiry regarding global issues and to perform a responsible ethical agency within the global arena.

A global conscience implies also the acknowledgement of the need for a global citizenship grounded on a keen awareness of the political, economic, social, and environmental concerns of our time on a global perspective, which calls for a deep understanding of nations, cultures, languages, and religions around the globe taking into account their diversities and similarities.

It is true that these issues may receive different analyses and responses according to the variation of conditions and perspectives characterizing different cultural, social and territorial frameworks.

However, it is also true that different analyses and responses can implement a wide range of possible positionings, thereby generating new forms of human agency, experience and practice which can lead to greater social accomplishment as far as they are developed and implemented through appropriate educational actions.

From the above mentioned conditions, which are strictly interconnected, stem clear educational demands which need to be addressed by specific interventions characterized by having a common matrix (as far as they address global issues in their inner structure and meaning), but also to be realized and implemented in different ways according to the social contexts they are situated in. The challenge here is to integrate contextual and more general perspectives in a mirror game which can help us to have an effective portrait of the complex reality we are asked to deal with.

To the development of a "global needs conscience" and of a "global citizenship" it is necessary to connect a wide awareness of the opportunities available in the different social systems within a global scenario, in order to sustain greater aspirations and release greater energies.

Within this framework, "global citizenship" can be considered as a result of both "global education" and the "globalization of education".

Indeed, the call for a "global education" is a problematic issue from a pedagogical point of view.

Global education is not only a process aimed at providing all global citizens with abilities, knowledge, skills and understanding in order to create a well informed, trained, and motivated workforce (which may have an effective inclusion in a globalized job market 
within a globalized economy), but a more complex and articulated process of cultural and social change and development, based on a new vision and a new understanding of global problems.

This perspective is enlightened in the Maastricht Global Education Declaration, which emphasizes that global education is "essential for strengthening public support for spending on development co-operation. All citizens need knowledge and skills to understand, participate in and interact critically with our global society as empowered global citizens" (EU, 2002).

From this perspective global education is principally envisaged as a process of empowerment for individuals and groups as far as we consider empowerment to be a multidimensional, complex process (Cuzba, Page, 1999), which leads to individual and collective growth, grounded on the possibility of a full acknowledgment and use of inner resources.

It must be considered that there is always the risk of a progressive process of deprivation of capabilities for the individuals and groups who are not able to cope with the new living conditions imposed by the globalization processes and are therefore not able to deal with the global issues at stake.

Empowerment, indeed, enables people to take control of their own lives but also to free themselves from the structures which dominate and constrain them. For these reasons, it is strictly connected to emancipation, considered as a process of progressive liberation from any kind of cultural and social constraint which may condition or limit one's own agency and range of capability.

This connection is visible as far as the journey through which individuals and communities become more and more active, aware, conscious and responsible in respect of global issues leads them to identify the cultural, economic and social constraints that limit their possibility to grow, express themselves and participate.

On the basis of this progressive process of conscietization, in Freire's terms, it is possible to get rid of beliefs, patterns of action, perspectives, representations, theories and world views and to construct new understandings of the worlds people live and grow in and, therefore, to plan and act in a different way.

Thinking globally imposes a different positioning regarding the events people experience directly and indirectly in their daily life through different kinds of media devices; this conclusion is based on the acknowledgement that it becomes easier to "care about" issues and problems which are no longer far away and therefore invisible and un-thinkable.

On this basis both individuals and communities are engaged in the development of the cultural, economic, political and social conditions which make it possible to "care for" these issues and problems through a more aware and reflexive management (Noddings, 2005).

Within this framework, it is possible to envisage the transformative potential of Global Education since "globality" requires a deep reframing of one's meaning, perspectives and schemes (Mezirow, 1991, 2000) and the construction of new forms of agency in the social contexts people live in.

This implies that individuals and communities may come to identify themselves as global agents (therefore reframing their psychological, epistemic and socio-linguistic perspectives) 
on the basis of the acknowledgement of the possibility to play increasingly significant roles within the processes leading to social change and social development at different levels.

For these reasons, Global Education calls for educational models, strategies and practices aimed at promoting the acquisition and development of conceptual tools; knowledge structures; and patterns of action useful to sustain differentiated and multiple forms of global agency in various contexts.

Global agency is a form of social agency which places each action, choice and performance within a global scenario and gives it a new meaning and significance. This requires a high level of awareness and reflexivity as far as it leads to a focus not only on the immediate effects and impacts of the above mentioned actions, choices and performances but on their broader consequences and effects within a global perspective. In these terms, it is also the essential condition for a full participation in all processes of change and development occurring at different degrees and levels worldwide.

Participation within a global perspective requires specific conditions which facilitate and sustain increasingly articulated and widespread information, communication and exchange processes, to be necessarily sustained by specific resources and tools, essential for any form of global agency.

Within this framework, global agency is therefore identifiable as a fundamental educational need, which asks to be fulfilled through dedicated educational actions and practices aimed at fostering and promoting new attitudes, abilities, capacities, competences and understandings.

Global agency requires first of all a specific attitude to look at each event, issue, problem and situation from a global perspective; secondly, the ability to analyze and explore them using categories, concepts, constructs and methodologies useful to frame and reframe them within a complex, multifaceted scenario; thirdly, the capacity to engage in a sound process of indepth exploration of the conditions generating them; fourthly, articulated competences of action planning, positioning and revision on the basis of the elements of knowledge constructed through inquiry and reflective processes; and fifthly, a broad understanding of the meanings involved in the above mentioned issues, problems and situations.

Global agency can be fully expressed only under some circumstances and conditions since it requires people to have the possibilities and the tools to work out global issues and to plan and perform sustainable action and interventions within a complex scenario, requiring articulated connections and interactions.

For this reason, global education involves a radical turn towards interconnectedness and creates possibilities for achieving more equality, social justice, understanding and cooperation amongst peoples.

This can happen on the basis of a deep, structural shift in the basic premises of thoughts, feelings and actions of individuals and groups which foster mutual knowledge and collective self-awareness.

Higher levels of global consciousness and social awareness are sustained by attitudes, competences, knowledge, skills and values expressed both at an individual as well as at a collective level. 
One of the most powerful devices aimed at the acquisition and development of these essential elements is the system of education available in the different societies, which needs to be therefore acknowledged as a social development device as far as -within a lifelong perspective-it offers challenges and opportunities to raise social awareness and consciousness and, at the same time, develops individual and collective capabilities.

Global education calls for a deep change in educational models, theories and practices on the basis of a deep relationship between globalization and educational change.

This results from educational systems being involved - at different levels - in a deep process of transformation in order to respond to the educational demands emerging in the globalized scenario.

This transformation occurs through a re-organization of structures, curricula, methodologies and materials which require to be specifically tailored to both global and local educational needs.

Within this framework, the "globalization of education" is a very articulated process determined by the impact that worldwide discussions, processes and institutions may have on local educational practices and policies.

Indeed, in the globalized world all events happening on a global scale have an impact on events happening on a local scale (Spring, 2009) but, at the same time, it is also true that events and phenomena occurring on a local scale may become significant on a global scale as far as they impact on global issues. This means that some educational activities, policies and practices designed and developed to respond to local needs, may become a new input for global educational change.

Educational change is indeed a central issue in the globalized scenario. Economic and social change and development are strictly connected to the devices through which the different societies promote growth and circulate knowledge and information, considered as essential resources.

Within this framework, globalization and global economy shape the nature of educational opportunities and institutions and this poses a deep challenge to educational systems (Striano, 2009) which are forced to develop according to shared guidelines (Carnoy \& Rothen, 2002) but, at the same time, to maintain a specific cultural and territorial configuration.

International organizations, such as the United Nations and UNESCO, but also the World Bank and the European Community, together with many scientific and cultural organizations -at an international or national level- are strongly involved in the expansion of global education according to different aims and interests.

This process requires, indeed, the intervention of multiple actors and forces (governments, international organizations, nongovernmental organizations public and private schools, multinational corporations, communities and families...) which play a dynamic role in meeting multiple educational demands through the effort of constructing a global education superstructure.

Even if there is an increasing collaboration among these organizations (which are directly and indirectly connected on a global basis) there are also cultural and political drives which 
tend to react to a wider unification of educational systems and call for new educational models and strategies, specifically tailored to the specificity of different cultural and territorial contexts.

Indeed, the analysis of educational systems within a global perspective requires a consideration of the presence of multiple elements which are, over time, deeply interconnected.

In the last few years, we have seen a transformation of the public educational sector which has been challenged by multiple and diverse requests and is working very hard to cope with the call for a global and intercultural education through a deep change of curricular structures, inner organization, activities and practices.

Moreover, we observe a strong development of the private educational sector, together with an expansion of a global education industry, which has involved several multi-national private educational companies, together with dedicated educational services.

This is connected to the emergence and growth of non-profit educational institutions at primary, secondary, and tertiary levels, which have an increasing impact on educational processes.

Within this articulated framework, at different levels, the call for global education requires: a) the development of educational models and strategies that, beyond traditional modes of education, can cope with the characteristics and requests of very different kinds of people, from various parts of the world, who share common conditions and demands; and b) the development and implementation of specific educational practices which can be considered as a repertory to build up and share within a broad community of educational practitioners disseminated in different territorial contexts, who are called on to cope with the same educational needs within a globalized perspective.

\section{Educational practices for the globalized world}

What kind of educational models and strategies are required to cope with global change in order to sustain global development in an articulated educational scenario?

As we have previously pointed out, social change and social development are not brought about only by an economic development sustained by a competent, qualified and skilled workforce, but they occur and continue on the basis of greater levels of awareness and consciousness involving both individuals and communities.

The above mentioned processes are therefore sustained by educational actions, policies and practices which are intentionally directed towards individual and collective growth building community and mutual respect, creating social responsibility, instilling an appreciation for diversity, promoting emotional literacy and managing and resolving conflicts (Noddings, 2005).

This is a consequence of a "mental" stage of development, which therefore calls upon the necessity to invest most of all in actions and practices aimed at supporting the enhancement of mental forces and resources both at an individual as well as at a collective level.

Within this framework, education has to be considered as a powerful device for social development as far as it points to: a) the implementation and support of processes of 
continuing growth; b) the growth of higher levels of global and social awareness and consciousness, which are the key elements of a global citizenship; and c) the acquisition, enhancement and implementation of abilities, competences, knowledge, skills and understandings meant as tools to cope with the requests of the global productive scenario.

Within this perspective, education becomes the only device that can support the elimination of cultural barriers, the development of capabilities and the enhancement of levels of civil and social consciousness both for individuals and communities.

On this basis, educational processes have to be strongly addressed to the enhancement of the levels of comprehension, creativity and mastery both for individuals and groups, who are constantly asked for an active and participatory involvement in activities and tasks, which produce more aware and responsible forms of agency, experience and practice.

This requires the design of specific educational models and methodologies aimed at sustaining and justifying educational strategies and practices.

A model is the product of cultural elaborations leading to collectively acknowledged and shared representations of determined social practices in their inner structure.

It can be understood as a conceptual schemata which helps in the connecting and ordering of different and multiple aspects and elements of educational situations according to guiding criteria or principles, which guarantee the model coherence and sustainability.

Each model is the expression of a particular educational perspective and performs a normative function within educational systems; for these reasons it has to be considered as a schema of connection between a specific educational aim (which comes from the direct experience and interpretation of the educational situation) and a series of specific educational practices (constructed, developed, implemented over time) which come to have meaning and sense but also concreteness, viability and visibility through specific structures.

Every model is strictly connected to the belief system as well as the organizational forms embedded in a specific society, guiding the organization of daily educational experiences and practices.

Within the contemporary cultural and social framework we notice the presence of two big educational models: a "specialist" model (technical and professionalizing) (which has evolved with the beginning of the modern age) and a "polyvalent" model (reflective, multifunctional) developed within a post-modern scenario (Bruner, 1996).

These models have been considered, indeed, somehow competitive but not alternative within the current global scenario, where we acknowledge the need for both specific technical and professional abilities and skills and for self awareness, consciousness, flexibility and reflectiveness.

Which educational model could be more suitable for the globalized world?

Should we orient educational processes towards the acquisition of abilities, competences, knowledge, skills and understandings in order to create professional profiles who can be effectively positioned in the global market scenarios or should we orient them towards the development of aware, capable, creative, flexible, reflective and responsible personal identities who can be active and purposive agents in multiple social contexts, therefore contributing to social change and development? 
Indeed, both paths are required, but in order to fulfil the emerging educational needs in contemporary scenarios, they should be more and more integrated and interconnected.

The challenge is to select and use different elements from both the models, in other to construct and develop effective educational strategies, methodologies and practices, aimed at raising the levels of agency, ethical positioning and responsibility both within a local and a global perspective.

Moreover, in order to respond to the above envisaged educational aims, the educational models selected should be translated into an articulated, adaptive, comprehensive and flexible plan of action identifiable as a general strategy to govern and monitor educational processes within a global perspective.

For this plan to be effective, it is, moreover, necessary to refer to an operational methodology (intended as the scientific foundation and development of methods and practices) which should support different courses of action.

The Maastricht Declaration indicates a general methodology for Global Education aimed at "supporting active learning and encouraging reflection with active participation of learners and educators" (EC, 2002).

This methodology is based on the acknowledgement that the essential requirement of an educational process is its impact on social change and development; this means that all educational processes should be mainly oriented to provide resources and tools aimed at sustaining the above mentioned social goals within the UN Millennium Goals Scenario.

Active participation is therefore a basic condition as well as a target objective of all educational processes since it refers to a fundamental element for any social advancement and evolution.

This means that these processes should be methodologically sustained by participatory approaches and devices in order to make them consistent with global development requirements.

Interesting educational possibilities in these perspectives are offered by the use -in different contexts- of participatory methodologies, as far as these sustain the progressive active and responsible involvement of individuals and groups in processes leading to the construction of new understandings and the development of new social practices aimed at promoting and sustaining social development.

Within this framework, there is a strong connection between global education and participatory education considered as a "collective effort in which the participants are committed to building a just society through individual and socioeconomic transformation and ending domination through changing power relations" (Campbell, Burnaby: 2001, 1). Participatory education is a cyclical process during which participants identify and share problems emerging from individual and collective experiences and later move on to reflecting and developing a critical social analysis, in order to construct a deeper understanding of the social conditions affecting the problems at stake. This process is undertaken in order to develop strategies aimed at promoting action and change.

But it is also a process which helps people to explore power dynamics and power issues and to construct new patterns of power relationships, strongly modifying the pre-existing ones. 
For this reason, participatory education can be seen as a device for individual and community empowerment as far as it allows the construction of focuses on both individual and community change, therefore identifying and sharing educational objectives and goals as common commitments, involving individuals and communities in a journey towards a continuous growth.

This can occur through dedicated pathways such as, for example, participatory action research projects (Orefice, 2004; Kandoor, Jordan, 2009) intended as educational opportunities aimed at the enhancement of levels of awareness, conscience and participation for individuals and groups starting from the analysis of local problems which can be related to global issues.

Participatory action research can therefore be understood both as a method for social research (as far as it helps in the identifying and working out of social issues) as well as a powerful educational device (as far as it works as an endogenous drive within social contexts aimed at promoting awareness, reflection and understanding).

One of the most relevant educational outcomes of participatory action research is a deep reframing and transformation of the meaning perspectives held by individuals and communities, which may be identified as the habits of expectation and the structures of assumptions within which new experiences are assimilated and transformed by past experiences (Mezirow, 1991); this happens during a culturally situated process of interpretation of the meaning and sense of those experiences, which constructs strong frames of reference.

The only possible way to de-construct and re-construct these frames of reference is to promote a critical and reflexive analysis of their origin and implications, which leads to a deep transformation of individual and collective understandings.

The focus here is not only on participation (both as a condition and a target objective) but also on the necessity that educational processes have a significant outcome in terms of learning considered as a transformative tool for individuals, communities and societies.

Within this framework, the Guidelines for Global Education provided by the Council of Europe suggest a methodological approach mainly focused on transformative learning processes as far as they promote a deep reframing of meaning schemes and perspectives regarding global issues.

According to the Guidelines, the above mentioned methodological approach is focused on some specific kinds of practices such as: experiential practices; collaborative practices; intercultural practices; action practices; and contextual practices, which are characterized as being powerfully involving and supporting active participation as well as critical reflection.

Within the transformative learning approach critical reflection is a process through which people become "critically aware" of their own and others' tacit assumptions and expectations and get to a deep "transformation" of meaning perspectives which implies changes in self understandings, a revision of belief systems and changes in lifestyles (Mezirow, 1991, 2000); on these bases, this process leads to an expansion of consciousness through the transformation of the basic worldview.

With reference to Global Education, considered as a primary educational goal in the globalized world scenario, the use of the transformative learning approach "implies a 
radical change towards interconnectedness and creates possibilities for achieving more equality, social justice, understanding and cooperation amongst peoples"(EC, 2004).

This is not to be considered as an outcome only limited to Global Education contexts and processes but as a general outcome of any educational process conceived and developed within a global framework according to global development goals.

The reference to the transformative learning methodology is particularly interesting also because it contributes to a reframing of the meaning and role of education in global development processes.

Within this framework, it becomes possible to conceive of educational processes as transformative devices leading to a deep change of personal and collective perspectives, representations and theories.

This change is functional to a more aware and responsible process of the acquisition and use of knowledge conceived as a resource for development as well as a process of the construction of new understandings regarding different kinds of issues and problems.

In a globalized scenario education can be acknowledged and used as a powerful transformative device as far as it is conceived as a tool which can be easily suited to the specificity of the social and educational needs characterizing a determined cultural and territorial context but also understood (according to the "globality" approach) as a global resource that needs to be discovered (or re-discovered) in its general characterization and connotation (as well as in its intrinsic potential of development and growth) even in very different socio-political contexts.

We acknowledge, indeed, the above mentioned strategies, methodologies and practices as examples of empowering social devices as far as they activate processes aimed at: the overcoming of cultural, ideological and structural barriers as well as at the construction and use of new forms of knowledge; the development of attitudes, competences, knowledge, skills and values (combined at an individual and collective level); and the enhancement of individual and collective capabilities.

Through empowering educational devices individuals and communities (who are mutually interconnected) can recognize the inherent possibility they possess to control their own lives and access personal/collective power, authority and influence in order to use them when engaging in different kinds of social activities and processes (Jones, 2006).

Empowering educational devices require the design, cultivation and implementation of dedicated educational practices which have significant outcome in terms of social participation and transformative learning.

Good examples are reflective as well as inquiry based educational practices in different declinations since they: a) generate higher levels of critical awareness of individual and collective beliefs and forms of knowledge; b) help in projecting and realizing new patterns of agency reflectively constructed; and c) produce new structures of knowledge and new understandings.

These practices should not be localized only within formal educational contexts, but should be widely disseminated within educational systems with a lifelong and lifewide perspective, involving non formal and informal contexts as well. 
This stems from the need to involve the whole social body in educational actions, which should not be confined to delimited areas and fields of influence but must have a greater impact on social growth.

As we have seen, within a global scenario, education is increasingly a shared concern which involves different actors and forces operating in multiple and various contexts and situations and according to different patterns.

In their differences, these actors and forces nonetheless acknowledge themselves as involved in practices characterized both by common elements as well as by particular differences linked to the specificity of the different contexts they are situated in.

Within this framework, educational practices should not be acknowledged as a technical repertory of tools to support educational processes, but as a fund of experiential and empirical resources, which can be adapted, shared, transferred and transformed within a wide community of practitioners involved at different levels, with different responsibilities and different roles in educational processes.

Moreover, practices are cultivated, developed and implemented by one or more communities of people (professionals, stakeholders and learners) who, with different documentation and reflection devices, contribute to the texture of an ongoing process of redefinition, re -interpretation and re-construction of those practices.

Within a global perspective, educational practices are not limited to a specific context but can become a shared repertory which can be cultivated and implemented over and over by a global community of educational practitioners disseminated in different territorial contexts, as far as they are called on to cope with the same educational needs all over the world.

For this reason, it is particularly important to create and maintain connections among the different communities of educational practices spread all over the world, through different forms of communication, exchange of experiences, materials and reflections.

These connections should therefore be documented and shared through multiple devices in order to allow their circulation and dissemination in different educational contexts and their adaptation, experimentation and modification by educational professionals.

In order that they do not lose their empowering and transformative potential, it is extremely important that educational practices do not become routine, but are developed, revised and transformed by different communities of practice worldwide.

An effective development of educational practices occurs when they are first of all acknowledged, identified and traced either within the communities of practice where they have initially emerged or within a broader network of educational communities which find them useful for their specific needs.

Through their application and experimentation in different and multiple contexts, these practices are then formalized, modelled and studied in a circular process connecting practice and theory.

It is therefore particularly useful to sustain this process with dedicated devices and tools which can help educational communities all over the world in the cultivation of their 
practices, which may be further developed and implemented through a continuous process of reframing of their range of application and transfer all over the world.

There is, indeed, a constant interplay between processes of conservation and preservation of existing practices, acknowledged as "good practices" and therefore celebrated, sustained and transmitted and processes of critical revision, modification and transformation of practices which prove to be ineffective.

Communities of educational practices are conceived as "learning systems" in which "dynamic conservatism" operates at such a level and in such a way as to permit a "change of state", without threatening the essential functions and practices the system fulfils for the self; these communities indeed, require to maintain their identity as well as to support the self-identity of those who belong to them, but they must at the same time be capable of transforming themselves and their practices (Schön 1973: 57).

As Schön points out, a community learns whenever it acquires a new capacity for agency and practice; learning may take the form of direct or indirect interaction between different kinds of communities acquiring a new capacity to act through continuing, directed inquiry into the nature, causes and resolution of the problems emerging from their practices.

The movement of learning may occur as much from periphery to periphery, or from periphery to centre, as from centre to periphery; therefore communities may function as facilitators of learning for broader networks just as the networks may help the communities in their learning processes (Schön 1973).

A true development of educational practices occurs, indeed, through reflective processes, emerging inside the educational practices, in particular, in the course of educational actions implied within those practices (Schön, 1987; 1991).

This may happen through the use of devices, which help education professionals to focus on their practices, analyze them, identify the internal processes which may undermine them making them less effective and powerful and conduct an inquiry on the problems emerging from inside the educational activities and contexts.

The act of reflecting-on-action enables professionals to spend time exploring why they acted as they did and what was happening in a group or in a situation; in so doing they develop sets of questions and ideas about their activities and practices.

Reflection involves looking to professional experiences, attending to the theories in use and building new understandings in order to inform educational actions in situations that are constantly unfolding.

Through reflection educational practitioners allow themselves to experience surprise, puzzlement, or confusion in situations which they find uncertain or unique; they reflect on the phenomenon before them, and on the prior understandings which have been implicit in their agency and in their performances; moreover, by reflecting on their actions professionals carry out an experiment which serves to generate both a new understanding of the phenomenon and a change in the situation (Schön 1987).

Reflective processes help practitioners to build up a collection of images, ideas, examples and actions that they can draw upon and that can be used as a repertory, which is constantly 
implemented through further reflection as far as practitioners fall back on the routines in which previous thought and understanding has been sedimented.

The ability to draw upon a repertory of metaphors and images that allow for different ways of framing a situation is clearly important in creative practice and is a crucial insight for practitioners in their daily agency.

In order to do this, educational practitioners may write up recordings, talk things through with colleagues or with a supervisor, analyze and discuss their actions and practices in a small group, or compare with other professionals through multiple communication and interaction devices.

As practitioners think and act, questions arise that cannot be answered in the present, but the reflective space afforded by recording, supervision and conversation with other colleagues allows them to approach these as problems to be deeply explored through various approaches and perspectives (Smith 1994).

Reflective spaces are not only spaces for interactions in person but may also be virtual spaces which- on a global perspective-allow people belonging to different educational communities, widespread all over the world, to join together to focus on their problems and practices, to share experiences and repertories and to learn together through an ongoing process of reflection.

In this process we can see the significance of networks, flexibility, feedback and transformation, which can help educational communities in the construction of new learning and understandings in order to perform their educational agency in a more effective and powerful way.

\section{References}

Archer M. (1995), Realist Social Theory: The Morphogenetic Approach, Cambridge University Press: Cambridge, ISBN: 0521481767

Aron R. (1972), Progress and Disillusion, the Dialectics of Modern Society, New York: Penguin Books, ISBN: 0140214054

Agulnik P., Hills, J., Le Grand, J., Piachaud, D. (2002), Understanding Social Exclusion, Oxford: Oxford University Press, ISBN: 0199251940

Bruner J. (1996), The Culture of Education, Harvard: Harvard Univ. Press, ISBN: 0674179528

Buckley W.F. (1998), Society as a Complex Adaptive System: Essays in Social Theory, New York: Gordon and Breach, ISBN 9057005379

Campbell P., Burnaby B. (2001), Participatory Practices in Adult Education, Mahwak: Lawrence Erlbaum, ISBN: 0805837043.

Carnoy, M., Rothen, D. (2002): “What does globalization mean for Educational Change?. A comparative approach" in Comparative Education Review, vol. 46, n 1, pp. 1-9, ISSN: 00104086

Cleveland H., Jacobs G., (1999), "Human Choice The Genetic Code for Social Development" in Futures, Volume 31, Issues 9-10, November, Pages 959-970, ISSN: 0016-3287

Czuba, C., Page, N. (1999), "Empowerment: What Is It?" in Journal of Extension Volume 37, 5, http://www.joe.org/joe/1999october/comm1.html

Dewey J. (1916), Democracy and Education, Carbondale: Southern Illinois University Press, ISBN: 080931259X 
Dreher, A., Gaston N., Martens, P. (2008), Measuring Globalization. Gauging its Consequences, New York: Springer, ISBN: 0387740678

Etzioni A. (1968), The Active Society: A Theory of Societal and Political Processes. New York: Collier-MacMillan, ISBN: 0029095808

Eriksen, T. H. (2001), Tyranny of the Moment: Fast and Slow Time in the Information Age, London: Pluto Press, ISBN: 074531774X

European Union (2002), The Maastricht Declaration for Global Education, http://www.coe.int/t/dg4/nscentre/ge/GE-Guidelines/GEgs-app1.pdf

European Union (2004), Joint Report on Social Inclusion, Directorate General for Employment and Social Affairs.

http:/ /ec.europa.eu/employment_social/soc-prot/soc-incl/joint_rep_en.htm

European Union (2010), Joint Report on Social Protection and Social Inclusion, Directorate General for Employment and Social Affairs. http:/ / ec.europa.eu/social/ main.jsp?catId=750\&langId=en

Friedman T., (2000), The Lexus and the Olive Tree, New York, Anchor Books, ISBN: 0385499345

Giddens, A., (1990), The Consequences of Modernity, Stanford: Stanford University Press, ISBN: 0804717621

Harvey, D., (1989), The Condition of Postmodernity, Oxford: Blackwell, ISBN: 0631162925

Harvey, D., (1996), Justice, Nature, \& the Geography of Difference, Oxford: Blackwell, ISBN: 1557866805

Held, D., Mcgrew A., Goldblatt, D., Perraton, J., (1999), Global Transformations: Politics, Economics and Culture, Stanford: Stanford University Press, ISBN: 0804736278

Hobcraft, J. (2002), "Social Exclusion and the Generations" in Agulnik P., Hills, J., Le Grand, J., Piachaud, D., Understanding Social Exclusion, Oxford: Oxford University Press, pp. 62-83, ISBN: 0199251940

Inglis T. (1997) "Empowerment and Emancipation", in Adult Education Quarterly, Fall, vol. 48 no. $13-17$ doi: $10.1177 / 074171369704800102$

Jacobs G., Natrajan A. (1999), Toward a Comprehensive Theory http://www.mssresearch.org/?q=Human_Choice_Page5

Jones A., (2006), Dictionary of Globalization, Cambridge: Polit,. ISBN: 0745634419

Kapoor D., Jordan S. (2009), Education, Participatory Action Research, and Social Change: International Perspectives, New York: Palgrave MacMillan, ISBN: 0230615139

Kofman E.,Youngs G. (eds.), Globalization: Theory and Practice, London: Pinter, ISBN: 1-85567347-9

Lupton, R , Power A. (2002), "Social Exclusion and Neighbourhoods" in Agulnik P., Hills, J., Le Grand, J., Piachaud, D. (2002), Understanding Social Exclusion, Oxford: Oxford University Press, pp. 118-140, ISBN: 0199251940

Mezirow J. (1991), Transformative Dimensions of Adult Learning, San Francisco, CA: JosseyBass, ISBN: 1555423396

Mezirow J., Taylor E.W. (2009), Transformative Learning in Practice: Insights from Community, Workplace, and Higher Education, San Francisco: Jossey Bass, ISBN: 0470257903.

Mezirow, J. (2000), Learning as Transformation: Critical Perspectives on a Theory in Progress, San Francisco: Jossey Bass, ISBN: 0787948454

Noddings N., (2005), (ed.) Educating Citizens for Global Awareness, New York: Teachers College Press, ISBN: 0-8077-4534-0

Orefice P. (2004), Higher education and Interculturality. University, scientific knowledge, global and diverse learning, http:/ / www.yorku.ca/hdrnet/library.asp?id=169\&subid=177 
Reason, P., Bradbury, H. (Eds.) (2001) Handbook of Action Research: Participative Inquiry and Practice, Thousand Oaks, CA: Sage, ISBN: 1412920299

Robertson, R. (1991), "The Globalization Paradigm: Thinking Globally", in .BROMLEY D.G. Religion and Social Order. Greenwich: JAI Press, pp. 207-224, ISBN: 1559387637

Robertson, R., (1992), Globalization: Social Theory and Global Culture, London: Sage, ISBN: 0803981864

Ruggie, J. G. (1993), “Territoriality and Beyond: Problematizing Modernity in International Relations," in International Organization, 47, pp. 139-174, ISSN: 0020-8183.

Saraceno, C. (2001), Social Exclusion. Cultural Roots and Diversities of a Popular Concept, Social Exclusion and Cabinet Office:2, www.socialexclusionunit.gov.uk

Scheuerman, W, E., (2004), Liberal Democracy and the Social Acceleration of Time, Baltimore: Johns Hopkins Press, ISBN 0-818-7885-3

Scheuerman W.E. (2010), Globalization, in Stanford Encyclopedia of Philosophy, http:/ / plato.stanford.edu/entries/globalization/

Scholte, J. A., (1996), "Beyond the Buzzword: Towards a Critical Theory of Globalization," in KOFMAN E., Scholte, J.A., (2000), Globalization: A Critical Introduction, New York: Palgrave Mac Millan, ISBN 13: 978-1-4039-0448-5

Schön, D. A. (1973) Beyond the Stable State. Public and private learning in a changing society, Harmondsworth: Penguin, ISBN: 0140215638

Schön, D. A. (1987), Educating the Reflective Practitioner: Toward a New Design for Teaching and Learning in the Professions, San Francisco: Jossey Bass, ISBN: 1555420257.

Schön D.A. (ed.) (1991) The Reflective Turn: Case studies in and on educational practice, New York: Teachers College Press, ISBN: 0807730467.

Sen, A. (1989), “Development as Capability Expansion”, in Journal of Development Planning 19 , pp- 41-58, ISSN 0085-2392

Sen, A. (1993), "Capability and Well-Being" in NUSSBAUM M. AND SEN A., (eds), The Quality of Life, New York: Oxford Clarendon Press, pp. 30-53, ISBN: 0198283954

Sen, A. (2000), Social Exclusion: Concept, application and scrutiny, Social Development Papers, Asian Development Bank, http:/ / www.gsdrc.org/go/display\&type=Document\&id=1916

Smith, M. K. (1994) Local Education, Buckingham: Open University Press, ISBN: 0335192742

Spring J.H. (2009) Globalization of Education. An Introduction, London and New York: Routlege, ISBN 0-203-88685-2.

Srinivasan, T.N. (1994) "Human Development: A New Paradigm or Reinvention of the Wheel?" in American Economic Review 84, (2), pp. 238-243, http://www.jstor.org/pss/2117836

Streeten, P. (1994) "Human Development: Means and Ends." in American Economic Review, 84(2), pp. 232-237, http://www.jstor.org/pss/2117835

Striano M. (2009), "Managing Educational Transformation in The Globalized World: A Deweyan Perspective", in Educational Theory, Volume 59, Number 4, November, pp. 379-393(15), ISSN 0013-2004

Tomlinson, J., (1999), Globalization and Culture, Cambridge: Polity Press, ISBN: 9780745613376

United Nations (2009) United Nations Millennium Development Goals, http://www.un.org/millenniumgoals/index.shtml

United Nations (2010), Human Development Report; http://hdr.undp.org/en/media/HDR_2010_EN_Complete_reprint.pdf 


\title{
Strengthening the 'Social' in Sustainable Development: Finding the Impact of Social Sustainability in Business Performance of Hospitality Sector of Pakistan
}

\author{
Khuram Shehzad Bukhari', M. Ishaq Bhati², \\ Hayat Muhammad Awan ${ }^{1}$ and Amna Wahid ${ }^{1}$ \\ IInstitute of Management Sciences, \\ Bahauddin Zakariya University Multan, \\ ${ }^{2}$ La Trobe University, Melbourne \\ ${ }^{1}$ Pakistan \\ ${ }^{2}$ Australia
}

\section{Introduction}

The relationship between business and society, and the way this is confined by ethics and institutions, has long been a subject of discussion. Adam Smith, the father of modern economics, give emphasis to how economic dealings were premised on a range of ethical postulations and foundations. At least since Smith's days, ascertaining an institutional context in which business activity, broadly speaking, can augment social outcomes has been a key objective and legitimating foundation for the development of modern states.

Corporate citizenship is not a novel concept rather its history and political economy is quite enthralling, similarly the questions relating the social responsibility of businesses always remain in debates, even if there were not been discussed by making use of 'sustainable development' concept, as they are currently. "So is there really a new, socially responsible role for business in sustainable development?" The answer is yes, to the extent that now there is an ever increasing demand and expectations relating to the business experts and leaders in making their contribution to more comprehensively fulfill the broader objectives then they used to, even now many largest companies themselves are very interested in adopting these responsibilities at least rhetorically.

The increasingly mainstream and high-level expectation that business can and should contribute to sustainable development is perhaps more important for the developing nation like Pakistan, Pakistani industries are faced with increased threats of the global warming and social concerns, the measures taken by our industries need to be modified, and require to have proper understanding regarding the concept of sustainability in both manufacturing and service sector.

In Pakistan sustainable development concept justly makes the differentiation. Pakistan is facing both the green and brown environmental problems. Over the precedent decade so 
many years a multifaceted interweaving of interconnected issues such as structural changes in the economy declining infrastructure provision, and work force and rapid demographic and social changes have had negative influence on individuals and communities. The collective and longer term influence from these concerns are not yet well understood. However, we are beginning to see the indicators of these changes. Specifically, these are current testimonies of negative social upshots associated with cotemporary advancement pattern.

Pakistan has now started given the significance to environmental tribulations, like Pakistan environmental protection ordinance 1983 was the first endeavor to gear environmental problems methodically. It create a lawful basis for complete environmental policy making, the institution and enforcement of customaries, environmental impact evaluations and the inclusion of environmental deliberation in the development policies. The ministry of Pakistan and Pak-EPA has started preparation of national environmental action plan.

But the concept social sustainable development is unnoticed which is pre-requisite to economic development, a vivacious economy requires having social investment.

As the goal of sustainable development is clearly to secure economic development, social equity and environmental protection. As much as they could work in harmony, these goals sometimes work against each other in our modern world. The rapid development of good living, travel and in general of the consumer society has often resulted in less protection to the environment and to some groups of the world population. Ferocious search for profitability has not co-existed harmoniously with making the world a better place. However there is general consensus that it cannot go on for ever and those who are favored by life now feel responsible for those who have not had the same chance. Economic growth will always remain the basis of human development but it should integrate as well its impact on the people and on the planet. Sustainable development focuses on having a holistic approach to development taking into consideration economic, social and environmental needs while avoiding over utilizing key natural resources. It entices us to change the way we develop and use technologies. It makes us acutely aware that the interest of the developed countries is to help the development of the emerging countries and underprivileged peoples.

\section{Literature review}

Literature is reviewed in order to probe that, how our journey starting from financial performance measures departs at non-financial performance indicators, and then further leading to the novel concept like 'social sustainability', which is taking its place and influencing the business practices. "What is social sustainability and how it relates to current business practices"? is one of our research question which is answered by reviewing the entire process of revolutions that taken place in performance measures, we see that how $1950 s^{\prime}$ operations turned into the new world view i.e. sustainable efficiency.

All that previous cost associated methods depleted by time, once they were the only measures for assessing and evaluating the performance but now depending on them solely would be a mistake. In 1950s and 1960s development regarding the management of accounting taken place, which is further developed, documented and recognized by the work of Johnson and Kaplan (1983). Then we see that how different other concepts emerge, in 1987 return on investment (ROI) was been emphasized but as a result of criticism leveled 
at 'traditional management accountant' (1989) Cooper developed another concept named on 'activity costs' (ABC), which further led to the determination of productivity ratios in 1900s. By the time competition becomes more enhanced, business leader start finding the new areas which they can address and be profitable, names like 'Deming', 'Juran', 'Crosby', 'Ishikawa' and 'Feigenbaum' are very much significant in real, because of their remarkable theories and giving the world, about idea of total quality management (TQM), which is the basic concept, that starts from proper addressing the customer requirements to the customer satisfaction. Then in 1993 and 1994, 'Andersen Consulting' 'IBM consulting' and 'London Business School' made use of benchmarking, which is even today's well known practice. From their businesses focus, the process of improving continually and making the application of continuous improvement is the part of their management. Then further in 2000, statistical processes taken their place and in 2006 one of the statistical process named as six-sigma gave the saving of US\$ 17 billion to Motorola. Afterwards the organizations diverge from the emphasis of just financial performance measures to the different nonfinancial performance criteria, from their, the awards like Deaming, Malcolm Baldrige quality award (MBQNA) and European National Quality Award (ENQA) introduced which gave more focus to the practices like leadership, people orientation, process orientation and assessing the results in term of society and customer satisfaction.

Now being a part of $21^{\text {st }}$ century we required to have changed sort of understanding as there is more customization, and ever changing demand, previously manager just deal with short term solutions don't give importance to the future implications, impact and effects. So this is the reason why we are giving more importance to sustainability, which is based from the triple bottom line concept given by John Elkington (1998),

"Sustainable business is business that is conducted with both an awareness of, and consideration for, the impact on the physical and social environments, both directly and indirectly, now and in the future. The awareness and consideration are manifest through decisions, policies, actions, and reactions".

\subsection{Sustainability and sustainable development}

The issue of sustainable development is becoming central to discussions about the future. Sustainable development is "development that meets the needs of the present without compromising the ability of future generations to meet their own needs" (Bruntland 1987) it is seen now that if the organizations don't give importance in contribution towards sustainable development, then there is quite risk of having loosing their shareholders.

Sustainable development is progressively more, been seen as major challenge (white and lee; 2007).According to the 'world commission on environment and development', sustainability became the watch word. More recently sustainability has been the subject of renewed interest and debate (Rao;2000), literature is not that much developed to define the term sustainability (Robbinson 2004) and there are many terms in literature such as 'sustainable development', 'human sustainability', 'social sustainability', 'ecological sustainability', 'environmental sustainability', and 'corporate sustainability' as well as aligned concepts of CSR and 'corporate citizenship'.

In 1960 at an international discourse, concept of sustainable development emerged (Carson, 1962; United Nations Environment Programme, 1972; International Union for Conservation 
of Nature, 1980; World Commission on Environment and Development, 1987; United Nations Conference on Environment and Development, 1993), progressing through to more recent international conferences such as the Kyoto Climate Change Conference in 1997 and the World Summit on Sustainable Development at Johannesburg in 2002. Becker et al. 1999, argue that;

"Sustainable development might best be characterized as a contested discursive field which allows for the articulation of political and economic differences between North and South and introduces to environmental issues a concern with social justice and political participation."

The sustainable development concept is not the dream of some political party that disdains capitalism and considers it to be evil. Nor is it the consequence of the delusion of people who determined that this world would be better of if it we were going back to our natural roots and resources. Sustainable development is definitely geared toward profitability and the future. Without profit it seems obvious that no business would be sustainable."

Regardless of the substantial scholastic and political attention paid to wide concept of sustainable development, there is some impression that the "social" has been ignored and is not seen to be equivalent to economic or environmental aspects of sustainable development. As a result of this ignorance, social sustainability is the least abstractly formulated concept of the three pillars (Kunz, 2008; Littig and Griebler, 2007; Partridge, 2006). This paper seeks to fill this gap and to strengthen the term 'social' in the sustainability which is one of the most important element of today's highly competitive environment. The purpose of this paper is to systematically develop a broader conceptualization of social sustainability and seeing its impact on the over-all business performance of the hospitality sector of Pakistan.

\subsection{Social sustainable development origin}

Social sustainability concept basically originate from stake holder interest and Interest in stakeholder theory took root in the field of strategic management (e.g., Clarkson, 1995; Freeman, 1984; Frooman, 1999), then grew into organization theory (e.g., Donaldson \& Preston, 1995; Jones, 1995; Rowley, 1997) and business ethics (e.g., Phillips \& Reichart, 2000; Starik, 1995). Stakeholder theory's social responsibility element allowed it to blend into social issues in management (e.g.,Wood, 1991a, 1991b), and, more recently, it has begun to enter the conversation about sustainable development (e.g., S. Sharma \& Henriques, 2005; Steurer, Langer, Konrad, \& Martinuzzi, 2005). The theory came into prominence only in the mid-1990s, apparently owing to the attention it received in a special issue of Academy of Management Review in 1995, and gathered momentum in the late 90s.

"It is evident that contemporary approaches to development have not provided equitable outcomes for all, and in some situations have contributed to the 'breakdown' of community" (Greider, 1997; Saul, 1997). There is clearly a pressing need to develop a stronger conceptual understanding of the social dimension of sustainable development that links to and is grounded in real life policies and practices.

Social capital, social infrastructure, social justice and equity and engaged governance have been identified by exploring literature (e.g. Barron and Gauntlett, 2002; Cuthill and Fien, 2005; Empacher and Wehling, 2002; Greater Vancouver Regional District, 2004; Magis and 
Shinn, 2008; Sachs, 1999). At this stage the framework is quite simple (as opposed to simplistic) and is intended to provide a foundation for further empirical testing and critique (Rapoport, 1985).

With the intent of empirical testing of the framework in mind, these four components have been allocated specific roles relating to social sustainability.(Cuthill,2009) These are that;

- Social capital provides a conjectural preparatory point for social sustainability,

- Social infrastructure provides an equipped (operational) viewpoint,

- Social justice and equity principally (ethically) very important and

- $\quad$ engaged governance aim for providing 'working together'.

\begin{tabular}{|c|c|c|}
\hline & Constructs & Sub-dimensions. \\
\hline $\begin{array}{l}\text { Coleman; 1990, } \\
\text { Fukuyama; 1995, } \\
\text { Putnam; } 1993\end{array}$ & Social capital & Social network, Norms and Trust \\
\hline World bank; 1998 & & Institutions \\
\hline Michael cuthill; 2005 & $\begin{array}{l}\text { Social } \\
\text { infrastructure } \\
\text { (hard) }\end{array}$ & $\begin{array}{l}\text { Health ; Education ; Rural development; } \\
\text { Activity ; Transport-oriented } \\
\text { development }\end{array}$ \\
\hline $\begin{array}{l}\text { Cuthill and Fien; 2005, } \\
\text { Eade; 1997, Graventa; } 2000 \\
\text { Lyon et al, } 2001\end{array}$ & Soft & $\begin{array}{l}\text { Needs of community; Informed and } \\
\text { active citizen(capacity) }\end{array}$ \\
\hline Sen; 1999 & $\begin{array}{l}\text { Social justice and } \\
\text { equity }\end{array}$ & $\begin{array}{l}\text { Appropriate and affordable; Housing; } \\
\text { Food sustenance; Guarantee of } \\
\text { individual and community safety. }\end{array}$ \\
\hline NSW; 2004 & & Equality of rights \\
\hline $\begin{array}{l}\text { Epstein et al; 2000, } \\
\text { Cuthill; 2002, } \\
\text { Saul; } 1997\end{array}$ & $\begin{array}{l}\text { Engaged } \\
\text { governance }\end{array}$ & $\begin{array}{l}\text { Involvement in decision making } \\
\text { Community engagement. }\end{array}$ \\
\hline
\end{tabular}

Table 1. Dimensions of sustainable development

\section{Conceptual framework}

Sustainable development based on three pillars that are economic, environment and social. Economic and environmental issues remain in discourse for so long, but in current practice we are dealing with social discourse, social sustainability is basically originate from stakeholder interest theory given by 'Freeman stake holder legacy'. A unanimously accepted definition for social sustainability is still not available, largely because of lacking harmony on what is meant and understood by the social, in reality what defines the social is properly resolute by underlying premises.

'Social sustainable development' is based on the following premises (Cuthill, 2009)

1. Environmental problems are basically themselves first and foremost social problems.

2. Economics is again something that is related to serving the people rather than people serve economic interests. This is what we call 'equitable distribution of resources.' 
These two factors are considered to be a sign of social sustainability framework, which in further explains an inter-reliant and self strengthening relationship between four key components: (1) social capital (2) social infrastructure (3) social justice and equity and (4) engaged governance.

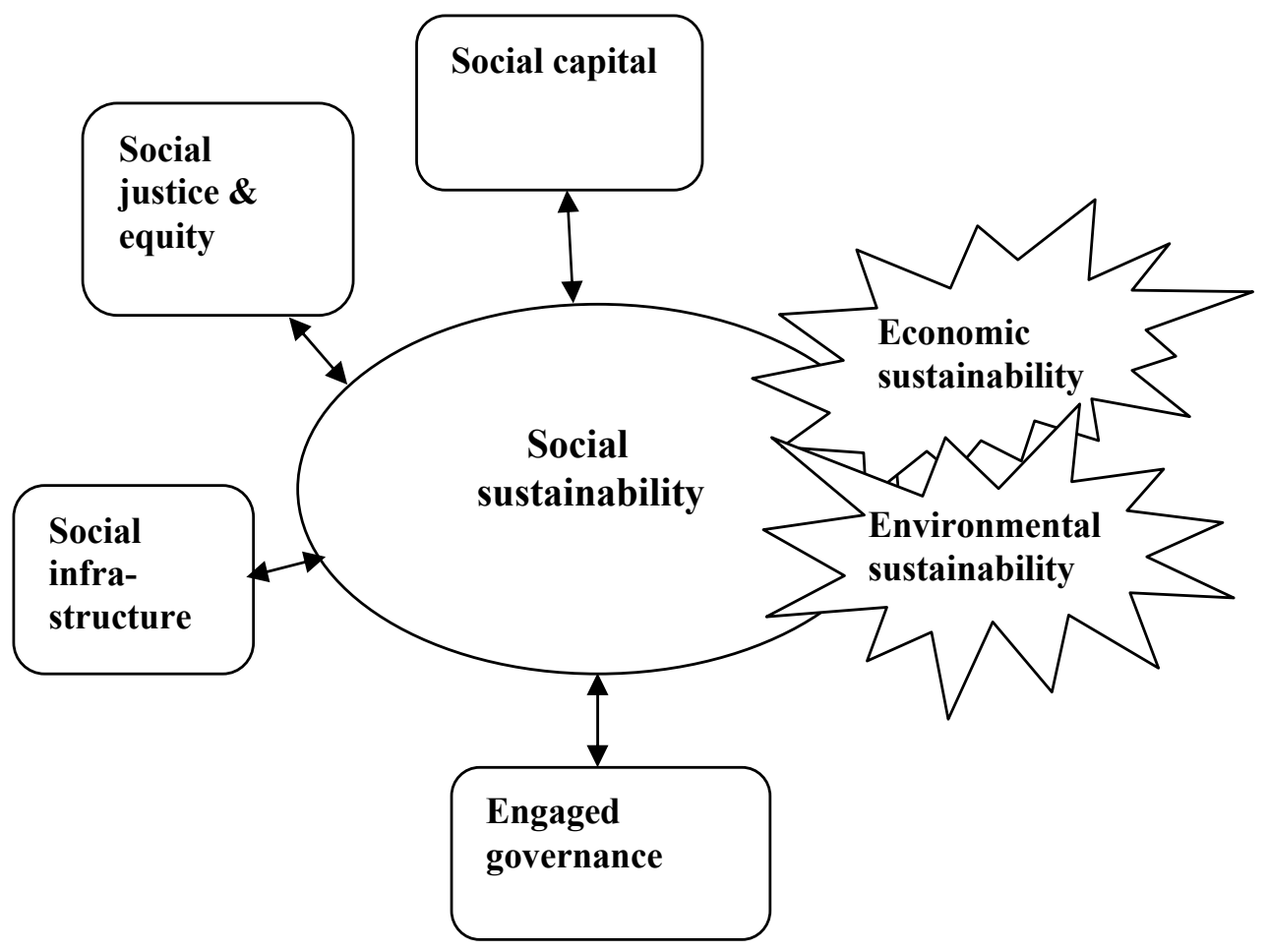

Fig. 1. Conceptualized framework for social sustainability

\section{Methodology}

This study is to develop a proper understanding of the concept of sustainability by having focus on social segment, it interrogates that how the service sector particularly hospitals and hotels of Pakistan develop their viewpoint towards sustainability. Research is aimed to propose the indices of critical factors, which one firm can adopt and be competitive, profitable, socially responsive and ethical.

The major research question identified for this study is:

Developing a "social sustainable framework" based on social capital, social infra- structure, social justice and equity and engaged governance in the service sector of Pakistan, other questions which are researched in the paper are as follow; 
What is social sustainability?

Is there any link of social sustainability with firm's business performance?

Which element of social sustainability is more responsible for corporate stewardship?

What is role of social sustainability in hospitality sector?

Is social sustainability more in hotels and hospitals of Pakistan?

What are the critical success factors of social sustainability?

\subsection{Specific design of research study}

In this research study, both qualitative and quantitative techniques are used in order to comprehend better results from the study. With the support of findings from literature review, an empirical study was devised composing a survey investigating the critical business strategy areas in hospitality sector of Pakistan from selected industries. They went through the design of research instrument, initial case studies and survey of firms sampled for the study followed by the analysis of data. The study used a questionnaire to acquire the empirical information as well as companies' annual reports and internet databases containing any information of our interest. Main part of the questionnaire designed required the respondent to give answer using five point Likert Scale ranging from 1=extremely satisfied to $5=$ extremely dissatisfied.

\subsection{Methods of collecting data}

Mainly the three different sources of information have been used: Interviews, observations and document. Interviews were used extensively to collect data from respondents within the organizations. The interviews in the study were open and semi-structured. Often the statements of the interviewees were repeated and concluded in order to avoid misunderstandings. The interviews were done in respondents' normal environment, to benefit from the advantages this brings, a fact that thus has meant various interruptions (Lantz, 1993).

In addition to information provided from interviews, documents were collected when possible during the research study. The objective was to get, yet another source of data to facilitate data triangulation, and thereby strengthen the construct validity of the research. Documents are sometimes hard to come by, and firms had different policies regarding sharing this kind of information with people outside of the firm.

This study based on the descriptive approach in the context of this research involves best organization agreeing to a set of critical success factors specific to their respective industry. Partly, questionnaire design used by Ramirez and Loney (1993) was adapted to measure the response rate of various critical factors important for being socially sustainable. Choice of variables used in questionnaire is the product of in-depth literature review.

\subsection{Criteria for site and participant selection}

This study examined different hospitals and hotels committed to lessening the negative impact their activity has on the social environment in which their business operate. 
Typically organizations interested in adopting more sustainable practices begin with what has become known as the "low hanging fruit." while important, this study seeks a deeper understanding regarding initiatives that go beyond the point of entry. Therefore, this study targeted those organizations that have been sum how or other involved in sustainability efforts.

In the research study, some statistical techniques are also used by using Statistical Package SPSS (Statistical Package for Social Sciences) for analyzing the service sector of Pakistan with reference to sustainable practices and its contribution in excellent performance. And other technique used is AHP.

\subsection{Research model}

AHP is a method that orders the priorities in a given situation, incorporating the element of subjectivity and intuition so that a final decision can be reached by making decisions for part-issues in a consistent way and gradually moves up levels to deal with the given situation having a clear view of what it entails. AHP is relatively simple and logical and given that a certain consistency in the part-decisions is maintained, AHP can help decision makers to deal with complicated issues where often not only tangible but also intangible parameters affect their decision makers affect their decision. It should be noted briefly at this point that AHP is as effective as its design in each individual case and that analysts should exercise care and precision in capturing the true sub-elements and requirements of the case in question. (Al-Harbi,2001).

The analysis of the data is carried out in different steps as explained in detail in the following paragraphs.

Step 1. I developed the hierarchical representation of the problem by defining levels of criteria and sub-criteria perceived as most important by respondent.

Step 2. In scale of 1 to 7 , elements are assigned different degrees of relative importance.

Step 3. The EIGEN value is calculated to determine the relative weight of each criterion in relation to the one immediately above in the hierarchy. The priority vector is established by calculating the row averages. At this point, the consistency index is calculated by the following equation $\mathrm{CR}=\mathrm{CI} / \mathrm{RI}$. Consistency index $(\mathrm{CI})$ is calculated by the following equation CI=LEMDA max-n/n-1, where $n$ is the number of sub-criteria of each criterion.

Step 4. The consistency ratio is used to check whether a criterion can be used for decisionmaking.

Step 5. The sub-criterion priorities are combined to disclose the most important sub-criteria for each criterion in order to develop an overall priority ranking.

Resulted items would be categorized in 4 tiers such as social capital, social infrastructure, social justice and equity and engaged governance according to their priority weights obtained for the sub-factors of each one of the four tiers.

The research model designed in this study is given below. In the current research model, the numbers of items per dimension are established in the qualitative part of the study, 


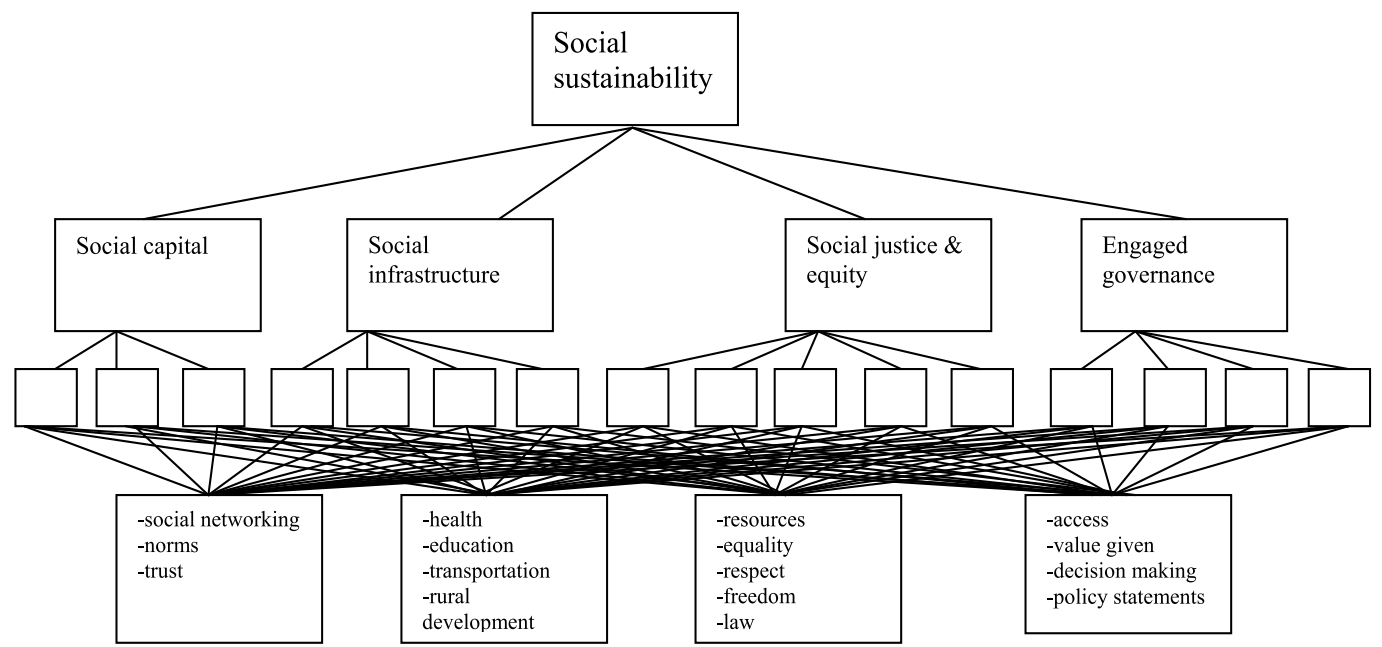

Fig. 2. Research pattern by making use of AHP.

\section{Data analysis}

\subsection{Hotel industry}

The hotel and restaurant industry is very popular in Pakistan. It is one of the heavily taxed and almost 75 to 80 percent of total revenue comes from the top hotel chains. Even in the long term it has the greater potential growth. Pakistan approximately attracts 1.5 million tourists every year.

Our empirical findings are quite supportive of the conceptual framework proposed, the four key constructs chosen in model are crucial. In hotel industry we have seen that social justice and equity among the other constructs have higher weightage, it is significantly valued, findings suggest that among all chosen measures of social justice and equity, the great priority is given to rule of law which cover all rights and liberties of employees in organizational practices that enhance performance ,freedom of thought is another element of social justice and equity by which innovative ideas develop and at the same time the social responsibility regarding the employees satisfaction is also increased, then once employees are satisfied we see by results that hotels' responsibility is diverted to the provision of individual and community safety and facilitation of fair access to resources.

Second construct which is highly prioritized is engaged governance which is measured by choosing different elements gathered from literature, so we find that for the incorporation of social sustainability and enhancement of business performance in hotels it is required that there should the proper involvement of stake and stock holders in decision making, customer demand is to be esteemed and the policy statements then designed accordingly, hotels can be socially sustainable if the transparency maintained by enabling the citizen access to their information and they can easily exert their demands on management for better services.

Other two constructs that is social capital and social infrastructure building lie at the same level, in social capital, findings of hotels suggest that for being socially sustainable they 
required to build the trust first with their management team and then with consumers, another element of social capital which is important in hotels is the building of norms, which basically enhance their efficiency and then helps in reduction of transaction cost in hotels perspective, social networking lie at the third level of importance in hotels in contrast to other two chosen dimensions, similarly in social infrastructure findings of the research validate the earlier researches that the hotels are the most earning sector of the society so their foremost responsibility is to develop their community in terms of providing employment opportunities and fulfillment of environmental responsibilities.

\begin{tabular}{lll}
\hline Rank & Social sustainability dimensions & Relative weights \\
\hline 1 & social justice and equity & 0.315 \\
2 & Engaged governance & 0.272 \\
3 & social capital & 0.209 \\
4 & Social infrastructure & 0.203 \\
\hline
\end{tabular}

Table 2. Social sustainable dimensions and their relative weights

\subsubsection{Index of social sustainability for hotels}

i. Critical: Factors those are critical and absolutely essential. Tier-I of Indices of social sustainability for hotels belong to fairness in policy making that comprise of policy statements, rule of law, trust building by policy and involvement in decision making, all these elements are related to the leadership role and top management commitment.

ii. Supporting: Factors those are important but not absolutely essential. Tier II related to social justice and equity elements, here the elements which come with more priorities in HOTELS are respect given to employees, genuine participation, guarantee of safety, freedom of thought and citizen involvement. And in equity most contributing elements in hotels are employment opportunities, transportation, education in terms of development of their employees and fairness in distribution of resources.

iii. Maintaining: Factors are of minor importance. Tier III includes norms, trust building and use of social networking for competition deterrence and hiring.

Tiers Critical factors of social sustainability in hotels of Pakistan

\begin{tabular}{llll}
\hline & $\#$ & Label & $\begin{array}{l}\text { Global Priority } \\
\text { Weight }\end{array}$ \\
Tier-1 & 1 & how much value is given to citizens demand & 0.072347 \\
& 2 & involvements in decision making & 0.068079 \\
& 3 & policy statements & 0.068079 \\
& 4 & rights and liberties covered by law & 0.066455 \\
& 5 & safeguards for rural sector & 0.061264 \\
Tier-II & 6 & Trust built by policy & 0.056817 \\
& & respect given & 0.042678 \\
& 9 & opportunities for all people & 0.038737 \\
& 10 & guarantee of safety & 0.038737 \\
& 11 & citizen exert demand & 0.034411 \\
& 12 & enable citizens to gain greater access to information & 0.032184 \\
\hline
\end{tabular}




\begin{tabular}{lllc} 
Tiers & & Critical factors of social sustainability in hotels of Pakistan \\
\hline Tier III & 13 & generates employment opportunities & 0.028965 \\
& 14 & Rent hybrid vehicles & 0.027185 \\
& 15 & fair access to economic resources & 0.026596 \\
& 16 & fairness in distribution of resources & 0.022915 \\
& 17 & subsidize public transportation & 0.022093 \\
& 18 & equality of rights & 0.022066 \\
19 & efficiency enhancement by norms & 0.018456 \\
20 & trust by self interested action & 0.01635 \\
21 & contribution in development of young & 0.016084 \\
22 & infrastructure support at village level & 0.014722 \\
23 & rent hybrid vehicles & 0.013735 \\
24 & deterrence of competition & 0.012915 \\
25 & helps in hiring desired employees & 0.011606 \\
26 & flexible working hours & 0.01062 \\
27 & how much value is given to citizens demand & 0.072347 \\
28 & involvements in decision making & 0.068079 \\
\hline
\end{tabular}

Table 3. Critical factors of social sustainability in hotels of Pakistan

\subsubsection{Regression analysis}

Then the regression analysis was done in order to find the relationship of social sustainability and business performance dimensions. For this research we select three basic dimensions that are customer satisfaction, which is measured by evaluating the hotels customer retention and customer feedback, second is employee satisfaction which is measured by choosing; cooperation among employees and their influence on personal development as the sub-measures, and top management commitment is chosen as moderating variable.

Following table show the all those business dimensions of hotels which have the significant relationship with social sustainability dimensions.

As in particular hotels it is found that there is significant relation with customer feedback and it has significance of 0.027 which is less than alpha value of 0.05 . With each individual sustainability dimension the result shows, customer feedback has positive relation with social infrastructure and capital building in relation to others, this is proven by literature that customers in hotels give more feedback for the proper management of social practices these include; building of norms, trust and networking as well as facilitation of health, education and transportation along with community development which is the major element of social infrastructure \& capital.

Another performance dimension showing significant relation is cooperation in hotels, its $\mathrm{p}$ value is 0.052 . Cooperation is positively correlated with one of the dimension i.e. social infrastructure and capital building and has the significance of 0.095 . Social capital as we have already discussed in detail is the element that relates to the development of social networking, norms and trust all of these would be developed only if the cooperation exist among the workers as well as with top management and in hotels this coordination and cooperation matters a lot. 
Another dimension which shows significant relation is top management commitment in hotels. Lying at the significance level of 0.01.It is the moderating variable without top management commitment idea of social sustainability cannot be incorporated, henceforth proved in our findings too.

\begin{tabular}{|c|c|c|c|c|c|c|c|c|c|}
\hline $\begin{array}{l}\text { Dependent } \\
\text { variables }\end{array}$ & $\begin{array}{l}\text { Independent } \\
\text { Variables }\end{array}$ & $\begin{array}{l}\text { Sum of } \\
\text { Squares }\end{array}$ & B & Df & Beta & $\begin{array}{l}\text { Means } \\
\text { Squares }\end{array}$ & $t$ & $\mathrm{~F}$ & Sig. \\
\hline \multirow{4}{*}{$\begin{array}{l}\text { Customer } \\
\text { Feedback }\end{array}$} & & \multirow[t]{4}{*}{17.020} & & \multirow[t]{4}{*}{3} & & \multirow[t]{4}{*}{5.673} & & \multirow[t]{4}{*}{36.242} & .027 \\
\hline & $\begin{array}{l}\text { Engaged } \\
\text { Governance }\end{array}$ & & 2.473 & & .779 & & 2.793 & & .108 \\
\hline & $\begin{array}{l}\text { Social justice } \\
\text { \& equity }\end{array}$ & & -2.63 & & -1.48 & & -5.37 & & .645 \\
\hline & $\begin{array}{l}\text { Social } \\
\text { infrastructure } \\
\text { \& capital }\end{array}$ & & 2.698 & & .578 & & .508 & & .043 \\
\hline \multirow[t]{4}{*}{ Cooperation } & & \multirow[t]{4}{*}{8.924} & & \multirow[t]{4}{*}{3} & & \multirow[t]{4}{*}{2.957} & & \multirow[t]{4}{*}{3.115} & .052 \\
\hline & $\begin{array}{l}\text { Engaged } \\
\text { Governance }\end{array}$ & & 1.237 & & .492 & & .565 & & .629 \\
\hline & $\begin{array}{l}\text { Social justice } \\
\text { \& equity }\end{array}$ & & -.188 & & -.134 & & -.156 & & .891 \\
\hline & $\begin{array}{l}\text { Social } \\
\text { infrastructure } \\
\text { \& capital } \\
\end{array}$ & & 4.292 & & 1.023 & & 3.009 & & .095 \\
\hline \multirow{4}{*}{$\begin{array}{l}\text { Top } \\
\text { management } \\
\text { Commitment }\end{array}$} & & \multirow[t]{4}{*}{13.151} & & \multirow[t]{4}{*}{3} & & \multirow[t]{4}{*}{4.384} & & \multirow[t]{4}{*}{3.733} & .018 \\
\hline & $\begin{array}{l}\text { Engaged } \\
\text { Governance }\end{array}$ & & 7.317 & & 2.434 & & 3.015 & & .095 \\
\hline & $\begin{array}{l}\text { Social justice } \\
\text { \& equity }\end{array}$ & & -3.18 & & -1.901 & & -2.37 & & .141 \\
\hline & $\begin{array}{l}\text { Social } \\
\text { infrastructure } \\
\text { \& capital } \\
\end{array}$ & & -.013 & & -.003 & & -.008 & & .994 \\
\hline
\end{tabular}

Table 4. Hotel's social sustainability dimensions and business performance:

\subsection{Hospital industry}

The health system in Pakistan is currently going through several restructuring at the federal, provincial and district levels particularly to advance the delivery of health services to the population. These reforms are part of the overall development framework that endeavors to raise the importance given to the social sectors, particularly the health sector, in the country to address their poor performance (Report of the Health System Review Mission - Pakistan 2007). So in this paper social sustainability framework is measured in number of different hospitals. Empirical findings revealed that the in hospital industry the results are almost the same as that of hotel industry, reason behind this is that both are component of service sector and facing the same situation where the services are directly provided to customers and without customer's intimate involvement it is quite impossible to deliver. Here the social justice and equity has the highest ranking and with respect to hospital industry it 
includes majorly the element of respect given to each individual member of staff starting from ward boy to the specialist doctor, every employee has its own importance, proper formulation of laws are required from the patients as well as management view point.

In hospitals just like hotels second highest construct is engaged governance, in order to properly encounter the social sustainability, hospitals' policy matters a lot to show commitment to promote environmental stewardship, waste management implications are required to be a part of their policy.

Facts about social capital show that trust is the foremost element and in hospitals security particular department in hopsital fulfills this challenging job round-the-clock with impeccable proficiency and responsibility. It provides security for the patients' vehicles, belongings and lives, while at the same time maintains close check on hospital property and hospital's overall discipline and decorum. Now a days hospitals premises are constantly monitored through close circuit televisions. Issuance of parking ticket, emergency help line and ever-vigilant security staff are a few steps taken by the Security Departments of different hospitals for ensuring a safe, healthy and peaceful healing environment for outpatients. Then comes norms and finally social networking. Norms are important for proper documentation, proper vision, mission, code of conduct discussed with their staff, properly documented visitor policy, registration policy and administration policy. Fresh hands are molded into skilled professionals by their proper orientation. Job descriptions \& hiring by keeping a match of skills and abilities, pre planned and pre scheduled work plan in each single hospital.

Social networking in hospitals is important, a devoted/energetic team for effective and timely distribution of information and instructions, a full fledge Intranet solution/ internal mailing system has been deployed in many of the hospitals to facilitate the departments/ users to communicate electronically. These steps have been taken to become cost effective and environment friendly by minimizing the paper use.

To facilitate the back office administrative activities the hospitals has also successfully implemented hospital wide browse based 'Material Requisition' and 'Management System', 'Procurement system' and the support the Human resource department as fully automated Human Resources Information Management System, with indigenously developed Biometric Time and attendance management systems.

Social infrastructure building in hospitals is important from the perspective of having Working under ISO 9001:2000, ISO Internal Auditor Certification. All type of waste collection / transportation / storage / incineration and final disposal within the hospitals are done by their material management department. Similarly for education, a department for Research \& Continuing Medical Education has been established to keep the doctors and medical staff updated with the latest research.

Transport Department in hospitals is a vibrant department that not only provides pick and drop to hundreds of clinical and administrative staff without failing but also meets emergent deadlines of various nature. Provision of ambulance service to inpatients as well as on call basis is also managed by this department. The department owns a varied fleet of busses, coasters, carriage carriers and staff cars. So proper policies regarding the management of transport is very much essential in hospitals. 
Over all social sustainability dimensions and their relative weights are given below;

\begin{tabular}{lll}
\hline Rank & Social sustainability dimensions & Relative weights \\
\hline 1 & social justice and equity & 0.397 \\
2 & Engaged governance & 0.278 \\
3 & social capital & 0.233 \\
4 & Social infrastructure & 0.092 \\
\hline
\end{tabular}

Table 5. Social sustainability dimensions and their relative weights (hospitals)

\subsubsection{Index of social sustainability for hospitals}

i. Critical: Tier-I of Indices of social sustainability for hospitals belong to the development of policy statements, as it is identified in literature review one of the most important factor for the proper working..

ii. Supporting: Tier-II comprises of second most critical set of performance indicators for social sustainability. Factors included in Tier-II belong to engaged governance. Here in hospitals the following elements of engaged governance are having more global priority that is the respect to staff, rule of law, freedom of thought, involvement in decision making, and the value given to citizen demand, so these elements from hospital perspective are more important. And further it is comprised of social justice and equity factors which are equality of rights, fair access and distribution of resources, opportunities and guarantee of safety. Along with this, it also includes the community involvement element specifically which are related to the infrastructure support and citizen involvement in every single aspect as it is service sector so role of direct involvement automatically advances in contrast to other factors.

iii. Maintaining Tier III related to social capital and infrastructure that is basically given importance to networking, norms, and trust, health and education elements.

Tiers

Critical factors of social sustainability in hospitals of Pakistan

\begin{tabular}{|c|c|c|c|}
\hline & \# & Label & $\begin{array}{l}\text { Global Priority } \\
\text { Weight }\end{array}$ \\
\hline Tier-1 & 1 & Policy statements & 0.084641071 \\
\hline \multirow[t]{11}{*}{ TierII } & 2 & Respect is given to every single individual of staff & 0.063646156 \\
\hline & 3 & Rights and liberties covered by the rule of law & 0.059628894 \\
\hline & 4 & Freedom of thought & 0.057238943 \\
\hline & 5 & $\begin{array}{l}\text { policy statements consists of a commitment to } \\
\text { promote environmental stewardship }\end{array}$ & 0.056359244 \\
\hline & 6 & How much value is given to the citizen's demand & 0.054242122 \\
\hline & & $\begin{array}{l}\text { Equality of rights established and promoted for all } \\
\text { people }\end{array}$ & 0.047875736 \\
\hline & 8 & fair access for all people to economic resources & 0.047875736 \\
\hline & 9 & $\begin{array}{l}\text { opportunities for all people to genuinely } \\
\text { participate }\end{array}$ & 0.047875736 \\
\hline & 10 & Guarantee of individual and community safety. & 0.047875736 \\
\hline & 11 & Infrastructure support & 0.046979999 \\
\hline & 12 & Enable citizens to gain greater access to information & 0.041378782 \\
\hline
\end{tabular}


Tiers

Critical factors of social sustainability in hospitals of Pakistan

13 Citizens exert demands on the management for 0.041378782 better services.

Tier III 14 Fairness in the distribution of resources

0.024983063

15 Trust can be built by policy

0.01666005

16 Norms reduces the risk of coordination failure

0.016153591

17 Efficiency enhances by following the norms

0.015104051

18 Trust is important for economic prosperity

0.015067791

19 Subsidize public transportation for employees

0.0149178

20 Helps in hiring desired employers

0.014499785

21 Norms reduce the transaction cost

0.014048194

22 Norms coordinate expectations

0.013412748

23 Generates employment opportunities for rural

0.012437524 sector.

24 Rent hybrid vehicles

0.0106329

25 Deterrence of the competition becomes easier

0.010616929

26 social connections generate valuable ideas

0.01033777

27 To what extent the workers feel free in sharing

0.010224048 information

28 Safeguards for the rural sector.

0.0092184

Table 6. Critical factors of social sustainability in hospitals of Pakistan

\subsubsection{Regression analysis}

Then the regression analysis was done in order to find the relationship of social sustainability and business performance dimensions. As we have already discussed that we have chosen three basic dimensions that are customer satisfaction, employee satisfaction and top management commitment is selected as moderating variable.

Following table show the all those business dimensions of hotels which have the significant relationship with social sustainability dimensions.

Hospitals is the sector where customer interaction is of high mark, they can develop themselves more rapidly if customers give proper feedback and it has already proven by literature as well as in our sampled firm we see that the level of significance is 0.023 which is less than value of alpha (0.05).

Individually if we see the results we can see that customer feedback particularly in hospitals have positive significance in all chosen dimensions. So it's the finding of the research that performance dimension which social sustainability in hospitals enhances is customer feedback, as details given in table.

Another dimension which shows significant relation with the help of statistical analysis is the top management commitment is highly significant to chosen social sustainability factors. Top management commitment has positive relation with engaged governance and social infrastructure and capital. No doubt as from literature we see that for the proper following the social sustainability guideline one requires to have support from top management (Detoni and Tonchia, 2001). 


\begin{tabular}{|c|c|c|c|c|c|c|c|c|c|}
\hline $\begin{array}{l}\text { Dependent } \\
\text { variables }\end{array}$ & $\begin{array}{l}\text { Independent } \\
\text { Variables }\end{array}$ & $\begin{array}{l}\text { Sum of } \\
\text { Squares }\end{array}$ & B & Df & Beta & $\begin{array}{l}\text { Means } \\
\text { Squares }\end{array}$ & $t$ & $\mathrm{~F}$ & Sig. \\
\hline \multirow{4}{*}{$\begin{array}{l}\text { Customer } \\
\text { Feedback }\end{array}$} & & \multirow[t]{4}{*}{3.999} & & \multirow[t]{4}{*}{3} & & \multirow[t]{4}{*}{1.333} & & \multirow{4}{*}{$\begin{array}{l}1064.4 \\
6\end{array}$} & .023 \\
\hline & $\begin{array}{l}\text { Engaged } \\
\text { Governance }\end{array}$ & & 10.16 & & 8.292 & & $\begin{array}{l}10.62 \\
8\end{array}$ & & .060 \\
\hline & $\begin{array}{l}\text { Social justice } \\
\& \text { equity }\end{array}$ & & 3.946 & & 4.430 & & 8.570 & & .074 \\
\hline & $\begin{array}{l}\text { Social } \\
\text { infrastructur } \\
\text { e \& capital }\end{array}$ & & 5.065 & & 4.817 & & $\begin{array}{l}15.60 \\
5\end{array}$ & & .041 \\
\hline \multirow{4}{*}{$\begin{array}{l}\text { Top } \\
\text { management } \\
\text { commitment }\end{array}$} & & \multirow[t]{4}{*}{19.061} & & \multirow[t]{4}{*}{3} & & \multirow[t]{4}{*}{6.354} & & \multirow[t]{4}{*}{4.975} & .001 \\
\hline & $\begin{array}{l}\text { Engaged } \\
\text { Governance }\end{array}$ & & 6.073 & & 2.280 & & 2.725 & & .000 \\
\hline & $\begin{array}{l}\text { Social justice } \\
\text { \& equity }\end{array}$ & & .953 & & .603 & & 1.198 & & .270 \\
\hline & $\begin{array}{l}\text { Social } \\
\text { infrastructure } \\
\& \text { capital }\end{array}$ & & 2.460 & & 1.171 & & 2.093 & & .075 \\
\hline
\end{tabular}

Table 7. Hospital's social sustainability dimensions and business performance:

\section{Findings and discussion}

From the gathered data and responses it is clearly seen that in overall hospitality sector ( hotels \& hospitals) 'engaged governance' and 'social justice \& equity' lie as at greater importance because in recent times, there are great number of forces which are impacting the human lives. These impacts are both empowering and disempowering the service sector of Pakistan. If we take an example of information revolution, we see that citizens' (consumers) are highly informative as they have greater access to information and on the basis of that they also exert their great demand on management for getting the better and desired services. And particularly in service sector where consumers are in direct contact there the management of their requirements becomes more sophisticated.

The approach used in this paper basically envisioned and comprised of all those unanimously renowned principles of good governance. so we try to include all those set of factors that basically relate to the concept of having balanced power and getting balanced results in return. These principles are relating to authenticity and voice, which is to gratitude, individuals to have an involvement in making decision. As it leads towards consensus, which intercede contradictory concerns in the best of interest of group and on their procedures and policies.

Another important principle and finding of research is to to have a proper orientation regarding direction that by the top management commitment or we can say that leaders as well as public both share wide and long-term viewpoints for having human development and good supremacy, along with the understanding of cultural, historical and social contexts which are mandatory for such development. 
Then further importance in social sustainability lie to the concept of 'accountability', which is very important for 'engaged governance' and 'social justice \& equity', it is basically refer to the transparency in their entire operations of hospitals and hotels.

Then organizations should have to give importance to fairness, in term of distribution of resources, equality of rights' establishment and promotion, fair access to economic resources, opportunities for genuine participation, all these elements ultimately results into freedom of thought.

'Social capital' and 'community infrastructure' building is another important constructs of social sustainability in hospitality industry, which by the results we see lie below in comparison to 'engaged governance' and 'social justice \& equity' as these are the basic services, which one organization provide and make available in retort to the demands of communities. They enhance the quality of life by building networking, norms, trust, health measures, education, transportation, and rural development. Over all these elements need to be further focused and developed in the selected organizations.

From the research we see that sampled hotels and hospitals lack recognition of these important elements and do mistakes in allocating the right amount of cost to proper project which resulted into the failure in term of building social infrastructure and local communities. This is the reason that many metropolitan and regional areas have been hard hit, only because of failure in encountering changing employment patterns as well as changes associated to demography and society, answer to this is simply having the proper social capital development and adequate provision for social infrastructure as it has exacerbated many problems in the past. Stake holders are more demanding than past so automatically for catering the competition, responsibilities shifted to the business leaders to amalgamate more sophisticated ways of operations in order to satisfy and have sustained relations with their customers. It could be only possible if they fulfill their social responsibilities, because environmental and economic areas have been now addressed a lot, now the need to cover the third segment in such a way that it become a source of providing vivacious economy.

\section{Managerial implications}

Furthermore, measuring the sustainability dimension on performance criteria, the findings of this study validate that social sustainability linked positively with the performance, that hotels and hospitals should improve their performance through the adoption of social sustainability. In addition, as far as the relative impact social sustainability on individual sector is concerned, the findings suggest that engaged governance and social justice \& equity among the four constructs of social sustainability that has positive and significant association with customer retention. All four chosen constructs for social sustainability i.e. social capital, infrastructure, engaged governance and justice \& equity are positively correlated with cooperation, where as with top management commitment which act as moderating variable shows positive link us with engaged governance, social capital and infrastructure. The implication of this finding is that hotels with a given magnitude of social sustainability would outperform those on customer feedback, cooperation and top management commitment. On the other in hospitals engaged governance, social capital, social justice \& equity and social infrastructure has positive impact on customer feedback which is used for the measurement of customer satisfaction. 
This study is a valuable source to those companies struggling with the issues of successful implementation of social sustainability techniques and they will be better able to benchmark themselves against the best practices found in the study. Reading of this study helps business professionals and practitioners to realize the critical importance of certain performance management related concepts in order to set an improvement plan for nonperforming areas. Finally, this study can be the base for the development of standard criteria for assessing "societal concern progress".

\section{References}

Andersen, (1993) The Lean Enterprise Benchmarking Project, February 1993, Andersen Consulting, London.

Anderson, E.W., Fornell, C. and Lehmann, D.R. (1994), Customer satisfaction, market share and profitability: findings from Sweden. Journal of Marketing, Vol. 58, pp. 53-66.

Al-Harbi,K. (2001) Application of the AHP in project management. International journal of Project Management.

Bruntland, G., H. (1987). Our Common Future; World Commission on Environnent and Développements In Scott-Morgan, P., Hoving, E., Smit, H., Van Der Slot, A. (1987). The End of Change; . McGraw Hill 2000.

Cooper, R. (1987a). The two-stage procedure in cost accounting: part one. Journal of Cost Management, summer, pp. 43-51.

Cooper, R. (1987b). The two-stage procedure in cost accounting: part two. Journal of Cost Management. Fall, pp. 39-45.

Cuthill, M. (2009). Strengthening the 'social' in sustainable development: Developing a conceptual framework for social sustainability in a rapid urban growth region in Australia. Sustainable Develiopment . 18 (6), pp-362-373,

Cuthill M. (2001). Developing local government policy and processes for community consultation and participation. Urban Policy and Research. 19(2): 183-202.

Cuthill M. (2002). Exploratory research: citizen participation, local governance and sustainable development in Australia. Sustainable Development 10(2): pp- 79-89.

Cuthill M. (2003). The contribution of human and social capital to building community wellbeing: a research agenda relating to citizen. Urban Policy and Research, 21(4), pp. 373-391

Cuthill M, Fien J. (2005). Capacity building: facilitating citizen participation in local governance. Australian Journal of Public Administration. 64 (4), pp-63-80 Vancouver City Council (2006). A Social Development Plan for the City of Vancouver: Moving Towards Social Sustainability. [http://vancouver.ca/ sustainability/res_councilrpts.htm

Carson, R. (1962). Silent Spring. Penguin: Harmondsworth, UK.

Clarkson, M. B. E. (1995). A stakeholder framework of analyzing and evaluating corporate social performance. Academy of Management Review, 20(1): 92-117.

Deming, W.E. (1986). Out of the Crisis: Quality, Productivity, and Competitive Position, Cambridge University Press, Cambridge.

Donaldson, T., \& Preston, L. E. (1995). The stakeholder theory and the corporation: Concepts, evidence and implications. Academy of Management Review, 20(1): 65-91. 
Empacher C, Wehling P. (2002). Social Dimensions of Sustainability: Concretisation and Operationalisation Perspectives, ISOE Study Text 11. Frankfurt. www.isoe.de/english/public/stud11.htm [June 2007].

Elkington, J. (1998) Cannibals with Forks: The Triple Bottom Line of 21st Century Business"; Gabriola Island, BC Canada ; New Society Publisher 1998

J.E., Preston, L.E., Sachs, S. “Managing the Extended Enterprise: The New Stakeholder View"; in Post, J.E., Preston, L.E., Sachs, S Redefining the Corporation: Stakeholder Management and Organisational Wealth; Stanford University Press. 2002

Frooman, J. (1999). Stakeholder influence strategies. Academy of Management Journal, 24(2): 191-205.

Freeman, R. E. (1984). Strategic management: A stakeholder approach. Boston: Pitman.

Greider W. (1997). One World, Ready or Not: the Manic Logic of Global Capitalism. Simon and Schuster: New York.

Johnson, H.T. (1983), "The search for gain in markets and firms: a review of the historical emergence of management accounting systems", Accounting, Organisations and Society, Vol. 2/3, pp. 139-46.

Jones, T. M. (1995). Instrumental stakeholder theory: A synthesis of ethics and economics. Academy of Management Review, 20(2): 404-437.

Kaplan, R.S. (1983). Measuring manufacturing performance: a new challenge for managerial accounting research. The Accounting Review, Vol. 58 No. 4, pp. 686-705.

Kunz J. (2006). Social Sustainability and Community Involvement in Urban Planning. University of Tampere: Tampere, Finland.

Littig B, Grießler E. (2005). Social sustainability: a catchword between political pragmatism and social theory. International Journal of Sustainable Development 8(1/2): 65-79.

Magis K, Shinn C. (2008). Emergent principles of social sustainability: human well-being, equity, democratic government and democratic civil society. In Understanding the Social Dimension of Sustainability, Dillard J, Dujon V, King M (eds). Routledge: New York; $15-44$.

Partridge E. (2005). Social Sustainability: a Useful Theoretical Framework, paper presented to the Australasian Political Science Association Annual Conference, Dunedin, New Zealand.

Phillips, R. A., \& Reichart, J. (2000). The environment as a stakeholder? A fairness-based approach. Journal of Business Ethics, 23: 185-197.

Rowley, T. J. (1997). Moving beyond dyadic ties: A network theory of stakeholder influences. Academy of Management Journal, 22(4): 887-910.

Report of the Health System Review Mission - Pakistan 2007

Rapoport A. (1985). Thinking about home environments: a conceptual framework. In Home Environments, Altman I, Werner C (eds). Plenum: New York; 255-286.

Sachs I. (1999). Social sustainability and whole development: exploring the dimensions of sustainable development. In Sustainability and the Social Sciences: a CrossDisciplinary Approach to Integrating Environmental Considerations into Theoretical Orientation, Becker E, Jahn T (eds). Zed: New York; 25-36.

Saul J. (1997). The Unconscious Civilization. Penguin: Ringwood, Australia.

Sharma, S., \& Henriques, I. (2005). Stakeholder influences on sustainability practices in the Canadian forest services industry. Strategic Management Journal, 26: 159-180. 
Starik, M. (1995). Should trees have managerial standing? Toward stakeholder status for non-human nature. Journal of Business Ethics, 14: 207-217.

Steurer, R., Langer, M. E., Konrad, A., \& Martinuzzi, A. (2005). Corporations, stakeholders and sustainable development: A theoretical exploration of business-society relations. Journal of Business Ethics, 61: 263-281.

Triple Bottom Line - http://www.rolltronics.com/tbl.tbl.shtml 1994

United Nations Conference on Environment and Development. 1993. Agenda 21, Programme of Action for Sustainable Development. United Nations: New York.

United Nations Environment Programme. 1972. Declaration of the United Nations Conference on the Human Environment. http://www.unep. org/ Documents. Multilingual/Default.asp?DocumentID=97andArticleID=1503 [5 April 2003].

World Resources Institute, United Nations Environment Programme, World Business Council for Sustainable Development. 2002 The World Commission on Environment and Development, Our Common Future. OUP, Oxford, 1987, p. 43.

Wood, D. J. (1991a). Corporate social performance revisited. Academy of Management Review, 16(4): 691-718.

Wood, D. J. (1991b). Social issues in management: Theory and research in corporate social performance. Journal of Management, 17(2): 383-406.

World Summit on Sustainable Development at Johannesburg in 2002 


\title{
Globalization and Human Development: The Experience of Cuba
}

\author{
Miguel Márquez ${ }^{1}$, Blanca Munster Infante ${ }^{2}$ and Camilo Márquez Cerezo ${ }^{3}$ \\ ${ }^{1}$ Cuban Academy of Sciences, Public Health Hero of the Republic of Ecuador, \\ ${ }^{2}$ Research Center on World Economy, Havana, \\ ${ }^{3}$ Ministry of Interior, \\ ${ }^{1,3}$ Ecuador \\ ${ }^{2} \mathrm{Cuba}$
}

"Human development is the expression of people's freedom to live a long-lasting, healthy and creative life, pursuing objectives that are valued as worthy, and participating and contributing to a sustainable and equitable development of the planet that all share"

\section{Part I}

\subsection{General overview}

\subsubsection{The world at the beginnings of the $21^{\text {st }}$ century}

Since the beginnings of the 1990s and the first decade of the $21^{\text {st }}$ Century, mankind has been suffering the destructive effects of the economic-financial crisis of capitalism, together with a food crisis, the global warming and the climate change; an energy crisis that has been aggravated by the thermo-nuclear threat that became evident in the Fukushima disaster in Japan, showing the lack of safety in nuclear-power plants and the lack of control of radioactive wastes and their impact on environmental pollution. In connection with these crises with unforeseeable consequences, Joseph Stiglitz, winner of the Nobel Prize in Economics 2002, stated, for example, that: "The costs of reducing emissions are insignificant if compared to the risks faced by the world." In addition, he pointed out to another crisis, the crisis of values, when he mentioned "The experts in the nuclear industry and in the finance sector reassured us that micro-technology had practically eliminated all risks of a disaster. The events have proved that they were wrong; because not only risks existed, but their effects were so appalling that they easily did away with the security systems extolled by the industry's leaders. "(1)

The international situation at the beginning of the new Millenium has also been negatively affected by military conflicts in Iraq, Afghanistan and Libya, with the idea of favoring democracy and boosting changes in the Near East. All of this seems fiction today and has brought about disastrous consequences for peace, global economy and for the construction of a new global politico-economic order, which is aspired by the majority of the peoples worldwide who are aware that the fundamentalist conflicts that are promoting wars in the 
21st Century will take a heavy toll on all of us for decades. Stiglitz, in his book entitled "The War of the Three Billion Dollars", when referring to the human suffering, stated: "The human suffering that has been caused by the war in Iraq could be seen as useless; even the thought of its financial cost in sterile numbers could never express the pain of those who died, who have been wounded and crippled for life."(2)

\subsection{The neo-liberal globalization and the Washington Consensus}

Since the 1980s, neo-liberal globalization has been one of the most complex and controversial processes within industrialized nations and developing countries alike. Globalization is understood as the broadening and strengthening of financial and technological trends, linked to an ideological belief that the emancipation of markets for capital, commerce, and information would lead to growth, development and human wellbeing.

This vision of the neo-liberal globalization prevailing since the late 1980s and the beginnings of the 1990s, coalesced into a single doctrine the so-called Washington Consensus. One of the founding tenets of neo-liberal globalization is that it is inevitable and that the technological, economic and political developments converge to shape a New Global Order, linked to the capitalist market and the observance of specific norms as guidelines for the modus operandi among nations worldwide. These norms are: austerity and fiscal discipline, the restructuring of public expenditure, tax reforms, the privatization of public enterprises, the establishment of competitive money exchange rates, free markets, the deregulation of the financial world, openness to capital flows, removal of restrictions to direct foreign investments, flexibility in economic and work relationships, and the guarantee of the rights of private property. The abovementioned norms are expected to create the appropriate conditions to ensure global economic restructuring, under the rationality of the capitalist system.

The above tautological vision of the neo-liberal globalization could lead us to neglect the historical reasons for globalization: the heterogeneity of socioeconomic formations in a given historical period; the antagonisms and contradictions which, as dynamic processes, can overcome different moments to redefine or reconstruct the doctrinal bases; and the interrelations between the modes of production and governments, in the light of the desideratum of blind laws of the free market, as the supreme expression of governing capacity.

Several experts in the field of economics and finance have questioned the rationale of the Washington Consensus. Joseph Stiglitz, winner of the Nobel Prize in Economics, considered that those were not the actual reasons, but simply a collection of "myths", so powerful and hegemonic when implemented, that to understand them it is necessary to resort to scientific reasoning, to economic theory and its very practice, to re-address a new global economic order. Stiglitz advanced this idea in his book The Roaring Nineties. The Seed of Destruction (2003). (3)

Dominique Strauss-Kahn, then the Managing Director of the International Monetary Fund (IMF) of the IMF, further elaborated Stiglitz's observations in a lecture at George Washington University in April, 2011. In that lecture, Strauss-Kahn announced the death of the Washington Consensus, when he stated: "The Consensus is history; it should be 
replaced by a new economic policy that emphasizes social cohesion and multilateralism." While admitting that what had been promised to Latin America instead of favoring development brought about a severe economic crisis in the late 1990s and early 2000s, an increase in the external debt and more underdevelopment, he argued that governments should be urged to play a bigger role in controlling market excesses, because a more humane face of globalization is needed and because inequalities are the silent causes of the crisis, so as to reach a new economic policy, that emphasizes social cohesion and multilateralism." (4)

The ideas expressed by Stiglitz and Strauss-Kahn are based on solid and scientific foundations and take into account the broken promises and crises in Ethiopia, East Asia, Mexico, Argentina, Greece, Ireland, Portugal, Spain, and the United States, all of which are in what seems to be an economic dead-end.

\subsection{United Nations's Human Development Initiative}

In the light of a complex global situation, the United Nations and the governments of its member states, made political and economic efforts to convene in the 1990s, the largest number of Summits and Conferences held by the United Nations in a decade to discuss topics and problems of global interest, namely: the World Summit for Children (New York, 1990); World Summit on Environment and Development (Rio de Janeiro,1992); the International Conference on Population and Development (Cairo, 1994); World Conference on Women (Beijing 1995); World Conference on Social Development ( Copenhagen,1995); the Second Conference on Human Settlements (Habitat II) (Istanbul, 1996); and the World Food Summit (Rome, 1996). This historical decade for the United Nations and the Governments of its member states was rounded up in New York in 2000 with the Declaration of the Millennium Development and Goals towards 2015, underpinned by the agreements and resolutions approved in the previous summits.

Despite the enormous efforts made within the United Nations, there is still no consensus concerning development policies; there are opposed trends, as a binary antagonism, between the concept of development advocated by the United Nations and the paradigm of the Neo-Liberal Globalization that fosters market fundamentalism, arguing that it could resolve by itself the global economic and social problems, through a collection of myths, such as: the reduction of fiscal deficit; the idea that prosperity was due to economic gurus; the myth of the invisible hand in the free market and the financial "bubbles"; the myth that strong governments are bad ; and the myth of global capitalism, a triumphant capitalism, following the US model.

In the Report on Human Development (2010) it is clearly stated that the conventional package for development advocated in the global document of the Washington Consensus is unsustainable as a collection of universal prescriptions, although it admits that it still has influence on many levels. In the current situation, in the reflection made concerning development, there are opposing views, which are not all new, and some are complementary. Their actual influence depends on the country and in many of them the influence of the approach of human development is used to resolve the disastrous effects existing in those countries which opted for the Washington Consensus. As indicated in Box 1 , it is now accepted that: 
"There is need to adopt measures to regulate the economy, to outreach vulnerable groups and produce social goods:-health education, infrastructure, and to overcome the crisis of the climate change.

- The multiple dimensions of well-being should be made operational so as to go beyond average income and the monetary measurements of poverty.

- Poverty, growth, and inequity are essentially indivisible. The reduction of poverty does not depend on the growth rate, but on the levels and changes of the distribution of income.

- There is not a one and only solution. The advantages and benefits of some normative reforms are different depending on the circumstances and the suitability of strategies at a local level.

- The importance of the national role is now highlighted, as a key element to support and achieve sustainability in the ongoing reforms." (5).

\begin{tabular}{|c|c|}
\hline \multicolumn{2}{|c|}{$\begin{array}{l}\text { Challenges faced by humanity to advance in the road to } \\
\text { Human Development in the } 21^{\text {st }} \text { Century }\end{array}$} \\
\hline KEY ASPECTS & CHALLENGES \\
\hline $\begin{array}{l}\text { Opposing views with the conventional } \\
\text { package of development policies proposed by } \\
\text { the Washington Consensus, as being } \\
\text { unsustainable given its universal } \\
\text { prescriptions. }\end{array}$ & $\begin{array}{l}\text { Admitting that there is not a one and only } \\
\text { solution to development. } \\
\text { Resuming national roles in government } \\
\text { policies } \\
\text { Considering restrictions on external } \\
\text { cooperation, its negative effects, and } \\
\text { limitations }\end{array}$ \\
\hline $\begin{array}{l}\text { The economic and financial crisis; the crisis of } \\
\text { climate change; the crisis of traditional } \\
\text { energy boosted by the thermonuclear energy; } \\
\text { the food crisis and human poverty and the } \\
\text { crisis of moral values }\end{array}$ & $\begin{array}{l}\text { Recognizing that the crises are systemic and } \\
\text { that solutions depend on all the actors. } \\
\text { Raising awareness that the disastrous effects } \\
\text { of the crisis are bigger and the consequences } \\
\text { more negative for developing countries } \\
\text { Reaching global consensus on how to } \\
\text { overcome the crises }\end{array}$ \\
\hline $\begin{array}{l}\text { Alignment of public policies with economic } \\
\text { policies }\end{array}$ & $\begin{array}{l}\text { Admitting that an economy market without } \\
\text { restrictions is not sustainable }\end{array}$ \\
\hline $\begin{array}{l}\text { Human poverty, growth and inequity are } \\
\text { indivisible }\end{array}$ & $\begin{array}{l}\text { Recognizing that the reduction of poverty } \\
\text { does not only depend on growth rates but } \\
\text { mainly on levels of change in the distribution }\end{array}$ \\
\hline Gender inequity and gender empowerment & $\begin{array}{l}\text { Redirecting public policies for the expansion } \\
\text { of freedom for all - women and men - to live } \\
\text { a long-lasting, healthy and creative life. }\end{array}$ \\
\hline $\begin{array}{l}\text { Discrepancies between local and national } \\
\text { development }\end{array}$ & $\begin{array}{l}\text { Strengthening local dimension and promoting } \\
\text { the development of local capacity. }\end{array}$ \\
\hline
\end{tabular}


Ten years have passed since the world leaders settled the objectives and goals to emancipate humankind from extreme poverty, hunger, illiteracy and diseases.

The Report released in 2011 on the progress achieved towards reaching the targets set by the Millennium Development Goals, stated that:

- "Poverty is being reduced in many countries and regions. It is expected that by 2015 the global poverty rate would be less than $15 \%$, quite distant from the $23 \%$ in the objective.

- Some of the poorest countries have achieved outstanding advances in education and it is expected that this objective will be fulfilled.

- The specific interventions have reduced infant mortality rate in children under 5 years of age. The deaths prevented represent a fourth of the decrease in the mortality rate and every day 12, 000 deaths among children are prevented.

- $\quad$ The increase in funding and the efforts made to curb malaria have reduced mortality in $20 \%$.

- $\quad$ The investment made in the prevention and treatment of HIV is yielding fruit. In 2009 there was a fall in $21 \%$ in reported cases and $19 \%$ in mortality.

- As a result of effective strategies against tuberculosis, the deaths attributed to this disease have decreased in more than one third since 1990.

- All the regions have made progress concerning access to drinking water. It is estimated that in 2008, 1, 100 million people in urban areas and 723 million in rural areas had access to sources of drinking water." (6)

Furthermore, the Report underlines that despite the progress achieved, no attention is paid to the living standards of the most vulnerable groups:

- "The people living in extreme poverty and those with disadvantages due to sex, age, ethnic group or special needs, show outrageous differences.

- The poor children have been the less benefited with respect to an improved diet. This was reflected in the indicator of $25 \%$ of children in developing countries are underweigth. Opportunities for a productive and full-time job are still scarce, particularly for women.

- Advances in sanitary conditions often neither reach the poor people nor those living in rural areas.

- Improving the lives of the increasing number of poor people in urban areas is still a colossal challenge.

- Improved access to sources of drinking water has not been even among the vulnerable population groups."

In the top-level plenary session at the General Assembly of the United Nations, when approving the Millennium Development Goals, world leaders emphasized that steady progress demands a full commitment to peace, equity, equality, and sustainability.

\subsection{Cuba in the $21^{\text {st }}$ century}

In the period $2004-2011$, Cuba has shown an outstanding improvement of all its social indicators: health, education, and social security. Alongside, it has shown a slow but steady 
advance in its economy, as reflected in the increase of its GDP $1.4 \%$ in 2009; $1.91 \%$ in 2010, and $2.9 \%$ in 2011. (4). Of great significance this year was the adoption by the $6^{\text {th }}$ Congress of the Communist Party of Cuba, in April 2011, of the "Guidelines for the Political and Social Policy of the Party and the Revolution", which will be the basis for the work of the Cuban Parliament, the Government and other State bodies which will devise and approve, in some cases, the norms required for the establishment of a legal and institutional framework to support the economic changes to be further adopted.

In his book entitled Notes on Cuban Economy (2011), Rodriguez presents, with a solid scientific reasoning, the experience that Cuba has undergone in the past 50 years, including the so called Special Period (1990-2003) that ensued after the breakup of the former Soviet Union. He stated: "A factor of vital importance is expressed in the political will of maintaining Cuban economy as a planned economy, while opening to some extent to nonstate forms of property, but establishing limits. " Rodriguez underlined that "...in the updating of the economic model, it will be planning and not the market, what will prevail in the new forms of individual economic activities outside the realm of the state non-state management. The concentration of property in the hands of legal entities or individuals will not be allowed." (7)

When implemented, the guidelines will represent the beginning of a new stage in the country's development strategy, which will move from a phase of survival and of tackling the crisis, to another phase of paving the way to a sustainable development of the economy, by overcoming the essential limitations of the Special Period. (Castro, 2010a).

Nonetheless, the decisions made and their implementation at a short term, particularly concerning the adoption of new forms of employment and inidividual economic activity are complex and are expected to bring about some social tensions; but, at the same time, they are indispensable for introducing the rationality and efficiency so required by the Cuban economy. In this respect, and due to its alignment in the main considerations with the abovementioned economic policies, the principal efforts to be made in the coming years at the macroeconomic level could be summarized as follows:

- In the first place, in the short-term a solution has to be found to the deficit in the balance of payments, by reducing the expenditures in convertible pesos and by negotiating anew the service of the external debt. More importantly, special efforts will be made to increase exports, since the reduction of the expenditures has material and social limits which prevent from advancing beyond a given point.

- Secondly, a financial domestic balance should be maintained, with control of inflationary pressures, together with the development and introduction of new incentives to increase work productivity significantly. At the same time, all the measures should take into consideration the need for a gradual reduction of disparities in the distribution of income generated during the Special Period. This should be done by prioritizing the recognition of higher payments pay to the most efficient work.

- Lastly, an increase should be attained in the investment rate, so as to allow for completing the productive infrastructure necessary for development, on the one hand, and for resuming the road to industrialization in more competitive branches and with greater added value, on the other. 
The Cuban experience in the past 50 years, including the twenty years of the Special Period, clearly shows the complexity on an economy while building Socialism, where errors pay dearly and can destroy the Revolution. (Castro, F. 2005).

If the country has reached its current development state, overcoming obstacles that seemed insurmountable, it is because the policies adopted to promote the country's development have taken into account economic considerations as well as social and political objectives and priorities.

\section{Part II}

\subsection{Cuba's strategy for human development}

The experience of multiple countries at different levels of development has shown that although economic growth is an indispensable condition for Human Development, not all economic growth leads to development. To attain a positive outcome, the growth must occur in the strategic economic sectors that can assure steady and balanced levels of economic activity.

At the same time, the implementation of adequate strategies is required to assure a rational income distribution to favor social development programs. This requires a consistent government intervention, something which is one of the most controversial issues at present.

In recent years, several experts have shown through research that social investment - for a long time considered as a non-productive expenditure - is actually the capital needed to boost development.

Ironically, a new scenario is emerging which pits theories of social justice against neo-liberal strategies and policies that results in the deterioration of living standards.

This process is not rational since the global problems that affect humankind are threatening the very survival of the human race. In the light of this situation, a focus on human needs should be prioritized, because people are not only the agents of development but also the fundamental recipients.

From the outset and with a view to providing a comprehensive solution to this dilemma, the Cuban Revolution envisaged the close relationship between the economic foundation and social outcomes.

The Revolution conceived the process of development as one which would be simultaneously dealing with both economic and social problems. The attention to social aspects was fully in line with the belief that a social revolution is meaningful to the extent that it solves existing social problems.

Fidel Castro, in his historical speech, History Will Absolve Me, which was delivered during the trail of the participants in the assault on the Moncada Garrison more than 50 years ago, pointed out the fundamental problems that had to be solved in the country. (1)

The political platform of the revolutionary movement was devised taking into consideration the possible solutions to such problems; it defined the socio-economic objectives of the Cuban Revolution. 


\section{Socio-economic problems in Cuba before 1959}

The problems were related to the land, industrialization, housing, unemployment, public education, and public health. In a nutshell, these are the six issues which would receive our full attention, together with ensuring public liberties and political democracy.

Castro. F La Historia me Absolverá. La Habana. Editorial de Ciencias Sociales, 1981, p.41

Table 1.

Without doubt, the elimination of centuries-old problems of underdevelopment, such as extreme poverty, monoculture and concentrated landownership, high rates of unemployment, and industrial backwardness, demanded the resolution of structural problems, such as the distorted economic sector and the dependency relationship on the United States of America. (1)

- $43 \%$ illiterates; $44 \%$ never attended school

- $74.2 \%$ of houses in rural areas were in an appalling or bad state; only $10 \%$ had electric power.

- Only $8 \%$ of the population received free medical care from the State; $14 \%$ suffered or had suffered from TB; $13 \%$ from typhoid and 36\% from parasitism

- Only $11 . \%$ drank milk, $4 \%$ ate meat; $2.1 \%$ ate eggs; $1 \%$ ate fish and $3.4 \%$ ate bread

Castro. F La Historia me Absolverá. La Habana. Editorial de Ciencias Sociales, 1981

Table 2. Social conditions of Cuban peasants before 1959

In 1959 Cuba presented a socio-economic panorama typical of a neo-colonial country, mainly characterized by the following features: (2-3-4)

- High dependency on the United States of America, which ran the most important national industry: sugar production. US capital owned 1200000 hectares, including $25 \%$ of the best arable lands. In addition the US controlled the generation and marketing of electric power, a share of the dairy industry, the importation of fuels and financial credits.

- $\quad$ The structure of landownership was characterized by large estates that dramatically increased in the 1950s. In 1958, 73.3\% of the country's arable land was distributed into farms with more than 400 hectares, while $8 \%$ of the owners controlled $75 \%$ of the land. In this period, a growing trend of eliminating small subsistence landholdings began to be seen, due to massive exodus of impoverished peasants to the cities. Some estimates indicate that by 1952 big landownership devoted to sugarcane and to livestock accounted for $87 \%$ of the total farm area nationwide.

- The prevailing economic structure was agricultural. The principal industry was that of sugarcane, which was developed through traditional means; the remaining sectors did not show a significant development.

- Dependency on foreign trade, which generated a fully open economy that registered between 25 and 28 cents of imports per peso of material produced. Geographically, commerce was concentrated with the USA, which imported $60 \%$ of Cuba's productions 
(sugarcane monoproduction accounted for $80 \%$ of total exports) and provided $75-80 \%$ of Cuban imports.

- High polarization of incomes: The top $20 \%$ of the population received $58 \%$ of the income, while the poorest $20 \%$ received only $2 \%$.

- $\quad$ The economic situation previously described was reflected in the few advances made in the period in key social support sectors, such as education and health care.

- Actually in 1958 around $45 \%$ of children aged 6 to14 did not attend school; $23.6 \%$ of the population over 10 years of age was illiterate; $22.6 \%$ of the population aged 10 years or older had completed basic schooling; and the average schooling level among the population over 15 years of age was below third grade. Paradoxically, 10, 000 teachers were unemployed, and no serious effort was made to attain quality education.

- The health care provided by the state was insufficient and of poor quality, and there was no national health care system. Private health care institutions prevailed. The services provided were mainly curative in nature, with practically no preventive medical care. The training of medical doctors did not take into consideration the social needs of the population, and there was an almost complete lack of health care services in rural areas. There were 98 hospitals and one medical doctor per 1, 067 inhabitants. There was only one rural hospital in the country and the system of emergency medical posts mainly provided only first-aid services. Havana, the capital city, with only $22 \%$ of the country's population had $65 \%$ of all medical doctors and $62 \%$ of hospital beds. The state budget allotted to public health in the fiscal year 1956-1957 was of 18 million pesos, representing only $5.3 \%$ of all government expenditures for that year.

- Levels of unemployment and underemployment were very high and proportionally higher than the ones observed in other Latin American countries, since they often affected more than the $25 \%$ of the workforce. There were more than 600,000 unemployed in the periods between sugarcane harvests and an average of 300,000 unemployed year round.

- Women were particularly negatively impacted by the poor level of economic and cultural underdevelopment. Only $12 \%$ of the labor force was made up of women, and their activities were practically limited to the service sector and household chores. Women were prohibited from holding official and government positions.

- Housing conditions were extremely poor. According to the Population and Housing Census carried out in 1953,46.6\% of dwellings showed deplorable or bad conditions, and only $33 \%$ were made of stone masonry. In rural areas these indicators were even worse: $74.2 \%$ and $2.5 \%$ respectively.

Since 1959 the Cuban Government has sought to transform all the aforementioned structural problems.

The first steps towards the fulfillment of the main objective - the comprehensive development of Cuba-- were taken in the early years of the Revolution. Transformations in the economy and in the social structure have been governed by the basic tenet of the Cuban revolutionary process: to attain development through an equitable distribution of incomes, with top priority given to social justice.

Socio-economic transformations were reflected in the measures taken to immediately redistribute incomes to favor workers and marginalized groups, eliminate unemployment and to enhance living standards. 


\section{Part III}

\subsection{Main features of the policies for human development in Cuba}

The concept of comprehensive development is the first feature of Human Development. Another essential feature is the implementation of a unified social policy directed by the State which allowed for the concentration and distribution of available resources to favor Human Development policy. This approach has proven to be appropriate, particularly in times of economic restrictions that have brought about a sharp reduction in the availability of resources. In spite of this, Cuba maintains favorable indicators of Human Development.

On the other hand, the actions of the State could not have produced such outstanding results if there had not been the support and the participation of the people in the programs for educational and health development, and advances in areas such as the availability of housing, the supply of consumer goods, and in cultural and sports programs.

Social organizations particularly the Committees for the Defense of the Revolution (CDR), the Central Union of Cuban Workers (CTC) and the Federation of Cuban Women (FMC) have developed diverse campaigns to support the social policy.

The CDRs --founded on September 28, 1960 -- have more than 6.7 million members and have carried out diverse campaigns:

- Campaigns to foster a health culture through massive education.

- Campaigns for epidemiological surveillance

- Campaigns for massive vaccination and screening

- Promotion of blood donations

- Movement for recruiting teachers and for strengthening the school-family relationship.

- Support for the organization and distribution of consumer goods and supplies

Trade unions have played a decisive role through the CTC. They participated in the National Literacy Campaign in 1961 and have been participating in several campaigns for the educational development of workers such as the campaigns to help them reach the $6^{\text {th }}$ and $9^{\text {th }}$ grades, the promotion of social services, social security and social welfare, and the adoption of measures to improve working conditions and hygiene in the workplace.

The FMC was founded on August 23, 1960 to demand women's rights, ensure attention to gender interests, eliminate all discriminatory practices and promote the broadest participation of women in the country's economic, social and political spheres.

To look after the interests of peasants nationwide, the National Association of Small Farmers (ANAP) was created to support socio-economic transformations in rural areas.

This policy of social development has improved the living standards of the Cuban people, combining an increase of individual consumption with the implementation of basic social services.

At the same time, the policies implemented have included a preferential treatment to certain sectors of the population, namely: women, children, elderly citizens and inhabitants of rural areas. It is precisely in such vulnerable groups where the structural problems of underdevelopment become more critical. Their solution demands not only profound 
changes in the socio-economic system, but also a gradual and steady process of assimilation of these vulnerable groups into all processes of social and economic changes.

It is difficult to overcome centuries-old prejudices generated by economic and cultural distortions. Therefore, this special treatment demanded attention far beyond the establishment of balanced social relationships.

In the Cuban case, the basic premises for the implementation of a strategy for comprehensive development lay in the adoption of a Socialist system.

The nationalization of the fundamental means of production during the initial years of the Revolution laid the foundations for the establishment of a single socio-economic core, capable of coordinating in a gradual and planned manner the different actors in the development process.

On the other hand, the possibility of counting on the support of the Socialist countries, particularly the Union of Soviet Socialist Republics (USSR) was a significant factor in the development of the country during thirty years.

After 1959, the development strategy implemented by Cuba would have to face simultaneously the following two obstacles:

- An inherited centuries-old underdevelopment, with a worsening trend due to the new challenges posed by the transformations

- The negative effects of the US economic blockade, with intensified once the Revolution demonstrated its capacity to survive.

From 1961 to 1963, priority was given to the strategy that promoted an intensive industrialization of the country, which had as its counterpart a diversification of agricultural production. At that time, Cuba did not have the internal conditions that such a process required. Therefore, it brought about an enormous tension in the balance of payments, and the development program had to be reconsidered.

Between 1964 and 1975 efforts were geared to ensuring the conditions to start the industrialization process that had been postponed. To this end, sugarcane production was selected as the generator of the revenue necessary for development.

It was only after 1976 that the minimum of conditions necessary could be attained to start a gradual process of industrialization. The essential feature of this process was that it had to be embedded in the international Socialist division of labor. Within this system, which prevailed until 1989, Cuba was considered as a country with a lesser relative development. The sectors susceptible to being developed were the production of sugarcane, tobacco, citrus and nickel. The remaining sectors received minor attention influenced by - among other factors - the flow of goods from other Socialist countries to meet the other needs of the country.

From a qualitative point of view, the development strategy of the Revolution was, from the outset, conceived as a process in which economic and social advances were supposed to be profoundly interrelated and complementary to each other.

Following this approach has enabled Cuba to address the entire process of economic growth while at the same time adequately satisfying the level of basic social needs. 
The history of the development process reveals that although the vision towards a comprehensive development was present from the start, it did not automatically guarantee the appropriate relationship among all the factors that such a process demanded.

The reality of life has shown that for thirty years, the economic policy witnessed unquestionable advances, but also deficiencies and errors that although common to any development process, in the Cuban case these were worsened by the conditions imposed by the US blockade.

In this context, the country's capacity to continually adapt to emerging circumstances has been vital, while maintaining a flexible approach and a sense of self-criticism in the evaluation of adopted policies.

After an initial stage of searching for appropriate mechanisms for the economic development - which lasted up to the mid 1960s - the 1967-1970 period was characterized by an idealistic spirit that neglected the existence of economic -commercial relationships under the conditions of Socialism. This approach was corrected in the 1971-1975 period and was critically analyzed during the First Congress of the Communist Party of Cuba.

In contrast, between 1976 and 1985 the economic policy gave too much emphasis to the capacity of economic mechanisms in the solution of most problems faced by our society, neglecting political and social factors. The outcome of that period is considered to have been a constraining effect on the comprehensive development of the system. The fulfillment of strategic objectives was equally threatened.

Between 1986 and 1989, a process of rectification was started in an attempt to correct the abovementioned imbalances, trying to strike a balance between economic factors and political and social factors. This process became known in our history as "period of transition" -- the search for unprecedented solutions, not only to specific problems of the Cuban Revolution, but also to general problems of the Socialist system which were not solved in a timely way globally.(5)

The process of rectification of errors was curtailed by the worsening of external conditions in the 1990s. Both the disappearance of the former Soviet Union and the political changes in other Eastern European countries as well as the toughening of the US blockade put Cuba on the threshold of a qualitatively new stage of development.

However, despite the aforementioned deficiencies, there is no doubt concerning the outstanding economic and social advances achieved in Cuba in the period 1959-1989. These achievements reflected the country's strategic objectives: to eliminate the causes that generated poverty and to place the development of human beings as active social agents, and to consider this as the ultimate goal of the development model.

The reality of life shows that during this period the social development attained in Cuba took the utmost advantage of the opportunities generated by the economic growth, which was based, to a great extent, on a system of specific economic relations with the Socialist countries, particularly with the USSR.

The economic development of the country has been directly linked to the performance of its main national industry: the sugarcane industry. This was a traditional industry that greatly 
fluctuates in response to international markets. Between 1972 and 1976 the rate of economic growth was higher than $10 \%$, as a result of increased prices in sugar and the increasing demand for it, while by the end of that decade, between 1976 and 1980, when the demand was moderate, economic growth averaged only $3.5 \%$.

\section{The process of rectification 1986-1989}

People living in Cuba during the process of rectification almost unanimously emphasize that its momentous effects transcended the narrow economic framework. According to Jean Stubbs: "Although it is generally assumed that the objective was the rectification of errors in the economic sphere, it also included rectification in the political and sociocultural spheres." Fernando Martínez agrees that "in the Cuban process of rectification... although absolutely concerned with the economy, in no way was it limited to the economy. " The campaign devised to improve public communication in the period 19861987 and the broad debates about the need to improve the functioning of the Party and of the People's Power, prior to the celebration of the $4^{\text {th }}$ PCC Congress are examples that clearly illustrate this reality.

Campbell, A “Una introducción a la economía cubana: sus objetivos, estrategias y desempeño". Temas. Havana. Num. 2. 1995 p.43

Table 3.

The efforts to reduce dependency on the sugarcane sector and to achieve an industrial diversification began to yield fruit in the 1980s, when a strong investment process began to consolidate itself.

During the 1981-1985 five-year period, the growth of the gross domestic product (GDP) reached an annual rate of $8.5 \%, 3.5 \%$ higher than planned. Although the economy experienced a significant growth in this period, it was insufficient in important sectors such as the exports of goods and services, and the substitution of exports.

The Cuban economy did not develop in the expected way during the 1985-1989 period, and its average annual growth rate was only $0.7 \%$ in the GDP product per capita.

By the 1980s it became evident that there was a need to move on from a quantitative to a qualitative growth, an essential element included as one of the main objectives of the rectification process. The most remarkable deficiencies in this respect were found in the investment process, with delays in the construction, restoration, and modernization of buildings and in the quality of the services offered to the population.

During this period advances could be observed in relation to the equitable growth in the consumption of calories and proteins, but there was a need to improve the quality and content of the diet. The system of food supply generated a high dependency of the population on the State, which in turn depended on an agricultural sector that highly depended on imports. Estimates made by the Institute of Economic Research in Havana revealed that approximately $57 \%$ of proteins and more than $50 \%$ of the calories consumed came from abroad. 
On the other hand, the problem of unemployment had been partially solved because although access to a job had been practically guaranteed to the population and the participation of women had been increased, both were more in line with the strategy concerning social justice than with criteria of economic efficiency. Therefore, enterprises absorbed more workers than the numbers actually needed.

Neither did the construction of dwellings grew in accordance with the demand or needs of the population. At the same time, maintenance of existing buildings and houses declined. In fact in the 1980s the levels of construction of new dwellings were lower than the levels of deterioration of existing ones.

By the end of the 1980s, some of the difficulties in the international arena became more evident, and the country was to face them with the crumbling of the Socialist community.

However, the problems that have been mentioned should not mar the results achieved in this period by an underdeveloped country under the conditions and characteristics previously analyzed.

Between 1959 and 1989, the national economy showed an average annual growth of $4.3 \%$, and the GDP per capita, a growth of $2.8 \%$, with an estimated increase in worker productivity of $2 \%$.

Such results were based on a gross state investment of 62, 250 million pesos, for an accumulation rate between $20 \%$ and $25 \%$. Per capita industrial production grew by $2.9 \%$, agriculture by $0.9 \%$ and the construction sector by $6 \%$.

These results are higher, in general, than the ones attained in the Latin American region as a whole between 1960 and 1985. In the region, the GDP per capita grew at an average annual rate of $1.8 \%$, while Cuba showed 3.1\%. According to some estimates, in the 1981-1989 period, the GDP per capita in Cuba had an average annual growth rate of $3.8 \%$, while in Latin America it showed a decrease in an annual 1\%. (7)

With the transformations undertaken, in 1989 the country was experiencing a process of creation of the basic conditions to commence the plans for its gradual industrialization, once the essential problems for doing this had been solved.

It is obvious that the economic development as well as the opportunities provided by the commercial exchange with the USSR and other Socialist countries and the relatively stability of financial conditions contributed to ensuring a significant level of development.

The different policies aimed at distributing wealth with equity have brought about a substantial reduction in social imbalances and disparities. Whereas in 1953, the poorest $20 \%$ only received $6.5 \%$ of the total income and the wealthiest $20 \%$ received $57.9 \%$, by the $1980 \mathrm{~s}$, the results were of $11.3 \%$ and $33.8 \%$, respectively, 19 according to academic estimates.

After 1989, the situation changed as the tensions provoked by external events generated limitations and shortages in the country. Even under these circumstances, the rational distribution of available resources has reduced the social cost of the present crisis. 


\section{Part IV}

\subsection{Current situation and prospects of human development after 1989}

The problems faced by the country were worsened by the adverse international situation, which was characterized by two factors: the disappearance of the European Socialist system and the toughening of the blockade imposed by the United States.

The crisis not only revealed phenomena that demanded top priority attention and that questioned the rationale of the development model that had been implemented up to that moment, but it also threatened the very continuation of the revolutionary project.

In 1990 and as a reaction to the situation taking shape, the country started a stage known as the special period in times of peace. The need to preserve the integrity of the model, in opposition to the external economic tensions that emerged after 1989, began to shape the economic strategy that underlies the concept of the special period: the minimum time that the Cuban society needs to reorient its international economic and commercial relations and to restructure its productive and service sectors to cope with the new circumstances and to do so with a view to preserving the main achievements of the Socialist revolution and the right and determination to resume the construction of Socialism when conditions make it possible. (8)

The crumbling of the Socialist camp meant the extinction of the system of economic integration and of participation in the world economy that had guaranteed the development strategy for more than thirty years.

It should be borne in mind that the Cuban economy showed an index of external openness of about $50 \%$ and that imports represented somewhat more that a third of the country's GDP. The Socialist countries participated in more than $80 \%$ of total trade. The member countries of the Council for Mutual Economic Assistance (CMEA) supplied Cuba with the $86 \%$ of raw materials; $98 \%$ of fuels; $80 \%$ machinery and equipment and over $70 \%$ of consumer goods.

Moreover, the problems caused by the blockade imposed by the United States have become more critical.

Among the measures taken under the blockade are the following:

- Cuba has been denied the purchase of any US product made in the USA or in a third country. US companies are banned from buying any Cuban product.

- Citizens of third countries are banned from re-exporting to Cuba goods of US origin or containing any US components. Banks and companies in third countries are banned from using US dollars in their accounts with Cuba.

- The representatives of the US Government in international financial institutions have been instructed to oppose the granting of credits or financial concessions to Cuba

- The rights of US citizens have been restricted, since they are banned from visiting Cuba.

With the cooperation of the Socialist camp the Cuban economy had defined its strategy to tackle the obstacles imposed by the blockade. However, since 1990 Cuba has needed to 
redirect its foreign trade, in a context in which the blockade imposed by the United States was toughened by the passage of the Torricelli Act in 1992. This Act provides for, among other measures, the ban on branch offices of US companies in third countries carrying out transactions with Cuba. In 1991, these subsidiary companies had sold products to Cuba with a value of 718.7 million dollars, $90 \%$ of which were for food and drugs. In addition, the Act bans the entrance in US harbors, within 180 days, to vessels shipping goods to Cuba or from Cuba, or on Cuba's account, and establishes sanctions to countries providing assistance to the island.

The Torricelli Act put the Cuban economy under new pressures. Delays in ship freight increased as a result of the immobility of financial resources. There was also an increase in storage charges. The flow of supplies for the population faced interruptions. More difficulties arose in signing contracts with ships with the appropriate technical features, and the terms of contracts concerning storage and freight worsened. Under a new law, which was adopted to tigthen the embargo, Helms-Burton Act, a failure of any country to comply with the measures of the economic blockade is seen as an obstacle for the relations between such country and the USA. The Act includes provisions such as a ban on entering the USA for on CEOs (and their families) of foreign companies that had acquired former US properties (and also properties owned by Cuban citizens who are now American citizens) that were nationalized in Cuba; the reduction of US contributions to financial international bodies in the same amount that they had granted to Cuba; the instruction given by the President to eliminate commercial preferential treatment to those countries that sell sugar previously bought from Cuba, and the elimination of US assistance to countries that had belonged to the former USSR which subsidize their commerce with Cuba or provide Cuba with any form of aid or credits.

Estimates made by the Institute of Economic Research of Cuba show that in cumulative terms, through 1995 the blockade has cost Cuba more than 60 billion dollars.

In fact, these actions have directly affected the Cuban people to the extent that there has also been a ban on the acquisition of drugs, food and other consumer goods required by the population.

Within this context it is understandable that the search for internal solutions and the adaptation to the new conditions were accompanied by a period of economic contraction. The economic policy was determined to allocate the scarce available resources to the development of productions that could generate income in hard currency.

CUBA: SOME BASIC INDICATORS OF SOCIAL DEVELOPMENT

\begin{tabular}{|l|c|c|c|c|c|}
\hline & 1980 & 1989 & 1995 & 2004 & 2009 \\
\hline EMPLOYMENT & 2734 & 3527 & $\ldots$ & 4779 & 5158 \\
\hline $\begin{array}{l}\text { Average number of workers } \\
\text { (thousands) }\end{array}$ & 72 & 71 & $\ldots$ & 37 & 41 \\
\hline$\%$ productive sector & 32 & 38 & $\ldots$ & 44 & 67 \\
\hline $\begin{array}{l}\text { Female participation in the } \\
\text { workforce (\%) }\end{array}$ & 25 & 39 & $\ldots$ & & \\
\hline $\begin{array}{l}\text { Workers with secondary or } \\
\text { higher education (\%) }\end{array}$ & 25 & & & \\
\hline
\end{tabular}




\begin{tabular}{|c|c|c|c|c|c|}
\hline & 1980 & 1989 & 1995 & 2004 & 2009 \\
\hline EDUCATION & & & & & (1) \\
\hline Number of day-care centers (U) & 832 & 1072 & 1107 & 1123 & 1108 \\
\hline $\begin{array}{l}\text { Enrollment in day-care centres } \\
\text { (thousands) }\end{array}$ & 92 & 149 & 149 & 140 & 130 \\
\hline $\begin{array}{l}\text { Enrollment in pre-primary and } \\
\text { primary education (thousands) }\end{array}$ & 1673 & 1015 & 1026 & 1487 & 938 \\
\hline $\begin{array}{l}\text { Enrollment in secondary } \\
\text { education (thousands) }\end{array}$ & 1128 & 1073 & 703 & 1000 & 871.470 \\
\hline $\begin{array}{l}\text { Enrollment in higher education } \\
\text { (thousands) }\end{array}$ & 146 & 243 & 122 & 361,0 & 606.8 \\
\hline $\begin{array}{l}\text { Enrollment in special education } \\
\text { (thousands) }\end{array}$ & 25 & 55 & $54(2)$ & 46.900 & 411.200 \\
\hline $\begin{array}{l}\text { Graduates from higher } \\
\text { education (thousands) }\end{array}$ & 9.4 & 33.2 & 31.7 & 23.891 & 74.845 \\
\hline Schooling rate (6-14 years) & 92.0 & 98.0 & $97.1(2)$ & 98.000 & 99.31 \\
\hline \multicolumn{6}{|l|}{ HEALTH } \\
\hline $\begin{array}{l}\text { Infant mortality rate (per one } \\
\text { thousand live births) }\end{array}$ & 19.6 & 11.1 & 9.4 & & \\
\hline Life expectancy (years) & 74.2 & 75.22 & $75.48(3)$ & 76.9 & 79.97 \\
\hline Men & 72.6 & 73.4 & 73.5 & 75.0 & 77.0 \\
\hline Women & 76 & 77.0 & 77.5 & 78.0 & 81.0 \\
\hline Population per medical doctor & 635 & 302 & 193 & & 66 \\
\hline Population per dentist & 2667 & 1621 & 1200 & 1.100 & 1.000 \\
\hline $\begin{array}{l}\text { Hospital beds (per one } \\
\text { thousand population) }\end{array}$ & 4.5 & 6.0 & & & \\
\hline Medical doctors (thousands) & 15.2 & 34.8 & 56.8 & 69.000 & 74.800 \\
\hline Dentists (thousands) & 3.6 & 6.4 & 9.1 & 10.000 & 11.572 \\
\hline
\end{tabular}

CEE Anuario Estadístico de Cuba.1989. La Habana. Editorial Estadística, 1989, 2004-2009

MINSAP Anuario Estadístico 1995. La Habana.1996, 2004-2009

ONE. Indicadores sociales y demográficos de Cuba. 1995 La Habana, junio 1996

CEE Cuba: Proyección de la población a nivel nacional y provincial, período 1993-200. La Habana,

Editorial Estadística, 1993, 2000 -2004-2009.

Table 4.

In 1990, the Cuban Government started a number of reforms that gave way to new market mechanisms within the model of a planned economy. In their initial stage, these reforms affected the external sector, the promotion of foreign investments, and tourism. Since 1993, the reforms have directly impacted the functioning of the economy. The principal ones are the following:

- The concentration of investments in sectors with rapid recovery, mainly the tourism sector.

- Greater opening-up to foreign capital, assumed as a complement to the internal forces of accumulation and savings. 
- Elimination of the state monopoly on foreign trade, together with the implementation of schemes for self-financing in hard currency.

- Legalizing the possession of hard currency with the purpose of incorporating in the legal economy the dollars that circulated in the black market, of increasing hardcurrency reserves and of alleviating the shortage of goods

- Broadening the spheres of action of self-employed workers, with the passage of an Act that lists 135 activities in the private sector. At present, around 200,000 workers have been authorized to be self-employed in 160 work activities.

- Restructuring of State agricultural estates with a view to increasing efficiency in that sector. Creation of the Basic Units of Cooperative Production (UBPC), which for an unlimited period will have the usufruct right to the land.

- Restructuring of the State organization that simplified and rationalized the State apparatus.

- Implementation of a more flexible and active financial policy to cope with internal and external financial imbalances

- Opening of free markets (agricultural, industrial and crafts) that are ruled by supply and demand with respect to prices. These markets provide the population with options for consumer goods, and they also stimulate production.

Following 1990 there was a widespread drop in all economic indicators. The most characteristic feature was the fall by 34.8\% of the GDP until 1993. In 1994 there was a slight growth of $0.7 \%$ since the fall of principal indicators was stopped and some growth could be observed in strategic sectors and in some non-traditional productions.

By 1995, the growth of 2. 5\% of GDP ratified the trend of improvement which had started a year earlier. Such growth was based on growth in GDP in agriculture (4.1\%) and in the manufacturing section (6.4\%), as well as in the service sector. (9)

In 1989 the import capacity was of 8.1 billion dollars. In 1993, it had shrunk by 75\% to 2 billion dollars. An increase was observed in 1995, when it reached 3.527 billion dollars.

The reduction of oil imports affected both industrial and population consumption. In 1989, oil imports were at the level of 13.4 million tons, while in 1993 this had reduced to approximately 6 million, thus severely affecting the country in many ways, including daily power-outages.

As a result of enormous efforts made, there has been an increase in the national oil extractions, although the domestic demand has not been satisfied yet. In addition, the oil being extracted so far has a high content of sulphur, thus making it more difficult to use with the existing technologies. In 1995, oil extracting reached 1.4 million tons, which represents $30 \%$ of the oil consumption needed for generating electric power.

The sugarcane industry, considered the most important sector in the generation of hard currency, has neither had a favorable evolution. Since 1991, sugarcane production has been decreasing. In the 1993-1994 period 4.3 million tons were produced; while in the 1994-95 harvest, only 4 million. Such performance meant a loss of approximately a billion dollars in national incomes. 
The incomes generated by tourism and the high-tech sectors (medical equipment and the biotechnology-based medical-pharmaceutical industry) have kept on growing, although they have not yet been able to compensate for the decline in other productive sectors. Tourism has been developing rapidly. In 1994 it contributed a gross income of about 800 million dollars, and it has kept on growing at an annual rate of approximately $17 \%$ since 1991.

Incomes in the biotechnology sector and the medical pharmaceutical industry surpassed 100 million dollars in 1994.

Industry has been one of the sectors most affected by the crisis. In 1993 the utilized industrial capacity was estimated between 10 and $20 \%$. In spite of this, in 1994 there was an $8.5 \%$ growth because some industrial sectors had recovered.

In contrast, agriculture has not managed to eliminate its deficiencies and the lack of inputs that affect it. In 1995 it showed a better performance with an increase in the production of root-crops and vegetables.

The country's internal financial situation became more critical as a result of the abovementioned difficulties. The absence of a satisfactory production, as well as the continuity of the policy concerning full employment and subsidies brought about an excess of accumulated liquidity that reached around 11 million pesos (about 15 months of salaries) in July 1993. In addition, there was a budget deficit estimated at 4, 200 billion pesos (over $30 \%$ of GNP).(10)

In this sense, the fiscal adjustment implemented has shown positive results. Taking into account the impossibility of a rapid economic recovery, the measures that have been taken have managed to strike a balance between the adjustment and the interests of the population, since there has been a reduction of negative effects on the main achievements of the process.

In 1994, the budget deficit was reduced to 1, 400 billion pesos (7.3\% of GNP) and liquidity closed the year around 9, 500 billion, for a $20 \%$ reduction in only eight months.

The year ended in 1995 with a reduction of the deficit by 775 million pesos, which represented $5.8 \%$ of GDP (3.6\% of GDP at market prices). In relation to 1994, it represented a reduction of $56 \%$.(11)

The fiscal adjustment has been reached in a relatively short period and the deficit is $85 \%$ smaller than the deficit two years before, representing $8 \%$ of GDP compared to $33.5 \%$ in February 1994. This process has been developing under very harsh conditions without support of lines of credit. Although it has been based on the reduction of the added demand, it has allowed for a growth in the GDP.(12)

Since the beginnings, the Cuban State decided to assume the cost of the crisis so as to prevent, to the extent possible, the negative impacts on basic social programs. This has resulted in maintenance of popular support for the government's socio-economic project.

For the Cuban Government, it was essential to avoid the implementation of any measure of the classical neo-liberal nature as were taken by the former Socialist countries and also in Latin America. The State has ensured an equitable distribution of the negative effect of the 
crisis and has given priority to social assistances to sectors of the population that have been more naturally affected.

The reality of life has shown that the preservation of social achievements amidst economic restructuring necessarily poses new challenges, since centuries-old problems are exacerbated and new ones emerge. Despite the difficulties, basic health services and education have been maintained, although the population, particularly the most vulnerable groups, suffers from a shortage of goods and lack of services. Both the current economic situation as well as the reforms undertaken has posed diverse economic and social challenges.

The closing down of enterprises due to shortages of raw material and fuel made unemployment a problem of structural nature. The search for efficiency demands the current economic and institutional restructuring, because for a long time the industries assimilated a level of workforce beyond their needs.

At present the readjustment of workforce has been envisaged in a gradual manner, without causing traumas, and providing the corresponding social compensation. Likewise, other options of employment have been opened, such as the authorization for self-employment, the retraining of redundant personnel and special attention to the groups that are most affected: young people and women.

It is obvious that the financial measures taken to control the added demand (an increase in prices on non-basic goods, an increase in the electric power tariff, elimination of gratuities, among others) directly affect the population at large, particularly the most vulnerable sectors. At present, steps are being taken to implement a system of social assistance or some other alternative solutions to protect these social groups.

Since 1993 measures have been taken to improve food production, such as the creation of the UBPC, the authorization for self-employment, the establishment of the agricultural markets (with prices following the law of supply and demand), the decriminalization of possession of hard currency and the expansion of stores charging in hard currency. (It has been estimated that $40-50 \%$ of the population had access to hard currency in 1996.)

The high degree of dependency on food imports and the deficiencies of the agricultural sector have been reflected in the reduction of the consumption of calories and proteins.

Consequently, with the new measures the sources of food consumption have been diversified, thus reducing the high dependency on the State-rationed market and broadening the possibilities of consumption concerning quality and assortment. However, this has brought about a heightening of differential access among different social groups.

The State has maintained the rationing system, thus ensuring a basic food basket.

Social security is under improvement and expansion, with an increase in its expenditures in recent years, but it has to face the challenge of assuming the protection of the most vulnerable groups, with alternatives and compensatory options until macroeconomic imbalances that affect the country are overcome.

In the political sphere, important decisions were also made in 2005, when the dollar was devalued as to the convertible peso, there was an increase in the minimum wages, pensions and social assistance with a view to compensating for increase in the cost of living. 
Alternative solutions are important, but what is really essential is to preserve the levels of comprehensive development attained, by introducing the necessary social changes and by generating new mechanisms of participation adapted to changing realities.

It is important to increase the supply of goods and services to the population, implementing policies to revive agricultural and industrial production, as a decisive element for stabilizing domestic markets and the level of unemployment.

The social policy is also experiencing changes, and it owes its capacity to adapt to the fundamental principles upon which it is based, namely:

- A centralization run by the State that has permitted more comprehensiveness, equal opportunities in the access to social services, stability and the possibility to give priority attention to the most vulnerable sectors.

- A high level of popular participation in decision-making, which has ensured the understanding and support of the population to the measures implemented to overcome the crisis.

When assessing social development in Cuba, it is necessary to underline that the greatest success of this process is precisely that it has managed to sustain and improve the chosen strategy that has tended to protect the negative social impact of economic measures. Despite the current problems, the achievements reached until 2001 have allowed the continuation and improvement of a considerable number of them in the past years.

\section{References}

[1] Granma Nacional. La Habana, Cuba; abril 15, 2011. Stiglitz, J. Jugar con el planeta.

[2] Stiglitz, J y Bolmes, L. La Guerra de los tres billones de dólares. El coste real del conflicto de Irak. Madrid; Santillano Ediciones Generales, 2008.

[3] Granma Internacional. La Habana. Cuba. 15 de mayo 2011. "Esas sospechosas acusaciones en boga." Declaración de Strauss-Kahn. Presidente del Fondo Monetario Internacional.

[4] PNUD. Informe sobre Desarrollo Humano 2010. Edición Vigésimo Aniversario. La verdadera riqueza de las naciones: caminos al desarrollo humano. Madrid. Ediciones Mundi Prensa; 2010.

[5] Naciones Unidas. Objetivos de Desarrollo del Milenio. Informe del 2011. New York. ONU 2011.

[6] VI Congreso del Partido Comunista de Cuba. Lineamientos de la Política Económica y Social del Partido y la Revolución. La Habana, Cuba 18 de abril del 2011.

[7] Rodríguez, J.L. Notas sobre economía cubana. La Habana, Cuba. Ruth Casa Editorial; 2011.

[8] Castro, F La Historia me absolverá. La Habana, 1973.

[9] Rodríguez, J.L. Apuntes sobre la estrategia, la planificación del desarrollo y la construcción del socialismo. Economía y Desarrollo, 1982.

[10] 3. CIEM. Estudio sobre la erradicación de la pobreza en Cuba. La habana 1983.

[11] Leo Graude, W Dependency A Comparison of Pre-Revolutionary and PostRevolutionary International Economics-relations. Cuba, Studies. Vol 9 No.2, 1979

[12] CEE Anuario Estadístico de Cuba.1988. La Habana. Cuba 
[13] Op.cit. 2

[14] Rodríguez, J.L. La economía cubana: algunos problemas actuales y perspectivas. Paper presented at XVII LASA Congress. Los Angeles, 1992.

[15] MINSAP Análisis del Sector Salud. Cuba La Habana, 1996.

[16] Pichs, R. La industria petrolera cubana en un contexto de apertura económica. Investigación Económica. UNAM.1996.

[17] BNC. Informe Económico. La Habana. 1995

[18] Op.cit.10

[19] Triana, J El desempeño de la economía en 1995 y el proceso de transformaciones económicas. Boletín Informativo Economía Cubana. CIEM. Cuba.1996. 


\title{
How Third World Countries Can Take Advantage of Globalization - A Mexican Experience in Learning and Research
}

\author{
Jaime Jiménez \\ Instituto de Investigaciones en Matemáticas Aplicadas y en Sistemas, \\ Universidad Nacional Autónoma de México, \\ Mexico
}

\section{Introduction}

This chapter shows how a number of university professors, not inserted into the "mainstream" science takes advantage of some features of globalization to help nonconventional students to get a $\mathrm{PhD}$ degree in sciences, putting in practice an innovative way of learning and research aimed to prepare new scientists and, concurrently solve specific research problems detected by the students in their own geographic region.

They created the Innovation and Educational Development Centre (Centro de Innovación y Desarrollo Educativo, CIDE) in the 80's (CIDE, 2003). The CIDE model is an eclectic amalgam of several advanced proposals that emerge from innovative, new, and alternative education models: open education, teaching at a distance, and problem-based learning. The Centre brings together all three of the above methods in a unique combination that aims to educate students to learn, by doing research, on specific topics and problems brought about or discovered by the students themselves.

CIDE is an attractive educational alternative for students, who are not as comfortable following conventional education methods, or whose age and occupation does not allow them to engage in a formal graduate program. One of the main features of this model is the intensive use of the ICTs along with powerful and sophisticated search engines. This allows users to get in touch with the frontier literature in their fields of specialty, and also communicate with top scientists engaged in up-to-date research.

This learning/research model responds to the need to make scientific research more participative, including social sectors that have a stake in the application of scientific findings. The results of this effort are very promising since the $\mathrm{PhD}$ graduates obtain a good education, contribute to solve local/regional problems, and engage in "mainstream science" research networks. The conclusion is that globalization offers opportunities to countries in the process of development to enhance their possibilities of progress that benefit sectors of the population that could not be benefited by globalization otherwise.

The world is experiencing an enormous acceleration in the interchange of goods and services due in great part to the globalization in general and the globalization of the economy in 
particular. Goods and services spread around the world coming from unsuspected countries. As we progress into the XXI Century it becomes clear that people's advancement is strongly tight to the way we acquire and apply knowledge. Those countries with advanced technology have a competitive advantage over those whose technology is lagging behind.

Although cheap labor force still plays a role in the selection of countries where 'maquila' is carried out, it gradually will lose importance as automation takes over. Since the end of the XX Century it became fashionable the assertion that society as a whole was approaching a new era, the era of knowledge, meaning that every human activity would be permeated by the frontier knowledge used, either currently available worldwide or produced within some organization/institution bounds. Indeed, the most important factor for the progress of the world's inhabitants is neither capital, nor labor force but the knowledge they put into their products and services (Jiménez, 2008).

What is behind the era of knowledge motto? Several phenomena compose this current global trend, namely: the globalization of the economy, the fierce competition for world markets, the vertiginous technological and innovation development, having a special place the information and communication technologies, the 'reification' of science and technology, and the assertion that 'knowledge is power' (Jiménez, 2009).

In a world that is in continuous change, we observe new ways of scientific cooperation, new purposes for developing S\&T, new impetus and organization for research innovation. Countries traditionally behind in the production of knowledge, although still far away the big scientific powers, are now at the forefront, such as China, South Korea and to a lesser extent India. With the advent of the new ICTs alternative opportunities arise for scientific development in the economic South such as those in Asia, Africa and Latin America.

New "invisible colleges" (Wagner, 2008) connect scientists both North-South and South-South, enhancing research interests across hemispheres. Some new research is responding to current local or regional problems and opportunities in less developed countries. Since it is research responding to initiatives from "bottom-up", is dissociated from what global markets demand, thus making science more both socially accountable and responsible (Jiménez et al, 2011).

Much has been written about the technology gap and the digital divide between the countries that "have" and those that "have not". However, not all the progress related to the explosion of the information and communication technologies has been of disadvantage for the economic South countries. Some wise use of these technologies has produced positive results in segments of the population not in the upper privileged part of the social pyramid, as shown in the following sections.

\section{The Centre for Innovation and Educational Development (CIDE)}

In the decade of the 80 's, a university professor had the idea to support higher education geared to research with alternative methods, in the official universities of the Mexican provinces. He and his colleagues were convinced that:

The education imparted in universities was not appropriate for the learning of students. Mexico needed to produce more scientists to cover national needs and the official system was unable to carry out that work by itself (CIDE, 2003). 
They set themselves the task of helping students in the provinces to "learn to learn" with alternative methods which included: problem-based learning methodology, consisting of reversing the pedagogic process of knowledge transmission from teacher to student, to a process of knowledge creation which starts-off with the student confronted with a real problem, where the professor acts as a guide and facilitator of the learning process. Problembased learning, as any suitable methodology, has shown some inconveniences as expressed by Fenwick \& Parsons (1997), however regardless some setbacks, the method is quite reliable and has produced, in our experience, positive results. The CIDE model bases its methodology on the advances made by the cognitive sciences, which demonstrate that learning is achieved especially concerning higher learning and mastering abilities- when emphasis is changed from teaching to learning, based on the student's individual and group learning activities.

This method considers the students' heterogeneity of conditions, which makes it necessary to design non-uniform programs, adapted to the special circumstances of the individual. The model guarantees the democratization of education, providing the student equal access, regardless of his/her personal situation, as well as individualized attention, liberating education from the dogmas of traditional pedagogy so that the student is able to go through an individual process and design his/her own learning, reaching intellectual independence through the permanent exercise of critical judgement (Jiménez and Escalante, 2007).

With the aim of following-up on the advances of the participants' research, socialization of knowledge sessions are regularly organized where students exchange experiences regarding both the learning method and the progress of their research projects.

The socialization of knowledge is one of the innovating contributions of the CIDE, since, in contrast with other systems based on learning, the student has the opportunity to present his advances, air doubts, receive critiques, not only from his adviser, but also from other students that have different levels of advance. He/she receives feedback at once from all participants that want to contribute, complement, or help solve important inquiries, based on their own experience, and ways to solve the problems posed by the students research.

The socialization of knowledge takes place in monthly meetings, which are attended by students of each region. The meetings occur normally in facilities provided by host institutions that are normally the place of work of a professor and/or a student. They are two intense workdays of 10 to 12 hours each, Saturdays and Sundays.

At the end of the contributions/comments session, the adviser provides his expert opinion as well as his own contribution to the work of the student, collects his advances, in agreement with a previously accorded schedule, and sums up with general considerations on the results (Jiménez and Escalante, 2007).

The observations that peers make are both of form and content. The teacher-adviser plays an important role in the academic life of the student. Through his advice, allowing the student to become independent in the construction and approach of his object of study, the teacheradviser becomes a counsellor and interlocutor, aiding the student to fulfill those activities that will conduct him to learn and demonstrate that he has the attributes that identify him as a Master or Doctor in Science. As part of the evaluation process, the teacher-adviser certifies the formation of the student as he validates the fulfillment of his work program (Jiménez and Escalante, 2007). 
We have observed through the realization of inquiries, that the feeling of belonging to CIDE is strong, since participants express having had the opportunity to be part of a scientific community committed with its objectives.

CIDE's methodology brings together the most advanced proposals that emerge from innovating, new and alternative education which has recently materialized in the concepts of open education and distance education.

In essence, the defining characteristics of open and distance education, based on the model of one of the most prestigious institutions in the field, the Open University of the United Kingdom (2011), are freedom in registration, of place of study, of method, and of ideas. They provide learning opportunities to all individuals that lack economic means and education certification, regardless of lack of prior education or social and economic status, or place of residence.

However, alternative education must convince other social institutions that its quality is equivalent at least to the education imparted by traditional institutions that offer education in face-to-face environments. The assumption behind the above is that to achieve social objectives of equality in access, both open and distance education have to be of high quality (Cookson, 2002). Torres Barreto (2006) enlists the principal pedagogic-cognitive characteristics that these models exhibit:

- $\quad$ The system must gear the student to pinpoint, interpret and analyse his goals, both in the initial moment as well as during his interaction with the instruction program.

- The system must formulate learning objectives so that they will become the basis for the selection of pedagogic methods, including the evaluation, so that they can be fully known, accepted or modified by the students.

- The system must facilitate the participation of all those that want to learn without imposing traditional entrance requirements upon them and eliminate the degree or other certification as the only reward to be obtained for study.

- With the object of obtaining the flexibility required to satisfy a broad spectrum of individual needs, the system should allow the effective and optional use of sound, television, film or printed media as vehicles for learning.

- The system must recur to task assignment and evaluation principally to diagnose and analyse to what extent learning objectives have been accomplished. In other words, the system must be based on the student's own competences.

- The system must be able to overcome the distance between teaching staff and students, utilizing that distance as a positive element for the development of learning autonomy.

As the same author asserts, it is not just about one more variation of traditional academic modalities, a semi-schooled, bi-modal type or integrated model variation, in which within one same system, face-to-face and off-site students share the same programs and the same teachers. The really open and innovating education system needs an organizational and administrative structure that is different to face-to-face modes.

The regional scientific communities in Mexico, described in section 4, put precisely that in practice, and in addition, they gear the student to concentrate on a specific object of study of interest to him, that is associated to a field of work in which the student is engaged. Thus, CIDE's strategy responds to the most immediate social needs, emphasizing the principle of 
direct participation of stakeholders, including those that receive the benefits of science, in all levels of decision.

CIDE offers students an educational experience geared to the acquisition of a higher degree, mainly in the earth and life sciences based on applied research. This opportunity allows them to complete their studies to those who for different reasons have not, and then be in a position to start or enhance their scientific careers. Students work from their home, place of work, or wherever they can find a space to fulfill their experiments and/or their "advanced markers."1

CIDE has no physical infrastructure. Professor-advisors do not receive a salary. Students and advisors meet once a month for two full days to socialize knowledge and advance the students' projects. Students usually already teach full time in educational institutions. CIDE attracts students that are unable, for different reasons (age, workload, family obligations), to join a conventional $\mathrm{PhD}$ program. This situation leads to the formulation of individualized programs.

CIDE's explicit objectives in the production of knowledge are the following (CIDE, 2003):

- To develop an innovative model of research where projects are linked to social needs.

- To reach an internationally competitive level in the results of research through scientific production in visible publications.

- To produce reliable, precise and repeatable research results with scientific relevance, within the limits set by measuring standards.

- To promote inter-institutional agreements that will make achievements of institutional educational objectives possible.

- To produce scientific knowledge that will aid national development by the search for solutions to the problems related to the biological environment.

\section{Brief CIDE's history}

In the beginning, the idea of CIDE is advanced by Dr. Miguel Arenas, a professor of the Autonomous Metropolitan University-Xochimilco, located in Mexico City, to put in practice a model of innovative education in diverse universities throughout Mexico, based on the acknowledgement that the demand for higher education for the first 20 years of the XXI Century, would not be able to be satisfied through traditional educational systems.

After a number of failures, Dr. Arenas finally obtains an agreement with the University of Colima, in the state of the same name, in Mexico, to have his model established side by side the traditional program, as an alternative graduate program. After one generation, however, the University of Colima decides to end the relationship with Dr. Arenas' group, and suspends the program. Some of the graduates however, established already in higher education institutions in other parts of the country, some even at Colima, give following to the idea, and struggle to have it revived.

\footnotetext{
1 "Advanced markers" are academic "products", as named by CIDE. These consist of experimentation reports and briefs, bibliographic reviews and essays, which are required from students, as per a previously agreed-upon program, that constitute "proof" of his/her research capabilities.
} 
In 1984, a group of these professors at the Autonomous University Antonio Narro in Torreón, Coahuila, formalize the creation of CIDE, and are able to have the program established in that institution as part of the educational offer. Unfortunately, the experiment followed the same fate experienced by the University of Colima, and the program was closed definitively, although the students that were already enrolled were able to complete the program and obtain a degree from that institution.

CIDE thus continued as a virtual network of concerned professors aware of the lack of opportunity and access to graduate education in formal institutions for individuals unable to attend face-to-face programs. It is not until 2005 that CIDE finally obtains official recognition through the State of Sinaloa's Ministry of Public Education and Culture, when it associates with the Justo Sierra Studies Centre (Centro de Estudios Justo Sierra, CEJUS), another alternative education experiment, in an arrangement that was to provide benefits for both organizations. While it allowed CIDE to obtain official recognition, it satisfied the latter's aspiration to extend its educational offer to include higher education and graduate studies.

CEJUS, founded in 1978, is in itself another experience in innovating education which merits special mention, where this author has participated for more than 30 years. The Centre, located in the middle of the mountain range in the State of Sinaloa, Northwest Mexico, was created as a result of the demands of the local Parents' Association to improve the quality of elementary education for their children. In subsequent stages, their demand broadened to include pre-school as well as post-elementary education. In part, their goal was to prevent the flight of their youth, as they were forced to abandon their community if they wished to continue studies, and relocate in the state's capital or other nearby urban area. At the present time, with the assistance of CIDE, the CEJUS now boasts the "University of the Mountain Range", offering from bachelors' to Master's and Doctoral degrees in agricultural and life sciences. For more information regarding this important educational experience, see Jiménez \& Ramón (1989), Jiménez (1992), Jiménez \& Escalante (1999), Zúñiga-Barrón (2004), and CEJUS' own publication concerning its origins (Comité de Planeación Educativa, 1980).

\section{Regional scientific communities (Jiménez, 2008)}

CIDE constitutes itself a learning community whose basis is scientific activity, scientific methodology, and access to a technological platform (for instance EndNote ${ }^{\circledR 2}$ and other Internet tools) of the highest order made possible by current advances in informatics and communications.

CIDE's objective is to form regional scientific communities. The community is formed on the basis of a group of "brains" whose members share an interest in scientific development, and put all their efforts to attain that objective. Generally they are individuals, and their decision is based on personal interests, that belong to educational institutions, research centres or private enterprises. In the words of one of their founders:

We are above all interested in generating brains who are already involved in a professional activity (business, farm, teaching, agriculture, laboratory analysis, etc.), (López-Pérez, 2004).

It is clear that these communities do not emerge from universities, even when they are involved in research, since they exhibit different objectives.

${ }^{2}$ From Thomson ResearchSoft, a division of Thomson Scientific. 
These communities have given rise to virtual regional research centres, that is, facilities that are negotiated by CIDE's own members through contacts, as laboratories, to conduct experiments as needed by students, meeting rooms for the socialization of knowledge, or informal meetings. This was the case in the first institution where the program was offered, the University of Colima, where CIDE was able to use the institution's Laboratory of Biotechnology, to produce important scientific results that were published in international journals. Following is a list of the regional scientific communities that have been established and some of their lines of research.

- Colima (1982). The community has produced in the laboratory facilities more than 20 doctoral theses that have been published in international journals. Their fields of research are: adaptation to high temperature climates and droughts, vegetable domestication, biological fertility of the soil, ecology of the rumen, plant-pathogenic interaction, in-vitro production of thyroid cells.

- Torreón (1999). Research is conducted on portal hypertension of chickens, use of chromium in animal feed, degradation of cell walls by rumen organisms, immunology, dengue and malaria, animal reproduction, caloric shock proteins, pollination with bees.

- Sinaloa (2001). Work is conducted on phyto-remediation and phyto-extraction of gold, entomo-pathogenic nematodes, biotechnology applied to tuberculosis, determination of costs for the production of scientific data, bio-sensors, production of shrimp in farms, plant-pathogen interaction, construction of underground dams, territorial re-ordering, production of alternative species, populations genetics of crocodiles, eco-tourism.

- Puebla (2001). Research is conducted on prionic proteins, tuberculosis.

- Nayarit (in formation process). Research is conducted on tuberculosis, scientific principles of homeopathy.

CIDE is a social system of peculiar characteristics. It has been operating throughout more than 30 years, generating positive results. According to López-Pérez (2004), CIDE's objective, the formation of regional scientific communities, has gradually been reached. According to the same informant, by the year 2004, 77 individuals have graduated from CIDE with Masters and Doctorate degrees. This is not, nor does it pretend to be, the solution to the problems of high level human resources formation for the country, however, it is a viable alternative for professionals who need to reach a higher academic degree but cannot undertake traditional graduate programs. Moreover, since it has proved its efficacy, CIDE's model should be adopted by conventional higher education institutions.

\section{CIDE'S emphasis on the use of the Information and Communication Technologies (ICTs)}

The digital revolution, as many other revolutions, has raised enormous expectations to the point that the 'World Summit on the Information Society' (WSIS) in Geneva organized by the United Nations in December 2003, in a Declaration of Principles has put its hopes that the digital revolution was: to harness the potential of information and communication technology to promote the development goals of the Millennium Declaration, namely the eradication of extreme poverty and hunger; achievement of universal primary school education; promotion of gender equality and empowerment of women; reduction of child mortality; improvement of material health; to combat HIV/AIDS, malaria and other 
diseases; ensuring environmental sustainability; and development of global partnerships for development for the attainment of a more peaceful, just and prosperous world (WSIS, 2003, as cited in De Miranda, 2009).

Actually the digital revolution, as part of the globalization the world is enduring, has not lived up to such high expectations; however some clever professors in the Third World, have learned to take advantage of the capability of connecting via Internet with data banks of various kinds containing current scientific information available in the globe.

Indeed, given the contemporary importance of the use of up-to-date information, a basic methodological principle that this learning method encourages is the use of powerful search engines to identify information located in the frontier of knowledge. This practice guarantees that their research projects and actions are solidly grounded on data reported in the current and highly visible specialized literature.

The student's general topic of interest, expressed with a word or a combination of words is used as keywords to search relevant information in Internet, with the assistance of the bibliographic tools. Through the powerful Internet navigators, the most recent, no more than five years old, articles concerning the topic in question are identified, selecting, in addition, those published in the most prestigious journals, as ranked by the Science Citation Index (SCI). From here, the student selects a number of articles, placing special emphasis on reviews. A review provides the "state of the art" of the discipline, a synthesis of the most recent and relevant research in the student's area of interest.

A second step, still in the construction of the object of study, consists of carrying out what CIDE denotes as "horizontal reading" and "macro-reading" of the texts. "Horizontal reading" consists of placing side by side the selected articles and inspecting the different parts of each with the aim of detecting regularities or repetitions. In the title, introduction, and references, "horizontal reading" identifies "keywords" that denote specific objects of research, objects of study, or concrete experiments. On the one hand, this provides an idea of the most current objects of study in the specialized literature, and on the other, it identifies leaders on a specific object of research. This is detected by a simple rate of most cited authors within those articles.

"Macro-reading", for its part, consists in carrying out a more precise inspection of the original articles selected and the leaders in the field, once the "hottest" objects of study are identified, with the aim of extracting the essential part of the object of study selected by students. That is, without reading the entire article, identify in the introduction what is said about a fact, and what the article proposes to do. Subsequently, students go to the part that contains the development of what is proposed in the introduction and extracts the work's conclusion, thus contributing to their own work.

Once students are armed with this information, they proceed to conduct their experiments, as required for attaining a bachelors' degree. For the master's degree, they apply a proven experiment to a local problem, and for the doctoral degree, they contribute with original knowledge that emanates from a local problem that had not been contemplated in the relevant, current specialized literature (Jiménez, 2008).

The use of the most advanced electronic means to support the students' research activities is notable. First, most among these is the software program called EndNote ${ }^{\circledR}$, which is a 
system of administration of bibliographic resources, which considerably speeds up the search and construction of bibliographic notes. With the aid of this program, students have access to the largest data bases on academic information, accessed by way of keywords, author, or title of the article. In addition, the program builds a file of bibliographic notes for future reference, a process which takes place in an automatic manner. The program outputs a list of the most cited authors on a particular topic, that is, the topics of greater scientific relevance at the time.

With the use of this technology, students can have access even to manuscripts that have not been published yet (for instance, articles in the hands of the authors that have been accepted and programmed for publication at a later date). Since the program includes authors' affiliation, CIDE students are able to establish personal contact with leaders in a particular field of knowledge or research thematic, creating their own "network of experts", thus making reality what Caroline Wagner baptized as the new invisible colleges (Wagner, 2008).

One of the advantages of this personal contact is the possibility of asking for the authors' print-copies of past papers, at no cost. Some students have reached such closeness as to collaborate, co-authoring articles, with the most renown scientists in their field of research.

\section{Results}

A number of PhD students have obtained their degree and are doing research in "mainstream science". Concurrently, they become advisors to new students who are willing to take the same track, thus enhancing the benefits of this innovative way of learning and research. For the past five years the number of sites where this academic experiment takes place has gone from three to eight, most of them in the Northern part of the country.

Since its association with CEJUS, CIDE has granted several doctoral degrees in fields that stand out for their quality at the forefront of biological, medical, and innovative applied technologies. Table 1 shows data of the examination date, name, age, and sector of work of seven of the graduates. The average age of graduates is 48 years, showing that these are not ordinary PhD students, but persons who, after engaging in professional work, decided to go for the degree and made an extraordinary effort to achieve their objectives. Likewise, $86 \%$ of the graduates work in the public sector.

A brief description of some dissertations recently defended (July, 2008) presented at CEJUSCIDE follows:

Rocío González's dissertation was on "Molecular identification of Coccidioides SPP in the Comarca Lagunera Region, in North-eastern Mexico: a new endemic area for Coccidioidomicosis". The Coccidioidomicosis is a lung mycotic illness, endemic of the Southwest USA, Northern Mexico and several semi-arid regions in Central and South America. Dr. González's research was able to identify an endemic area of the disease located in the "Comarca Lagunera" region, Northeast Mexico. The identification of the endemic area helps diagnose the illness correctly, often mistaken as pneumonia, thus giving patients the right treatment, and saving many lives.

Víctor M. Wilson's dissertation in phyto-mining is titled "Hyper-accumulation of gold chemically induced in eight vegetable species". In 1998, it was discovered that gold absorption may be induced in plants. This procedure known as "induced hyper- 
accumulation" has drawn the attention of both scientists and entrepreneurs. Mexico, with a long mining tradition did not have a team of scientists to do research in "phyto-mining". Víctor contacted the only two existing specialists in the world, one in New Zealand, the other in Switzerland. With the advice of the experts, Víctor experimented with eight plant species. Three yielded a profitable gold "crop". With his results, Víctor was able to defend his dissertation and get the doctoral degree. Now he is considered a world specialist in phyto-mining.

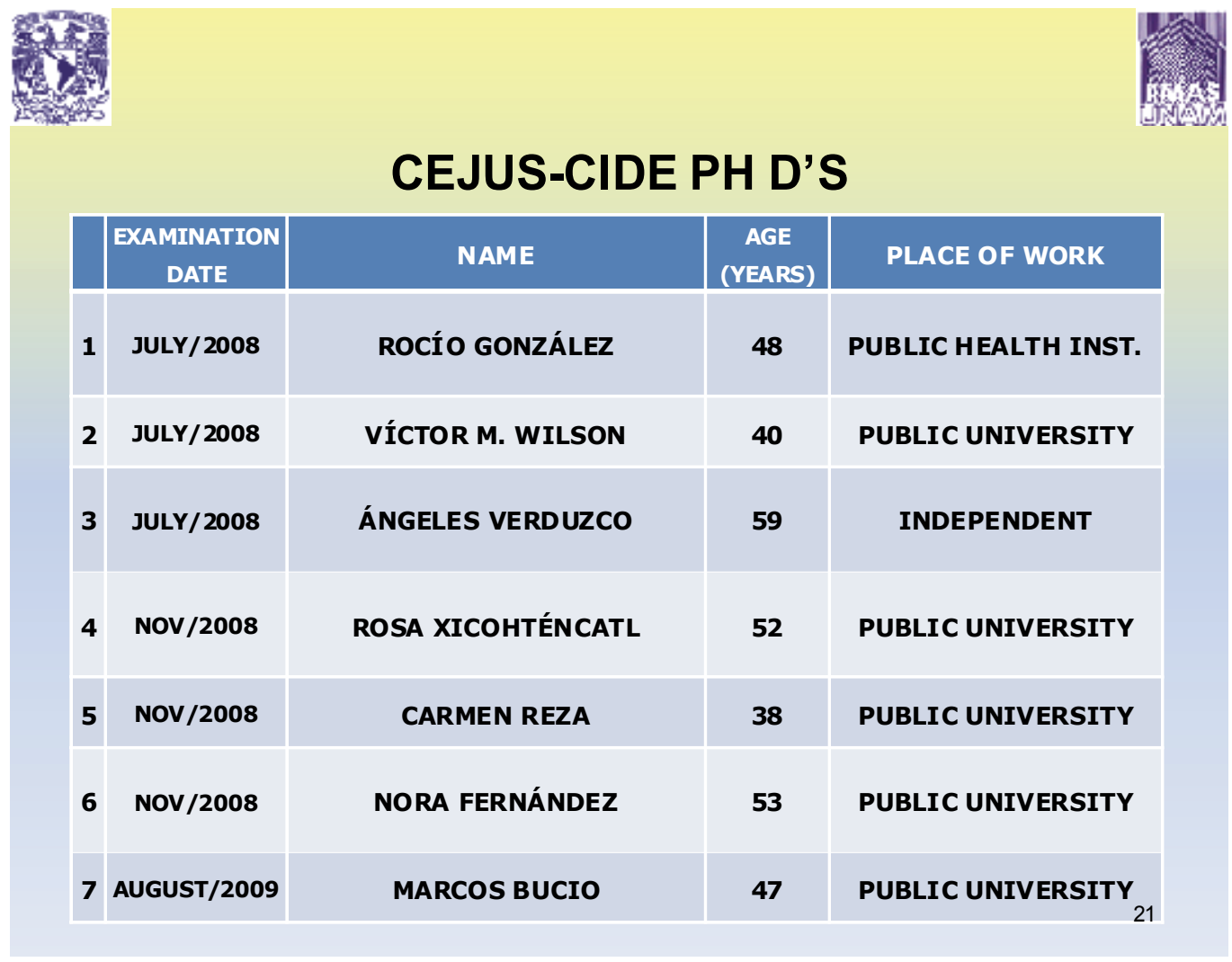

Table 1. CIDE's first seven PhD graduates since its association with CEJUS.

Marcos Bucio Pacheco made an important project with transcendental significance for the global warming issue. Dr. Bucio worked on tele-detection, via satellite imagery, of clorophyllic stress in an arid corridor in the state of Sinaloa. He composed a periodic series of satellite images that led to important implications for global warming. Dr. Bucio began work on this project after he detected a kangaroo rat population, i.e. a desert rodent, some 300 kilometres beyond the desert boundaries in the state of Sinaloa. Dr. Bucio's work provided accurate statistical data on changing climatic conditions for a period of three decades beginning with the 1970s. 


\subsection{Going from local to global}

CIDE's model enables students to get in contact with top people in their field of interest, making use of the information and communication technologies. These contacts enable graduates to participate in international conferences, sometimes in collaboration with "global" scientists, thus gradually inserting into mainstream science. The model promotes knowledge production from the bottom-up by recognizing locally felt problems of regional communities and working on the solutions, thus making it more socially responsible. Table 2 shows examples of renowned international contacts made by some of the graduates during their dissertation research.

\section{CEJUS-CIDE PH D'S CONTACTS}

\begin{tabular}{|c|c|c|c|}
\hline NAME & FIELD & IMPACT & INT. CONTACTS \\
\hline $\begin{array}{c}\text { ROCÍO } \\
\text { GONZÁLEZ }\end{array}$ & $\begin{array}{l}\text { Mycotic } \\
\text { Desease }\end{array}$ & Regional/Global & $\begin{array}{l}\text { Dr. Demostenes } \\
\text { Pappagianis. Faculty } \\
\text { of Medicine, U. of } \\
\text { Cal ifornia, Davis }\end{array}$ \\
\hline $\begin{array}{l}\text { VÍCTOR M. } \\
\text { WILSON }\end{array}$ & $\begin{array}{l}\text { Phyto- } \\
\text { minery }\end{array}$ & Regional/Global & $\begin{array}{l}\text { Dr. Christopher W. N. } \\
\text { Anderson. Natural } \\
\text { Resources Inst., U. of } \\
\text { Massey, New } \\
\text { Zealand. }\end{array}$ \\
\hline $\begin{array}{c}\text { ROSA } \\
\text { XICOHTÉNCATL }\end{array}$ & $\begin{array}{l}\text { Animal } \\
\text { Genetics }\end{array}$ & Local/Regional & $\begin{array}{l}\text { Dr. Wilfred } \\
\text { Goldmann. Rosl in } \\
\text { Inst., Edin bu rg, } \\
\text { Scotland. }\end{array}$ \\
\hline $\begin{array}{l}\text { MARCOS } \\
\text { BUCIO }\end{array}$ & $\begin{array}{c}\text { Global } \\
\text { Warming }\end{array}$ & Regional/Global & $\begin{array}{c}\text { Mario Molina, Nobel } \\
\text { Prize, MIT. }\end{array}$ \\
\hline
\end{tabular}

Table 2. Examples of "global" contacts made by PhD students in the course of their dissertation research.

\section{Conclusions}

Globalization does not necessarily mean a widening of the gap between the industrialized countries and the countries in the process of advancement. There are opportunities for lessdeveloped countries to take advantage of the world explosion of ICTs and the networking possibilities it implies, at a relatively low cost. The example described in this chapter is just one of the forms of using modern technologies to the benefit of communities apparently left behind from the general progress. 
It is interesting, and to a certain extent paradoxical, to notice that the professors who sustain the CIDE model are not themselves inserted into "mainstream" science. However, they have the ability to help students approach to higher and visible levels of academic recognition. The "secret" is that they both intelligently and generously designed and implemented an academic model to take advantage of some features of globalization to help non-conventional students to get a PhD degree in sciences, putting in practice an innovative way of learning and research aimed to prepare new scientists and, concurrently solve specific research problems detected by the students in their own geographic region. The professors dedicate one weekend per month to attend students, and during the week days, they revise the students' academic products to offer feedback to them during the socialization of knowledge events.

The CIDE learning and research model combines open education, teaching at a distance, and problem-based learning methods to educate students to learn, by doing research, on specific topics and problems usually brought about or discovered by the students themselves in the locations where they live. In the process of research, students interact with scientists at the frontier of knowledge thus creating themselves their own network that also includes national scientists. This type of new network is highlighted by Caroline Wagner as a product of the globalization of the ICTs, that connects scientists not only North-South but also South-South, bringing benefits to more segments of the world population.

In synthesis, CIDE's experience demonstrates that it is possible to reach desired objectives with a system whose parts enjoy ample flexibility, without the need for a costly physical and human infrastructure. The "glue" that brings together the different parts of this system is, convincingly, the motivation that each member has for reaching his/her particular objectives as well as CIDE's general objectives.

\section{References}

CIDE (2003). Plan de Desarrollo del Centro de Innovación y Desarrollo Educativo, S. C. (Development Plan of the Centre for Innovation and Educational Development, S. C.). Private document, Mexico City.

Comité de Planeación Educativa. (1980). Autodesarrollo Comunitario: Alternativa para el Medio Rural. Proyecto Experimental Educativo. Surutato: Comité de Planeación Educativa. Surutato, México.

Cookson, P. S. (2002). Acceso y Equidad en la Educación a Distancia: Investigación, Desarrollo y Criterios de Calidad. Revista Electrónica de Investigación Educativa, 4, 2. Consultado el 7 de marzo de 2006:

http://www.redie.uabc.mx/vol4no2/contenido-cookson.html

De Miranda, A. (2009). Technological Determinism and Ideology: Questioning the 'Information Society' and the 'Digital Divide', In: The Miths of Technology: Innovation and Inequality. Burnett, J., Senker, P. \& Walker, K. (Eds.), pp. 23-37, Peter Lang, ISBN 978-1-4331-0520-3. New York, USA.

Fenwick, T.J. \& Parsons, J. (1997). A Critical Investigation of the Problems with ProblemBased Learning. Research Report 143, US Department of Education, Educational Resource Information Centre, ED 409272. 
Jiménez, J. (1992). Surutato: an experience in Rural Participative Planning, In: Planning for Human Systems: Essays in Honor of Russell L. Ackoff, J-M. Choukroun \& R. Snow, (Eds.), 407-416, Philadelphia: University of Pennsylvania Press, Philadelphia, USA.

Jiménez, J (2007). Alternative ways of doing research vis-à-vis globalization of the economy. In The Problems of Scientists and Scientific Groups Activity. International Annual Papers. Volume XXIII. Papers of the XXII session of the International School of Science and Technology Sociology. St. Petersburg Scientific Centre. Russian Academy of Science. ISBN: 5-98187-068-0, 54 - 72. St. Petersburg, Russia.

Jiménez, J (2008). Research socially responsible: may we speak of a mode 3 knowledge production? Electronic Journal of Communication Information $\mathcal{E}$ Innovation in Health. Rio de Janeiro, 2(1), 48 - 56, Jan.-Jun., Rio de Janeiro, Brazil.

Jiménez, J. (2009). New Collaborative Forms of Doing Research". In The ISA Handbook in Contemporary Sociology. A. Dennis \& D. Kalekin-Fishman, eds. SAGE Studies in International Sociology. Sage (UK). ISBN: 978-1-4129-3463-3, 91 - 105. London, UK.

Jiménez, J. \& Ramón, F. (1989). Evaluación de Estrategias de Cambio en el Proyecto de Educación Comunitaria. Revista Latinoamericana de Estudios Educativos, XIX(3), 93 123.

Jiménez, J. \& Escalante, J.C. (1999). Community Development Through Participative Planning. A Conference to Celebrate the Work of Russell L. Ackoff on his 80th Birthday and Developments in Systems Theory and Practice, March 4-6, 1999, Villanova, PA. Proceedings of the Russell L. Ackoff and the Advent of Systems Thinking. Villanova University, pp. 167-178. Villanova, USA.

Jiménez, J. \& Escalante, J.C. (2007). Algunas Respuestas Alternativas en América Latina a la Globalización de la Investigación Científica. Primer Congreso Argentino de Estudios Sociales de la Ciencia y la Tecnología. Internacionalización de Actividades Científicas y Tecnológicas, 5 y 6 de Julio de 2007, Buenos Aires. Proceedings...ISBN 978-987-2252373. Universidad Nacional de Quilmes, Compact Disc, 1 - 20. Buenos Aires, Argentina.

Jiménez, J., Morales, M. A., Rodríguez, C. \& Escalante, J. C. (2011). Why projects in Science, Technology and Innovation in the economic South should be proposed from the bottom-up? Proceedings of the International Conference on Socio-economic and technological innovations in the lobalizing world (STIGE-2011): Mechanism and Institutions. National Institute of Science Technology and Development Studies (CSIR), New Delhi, November 2-5, 2011. New Delhi, India.

López-Pérez, J. (2004). Personal communication via e-mail, January 8th, 2004 12:15:18

Open University of the United Kindom. (2011). May 11, 2011, Available from $<$ http://www.open.ac.uk/>

Torres Barreto, Arturo. (2006). Necesidad de reforma universitaria y educación abierta y a distancia, 2006. At: www.unidad094.upn.mx/revista/39/reforma.htm. Accessed: March 7th. 2006.

Wagner, C. (2008). The New Invisible College. Science for Development. Washington. Brookings Institution Press. 
Zúñiga-Barrón, S. (2004). Pedagogía CEJUS: Algunos aspectos didácticos en su construcción y fortalecimiento. Tradición y Costumbres. Culiacán: Private print, Culiacán, México. 


\title{
The Stakes of Globalization in the Field of Health: The Tolerance in Self-Regulatory Ethics Perspective, a Solution for Health Professionals for the Management of All Differences
}

\author{
Antoine L. Ntetu and Marc Jean \\ University of Quebec at Chicoutimi,
}

Canada

\section{Introduction}

Cultural background builds a specific context in which individuals experiment life and learn the meaning of disease, suffering and death. In health care context, the way in which sick individuals, families and health professionals take decisions is widely influenced by culture. Also, what is considered as good or bad within a care relationship depends on the culture of involved partners (Chattopadhyay \& Simon, 2008). In this way, what seems obvious is the position that bioethical speech holds in the management of real facts. The big challenge for bioethicists is then to find a probity denominator, common to all cultures and which recognize and comply with cultural diversity (Chattopadhyay \& Simon, 2008).

When we look at the notion of common morality or of appliance of the universal principles deriving from the western philosophic reference, this may contain the risk of striking complex realities of the intercultural health which we have to take into account in the ethical process of decision-making (Turner, 2004). Accordingly, it is unsuitable to use and enforce, consciously or unintentionally, constructed ideas or western theories and ethical methods to other societies (Chattopadhyay \& Simon, 2008). Indeed, although ethnocultural groups share many similar values, it however exists between them some differences that can be a source of conflicts if the health professional is not aware of it or if he is little inclined to work within a framework which takes into account cultural, historic and structural influences (MacDonald, 1998), which have an impact on the process of decision-making relative to care (Thomas, 2001). According to Klessig (1992), it is not the ethnic membership in itself but social experiences of various groups that help a particular cultural organization and a values system to take shape. This system undergoes constantly, although sometimes slowly, changes as social experiences of the groups alter. Furthermore, since all the cultures are made up of individuals, intracultural variation can be huge, sometimes bigger than the intercultural variation.

With reference to the growth of the cultural diversity in the American society, Wray (1992) asserted that former policies initially conceived for a homogeneous population were outdated, and that it was compulsory to consider certain factors able to overcome obstacles, which prevent minority groups from getting adequate and suitable healthcare. According to 
this author, effects of race bias or of ethnicity on the status and health behavior must be separated from those of the biological, environmental, socioeconomic, cultural and temporal factors. Data collection and analysis methods must be improved; also methods of planning, of implementation and of programs evaluation must be revised in order to effectively meet healthcare needs.

With globalization, homogenization of health practices increases (Solomons, 2002). This situation puts a new challenge on health acitivities whose practices were always guided by ethical principles, which reflect the cultural frame in which they were created. Then, it becomes important to keep a balance when it comes to apply these principles in a global context, known as culturally diversified. If they are too wide or too vague, they can have few practical applications. On the other hand, if they are too specific or too concrete, they can be difficult to implement and to convince the all community concerned (Kastrup, 2010). Indeed, in this globalization era where religious, linguistic, and cultural pluralism has given way to a diverse society, values, standards, traditions and faiths system of involved partners (sick individual, family, health professional) play a more and more significant role when it comes to take decisions in context of care (Chattopadhyay \& Simon, 2008). Therefore, a patient should be healed as an individual first, then as member of a cultural group and even as member of a second cultural group (Klessig, 1992).

All this cannot be done without raising ethical questions, which generally appear because of the innate variety, which exists between populations because some individuals gain while others suffer from the same exposures. For the health professional, the challenge in the pursuit of the ethical plea in a globalized environment is: 1) to learn foundations of ethical principles and to keep in mind that he has to respect differences and differentiations which exist and which will continue to exist between individuals and between societies (Solomons, 2002); 2) to learn how to recognize what is of the culture which influences insight of the patient and the response of the health professional to difficulties which threaten health of the patient in his desire to offer culturally congruent quality care (Chattopadhyay \& Simon, 2008). It is important to indicate that there are at least two distinct ways in which crosscultural differences may become striking: 1) a health professional may come from a majority cultural group to interact with a patient who comes from a minority group; 2) a health professional himself may be from a minority group and his patient may be a member of a majority group (Jecker \& al., 1995).

Besides, the unprecedented medical technological evolutions of the last decades as well as change of the socioeconomic climate in medicine have raised ethical and legal questions (Meleis \& Jonsen, 1983). These issues appear as well in the private ground of patients, families, clinicians, in the semi-private ground of healthcare organizations and traditional communities, as in the public field of judicial, legal and of regulation authorities (Iltis, 2004). These issues are not only patients concerns and their families; health professionals, who are usually under stress by conflicts and ethical dilemmas, need to know that their organization understands the pressure under which they work and that by the means of an effective ethical structure and other mechanisms, it offers to them opportunities to explore ingenious technics in a supporting environment (Hofmann, 2001).

In daily practice, ethical dilemmas are unavoidable (Peer \& Rakich, 1999). For health care managers for example, they are the ones appearing regularly; nature of healthcare being 
such that decisions having ethical implications are daily taken for diverse situations such as accessibility to organized services, employees' behavior, clinical practices, allowance of restricted resources (Nelson, 2005). For health care managers, they appear particularly in the management of care systems where there are two allegiances (responsibility to a third party and responsibility to the patient) and where a set of responsibilities cannot be carried out without violating another one (Rakich \& al., 1992, as cited in Peer \& Rakich, 1999). These dilemmas appear at three overlap levels: 1) the macro level which includes the social and community concerns reflecting governmental measures or social policies, and which has a typically cultural base; 2) the meso level which focuses on professional or organizational concerns; and 3) the micro level interested in personal or individual concerns, and which can include interpersonal communication or relationship between the manager and another individual (Hiller, 1986). According to this author, an ethical dilemma has two components: 1) a real choice must be between the possible current actions; 2) every possible action or its consequences wears a significantly different value. The manager is therefore asked to develop a certain capacity to differentiate ethics and values, and to know the value, which often affects decisions.

Hunt (2008) has written about ethical concerns experimented by health professionals who are involved in humanitarian assistance organizations and in development projects around the world. Results of his phenomenological study realized among a ten persons sample (a director of a non governmental organization focused in healthcare projects and nine health professionals that is six nurses, a therapist physician, a doctor, a social worker) with at least seven years of experience in this type of missions and who have dedicated at least eight months to supply clinical services, indicate that several professionals involved in this category of mission have no training in international health and have to struggle in order to adjust themselves to new cultural and clinical realities. Hunt asserts that complex ethical concerns can have a substantial impact on the clinicians and can also be a source of anxiety, moral uncertainty and angst. The main sources of the ethical issues identified by participants to this study are: difficulty to choose between the respect of local customs and the imposition of values mostly when these customs get into conflict with their own moral convictions; obstacles (restricted resources) to the delivery of satisfactory care; difference in the understanding of health, of disease and of death between humanitarian workers and the local populations; confidence matters and of distrust between both groups; identity concern for humanitarian workers in the sense where humanitarian ethical dimension turn to a source of reflection and self-assessment.

Study conducted by Grönlund and al. (2011) among a group of doctors working in hemodialysis, shows that a doctor is morally disturbed when he feels torn by conflicting requests and trapped by indecisiveness due to ethical dilemmas when he is compelled to take key decisions regarding life or death, or when he is forced to prioritize between time constraints and professional or personal requests. When these ethical dilemmas occur, the doctor avoids waking conflicts, is afraid of using his authority, rots under the weight of the moral responsibility, feels devalued and questioned as for the way he treats these situations, by being allowed guide by his consciousness.

According to Gabel (2011), even when he simply witnesses that his colleagues or his organization have a practice which breaks certain ethical principles, a doctor or another health professional can live a conflict or a confusion with regard to values and to ethical 
principles, a situation which can lead to stress, to depression and to a burnout. O'Donnell and al. (2008) also support that values conflicts can be a source of stress during health care delivery, a stress which, if not properly managed through an effective ethical conflicts management structure, can generate job displeasure and urge professionals to leave their position.

\section{Ethics and its principles}

Globally, ethics is all the values, which individuals interiorize in a more or less aware and interactive way so as to reach internal coherence and to get closer to the hoped social cohesion (Dionne-Proulx \& Jean, 2007). Ethics can thus be defined as the assertion of individual convictions and as the expression of its sense of responsibility, because before committing an action and making a decision, an individual analyzes among other things the consequences of these on himself and on the others. Ethics so underlies the worry of greater welfare (peace of mind and personal coherence) and that to live better together (social cohesion) which the worker has to have as actor involved in an organizational environment (Ntetu \& al., 2010). The term "ethics" thus means behavioral basic rules intended for interactions in the society and with the physical environment; these rules are based on recognized principles which application allows resolving ethical dilemmas which appear when different interests are at stake (Solomons, 2002).

Recognized ethical principles are: autonomy, charity, justice and usefulness. With regard to the autonomy for example, when someone is free to exercise its independence concerning its own health and the treatment of its environment, this can compromise the health of the others (Solomons, 2002). So, although ethical statements focus generally on the individual, on the assumption that the relationship established between the patient and the health professional on a base of trust, confidence and mutual respect, has to be in the center of any intervention, it remains that the health professional does not have to only look at interests of the patient, he also has to consider interests of the other involved partners such the family or the society in general (Sartorius, 2000, as cited in Okasha \& al., 2002). As Nelson underlines (2005), because of their impact on the quality of care, decisions taken in response to ethical questions are very crucial so that every health care organization is called to set up an effective ethical infrastructure which includes a structured process to resolve ethical conflicts.

\section{Resolution of ethical dilemmas}

According to Nelson (2005), the principle of procedural justice is the foundation of ethical decision took at the organizational level. It implies to understand values, which are at stake in the answer to a particular ethical conflict and to investigate various options. From this principle, Nelson suggests an approach which takes into account rights, values and interests of a rather wide range of individuals and groups which are concerned by an ethical conflict and which will be by the fact either harmed by or benefit from the decision which will have been taken. This approach has several stages: clarify the conflict; identify all the involved individuals/groups and their values; understand circumstances surrounding the conflict; identify the ethical perspectives connected with the conflict; identify the various possible options for the action to be undertaken; choose an option to be privileged among the possible options; share and implement the decision; estimate the results. Furthermore, Nelson (2007) thinks that instead of waiting that ethical conflicts occur and then try to 
resolve them, organizations should rather adopt a proactive approach of prevention of ethical conflicts which would contain five stages: 1) identify persistent ethical issues that generates conflicts and uncertainty; 2) study the ethical concerns in a system-oriented manner; 3) develop and disseminate protocols to guide partners and managers in the case of a conflict reappearance; 4) register these protocols into organization's culture; 5) review protocols in terms of process and results.

The purpose of preventive ethics is to improve the quality of health care by identifying, prioritizing and raising ethical questions at the level of the systems. Thus, the role of preventive ethics must be well integrated with the other constituents of the organization. Its most specific domain is to bring assessable improvements on ethical health practices of the organization, by setting up at the systems level, changes which reduce distances between current practices and best practices which follow ethical principles (National Center for Ethics in Health Care/NCEHC, 2005). Its responsibility is to identify and to set right situations involving the processes and the organizational systems which create ethical issues (NCEHC, 2005).

As for Grönlund and al. (2011), they emphasize on the usefulness to increase "the level of communication within and among various professional groups - to transform being burdened by a troubled conscience into using conscience as a guide, the dishearten - in situations where no way of solving the problem seems to be good." In this kind of situations where health professionals and organization are involved as a whole, Gabel (2011) recommends that clinical and not clinical leaders receive an education and training in health care ethics, in resolution of conflicts and in negotiation. He also suggests seven different approaches that health professionals can use when they consider that their values are not congruent with those of their organization. Those approaches are:

1. Organize seminars, discussion groups, workshops on ethical issues and values recognized in medicine;

2. Integrate ethical issues and values as themes to be examined by medical staff during board of directors meetings;

3. Paying special attention to specific situations which cause moral strain, to think about it so as to know what are its meanings for us, patients, families and others, and if other perspectives can be envisaged with regard to these situations or issues;

4. Discuss these situations with trusted colleagues, families and friends; do not assume to be too sensitive, to be the only one who cares this kind of situations or issues, or you should not be concerned;

5. Discuss these situations or particular concerns with the medical staff and $\backslash$ or the committee of ethics, with the ombudsman if the organization has one, to know which perspective this person brings to the situation or issue;

6. Depending on the situation, address it with executive, administrative and $\backslash$ or clinical staff, directly or through the appropriate channels of communication; try to have allies and to be inclined to go beyond the disciplinary borders to contact colleagues of the other professional categories which share the same perceptions; discussions with organizational leaders are likely more to succeed if a group, or more than a person, is involved;

7. During discussions with organizational leaders, emphasize on ethical and values orientation as well as on the practical and administrative implications of moral strain or incongruence of values (burnout, demoralization, staff turnover). 
To manage the cultural conflits which raise in cross-cultural, Jecker and al. (1995) propose an ethical approach consisting of three distinct steps. The first, identifying goal, asks the health professional to identify the central alms that him and his patient bring together to the medical encounter in order to clarify their respective purposes; this requires the health professional to inquire information about the patient' ethical values and cultural orientation. The second, identifying mutually agreeable strategies, implies that the health professionnal to take the initiative in identifying alternative mutually agreeable strategies to meet these goals.The third step, meeting ethical constraints, engages the health professional in ethical deliberation about the acceptability of alternative means of realizing goals. From their part, Björn and Björn (2004) emphasize on the importance of discussions and ethical reflections in the clinical practice. They also believe that by analyzing in a repetitive and structured manner his decisions, the health professional increases his capacity to make decisions suited for the profits of the patient and of its surrounding families. The study of Sorta-Bilajac and al. (2011) conducted among a group of nurses and doctors of a Croatian hospital points out that clarifying ethical questions, having the literature suited on the situation, having a more complete information about the patient, speak to him on ethical questions are the most appreciated types of help by those professionals. They even assert that those types of help were highly appreciated by American and European health professionals.

According to Hofmann (2001), adressing significant differences between the patient, the members of his family and the health professional, is rarely easy. Some individual characteristics will always be very important to solve conflict. These characteristics are: have an outline of its own values; accept values and faiths which can be diametrically set against those of the nursing; be sensitive to irregular needs and to the hope of the involved actors who try to reach an agreement, while facing the consequences of a disease or a wound; have the patience to give the patient and/or his family time to think about advantages and inconveniences of the adoption of a given option; show some perseverance by working for a suitable conclusion.

On the other hand, Murray (2010) urges health professional to keep morally courageous when he encounters an ethical dilemma. According to him, it is the sole way for health professional to handle ethical matters and to act because acting properly is not often an easy thing. For a professional who has encountered an ethical dilemma, being in good spirits means investigating a possibility of action based on his ethical values and keeps right up to the end, in spite of consequences which he can incur (Aultman, 2008; Kidder, 2005). This requires a continuous commitment and a reflection on personal values and moral behavior, which influence ethical decision-making (Clancy, 2003; Kidder, 2005).

\section{Perspectives}

In consideration to the above facts, incorporation of an ethical dynamics within the organizational life constitutes a keystone to arouse a bigger harmonization between personal, professional and organizational projects. Ethical dynamics here mean an interactive and continuous process during which authors and actors of an organizational environment combine daily by their efforts, values, principles and standards, their aspirations, practices and objectives, in a way that personal coherence and social cohesion spread more inside the person. 
Regardful to take up the challenge to articulate the personal, professional and organizational ethics between them on one side, and between these ethics and the performance as a value on the other side, many authors advocate to firstly take an active interest in tacling ethical diagnoses and secondly in elaborating ethical devices mainly based on codes. Very often, they talk of integration of an ethical approach. It also appears that the health professional tends to guarantee as well the personal ethics as the professional ethics, even the organizational ethics according to the ethical dilemmas, which he encounters.

Ideally, no matter the problem to be treated, the health professional would not be anxious to choose the type of ethics if there was harmonization and stowage of these three levels in his organization. To support and encourage individually the worker to stay sensitive and mobilized compared to this balance which it is called to look for, managers' team can choose to make explicit an ethical organizational initiative as constituent of the process of coconstruction of an ethical organizational. When articulating an ethical dynamics, this type of initiative consists to start from expectations and views of the actors of an organization, from their values and practices to be inspired by it, so that tools which will stand out from it can carry the seal of those who develop it.

While encouraging this way of making, we firmly believe that to improve the sharing of the common values by all in an organization, oneself blossoming, that of everyone, of the organization, build codes on one hand or try on the other hand to make so that an organizational environment gives itself the other convincing tools for its development constitutes stages in the articulation of an ethical dynamics. For us, it is also important that every health professional comes there, by a joint representation, to appropriate values, which are carriers of sense for him and for his organization in a perspective of great coherence and ample cohesion. That is why, throughout the process of articulation of an ethical dynamics within organizational life, we encourage insertion of an ethical approach centred on the integration of values (self-regulatory ethics), as vector of harmonization and conciliation between the various forms of ethics (Ntetu \& al., 2010).

Besides, to get committed in a proficient practice, the health professional needs to understand and to know himself as actor, to regulate himself in an ethical perspective, to build a robust interpersonal and collective relation with the patient and family, to recognize the uniqueness and to use working strategies of nearness to join the members and professionals of diverse groups (Thomas, 2000). The solving of ethical dilemmas requires a detailed examination of the impact that it will have in concerned districts because the real dilemma appears when a resolution has conflicting effects on diverse districts (Price, 1992). As Peer and Rakich (1999) underline, an efficient manager has to take into account not only the importance of the decision which he must take but also the impact that this decision will have on all partners (community, organization, individual).

For that purpose, the proposition to choose an ethical approach centred on the incorporation of values is original because it aims at reaching a human balance between values such as performance, profitability or productivity and values like recognition of the other one, selfesteem, success. The purpose, instead of being centred on construction of tools, aims essentially at the harmonious development of individuals and communities within the organizational environments. In short, are taken into account decisions expressed by human beings, value systems that define all sorts of memberships, the desires and dreams that everyone carries (Dionne-Proulx \& Jean, 2007). 
The ethical dynamics which we propose through an approach centred on integration of values takes into account the authenticity of every health care organization and becomes integrated within the framework of management of this one by considering its view and its strategic and operational orientations. Such a problem rehabilitates the organization as a premise of collective learning and valuation of the individual, the person. The valuation of the individual is all the more important in this process since the actor is personally called to get involved in the approach in a way that his personal and professional values influence directly or indirectly the organizational perspective that we wish to implement. By involving the health professional in the strategic planning process where are discussed views, mission, orientations, values of his organization, the way to follow, increases its chances to support and to facilitate implementation of an organizational ethics co-built around common and shared values. Identification of common and shared values is not enough to say that there is an organizational ethics in a health environment. Actors (staff members, decision makers, employees' representatives, health professionals, etc.) have also to interiorize these values (Ntetu \& al., 2010).

Since their purpose is to find solutions to moral and ethical problems, and because to do that, partners need to understand diverse perspectives and learn some of the others, the dialogical approach can support their initiative. Anyway, Widdershoven (2005) privileges dialogue as the best means to communicate in health care ethics because, according to him, dialogue allows partners to submit and fully discuss various possible options; this explicitly or implicitly includes a discussion about the values, the standards and the virtues to make good choices. A dialogical approach must be concrete and contextual because a dialogue is an interaction between people involved in real problems. Indeed, dialogue presupposes that participants already have certain interests and an outline of the subject, which they can elaborate and know their interests through an exchange of perspectives (Widdershoven \& al., 2009). A dialogue opened to systems and ethical principles is moreover one of strategies used to develop bravery to health professional (Aultman, 2008; Kidder, 2005), to identify risk factors, to defuse potential conflicts, to diminish patient and family suffering and the health care professional's moral distress (Pavlish \& al., 2011).

\section{Conclusion}

In short, within health care organizations, there are individuals and communities who are about to initiate an integration process of an ethical dynamics. While looking for a framework through a professional ethic or by specifying organizational parameters, it appears that the research for an integration process of personal, professional and organizational values in the numerous daily challenges constitutes a keystone for the complete integration of an ethical dynamics. Since health care organization partners are choosing to invest themselves so as to change their behaviors and manners, since everyone agrees to get acquainted with common working tools in ethics, it may happen that life of an organization comes to experiment structural changes.

At the end of this discussion, it is effectively clear that a health care organization can still evolve normally without necessarily making use of the integration of such a process of ethical reflection. When an organization chooses this process, it opts for a life dynamics, which goes beyong formal agreements and beyong standards and principles. It looks for the best. With and for those who are members of the working group, it appoints the sense of 
which it is a carrier in terms of welfare and to live better together. Through its mission, aims and objectives, one recognizes its actual ethical nature.

\section{References}

Aultman, J. (2008). Moral courage through a collective voice. American Journal of Bioethics, Vol.8, N.4, (April 2008), pp. 67-69. ISSN 1526-5161.

Björn, G. J. and Björn, A. (2004). Ethical aspects when treating traumatized refugee children and their families. Nordic Journal of Psychiatry, Vol.58, N.3, (June 2004), pp. 193-198, ISSN 0803-9488.

Chattopadhyay, S. and Simon, A. (2008). East meets West: Cross-cultural perspective in endof-life decision making from Indian and German viewpoints. Medicine, Health Care and Philosophy, Vol.11, N.2, (June 2008), pp. 165-174, ISSN 1386-7423.

Clancy, T. (2003). Courage and today's nurse leader. Nursing Administration Quarterly, Vol.27, N.2, (April/June 2003), pp. 128-132, ISSN 03639568.

Dionne-Prouxl, J. and Jean, M. (2007). Pour une dynamique éthique au sein des organisations. Télé-Université, Université du Québec à Montréal, ISBN 978-2-7624-2160-6, Montréal, Canada.

Gabel, S. (2011). Ethics and Values in Clinical Practice: Whom Do They Help? Mayo Clinic Proceedings, Vol.86, N.5, (May 2011), pp. 421-424, ISSN 0025-6196.

Grönlund, C. and al. (2011). Feeling trapped and being torn: Physicians' narratives about ethical dilemmas in hemodialysis care that evoke a troubled conscience. BMC Medical Ethics, Vol.12, N.8, (May 2011), p. 8., ISSN 1472-6939.

Hiller, M. D. (1986). Ethics and health administration: Ethical decision making in Health management. Association of University Programs in Health Administration, Arlington. Available from

http://www.ethics.va.gov/docs/integratedethics/IntegratedEthics_monograph-20070808.pdf

Hofmann, P. B. (2001). Navigating differences in patient values. Healthcare Executive, Vol.16, N.2, (March/April 2001), pp. 58-59, ISSN 0883-5381.

Hunt, M. R. (2008). Ethics beyond borders; How health professionals experience ethics in humanitarian assistance and development work. Developing World Bioethics, Vol.8, N.2, (August 2008), pp. 59-69. ISSN 1471-8731.

Jecker, N.S. and al. (1995). Caring For Patients In Cross-Culrural Settings. The Hastings Center Report, Vol. 25, N.1, (January-February 1995), pp. 6-14, ISSN 0093-0334.

Kastrup, M. (2010). Ethical aspects in providing care to marginalized populations. International Review of Psychiatry, Vol.22, N.3, pp. 252-257, (June 2010), ISSN 0954-0261.

Klessig, J. (1992). The effect of values and culture on life-support decisions, In Cross-cultural Medicine-A Decade Later (Special Issue). Western Journal of Medicine, Vol.157, (September 1992), pp. 316-322. ISSN 0008-1264.

Kidder, R. M. (2005). Moral courage, Digital Distrust: Ethics in a Troubled World. Harper Collins Publishers, New York. Business and Society Review, Vol. 110, N.4, (December 2005), pp. 485-505, ISSN 0092-2706.

MacDonald, W. L. (1998). The difference between black' and white' attitudes toward voluntary euthanasia. Journal for The Scientific Study of Religion, Vol.37, N.3, (September 1998), pp. 411-57, ISSN 1468-5906.

Meleis, A. I. and Jonsen, A. R. (1983). Ethical crisis and cultural differences. Western Journal of Medicine, Vol.138, N.6, (June 1983), pp. 889-893, ISSN 0008-1264. 
Murray, J. S. (2010). Moral Courage in The Healthcare: Acting Ethically Even in The Presence of Risk. Online Journal of Issues in Nursing, Vol.15, N.3, (September 2010), 10 p, ISSN 1091-3734.

NCEHC (2005). Integrated ethics improving ethics quality in health care. Veterans Health Administration, Washington, United States. [URL] www.ethics.va.gov/docs/integratedethics/IntegratedEthics_monograph-20070808.pdf

Nelson, W. A. (2005). An organizational ethics decision-making process. Healthcare Executive, Vol.20, N.4, (July/ August 2005), pp. 8-14, ISSN 08835381.

Nelson, W. A. 2007. Dealing With Ethical Challenges. Healthcare Executive, Vol.22, N.2, (Mars/April 2007), pp. 36-38, ISSN 0883-5381.

Ntetu, A. L. and al. (2010). Pour une dynamique éthique de la conciliation « engagement professionnel - performance organisationnelle » chez les professionnels de la santé ». Colloque Le management des ressources humaines dans les entreprises du social et de la santé, Lille 7, Actes du colloque, Mai, 2010.

O'Donnell, P. and al. (2008). Predictors of Ethical Stress, Moral Action and Job Satisfaction in Health Care Social Workers. Social Work in Health Care, Vol.46, N.3, (October 2008), pp. 29-51, ISSN 0098-1389.

Okasha, A. and al. (2002). Ethical consequences for professionals from the globalization of food, nutrition and health. Asia Pacific Journal Clinical Nutrition, Vol.11, s3, (December 2002), S653-S665, ISSN 1440-6047.

Pavlish, C. and al. (2011). Early Indicators and Risk Factors for Ethical Issues in Clinical Practice. Journal of Nursing Scolarship, Vol.43, N.1, (March 2011), pp. 13-21, ISSN 1527-6546.

Peer, K. S. and Rakich, J. S. (1999). Decisions Making in Healthcare Management. Hospital Topics: Research and Perspectives on Healthcare, Vol.77, N.4, (January 1999), pp. 7-13, ISSN 0018-5868.

Price, S. J. (1992). Making an Ethical Decision: A Utilitarian Strategy. In: Ethics and standars institutional Research, M.E. Schiltz (Ed.), pp. 47-55, Jossey-Bass, ISBN 1555427553, San Francisco, United States.

Solomons, N. W. (2002). Ethical consequences for professionals from the globalization of food, nutrition and health. Asia Pacific Journal of Clinical Nutrition, Vol.11 (Suppl), (December 2002), S653-S665, ISSN 14406047.

Sorta-Bilajac, I. and al. (2011). How Nurses and physicians face ethical dilemmas - the Croatian experience. Nursing Ethics, Vol.18, N.3, (May 2011), pp. 341-355, ISSN: 0969-7330.

Thomas, N. (2000). Generalist practice with people of color, In: Collaborative social work: Strengths based Generalist Practice. J. Poulin, (Ed.), 205-325, Wadsworth Publishing Company, ISBN 978-0875814285, Belmont, United States.

Thomas, N. D. (2001). The Importance of Culture throughout All long Life and Beyond. Holistic Nursing Practice, Vol.15, N.2, (January 2001), pp. 40-46, ISSN 0887-9311.

Turner, L. (2004). Bioethics in a Pluralistics Societies. Medicine, Health Care and Philosophy, Vol.7, N.2, (May 2004), pp. 201-208, ISSN 1386-7423.

Wildershoven, G. (2005). Interpretation and Dialogue in Hermeneutic Ethics. In: Case analysis in clinical ethics. R. Ashcroft \& al. (Eds.), pp. 57-76, Cambridge University Press, ISBN 0521835496, Cambridge, United Kingdom.

Widdershoven, G. and al. (2009). Empirical Ethics as Dialogical Practice. Bioethics, Vol.23, N.4, (May 2009), pp. 236-248, ISSN 1467-8519.

Wray, L. A. (1992). Health Policy and Ethnic Diversity in Older Americans - Dissonance or Harmony? In Cross-cultural Medicine - A Decade Later (Special Issue). Western Journal of Medicine, Vol.157, N.3, (September 1992), pp. 357-361, ISSN 1547-5069. 


\title{
Globalization, Democracy, and Government Spending in Sub-Saharan Africa: Evidence from Panel Data
}

\author{
Samuel Adams ${ }^{1}$ and Daniel Sakyi ${ }^{2}$ \\ ${ }^{1}$ Ghana Institute of Management and \\ Public Administration (GIMPA), Accra, \\ 2Department of Economics, University of Pisa, Pisa, \\ ${ }^{1}$ Ghana \\ 2Italy
}

\section{Introduction}

Globalization represents one of the most influential forces determining the future of countries. The increasing integration of the world economy has led to a growing interest in its effect on national economies. With extraordinary global interdependence, increased financial liberalization, investment flows and international trade, it is obvious that we live in a global village. Accordingly, it can be said that not only can globalization be described as one of the most dominant forces in the present day world economy, but also that no nation can exist in isolation in today's world (Zhuang \& Koo, 2007).

Empirically, globalization translates into greater mobility of the factors of production (capital and labor) and greater world integration through increased trade and foreign direct investment. These indicators, however, measure only economic globalization and their effects are usually not the same across countries. Consequently, we also use a comprehensive measure of globalization, the index by Dreher (2006) to examine the effects of globalization. The Dreher (2006) index of globalization combines several variables from the economic, political, and social sectors.

The globalization agenda as seen in the drive toward trade liberalization and the growth in the influx of FDI has been remarkable in the past two decades. For example, the total world FDI stock which stood at about $\$ 2$ trillion in 1990 had grown to over $\$ 18$ trillion in 2009 compared to the total FDI inflows of $\$ 208$ billion in 1990 and $\$ 1.1$ trillion in 2009. The 2009 FDI inflows value, however, was 37\% lower than the 2008 value due to global financial crisis (World Investment Report (WIR), 2010). The WIR (2010) shows that after almost a decade of growth, FDI flows to Africa declined from a peak of $\$ 72$ billion in 2008 to $\$ 59$ billion in 2009 due to the contraction of global demand and the fall in commodity prices. Interesting though is the fact that Africa's share of global FDI did not change appreciably (between 2-3\%) over the past four decades but increased to $4.1 \%$ in 2008 and even higher in 2009 (5.3\%). 
Similarly, exports of goods and services which stood at $\$ 4.4$ trillion in 1990 increased to $\$ 13$ trillion in 2005, \$20 in 2008 but decreased to \$16 trillion in 2009 (World Investment Report $\{W I R\}, 2010)$. Overall, world trade growth slowed in both 2007 and 2008 but in some developed countries like the US and Japan import volume growth turned negative. Global trade flows rebounded strongly in 2010 (\$15.2 trillion) following their collapse in 2009 (\$12.5 trillion) (World Trade Report, 2011). The report indicates that the rise in the volume of exports in 2010 was the largest on record, enabling world trade to return to its pre-crisis level but not to its long term trend. It is in the light of the dramatic changes associated with globalization that many studies have been conducted to examine its macroeconomic effects especially globalization's effect on economic growth on one hand, and the other, is its effect on government spending. This study focuses on the latter relationship.

This study examines the impact of global integration on government spending in the context of Sub Saharan African countries. This is important because as noted by Tanzi (2000), globalization has led to a growing interdependence of fiscal policies affecting the composition of government expenditures. Further, the greater volatility of commodity prices of primary products (main export of most African countries), suggest that greater trade volatility is more likely to heighten insecurity unless governments take the necessary measures to provide for social protection. However, it is also true that many developing countries because of the low tax revenues and weakness of the states are unable to implement welfare support systems (Avelino and Vargas, 2001), which indicates that identifying the relationship between globalization and government spending is an empirical matter.

Though some empirical studies have been conducted, many of these studies have focused on OECD (e.g. Meinhard and Potrafke, 2011; Busemeyer, 2009; Garrett and Mitchell, 2001), with a few others focusing on Latin America (Avelino and Vargas, 2001; Kaufman and Segura-Ubergio, 2001), but not much on Africa. Consequently, we contribute to the literature by examining the specific case of SSA countries. This is important because many of the studies do suggest that differences in the empirical results could be attributed to regional differences (Busemeyer, 2009; Hays, 2006; Balcells, 2006). Hays (2006) observes that the globalization government spending relationship is not only historically contingent but also geographical. Busemeyer (2009) reports that the discussion of the examination of globalization's effect should not lead to the assumption of convergence of policy outcomes. Balcells (2006) also claims that the effects of trade openness on redistribution demands are not homogeneous, and argue that they depend both on the type of factor endowment of the economy and the level of development.

The rest of the paper is organized as follows. The next section presents a review of the literature on the globalization-government spending relationship after which the methodology is described, results discussed, and ends with concluding remarks.

\section{Literature review}

The effect of globalization on government spending has generally been discussed under two main perspectives: the compensation and the efficiency hypotheses. The issue at the heart of the literature is about whether governments respond to the challenges of globalization with social policy choices that are oriented more toward cutting costs (efficiency) or protecting people's welfare (compensation) (Avelino and Vargas, 2001). 
The efficiency hypothesis focuses on the supply side of the political market, highlights competitive pressures and threat of exit by mobile asset holders (Garret and Nickerson, 2001). The notion of efficiency is that government will reduce taxes and social welfare expenditures that diminish profits, discourage investment, economic growth and therefore overall international competitiveness. In essence, the competition between countries to promote trade and attract FDI, for example, leads to a reduction in taxation. The reduction in particular of corporate and capital taxes could lead to a reduction in the size of the public sector and consequently, a restructuring of government expenditures towards more productive private sector activities (Sanz and Velaquez, 2007; Klien et al., 2009). The view is not that government does not matter but rather that government spending - beyond minimal market friendly measures such as defence, securing property rights and other fundamental public goods - reduce the competitiveness of national producers in international goods and services markets (Garrett and Nickerson, 2001). Put simply, the efficiency approach posits that globalization places important constraints on welfare spending, leaving governments little choice but to restrict their social outlays (Avelino and Vargas, 2001).

In support of the efficiency view, Dreher et al. (2008), argue that globalization restrains government by inducing increased budgetary pressures. Empirically, Kaufman and SeguraUbergio (2001), Avelino and Getulio (2001), and Busemeyer (2009) report a negative effect of globalization on government spending. Busemeyer (2009) used various measures for globalization and report statistically significant negative relationship between globalization and government spending. Avelino and Vargas (2001) show a negative significant effect of globalization on government spending for Latin American countries for the period 19801997. In a related study of Latin America for the period 1973-1997, Kaufman and SeguraUbiergo (2001) also reported similar findings.

On the other hand, the compensation perspective recognizes the constraints imposed by globalization on the social policy options of governments, yet accords greater weight to the countervailing demands imposed by citizens seeking protection from the state. It stresses the perception among top elected officials and bureaucrats that the social instability and political discontent engendered by internationalization could ultimately endanger globalization and its further development. The core contention of the compensation thesis is that government officials use the latitude they have to strengthen social insurance mechanisms to cushion citizens from the effects of globalization. Accordingly, Garrett and Nickerson (2001) claim that the efficiency perspective in focusing on the economic costs of government overlooks the possibility that there are political incentives to expand the public economy in response to globalization and that these may outweigh the constraints imposed by market integration. The pressures of the political market dictate that government must respond to the demands of the voting public by counteracting any negative effect associated with global integration. The assumption is that increased trade and financial liberalization, in particular, lead to erosion of incomes and it is the responsibility of government to provide social insurance to mitigate the exposure to greater levels of external risk (Gemmell et al., 2008; Sanz and Velaquez, 2007).

The view that governments expand the welfare state to insure citizens against the increased economic risk and unemployment caused by globalization is consistent with Rugie's (1982) idea of embedded liberalism, where policy makers develop a series of domestic and 
international institutions which seek to combine a multilateral commitment to free trade, on the one hand, with domestic stability on the other. From this perspective, Wolfe and Mendelssohn (2004) argue that governments' response to globalization is not lower, but higher public spending. Thus, the demand side effects of globalization derive from the desire of government to direct the political process towards a redistribution of the induced losses or perceived risk (Dresher et al., 2008; Ruoff and Schaffer, 2009). In support of the compensation hypothesis, Meinhard and Potrafke (2011) in a study of 186 countries for the period 1970-2004 demonstrate that globalization had contributed to the increase in size of government spending. In a related study of 100 countries for the period 1970-2000, Shelton (2007) reports a significant positive relationship. Epifani and Gancia (2008) studied a cross section of countries over a period of 50 years (1950-2000) using fixed effects and GMM estimation techniques and report a significant positive effect of globalization on government spending. The authors, however, provide an alternative to the compensation hypothesis arguing that trading countries tend to have bigger governments because they benefit from terms of trade externality that shifts part of the cost of taxation abroad.

Notwithstanding the potential efficiency or compensation effect of globalization on government spending, there are good reasons to believe that these two forces may mitigate each other such that there would be no effect of globalization on government spending (Gemmel et al., 2008; Dreher et al., 2008). Gemmel et al. (2008) examined a sample of OECD countries from 1980-1987 using both the inward FDI stock and trade openness as measures of globalization and report no significant relationship. Likewise, Dreher et al. (2008) investigated the impact of globalization on government size for 108 countries for the period 1970-2001 and show that globalization did not have an impact on the composition of government expenditures.

Other authors argue that the inconsistencies in the relationship between globalization and government spending are due to the fact that it is mediated by many country specific factors that are usually not controlled for. For instance, Adsera and Boix (2002) argue that the compensation hypothesis is likely to hold in more democratic countries, whereas the efficiency hypothesis is more likely to hold in non democratic countries. Klien et al. (2009) have shown that the globalization-government spending nexus is mediated by the regime type. They find that efficiency effect dominated in Western Europe and the compensation effect was more pronounced in Eastern Europe. Garrett and Nickerson (2001) make a similar argument that democratization has significantly mediated the globalization - government spending relationship. They observe that in countries that became more democratic between the 1980s and 1990s, increasing market integration was associated with much faster growth in government spending - but the converse was true in countries that did not democratize. Additionally, Poftrake (2009) reports that left wing governments respond to globalization by implementing compensating policies, while right wing respond by implementing efficiency enhancing policies. Gemmel et al. (2008) suggest that having a more informed and politically active electorate strengthens incentives for governments to be responsive. This suggests that there is a role for democratic institutions in ensuring that the preferences of citizens are reflected in policy.

Per the discussion above, our contribution is twofold. Firstly, though some empirical studies have been conducted, many of these studies have focused on OECD countries (see Cameron, 1978; Busemeyer, 2009; Meinhard and Potrafke, 2011), with a few others focusing on Latin 
America countries (see Avelino and Vargas, 2001; Kaufman and Segura-Ubergio, 2001, Avelino et al, 2005), but not much on Africa. We contribute to the globalization - democracy - government spending debate by examining the specific case of 42 SSA countries for the period 1970-2009 to be able to capture the differential effects, if any, between the pre and post - liberalization reform eras. Secondly, we consider whether the democratic reforms in the region over the past two decades have had any effect or play a mediating role in the relationship between globalization and government spending. Obviously, the recent democratic transformation experienced by many countries in the region offers a unique opportunity to explore questions about how different political regimes respond to the external economic shocks associated with globalization (Rodrik, 1998). The methodology for the empirical analysis is based on Prais - Winsten regressions with panel-corrected standard errors, which is discussed next.

\section{Empirical methodology}

\subsection{Data}

We use annual dataset covering the period 1970-2009 for a total of 42SSA countries. However, since all the data used in the study is not available for all countries and time period considered the panel is unbalanced. The countries included are: Angola; Benin; Botswana; Burkina Faso; Burundi; Cameroon; Cape Verde; Central African Republic; Chad; Comoros; Congo, Dem. Rep; Congo, Republic of; Cote d'Ivoire; Gabon; Gambia, The; Ghana; Guinea; Guinea-Bissau; Kenya; Lesotho; Liberia; Madagascar; Malawi; Mali; Mauritania; Mauritius; Mozambique; Niger; Nigeria; Rwanda; Sao Tome and Principe; Senegal; Sierra Leone; Somalia; South Africa; Sudan; Swaziland; Tanzania; Togo; Uganda; Zambia; Zimbabwe ${ }^{1}$.

For the data on the size of government, we use the percentage share of government spending in real GDP (denoted GEXP) which is based on data obtained from the United Nations Statistical Database (2011). However, because both globalization and democracy have many dimensions we use various indicators to examine how they impact on government spending. For the globalization indicators we use the KOF globalization indices which provide a more comprehensive measure of globalization in general. KOF index of globalization combines three sub-indices of globalisation - economic, social and political into an overall index of globalization. The economic globalization index combines information on actual trade flows, foreign direct investment, income payments to foreign nationals and restrictions on trade and capital. The social globalization index combines data on personal contact with people, information flows and international cultural integration. The political globalization index combines information on international political integration of countries involving embassies in country, membership in international organisations, participation in U.N. Security Council missions and international treaties ${ }^{2}$. We denote the economic, social, political and overall indicators of globalization as EGLOB, SGLOB, PGLOB and $G L O B$ respectively.

${ }^{1}$ The selection of countries is influenced by data availability for all included variables

${ }^{2}$ Readers are referred to KOF website (http://globalization.kof.ethz.ch/) for additional information on these indices 
We use four indicators of democracy based on data obtained from Polity IV Project (Marshall and Jaggers, 2009) and the Heritage Foundation's Indices (Freedom House, 2011). The first indicator of democracy is based on Polity2 (Marshall and Jaggers, 2009) ${ }^{3}$ while the second and third are respectively based on Political Rights and Civil Liberties (Freedom House, 2011). As for the fourth and last indicator of democracy, we have used principal component analysis (PCA) to extract a composite index to proxy for the components of the first three indicators. The first principal component which is a linear combination of the original variables with maximum variance provides a good proxy for all three indicators as it explains up to $86 \%$ of the variations in the original data. The introduction of our fourth indicator does not only provide us with a composite indicator of democracy or for robustness issues, but most importantly help eliminate any potential multicollinearity problems that may plague estimated regressions with the first three indicators of democracy. This may be expected in models with both the squared and interaction terms of these indicators. The four indicators of democracy are denoted DM1, DM2, DM3 and DM4 respectively.

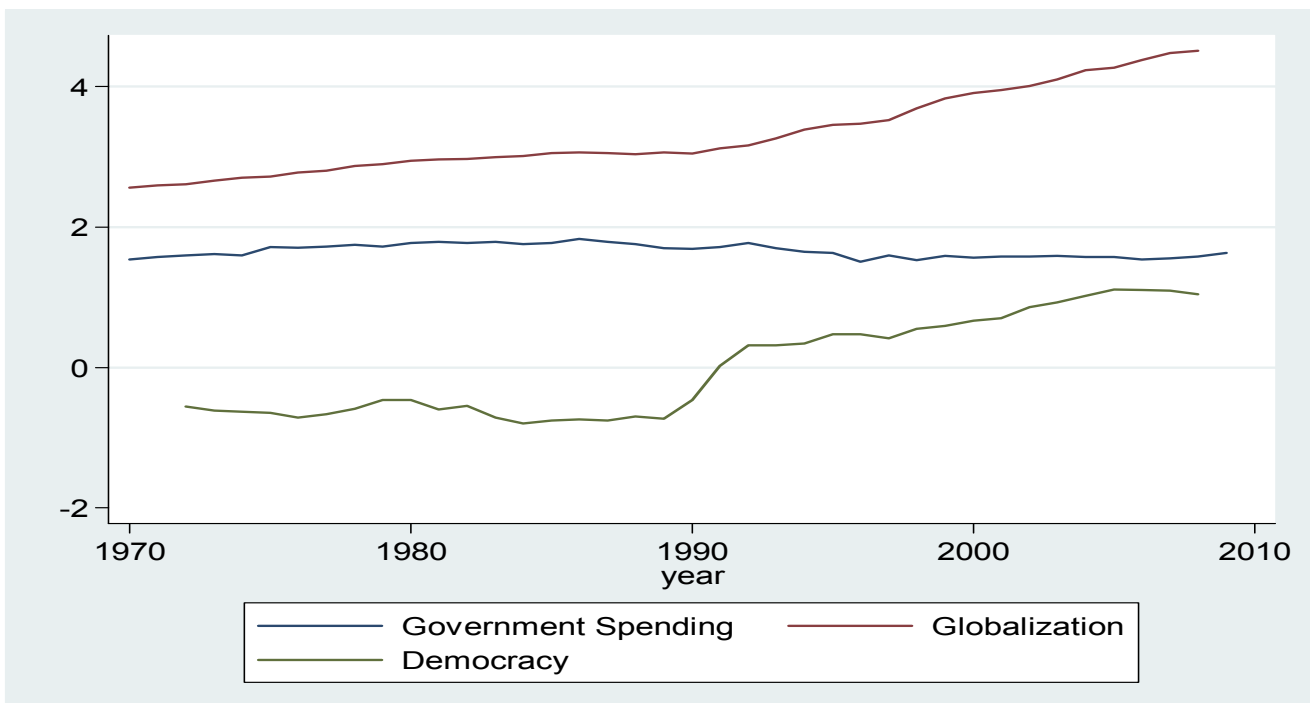

Fig. 1. Average development of government spending, globalization and democracy. Source: United Nations Statistical Database (2011), KOF Index of Globalization (2011), Freedom House (2011), Marshall and Jaggers (2009). Note: Government spending and globalization has been rescaled to fit the graph.

Figure 1 reports the averages over time of the percentage share of government spending in real GDP, KOF overall index of globalization (GLOB) and the PCA-based index of democracy $(D M 4)^{4}$. As can be seen, government spending increased from the 1970s through

3 Polity 2 ranges from -10 (strongly autocratic) to +10 (strongly democratic) while from 1 (the highest rank) to 7 (the lowest rank). We have normalise all indicators of democracy, so all range between 0 (full autocracy) to 10 (full democracy).

${ }^{4}$ The other globalization and democracy indicators show similar pattern and are thus not shown for presentation purposes 
the 1980s and then began to decline beginning in the 1990s. KOF overall index of globalization increased throughout the sample period while democracy which was almost stable in the 1970s and 1980s began to increase in the 1990s. Table 1 report the correlations among government spending, and our globalization and democracy indicators ${ }^{5}$. With the exception of the economic globalization indicator which is positively correlated with Table 1. Correlation matrix of the share of government spending in real GDP, globalization and democracy indicators government spending, all other indicators of both globalization and democracy are negatively correlated with government spending. The correlation results provide some indication that both globalization and democracy may have been crucial in the decline in the average government spending beginning in the 1990s as evident in Figure 1.

\begin{tabular}{llllllllll}
\hline Variables & GEXP & EGLOB & SGLOB & PGLOB & GLOB & DM1 & DM2 & DM3 & DM4 \\
\hline GEXP & 1 & & & & & & & & \\
EGLOB & 0.202 & 1 & & & & & & & \\
SGLOB & -0.128 & 0.541 & 1 & & & & & & \\
PGLOB & -0.239 & 0.094 & 0.134 & 1 & & & & & \\
GLOB & -0.049 & 0.806 & 0.749 & 0.570 & 1 & & & & \\
DM1 & -0.021 & 0.309 & 0.360 & 0.349 & 0.473 & 1 & & & \\
DM2 & -0.028 & 0.342 & 0.484 & 0.290 & 0.511 & 0.861 & 1 & & \\
DM3 & -0.073 & 0.313 & 0.536 & 0.366 & 0.551 & 0.788 & 0.889 & 1 & \\
DM4 & -0.042 & 0.340 & 0.485 & 0.355 & 0.541 & 0.932 & 0.969 & 0.940 & 1 \\
\hline
\end{tabular}

Source: United Nations Statistical Database (2011), KOF's Index of Globalization (2011), Freedom House (2011), Marshall and Jaggers (2009).

Table 1.

Based on the literature on the determinants of government spending we also consider control variables. In this paper we consider the log of real GDP per capita (i.e. our proxy for level of development $(\log I N C O M E))$, real GDP per capita growth (GROWTH), the percentage share of foreign aid in real GDP $(A I D)$, percentage of population age 65 and over $(D E P O)$, percentage of population in urban areas $(U R B A N)$ and the log of total population (i.e. our proxy for country size $(\log P O P))$. The data for foreign aid, percentage of population age 65 and over, percentage of population in urban areas are drawn from World Development Indicators (2011) database. The rest of the data are obtained from United Nations Statistical Database (2011).

\subsection{Model specification}

The basic panel data model we estimate has the following specification:

$$
y_{\text {it }}=\alpha_{i}+\beta_{1} x_{i t}+\beta_{2} z_{i t}+\beta_{3} w_{i t}+\varepsilon_{i t} \quad i=1,2 \ldots N ; \quad t=2,3 \ldots T
$$

where $y_{i t}$ is the observations for government spending of country $i$ in period $t$, we define $x_{i t}$ as an indicator of globalization or as the vector of the observations of globalization

\footnotetext{
${ }^{5}$ These correlations are based on transformed data discussed under econometric issues and estimation strategy in section 3 .
} 
indicators considered, $z_{i t}$ to include an indicator of democracy and the squared term of this indicator, and $w_{i t}$ as the vector of the observations of control variables considered relevant in explaining government spending in SSA, $\varepsilon_{i t}$ is the error term with the usual properties.

A priori, the coefficient on globalization indicators is unknown due to the potential impact of the compensation hypothesis, the efficiency hypothesis and/or the mitigating effect of the compensation and efficiency hypothesis on government spending. For this reason, globalisation could have negative, positive or no effect on government spending. Nonetheless, Hausken et al. (2004) note that a non-linear relationship exists between democracy and government spending such that an increase in democracy from autocracy to semi-democracy tends to reduce government spending, whilst further increase from semidemocracy to full democracy tends to increase government spending. The introduction of the squared term of democracy indicators (denoted DM1SQ,DM2SQ,DM3SQ and DM4SQ respectively) aim to capture this non-linear relationship between the level of democracy and government spending. If this non-linear relationship is supported in the SSA data then we should expect a robust and statistically significant negative (positive) coefficient on democracy (democracy squared). Following the literature on globalization, democracy and government spending (see Garret and Nickerson, 2005; Yoon, 2009), we go further to introduce interaction terms for these variables to determine if there are any mediating effects between globalization and democracy on government spending for SSA countries.

\subsection{Econometric issues and estimation strategy}

Series of relevant econometric issues arise when estimating equation (1). Firstly, we have yearly time span for our dataset. However, due to potential short term disturbances yearly time span may not be appropriate (see Islam, 1995). We therefore, use 5-year average for the 1970-2009 period for all variables ${ }^{6}$. This transformation reduces potential business cycle and non-stationarity effects that may be present in the yearly data. We split the data into 8-year periods $(\mathrm{T}=8)$ for each country in our sample (1970-1974, 1975-1979, 1980-1984, 1985-1989, 1990-1994, 1995-1999 and 2000-2004 and 2005-2009). Secondly, due to the presence of heteroskedasticity, autocorrelation, and cross section dependence in our models we are unable to rely on estimators such as pooled OLS which do not control for these effects?. However, as noted in (Islam, 1995), a common issue that arises when estimating (1) is the choice between fixed effect and random effect based estimators. In particular, while the unobservable individual random effects models depend on the existence of strictly exogenous explanatory variables, this is not usually the case with unobservable individual fixed effects models that are "highly likely to be correlated with the observed exogenous variables in the model" (Nickell, 1981). To resolve this issue we first determined which of fixed and random effect estimators is appropriate. For all models considered, both Hausman test and Breusch and Pagan Lagrangian multiplier test provides evidence in favour of

\footnotetext{
${ }^{6}$ For variables with missing values we have computed the average based on the number of data points in each period. For example, for Political Right and Civil Liberty indices which begin from 1972 we use a 3-year average for the 1972-1974 for the first time period. Similar rule is applied for the KOF indices where the data ends in 2008

7 We have performed the modified Wald test for groupwise heteroskedasticity, Wooldridge test for autocorrelation in panel data and the Frees' test (Frees, 1995) for cross section dependence that provides these evidence. These results are not reported but available from the authors upon request.
} 
random effect estimators as the most appropriate 8 . However, we are unable to use the random effect estimator due the problem of cross section dependence. Therefore, following Beck and Katz (1995) and Avelino et al. (2005), we use the panel-corrected standard errors in the framework of Prais-Winsten regressions to address these econometric issues raised. Prais-Winsten regressions are particular appropriate for panel data models plagued by heteroskedasticity, autocorrelation and cross section dependence. In all regressions estimated we have allowed panel-specific heteroskedastic errors and panel-specific (AR1) autocorrelation structure.

\section{Empirical results}

\subsection{Control variables}

We begin the empirical analysis with the control variables considered which yield the following results for all estimated models (see Tables 2 to 4). Table 2 reports the result with KOF sub-indices of globalization - economic (EGLOB), social (SGLOB) and political (PGLOB). In Table 3 we consider KOF overall index of globalization (GLOB) while Table 4 introduces the interaction terms between globalization indicators and the PCA-based indicator of democracy.

The coefficient on country size (proxied by log of population), although enters all regressions with the expected sign (i.e. negative), is not significant in most estimated models (especially where we use KOF's sub-indices of globalization) implying less robust association with government spending. This result implies that governments in large economies in SSA may not necessarily spend less, and hence little support for Alesina and Wacziarg (1998) hypothesis of a negative relationship between country size and government spending in SSA countries.

Other than country size, the rest of the control variables (the level of development, economic growth, foreign aid, percentage of population aged 65 and over, percentage of population in urban areas) show robust association with government spending in SSA countries. The level of development (proxied by log of per capita income) enters positive in all regressions and highly significant. This result lend support for Wagner's law and indicates that as these countries continue to develop their economies, government depends more on their per capita income to provide public goods and services for their citizens.

We also find statistical significant negative impact of economic growth on government spending consistent with Wildavsky hypothesis of a negative relationship between economic growth and government spending for low-growth countries (see Cameron, 1978). However, for SSA countries characterized by highly volatile economic growth patterns the explanation for this negative relationship may be more of government spending being constrained by the volatile economic growth patterns.

As expected, the coefficient on foreign aid enters positive and highly significant in all regressions. This result provides support for the overdependence on foreign aid by developing countries' government in pursuit of their developmental agenda. Thus foreign aid indeed increases the scope of the public sector in SSA countries.

8 These results are not reported, but are available from the authors upon request 


\begin{tabular}{|c|c|c|c|c|}
\hline & (1) & (2) & (3) & $(4)$ \\
\hline$\overline{E G L O B}$ & $0.787 \mathrm{a}[0.277]$ & $0.706^{b}[0.282]$ & $0.674 \mathrm{~b}[0.282]$ & $0.734 \mathrm{a}[0.277]$ \\
\hline SGLOB & $-2.217 a[0.600]$ & $-1.973 a[0.597]$ & $-1.982 \mathrm{a}[0.639]$ & $-2.159 a[0.610]$ \\
\hline PGLOB & $-0.369^{b}[0.151]$ & $-0.439 b[0.179]$ & $-0.405^{b}[0.159]$ & $-0.331^{b}[0.166]$ \\
\hline DM1 & $-0.369[0.468]$ & & & \\
\hline$D M 1 S Q$ & $0.044[0.046]$ & & & \\
\hline DM2 & & $-0.214[0.276]$ & & \\
\hline$D M 2 S Q$ & & $0.040[0.029]$ & & \\
\hline DM3 & & & $-0.837 \mathrm{~b}[0.355]$ & \\
\hline$D M 3 S Q$ & & & $0.110 \mathrm{a}[0.041]$ & \\
\hline DM4 & & & & $-0.248[0.196]$ \\
\hline$D M 4 S Q$ & & & & $0.251^{\mathrm{b}}[0.097]$ \\
\hline $\log I N C O M E$ & $4.188^{\mathrm{a}}[0.969]$ & $4.291 \mathrm{a}[0.955]$ & 4.233a[0.899] & $4.146^{\mathrm{a}}[0.857]$ \\
\hline GROWTH & $-0.166 \mathrm{a}[0.053]$ & $-0.178 \mathrm{a}[0.050]$ & $-0.179 a[0.048]$ & $-0.165^{a}[0.052]$ \\
\hline$A I D$ & $0.182 \mathrm{a}[0.048]$ & $0.249 \mathrm{a}[0.043]$ & $0.257 \mathrm{a}[0.041]$ & $0.193 \mathrm{a}[0.046]$ \\
\hline$D E P O$ & $-1.620 \mathrm{a}[0.268]$ & $-1.271 \mathrm{a}[0.172]$ & $-1.297 \mathrm{a}[0.180]$ & $-1.710 \mathrm{a}[0.286]$ \\
\hline URBAN & $-0.105^{a}[0.033]$ & $-0.106^{\mathrm{a}}[0.037]$ & $-0.099 \mathrm{a}[0.036]$ & $-0.097 a[0.033]$ \\
\hline $\log P O P$ & $-0.096[0.266]$ & $-0.409[0.230]$ & $-0.281[0.209]$ & $-0.136[0.272]$ \\
\hline Observations & 266 & 273 & 273 & 266 \\
\hline
\end{tabular}

Note: Symbols ${ }^{a}(b)[c]$ denote statistical significance at the $1 \%(5 \%)[10 \%]$ level. In parenthesis are PanelCorrected Standard Errors. For presentation purposes the constant term is not reported.

Table 2. Prais-Winsten regressions: KOF globalization indicators (economic, social, political) and democracy indicators

As for the demographic factors previous studies on government spending in SSA countries found no association between demographic factors and government spending (see for example Sobhee, 2010) ${ }^{9}$. Nonetheless, we find that the coefficient on the percentage of population aged $65+$ is negative and statistically significant in all regressions. This results is not surprising as in SSA countries (as in many other developing countries) the government does not generally care about the dependent population.

The most surprising result is the negative and statistically significant coefficient on the percentage of the population in urban areas. We would have expected urbanization that characterizes many SSA countries in recent years to have positive impact on government spending, not negative, as with the growing urbanization in these countries we would expect governments' provision of public services in urban areas to increase. This result could mean that in SSA countries government is probably not responding adequately to the demands posed by urbanization. Overall the control variables we have considered have shown that government spending in SSA countries is characterized by several determinants.

\footnotetext{
${ }^{9}$ For the case of dependency ratio, Sobhee used only the total dependency ratio [i.e. percentage of (population aged $0-14$ plus those aged $65+$ )]. We considered this total dependency ratio variable as well as percentage of population aged $0-14$ in all our regressions and found no association for these variables with government spending. We thus excluded these variables from our basic specification.
} 


\subsection{Results on globalization and democracy indicators}

We now turn to discuss the coefficients on our variables of interest (i.e. indicators of globalization and democracy). The result of the impact of democracy on government spending in SSA countries (see Table 2 and 3) depends on how democracy is measured (i.e. on the alternative indicators of democracy - DM1,DM2, DM3 and DM4 - and their respective squared terms - DM1SQ, DM2SQ, DM3SQ and DM4SQ). Although, in almost all regression results we obtain the expected signs on the coefficients of democracy indicators (i.e. negative) and their respective squared terms (i.e. positive), we only find robust support for

\begin{tabular}{lllll}
\hline & $(1)$ & $(2)$ & $(3)$ & $(4)$ \\
\hline GLOB & $-0.510[0.401]$ & $-0.429[0.413]$ & $-0.378[0.380]$ & $-0.457[0.425]$ \\
DM1 & $-0.013[0.422]$ & & & \\
DM1SQ & $0.004[0.043]$ & & & \\
DM2 & & $-0.308[0.311]$ & & \\
DM2SQ & & $0.046[0.039]$ & & \\
DM3 & & $-1.024 \mathrm{a}[0.351]$ & \\
DM3SQ & & & $0.123 \mathrm{a}[0.044]$ & \\
DM4 & & & $-0.249[0.180]$ \\
DM4SQ & & & $0.175 \mathrm{c}[0.099]$ \\
$\operatorname{logINCOME}$ & $3.541 \mathrm{a}[0.719]$ & $3.466 \mathrm{a}[0.812]$ & $3.413 \mathrm{a}[0.754]$ & $3.761 \mathrm{a}[0.637]$ \\
GROWTH & $-0.097 \mathrm{~b}[0.041]$ & $-0.113 \mathrm{~b}[0.054$ & $-0.111^{\mathrm{b}}[0.054]$ & $-0.099 \mathrm{~b}[0.040]$ \\
AID & $0.162 \mathrm{a}[0.033]$ & $0.177 \mathrm{a}[0.045]$ & $0.185 \mathrm{a}[0.044]$ & $0.171 \mathrm{a}[0.033]$ \\
DEPO & $-1.464 \mathrm{a}[0.273]$ & $-0.899 \mathrm{a}[0.250]$ & $-0.908 \mathrm{a}[0.248]$ & $-1.523 \mathrm{a}[0.270]$ \\
URBAN & $-0.150 \mathrm{a}[0.025]$ & $-0.119 \mathrm{a}[0.034]$ & $-0.121 \mathrm{a}[0.034]$ & $-0.147 \mathrm{a}[0.024]$ \\
$\log P O P$ & $-0.505 \mathrm{c}[0.304]$ & $-1.420 \mathrm{a}[0.042]$ & $-1.290[0.377]$ & $-0.416[0.310]$ \\
Observations & 304 & 318 & 318 & 304 \\
\hline
\end{tabular}

Note: Symbols ${ }^{a}(\mathfrak{b})\left[{ }^{[}\right]$denote statistical significance at the $1 \%(5 \%)[10 \%]$ level. In parenthesis are PanelCorrected Standard Errors. For presentation purposes the constant term is not reported.

Table 3. Prais-Winsten regressions: KOF globalization (overall index) and democracy indicators

Hausken et al. (2004) hypothesis of a non-linear relationship between democracy and government spending when we consider civil liberty as an indicator of democracy. Democracy measured by both polity 2 and political rights provides not enough evidence for this hypothesis while for the PCA democracy-based indicator only the squared term is statistically significant. These results are robust regardless of how globalisation is measured.

As already mentioned Table 2 reports the estimated result with KOF sub-indices of globalization. The estimated coefficients on these indicators show statistically significant positive (negative) impact of economic globalization (social and political globalization). While the result on economic globalization lends support to Rodrik's hypothesis of a positive relationship between economic globalisation and government spending10, social and political globalization tends to decrease the growth of government spending in SSA

${ }^{10}$ In place of economic globalization indicator we also estimated all models with trade openness and obtained similar conclusions. The result using trade openness indicator is available from the authors upon request. 
countries. On the other hand, we do not find any significant relationship between globalization (as measured by the overall KOF's index) and government spending in SSA countries (see Table 3). This result is consistent regardless of the indicator of democracy used and it may be explained by the potential mitigating effect of the sub-indices. This result implies that how globalization is measured is crucial in the globalization-government spending relationship.

Notwithstanding this, it is imperative that we also consider any potential interaction effect of globalization indicators and democracy (measured by the PCA-based indicator) that might have affected government spending in SSA countries. Table 4 summarizes the result with these interaction terms. As evident, the presence of the interaction terms does not affect our initial conclusions on the coefficients on KOF's sub-indices of globalization. Nonetheless, $\mathrm{KOF}^{\prime}$ 's overall index of globalization is now significant (at the $10 \%$ level) with the introduction of the interaction term. On the other hand, although all democracy indicators have negative impact on government spending (with the exception of the case where we consider the interaction between political globalisation and democracy), little evidence exist for a positive effect on the squared terms (with the exception of the model interaction between political globalisation and democracy which is positive and significant at the $10 \%$ level). This result lends little support for the Hausken et al. (2004) hypothesis. Thus, although the level of democracy decreases government spending in SSA countries, increasing democracy may not necessarily increase government spending.

\begin{tabular}{|c|c|c|c|c|}
\hline & (1) & (2) & (3) & (4) \\
\hline$\overline{E G L O B}$ & $0.594 \mathrm{~b}[0.274]$ & $0.656^{b}[0.263]$ & $0.701^{b}[0.281]$ & \\
\hline SGLOB & $-2.166^{a}[0.617]$ & $-2.849 \mathrm{a}[0.673]$ & $-2.139 a[0.623]$ & \\
\hline PGLOB & $-0.305[0.173]$ & $-0.202[0.178]$ & $-0.400^{b}[0.201]$ & \\
\hline GLOB & & & & $-0.751^{c}[0.427]$ \\
\hline DM4 & $-0.959 \mathrm{~b}[0.424]$ & $-1.222^{a}[0.372]$ & $-0.732[0.456]$ & $-1.685^{a}[0.361]$ \\
\hline$D M 4 S Q$ & $0.155[0.108]$ & $-0.007[0.147]$ & $0.193 \mathrm{c}[0.103]$ & $-0.018[0.113]$ \\
\hline$E G L O B^{*} D M 4$ & $0.223^{c}[0.127]$ & & & \\
\hline$S G L O B * D M 4$ & & $0.513 \mathrm{a}[0.167]$ & & \\
\hline PGLOB*DM4 & & & $0.114[0.091]$ & \\
\hline$G L O B^{*} D M 4$ & & & & $0.471 \mathrm{a}[0.128]$ \\
\hline $\log I N C O M E$ & $3.969 \mathrm{a}[0.848]$ & $4.334 \mathrm{a}[0.873]$ & $4.150 \mathrm{a}[0.853]$ & $3.638 \mathrm{a}[0.575]$ \\
\hline GROWTH & $-0.166 \mathrm{a}[0.051]$ & $-0.170 a[0.053]$ & $-0.164 \mathrm{a}[0.052]$ & $-0.095^{b}[0.041]$ \\
\hline$A I D$ & $0.199 \mathrm{a}[0.045]$ & $0.190 \mathrm{a}[0.046]$ & $0.193 \mathrm{a}[0.045]$ & $0.168 \mathrm{a}[0.034]$ \\
\hline DEPO & $-1.777 a[0.282]$ & $-1.789 a[0.255]$ & $-1.756 \mathrm{a}[0.292]$ & $-1.703 a[0.261]$ \\
\hline URBAN & $-0.087 \mathrm{a}[0.032]$ & $-0.093 \mathrm{a}[0.031]$ & $-0.092 \mathrm{~b}[0.036]$ & $-0.133 a[0.025]$ \\
\hline $\log P O P$ & $-0.385[0.295]$ & $-0.472 c[0.259]$ & $-0.205[0.254]$ & $-0.506^{c}[0.128]$ \\
\hline Observations & 266 & 266 & 266 & 304 \\
\hline
\end{tabular}

Note: Symbols ${ }^{a}(b)[c]$ denote statistical significance at the $1 \%(5 \%)[10 \%]$ level. In parenthesis are PanelCorrected Standard Errors. For presentation purposes the constant term is not reported.

Table 4. Prais-Winsten regressions: KOF globalization indicators and their interactions with democracy

Nonetheless, all the interaction terms enter positive and statistically significant (with the exception of the interaction between political globalisation and democracy) implying that 
globalization (economic, social and overall) and democracy (proxied by the PCA-based indicator) could potentially increase the scope of the public sector in SSA countries. Taken cognisance of all globalization and democracy related variables in Table 4, the result implies that (1) economic globalisation and democracy has increased government spending while (2) globalization (social, political and overall) and democracy have led to a reduction in government spending in SSA countries. Therefore, both globalization and democracy are important determinants of government spending in SSA countries.

\section{Concluding remarks}

The paper has investigated the relationships among globalization, democracy, and government spending in SSA countries. The findings of the study show that economic globalization did have a significant positive effect on government spending - supporting the compensation hypothesis-, while social and political globalization were negative and significantly related to government spending - supporting the efficiency hypothesis. Democracy did not show robust association with government spending. The other control variables, level of development and foreign aid are positive and significantly related to government spending, while economic growth, the percentage of the population aged $65+$ and the percentage of the population in urban areas are negatively related to economic growth.

The results indicate that the increasing global integration and democratic reforms underway in SSA countries, on the whole, have not been harmful so far as government spending growth is concerned. However, economic globalization's positive effect on government size should not be necessarily viewed as negative, as many studies have shown that increase in government spending in many developing countries could help to make them competitive in the long term especially if the spending promotes productivity. Yanikkaya (2003), for example, has shown that some form of government intervention to restrict trade could be important in enhancing the competitiveness of infant industries. Grossman and Helpman (1992) have also argued that government spending in the economy to restrict trade could facilitate long run growth especially if the spending is geared toward investment and research intensive sectors. The problem then is not the increase in government spending per se but what the money is spent on. Further research could look at the dynamics of global integration, government spending and growth in the context of Africa to provide policy direction to maximize the gains from globalization introduction.

In moving forward, many more country specific studies would have to be conducted to fully appreciate how globalization is impacting on individual countries. Data constraints did not allow us to do this. As data becomes available, it will also be of significance to policy makers to examine not just the level effects but also changes in the variables concerned and more importantly how globalization is impacting on the composition of government expenditure.

In concluding, we want to state that the problem for African countries is not globalization per se but how to manage it to ensure prosperity for its people. This could only be possible when the desire for global integration is combined with appropriate elements of policy direction. In this sense, the focus should shift from whether the size of government expenditure is small or big to identifying the right expenditures needed to promote long run economic and social welfare. 


\section{References}

Adsera, A., and C. Boix (2002), "Trade, Democracy, and the Size of the Public Sector: The Political Underpinnings of Openness". International Organization 95: 229-262

Alesina, A., and R. Wacziarg (1998), "Openness, Country Size and Government", Journal of Public Economics, 69: 305-321

Avelino, G., and F. G. Vargas (2001), "Globalization, Democracy, and Social Spending in Latin America, 1980-1997". Unpublished manuscript

Avelino, G., Brown, D. S., and W. Hunter (2005), "The Effects of Capital Mobility, Trade Openness, and Democracy on Social Spending in Latin America, 1980-1999", American Journal of Political Science, 49: 625-641

Balcells, V. (2006) "Trade Openness and Preferences for Redistribution: A Cross National Assessment of the Compensation Hypothesis," Business and Politics: Vol. 8: Iss. 2, Article 1.

Beck, N., and J. N. Katz (1995), "What To Do (and Not To Do) with Time-Series-CrossSection Data in Comparative Politics", American Political Science Review, 89: 634-647

Busemeyer, M. (2009), "From Myth to Reality: Globalization and Public Spending in OECD Countries Revisited", European Journal of Political Research, 48: 455-482

Cameron, D. (1978), "The Expansion of the Public Economy: A Comparative Analysis", American Political Science Review 72: 1243-1261

Dreher A., Sturm J., and H. W. Ursprung (2008), "The Impact of Globalization on the Composition of Government Expenditures: Evidence from Panel Data", Public Choice, 134: 263-292

Dreher, A. (2006). Does Globalization affect Growth: Evidence from a New Index of Globalization. World Develoment, 29(1): 1925-1936

Epifani, P., and G. Gancia (2008), "Openness, Government Size and the Terms of Trade," IEW - Working Papers No.359, Institute for Empirical Research in Economics University of Zurich

Freedom House (2011), Freedom in the World Country Ratings, 1972-2010

Frees, E. W. (1995), "Assessing Cross-sectional Correlations in Panel Data", Journal of Econometrics, 69: 393-414

Garrett, G. (2001), "Globalization and Government Spending Around the World" Studies in Comparative International Development, 35: 3-29

Garrett, G. and D. Nickerson (2005), "Globalisation, Democratization and Government Spending in Middle-Income Countries" in Globalization and the Future of the Welfare State, ed. Miguel Glatzer and Dietrich Rueschemeyer, Pittsburgh, PA: University of Pittsburgh Press.

Garrett, G., and D. Mitchell (2001), "Globalization, Government Spending and Taxation in the OECD", European Journal of Political Research, 39: 145-177

Gemmel N., Kneller R., and I. Sanz (2008), “Foreign Investment, International Trade and the Size and Structure of Public Expenditures", European Journal of Political Economy, 24: 151-171

Hausken, K., Martin, C. W., and T. Plumper (2004), “Government Spending and Taxation in Democracies and Autocracies", Constitutional Political Economy, 15: 239-259

Hays, J. (2006), "Government Spending and Public Support for Trade in the OECD", Unpublished manuscript 
Islam, N. (1995), "Growth Empirics: A Panel Data Approach", The Quarterly Journal of Economics, 110: 1127-1170

Kaufman, R. R., and A. Segura-Ubiergo (2001), "Globalization, Domestic Politics, and Social Spending in Latin America: A Time-Series Cross-Section Analysis, 1973-97", World Politics, 53: 553-587

Klien, M., Leibrecht, M., and O. Onaran (2009), "Globalization and the Structure of Public Spending in the Western and Eastern EU Member States"

KOF Index of Globalisation (2011), http:/ / globalization.kof.ethz.ch/

Marshall, M. G., Jaggers, K. (2009), Polity IV Project: Political Regime Characteristics and Transitions, 1800-2009, Center for Systemic Peace and Colorado State University. http://www.systemicpeace.org/polity/polity4.htm

Meinhanrd, S., and N. Potrafke (2011), "The Globalization of the Welfare State Nexus Reconsidered", University of Konstanz Department of Economics Working paper No. 2011-27

Nickell, S. (1981), "Biases in Dynamic Models with Fixed Effects", Econometrica, 49: 14171426

Potrafke, N. (2009), “Did Globalization Restrict Partisan Politics? An Empirical Evaluation of Social Expenditures in a Panel of OECD countries", Public Choice, 140: 105-124

Report (2009). Responding to the Global Crisis. United Nations, New York.

Rodrik, D. (1998), "Why do more Open Economies have bigger Governments?", Journal of Political Economy, 106: 997-1032

Rugie, G. J. (1982), “International Regimes, Transactions, and Change: Embedded Liberalism in the Postwar Economic System", International Organization, 36: 379-415.

Ruoff, G., and L. Schaffer (2009), "Adding Another Level: Individual Responses to Globalization and Government Welfare Policies".

Sanz, I., and F. J. Velazquez (2007). "The Role of Ageing in the Growth of Government and Social Welfar Spending in the OECD", European Journal of Political Economy, 23: 917931

Shelton, C. (2007), “The Size and Composition of Government Expenditure”, Journal of Public Economics, 91:2230-2260

Sobhee, S. K. (2010), “Would Better Institutional Quality Contribute towards Reducing the Size of Government in Sub-Saharan Africa?", The Journal of Applied Economic Research, 4: 265-278

Tanzi, V. (2000), "Globalization and the Future of Social Protection". IMF Working Paper No. 12.

UNCTAD, WIR (2010). Investing In a Low Carbon Economy. United Nations, New York

United Nations Conference on Trade and Development (UNCTAD) Trade and Development

United Nations Statistical Division Dataset (2011), United Nations, New York

Wolfe, R., and M. Mendelssohn (2004), "Embedded Liberalism in the Global Era. International Journal, Spring 2004, pp 261-280

WTO Publication, Geneva

WTO World Trade Report (2009) Trade Policy Commitments and Contingency Measures.

WTO, World Trade Report (2011). The WTO and Preferential Trade Agreements: From Coexistence to Coherence. WTO 
Yanikkaya, H. (2003). Trade Openness and Economic Growth: A Cross-Country Empirical Investigation. Journal of Development Economics, 72(1): 57-89.

Yoon, J. (2009), "Globalization and the Welfare State in Developing Countries", Business and Politics, 11: 1-31

Zhuang, R., and W. Koo (2007), “Economic Growth Under Globalization. Evidence for Panel data Analysis", Paper Presented for Presentation at the American Agricultural Economics Association Annual Conference, Portland, Oregon. 


\title{
Globalization and Chagas Disease
}

\author{
João Carlos Pinto Dias ${ }^{1}$ and José Rodrigues Coura ${ }^{2}$ \\ ${ }^{1}$ Minas Gerais Academy of Medicine, Belo Horizonte \\ ${ }^{2}$ National Academy of Medicine, Rio de Janeiro \\ 1,2Oswaldo Cruz Foundation, \\ Brasil
}

\section{Introduction}

Globalization and Chagas Disease reflect several historic and social situations in Latin America (LA), with important influences and repercussions in the general society and between themselves. Originally, the disease was restricted to LA, with a socio-political context strongly marked by poverty, migration and the progressive enfeeblement of the State. (CNBB 2003, Macedo 1997, Schmunis 1997, Schmunis \& Dias, 2000). In general, Chagas Disease emerges from a bio ecological context, deeply engaged with the people way of living and with the natural history of its etiological agent, the protozoan Trypanosoma (Schizotrypanum) cruzi (T.cruzi), circulating among several mammalian reservoirs and intermediate vectors, occurring in different sylvan sceneries of the Continent. Later on, this trypanosomiasis began to affect the human being in the so called domestic cycle, involving man invasion of natural environment, people migration, very poor dwellings and multiple situations of anthropic character (Dias \& Coura, 1997, WHO, 2002). In the last Century, the globalization phenomena influenced important changes in the endemic landscape of the Region, as well as the "urbanization" and the international migration of infected individuals, so increasing the risk of human Chagas Disease (HCD transmitted by blood transfusion or congenital route in endemic and non endemic countries.

Considering its original characteristics, $\mathrm{HCD}$ affects primordially rural people living in poor dwellings colonized by the vector insect. This disease can be extremely severe, with expressive mortality among children in its acute phase and severe heart lesions in about 10$20 \%$ of chronic adult patients. Its medical and social impact presupposes mortality, high hospital and social security costs, absenteeism and labor incapacity (Akhavan 2000, BriceñoLeón 2007, Dias et al. 1994). It has been estimated the prevalence of 8-9 million of infected individuals in LA, still being al under transmission risk about 30-40 million, in the Region (Carlier et al 2002, PAHO 2006, WHO 2010). The principal strategies for HCD prevention consist in vector chemical control, housing improvement and rigorous serologic screening of blood donors, chiefly in endemic areas. There is not available a strategy for congenital transmission prevention, but diagnosis and early specific treatment of infected babies are strongly recommended. The treatment with the current available drugs (Nifurtimox, Benznidasole) is more effective among young people and recent transmission, but is being also recommended to indeterminate and initial chronic cases (Albajar-Viñas 2007, Dias 2009- 
B, WHO 2007). The correct and permanent medical assistance in chronic cases is also an important tool to improve the quality and quantity of life of chronic patients (Dias 2001, Sosa Estani 2007).

\section{Globalization in Latin America}

Social and political changes of the whole society have been very expressive in the last decades, when the process of globalization was intensified. In the poorest world regions like LA, the impact of globalization has been very clear in terms of HCD epidemiology, management and prevention (Almeida, 2002, Dias \& Borges Dias, 1979). Besides the great complexity in the structure and relations of the society, with the increasing of communications and human migration, globalization has produced an economical effect tremendously unequal among different countries and social groups. Such a situation has been understood as depending on economical speculations, international \& supra national competition and political management, inducing situations of immediatism, egoism and individualism. Regarding globalization and neglected diseases overcoming, Dr. Margareth Chan, Director-General of WHO, pointed out very clearly that "efforts to control neglected tropical diseases constitutes a pro-poor strategy on a grand scale. The logic has changed: instead of waiting for these diseases to gradually disappear as countries develop and living conditions improve, a deliberate effort to make them disappear is now viewed as a route to poverty alleviation that can itself spur socioeconomic development". A very common result of globalization in poor countries has been the weakening of Public Policies, with remarkable consequences concerning social relations and solidarity. Regarding the political and socio-economical aspects, the consequences are clearly visible: distrust and disenchantment concerning politicians, weakening of State structures and social commitment, emptying of the low economies (mainly at the rural sector) and disordered swelling of urban peripheral zones could be some examples (CNBB 2003, Dias 2007). Particularly, the logic of globalization and of the different ways of market economy have deeply affected the developing countries, emphasizing social inequalities and making very hard the possibilities of social upgrade for marginal populations (Schmunis \& Dias, 2000). In other words, Professor Aluizio Prata pointed some years ago, that globalization implies in domestic deregulation, commercial liberalization and privatization by means of foreign and volatile capitals, resulting in progressive social inequalities and unstable economy, generating several and complexes influences in Health Sector 1. Among other globalization main antecedents, the wave of Neoliberlism (emerged in the 1970 decade) had a great importance, particularly in terms of the principles of Minimum State and free International Market. The major critics against Neoliberalism have pointed that this movement only (basically) benefit the great world potencies and the multinational enterprises. Poor countries usually suffer with neoliberal policies, in terms of underemployment, low salaries, inequity and strong dependency of international capitals, as well of the global market ${ }^{2}$. Another controversial point concerns with privatization of state enterprises or social programs, considering that poor populations

\footnotetext{
1 Prata, A.R., 2003. Conference about Tropical Medicine in Brazil. Congress of the Brazilian Society of Tropical Medicine. Belém, Pará, Brazil, February, 2003.(apud Dias, 2007)

${ }^{2} \mathrm{Http} / /$ www. WikimediaFoundation.org , access in June 27, 2011
} 
generally depends on public policies and investments, e.g., Public Health. Considering LA, after two decades of Neo Liberalism, the World Bank evaluation in 2005 considered that the results (economic grow) remained much lower than it was formerly awaited ( Dias 2007, Schmunis 2007).

\section{Globalization and Chagas disease}

By different ways globalization has affected the epidemiology, the prevention and the management perspectives of HCD. The intensification of migration and the progressive changes in rural economy modified the epidemiological patterns of the disease, in terms of transmission and medical access. In the last decades, the disease arrived in urban areas and non endemic countries, so increasing not only the risk of transfusion transmission but also the medical and social demand of infected individuals. (Dias 2007, Schmunis, 1997). Today, in Brazil, it has been calculated that at least $75 \%$ of "chagasic" people are living in urban spaces, a proportion that seems to be lower in other countries such as Bolivia and Paraguay. With the reduction of demographic densities in rural endemic areas, for the next decades a decreasing of vector is naturally expected, as a "positive" effect of globalization. In addition, Latin American rural areas have been slowly modernized in terms of housing and production aspects, as a "macro" transformation from the classical subsistence way of life to an agro-industrial and grand scale economy. By another angle, the expansion of agriculture frontier in some places has making possible the spreading of infected individuals and even of vectors, a situation particularly existing in the Amazonian Region. For instance, infected individuals and the risk of transfusion transmisson of T. cruzi have been registered in Beni and Pando (Amazonic regions of Bolívia), as a consequence of people migration from classical endemic areas where mining economy has failed (Dias et al 2002).

\section{The global market, the role of the state and HCD}

Considering the social and political evolution in LA, the expansion of HCD also can be considered a reflex of the regional historic evolution, particularly in terms of production relations and equity. By the stand point of the infected population, globalization as much as market implications produced bad and good results, spreading the disease for non endemic areas, but also improving the conditions for the treatment and access of infected individuals. In general, the market is weak in terms of HCD. Chagasic individuals are always very poor and usually depend of State resources. From market standpoint, the main commercial profits (relatively low) result from laboratory diagnostic reagents and insecticides. In addition, private enterprises not always rely on LA governments, making difficult sometimes the governmental acquisition of products. A correlated situation in the past was related to international insecticide prices, with high disparity among the different countries. In this aspect, globalization has been benefic, mainly after the emergence of Southern Cone Initiative, with the assistance of $\mathrm{WHO}$ and $\mathrm{PAHO}$, inducing the equalization of product prices. The specific treatment also did not stimulate the development of new drugs, chiefly in terms of private industry. For instance, Roche considerate its product Benznidazole as "a social drug" some years ago, and gave the patent to Brazilian Government. In terms of electoral gains, also HCD shows to be inexpressive, since the poor chagasic population 
usually has not political density, being unable to carry out an effective social and political demand.

By the side of preventive actions, different situations have been observed in LA. First of all, vector control depends basically on chemical control and housing improvement. In this aspect, the poor communities depend almost exclusively of governmental programs, in other words, of political will. Notwithstanding, several observations and also mathematical models have shown that vector control can follows simply social improvement of the community, without a direct governmental intervention (Dias et al 1994, TDR 1981). Conversely, two very positive situations were reinforced by globalization. From the side of Blood Banks, since the 1980 decade, the proportion and the quality of HCD control have been highly improved in endemic and non endemic countries, following the global demand for AIDS control (Carlier et al 2002, Coura \& Dias 2009, Miles et al. 2004). Another situation arose in the 1990's, considering international cooperation for HCD control. Following the economic and political commitments of globalization, sub regional "Initiatives" emerged in the regions of Southern Cone, Andean Pact, Central America and Amazon, to face HCD in terms of vector and transfusion transmissions, with technical assistance of PAHO and WHO. It is opportune to consider that the control of HCD is achieving great success not only on the epidemiological and scientific context. Briceño-León (2007), Dias et al (2008), and Schmunis (2007) observe that the correspondent activities, successes and difficulties are completely integrated in the scenario of retrieval and rescue possibilities of LA, as a region that seeks its identity and its better political and social expression.

Thus, it is admitted that HCD and other so called "neglected diseases" have received and will continue to receive strong influences of the globalization process. Poor, isolated and marginal areas in LA will continue to exist, as remaining foci of disease prevalence and active transmission, depending on poverty and social problems ( Briceño-León 2007, Dias \& Borges Dias 1979, Dias et al, 1994, Schmunis 1997). The overcoming of these constraints highly depends on political will and of the reduction of inequity all over the world. As mentioned in a recent WHO document, "sustaining the progress made in controlling Chagas disease will depend on political commitmentand the retention of public health resources. Resolution WHA 63.20, adopted by the Sixt-third World Health Assembly in May 2010, urges Member States where the disease is both endemic and non-endemic to control all transmission routes (namely vectors, transfusion, organ transplantation and vertical and oral routes) and to integrate the care of patients with all clinical forma of the disease into primary health-care services. WHO has been requested to facilitate networking at the global level and to reinforce regional and national capacities on strengthening global epidemiological surveillance of the disease... to advance intersectoral efforts and collaboration; and to support the mobilization of national and international public and private financial and human resources towards the achievement of these goals, (WHO 2010)

\section{Globalization and medical attention}

In spite of some social improvement recently observed in parts of endemic countries, the majority of infected individuals probably will continue poor and with little possibilities to access all the benefits of the modern medicine. The major challenge, at this point, consist in to assure an integral and permanent medical attention and social security to these individuals, by means of an adequate social policy all over the world. This point reflects the 
classical dilemma between globalization and equity (Briceño-León 2009, Dias 2007). Regarding medical attention, enormous technical progresses have been achieved in terms of cardiac and digestive management of HCD, mainly resulting from the global advances of Medicine in other diseases (more involved with rich populations and better market). For instance, several drugs developed for cardiac failure and several arrhythmias of other etiologies, as well as for systemic hypertension, showed to be very useful in chronic Chagas heart disease. The same could be said regarding medical resources such as pace makers and cardiac implantable defibrillators or, in case of mega esophagus, the modern surgeries employing video laparoscopy. Multiple evidences have shown a clear correspondence between adequate and precocious medical attention and the survival and better life conditions of chronic chagasic individuals. In Brazil, Argentine Chile and Venezuela, for instance, the age of death is becoming significantly higher than in two or three decades ago, in parallel with the decreasing of severe chagasic cardiopathies in infected individuals (Albajar Viñas 2007, Dias 2007, Sosa Estani 2007).

\section{The visibility of HCD and its trends in a globalised world}

Considering the reduction of transmission, the visibility of HCD tends to decrease as well as its political priority. In addition, the emergence of other public health problems such as dengue fever, influenza and epidemic AIDS will contribute to resources deviation from HCD programs (Dias, 1995, Schmunis \& Dias, 2000). Considering migration and urbanization, HCD during some years tends to call attention in urban spaces and non endemic countries (Albajar-Viñas 2007, Schmunis 2007). In terms of large scale economy, anthropic actions and a slow improvement of medical attention for chagasic patients, the future sceneries of HCD in endemic countries could be summarized as follows (Barretto 1979, Dias 1988, Dias \& Schofield 1999, Forattinni 1980):

- Main echological modifications: reduction and condensation of wild ecotopes (mosaic of sceneries and concentration of vectors, reservoirs and parasites)

- Progressive reduction and focalization of domiciliated vector population;

- Still existing risks of new vector foci in areas of agricultural frontiers (Amazonic Region e.g.);

- Reduction of rural demographic densities, resulting from sector modernization and massive implementation of agro-industries (economic scale)

- Increasing of marginal population in urban centers, with two principal consequences: a) Arrival of infected people from endemic areas, so increasing the risk of HCD transmission in blood banks as well as the theoretical betterment of patients access to medical care, and, b) The possible arrival of triatomines in urban houses, passively carried $^{3}$

- $\quad$ The facement of transfusion transmitted HCD all over the world;

- The progressive decreasing of infected individuals, reflecting in the reduction of risks both in congenital and transfusional transmission (progressive reduction of infected pregnant women and blood donors);

\footnotetext{
3 - In general, significant colonies of carried triatomines do not use to prosper in big towns of Brazil, Argentina and Venezuela. Nevertheless important colonies have been detected in San José (Uruguay), Cochabamba, Sucre and Santa Cruz (Bolivia), Guayaquil (Ecuador) and Tegucigalpa (Honduras).
} 
- The progressive reduction of severe acute and chronic cases, with the consequent decreasing of disease visibility;

- The expectable reduction of resources for HCD control and research;

\section{Macro policies and organization}

In terms of political strategy, these points must remain in the agenda of WHO and of the governments of endemic countries by the next two or three decades, to keep alive the interest and the priority of Chagas disease and its control. National and regional programs must be adapted to the decentralization of health systems, another universal consequence of globalization (Schmunis \& Dias 2000). New non-governmental partners such as Mèdicins Sans Frontiéres, JICA, IDRC, ECLAT and others are showing to be very effective and opportune to face HCD in endemic and non endemic countries. The recent institution of a global scientific network to face HCD by WHO Neglected Diseases Department is very opportune 4 . For the particular case of LA, it is very important to keep Pan American Health Organization in the coordination of the regional Initiatives (Dias et al 2008, OPS 2006).

\section{The role of the remaining sylvatic cycle of $T$. cruzi}

In terms of the next future, the wild cycles of the parasite will have an important role in the maintenance of HCD. It is expectable that with the improvement of domestic cycles control in endemic areas, the major risks of HCD incidence will depend of sylvatic triatomines and wild trypanosome populations. The enzootic cycle of T. cruzi also has some implications with globalization. Human intensive movements, intensive modifications of sylvatic ambient (macro projects considering deforestation, mono cultures, cattle and plant protection pesticides) are clearly changing the general landscape since America discovery. In the next decades, the existing domestic cycles of HCD vector transmission will remain in those more isolated and poor rural zones, with lower taxes of social and ambient changes. The future will be marked by the progressive reduction of some classical species such as $T$. infestans and $R$. prolixus, besides a residual peridomestic infestation by ubiquist species $(T$. dimidiata, T. pseudomaculata and T. brasiliensis, e.g.). Also, due to anthropic affaires, wild species such as P.geniculatus, R. pictipes, T. rubrofasciata and T. picturata could occasionally invade human dwellings, eventually stablishing little colonies and being able to transmit HCD . This is a typical situation requiring an effective epidemiological surveillance. The same can be said for some emergent foci of T. infestans, when passively carried to new áreas very far of its natural áreas of dispersion (Amazon, for instance). Until now, strong evidences of a high risk of domiciliation of sylvatic T. infestans in its areas of occurrence (Bolivia, Chile, Chaco) seem do not exist (Dias 2009-A, Moncayo \& Silveira 2009, Noireau 2009, Schofield et al. 2006). Another situations concerns with sporadic invasion of wild triatomines in dwellings located nearby sylvatic ambients, eventually resulting in HCD

\footnotetext{
${ }^{4}$ The basic structure of this network involves the following components (Albajar Viñas \& Dias 2009): to strength epidemiological surveillance and information systems (communities, vectors, cases, and other factors relevant to transmission), to prevent transfusion and organ transplantation transmission of $T$. cruzi in endemic and non-endemic countries (Policies and regulations), to achieve a consensus on diagnostic tests for screening and diagnosis of the infections and to identify improvements needed, to expand prevention and control of congenital transmission and case management of congenital and noncongenital infections in endemic and non-endemic countries. .
} 
transmission, such as in Panama (with R. pallescens), in Amazon (with R. pictipes), in Brazil Southwest (with T. vitticeps) and in Uruguay and Rio Grande do Sul (with T. rubrovaria). Another related speculation concerns with the pathogenesis of the "wild strains" of the parasite in HCD, considering mainly the T. cruzi I and III groups (Coura \& Dias 2009, Zingales et al 2009). As a conclusion, for the future, anthropic actions and globalization will be associated much more with the enfeeblement and focalization of the sylvatic cycle of $T$. cruzi than with its exacerbation (Dias et al 2008, Zingales et al 2009). Several examples can be remembered, showing strong linkages between HCD and globalization mainly involving the evolution of the poductive system, spatial occupation and human movements, such as (Dias \& Coura 1997, Dias et al. 2002, Schmunis 2007):

- Deforestation resulting of a strong wood market and the expansion of agro industries in endemic areas;

- The extensive use of pesticides in agro-industrial projects;

- The expansion of the use of electricity and industrial machinery, interfeering with wild triatomine behavior and influencing the rural demography;

- The progressive reduction of mammal reservoirs of the parasite, resulting from deforestation, pesticides and extensive monocultures;

- Progressive changes in the productive model, priorizeng agro industries instead the classical strategy of family subsistence;

- In the same logic, the dominant market and scale economy, overlaping classical micro economies;

- The global implementation of modernization factors, specially automatization, robotisation and housing improvement.

\section{The role and trends of urbanization}

The "urbanization" of HCD has been occurring all over the Continent, mainly after the second half part of the Century XX. In strict correspondence with globalization, the ruralurban migration was caused by several changes in the productive system, specially industrialization and weakening of the traditional rural economy. Concerning HCD the more visible consequences concern with the arrival of chronic infected individuals in urban centers, increasing the demand for medical \& social security assistance, as well as the risk of transfusional transmission. The access to medical attention certainly has been improved in the urban context, particularly in terms of more complexes interventions, mostly depending on public health sector.

\section{The medical management Chagas Disease in a globalised world}

Presently, all over the world, the increasing life expectance has been a great tendency of the population, resulting of better medical and social assistance. The management of HCD in old people requires new knowledge and practices in terms of disease physiopathology and of the superposition of several other medical problems occurring in elevated age groups, such as hypertension, diabetes, coronary diseases, Parkinson, physiological denervation etc. In such a scenery, the medical management of HCD involves three major challenges, highly depending of the political and social processes, as well as with the question of inequity (Albajar-Viñas 2007, Dias 1995): 
a. The improvement of medical expertise for HCD management in chronic cases all over the world, mainly in terms of the Primary Health Care level. In corollary, the improvement of drugs and other medical proceedings is highly desirable, considering the elder patients and the superposition of other chronic and degenerative diseases;

b. The betterment of medical and social security systems in order to assure adequate access and coverage for all infected individuals, in endemic and non endemic areas;

c. To ensure political and administrative conditions to maintain at least two decades more the medical expertise able to manage adequately the infected individuals;

Other predictable situations could be emphasized for HCD management at medium term, all of them being correlated with globalization: First of all, globalization has been a strong stimulus for the advance of medical security enterprises, able to increase the access of a number progressively higher of infected people to medical attention. The specific treatment is another important question, because it has been more and more indicated for chronic patients (because of its possibility to minimize and/or to prevent severe clinical conditions, specially advanced heart disease and sudden death). The basic problems considering this subject remain in diagnosis access, medical expertise and drug availability, besides a good treatment adherence (Albajar-Viñas 2007, Dias 2001, Dias et al. 2008, Sosa Estani 2007). In chronological terms, the best moment to improve specific treatment for chronic cases of HCD has been estimated from now until one or two decades more, a time when the number of young infected individuals is still high. After 2020, with the progression of transmission control and the natural aging of infected people, the demand for specific treatment will decrease significantly. In pragmatic terms, globalization tends to facilitate specific treatment, bettering the availability of drugs around the world, chiefly with the assistance of health and humanitarian institutions such as WHO, PAHO, DNDI and MSF (WHO 2010).

\section{Globalization and research on HCD}

Scientific development is very important to face HCD, mainly in Latin America.

Since its discovery, American Trypanosomiasis has showed to be an excellent model of research and scientific development in several correlated aspects, such as the parasite (Biochemistry, Genetics, Cell Biology), the disease (Physiopathology, treatment, diagnosis), the Epidemiology (incidence, prevalence, morbidity, social impact), the control (strategies, tools, political aspects) etc. Research, meetings, international networks and publications and scientific development agencies have been multiplied all over the word, mainly from the 1940 decade, an epoch when HCD became internationally recognized (Dias \& Schofield 1999). Particularly in the last forty years the "universal" and internationally shared research on HCD had an exponential growth, resulting in several practical advances, as well in scientific development of endemic countries (Coura 1997, Dias \& Schofield 1999). This aspect must be considered a very significant aspect of globalization (Dias 2007, Schmunis 2007). As a consequence, some correlated aspects of HCD management and research, such as the development of new drugs and combined drug strategies, the possible use of stem cells etc. Considering this particular aspect, globalization can represent an extraordinary element of help, by means of integrated universal internet programs and nets for HCD treatment and management. The most remarkable examples have been the international Benefit trial with Benznidazole in chronic cases of Chagas cardiomyopathy and the already 
existing internet sites for global discussion of disease management (Dias \& Schofield 1999, Marin Neto el al. 2009, WHO 2010).

\section{Globalization, social security, prevention and educational aspects}

In general terms, the great advance occurred in the scenery of the fight against HCD was the implementation of the intergovernmental control initiatives, launched in Brasilia, 1991 (Coura \& Dias 2009, Dias et al. 2002, OPS 2006, WHO 2002, 2010). This very successful movement can be considered a resultant product of the globalization in terms of the development of a more agile and less bureaucratic international market, but also as a strong determination and political pressure from the side of Latin American scientific community (Dias \& Schofield 1999, WHO 2010). As seen above, the predictable reduction of chagasic people will progressively minimize the costs of social security. The proportion of severe cases requiring social benefits tends to be reduced, chiefly because of the mortality occurred in previous years and the expectable betterment of disease medical care. By the side of blood banks, globalization has been very opportune in order to maximize the rules and strategies concerning blood donors all over the world, as well as to optimize the distribution of standardized kits and reagents (Dias 2007, Schmunis 2007). By the angle of vector control, the main challenge will be the maintenance of a permanent epidemiological surveillance, with special attention to peridomestic triatominae foci (Dias 2009-A, Schofield et al. 2006). As an indirect result of globalization, this task has been transferred to local (municipal) health services, thus generating the extinction or deactivation of the classic national institutions like FUNASA and Malariologies. The decentralized scheme has some important advantages such as local decisions, rapid responses and better social control, but also implies the risk of low quality and epidemiological loosing, as well as of the reduction of interest and technical expertise. The best thing to do, in this case, seems to be the reinforcement of national and regional technical staffs in order to ensure coordination, technical training and regular supervision of local teams (Dias et al 2008 Schmunis \& Dias 2000). By the side of housing improvement, the ancient national programs for rural dwellings improvement tend to disappear, because of the social and productive changes in countrified regions. As seen above, rural demography is rapidly decreasing and no market interest exists to improve rural houses in poor and economically depressed areas. In the same way, very little hope is expected in terms of the improvement of big national programs for people education in terms of HCD control and surveillance (Dias \& Schofield, 1999, Schmunis \& Dias, 2000). This is a very important aspect, since the modern surveillance against the vectors of HCD is primordially based on the effective community partipation with must be stimulated and oriented by educational activities (Dias 1995, Schmunis \& Dias 2000, WHO 2002). Facing these aspects, globalization is presenting positive (facilitators) and negative aspects. The main protagonists of surveillance are several and must be integrated at local and regional levels. The financial involved aspects are complexes and presuppose clear and sustainable public policies (Schmunis \& Dias, 2000).

\section{Globalization and macro policies of health}

At the macro political side, the question of globalization and HCD involves two basic situations, according social scientists such as Max Neef, Pedro Demo and Paulo Freire (In Dias, 1995): 
a. In Latin America, the political macro structures like governments and political parties require historical compromises and are charachterized by immediatism, corruption and the lack of ethical references;

b. From the programs and projects of real interest for the communities, such as the HCD control, a new collective consciousness can be reinforced, resulting several possibilities of a more healthful and consequent social reality.

In this way, the global effort concerning the persecution of non corruption and social equity is also considered as a fundamental challenge for HCD and other neglected disease overcoming. In other words, considering mainly Latin America, the mismanagement of globalization and inequity on endemic countries make to appear several and severe questions of political management, governmental administration and citizenship, according many Authors. The future claims for a sword, well organized and efficient State, at national, regional and municipal levels, besides a conscious and participative population

(Almeida, 2002, Macedo, 1997, Schmunis \& Dias, 2000). Concerning the fight against HCD, in particular, national and international efforts must to be made to reach specific preventive and curative actions progressively integrated with other Health and Social sectors and activities such as Family Medicine, Primary Health Care, Immunization, Formal Education, Social Security etc. (Dias 2007, Schmunis \& Dias 2000, WHO 2010). More over, following the new global wave of social control, the theme of HCD must be compulsorily inserted in the regular local, regional and national Health Conferences, consolidated in Brazil since 1988 and now being pursued all over Latin America, as a consequence of the new Policies for Health (Dias 2007).

\section{The role of scientific community}

Since its discovery, the fight against HCD has been progressively embraced by the researchers, beginning with the own Carlos Chagas. Besides the elucidation of several medical and biologic aspects of the disease, Chagas always was claiming for its recognition, its treatment and its prevention, stimulating his colleagues and international scientists to work in these themes and to advocate beyond everything else the overcoming of this so hard medical and social problem (Chagas 1911, Dias 1995, Dias \& Schofield 1999). Very soon it became clear that the more vulnerable point for disease coping was prevention, initially in terms of vector control (insecticides, housing improvement), and after blood banks control. Scientists such as Souza Araujo, Ezequiel Dias, Romaña, Emmanuel Dias, Mazza, Pedreira de Freitas, Nussenzweig, Schenone and others developed the necessary strategies and tools between 1918 and 1950, but very soon it became clear for them that the implementation of regular programs would depend of political will and of the mobilization of public financial and human resources. Among others, Dias, Freitas and Pinotti (Brazil), Torrealba and Pifano (Venezuela), Abalos, Romaña and Cichero (Argentina), Neghme and Schenone (Chile), were true scientific pioneers in the task of calling attention and commitment of their governments for Chagas program implementation. In 1958, E. Dias and Fred Soper were the protagonists of a memorable international discussion, resulting in the definitive engagement of PAHO and WHO in the challenge of HCD. In 1959, Carlos Chagas Filho organized a first International Congress on HCD, where E. Dias and A. Neghme declared that T. infestans could be eliminated from domestic foci. By the 1960's, a regular program was launched in São Paulo State (Brazil), involving many scientists and serving as a model for other regions. 
In 1979, another congress in Rio de Janeiro called the attention of João Figueiredo, the President of Brazil, who determined the prioritization of the National Program. Since 1990, a great scientific pressure on Argentina, Uruguay and Brazil governments resulted in the memorable launching of the Southern Cone Initiative against HCD, very soon followed by similar initiatives in Andean Pact, Central America and Amazon regions (Dias \& Schofield 1999, WHO 2002). Some years more, in an international scientific meeting promoted by WHO, in Geneva was launched the Initiative for HCD control and management in non endemic countries (WHO 2010). And since 2008, Argentine and Brazilian scientists have been stimulating their governmental authorities to put together the technicians of the Ministries of Education and Health in order to ensure better University curricula and regular formal education about HCD in endemic regions. In general terms, the scientific community involved with HCD has been consistently recognized as the most important defensor of chagasic people (Albajar-Vinas 2007, Briceño Leon 2007, Dias \& Dias 1994, Dias 2007, Schmunis 2007)

\section{Final remarks}

Chagas Disease has been a concrete and impacting social and medical problem in LA, with multiple aspects associated with iniquity and globalization. In spite of different financial and political constraints, HCD has been controlled, remaining two or three decades more of program consolidation and medical attention for infected people in the Region. This is a particular task for LA, not involving important global markets. Much more, HCD requires a main action of the State, as the basic social provider for the poorest citizens. The main strategies to face HCD have showed to be considerably effective at medium \& long term, depending on global people social improvement, as well as on transmission control and medical attention. Considering these points, the persistence of iniquity and other negative aspects of globalization have been hard challenges to be overcome in endemic areas. For instance, globalization has stimulated the State shrinkage and the decentralization of the health sector, both these aspects representing a high risk of deterioration of HCD programs in poor regions (Schmunis \& Dias 2000). The transition of Health Sector all over LA has been slow and complicated, in spite of its highly stimulant theoretical approach. Contextual difficulties and inequities exist but must be overcome by an universal effort involving people, governors and scientists, because HCD constitutes an important public health problem and because several examples showed that its control is an attainable goal. At the time of globalization, the expected success of the Initiatives and the consequent epidemiological results can represent and stimulate a new and positive time in the search for the Continent political coherence and self reliance (Almeida 2000, Briceño- León 2007, Dias et al.1994, Macedo 1997).

\section{References}

Albajar-Viñas P, 2007. Organización y estructura de la atención médica en la infección/enfermedad de Chagas. Lecciones aprendidas en 15 proyectos. In $\mathrm{La}$ enfermedad de Chagas a la puerta del conocimiento de una endemia americana ancestral. OPS/CD/426-06, Washington, pp. 97-108.

Almeida C., 2002. Reforma de sistemas de servicios de salud y equidad en América latina y el Caribe.: algunas lecciones de los años 80 y 90. CAD. S. Públ. 18: 905-926 
Akhavan D, 2000. Análise de custo-efetividade do programa de controle da doença de Chagas no Brasil. Brasília, OPAS/OMS, 271 p.

Barretto MP, 1979. Epidemiologia. In Brener Z, Andrade ZA (Orgs) Trypanosoma cruzi e Doença de Chagas, Rio de Janeiro, Guanabara Koogan ED. pp. 89-151.

Briceño-León R, 2007. La enfermedad de Chagas y lãs transformaciones sociales em America Latina. In La enfermedad de Chagas a la puerta del conocimiento de una endemia americana ancestral. OPS/CD/426-06, Washington, pp. 219-230.

Carlier Y, Dias JCP, Luquetti AO, Honteberye M, Torrico F, Truyens C 2002. Trypanosomiase Américaine ou maladie de Chagas. Encyclopedie MedicoChirurgicale. (Maladies infectieuses). Elsevier, Paris, 8-505-A-20.

Chagas CRJ 1911. Moléstia de Carlos Chagas ou thyreoidite parasitária. Nova doença humana transmitida pelo barbeiro (Conorhinus megistus). II Conferência na Academia Nacional de Medicina, em agosto de 1911. Tipografia Leuzinger, Rio de Janeiro, 20 p.

CNBB (Conferência Nacional dos Bispos do Brasil), 2003. Diretrizes Gerais da ação evangelizadora da Igreja no Brasil, 2003-2006. Documentos da CNBB, 71. São Paulo, Edições Paulinas, 139 p.

Coura JR 1997. Síntese histórica e evolução dos conhecimentos sobre a doença de Chagas. In: Clínica e Terapêutica da Doença de Chagas. Uma abordagem prática para o clínico geral. (J.C.P.Dias \& J.R.Coura, orgs.), pp. 453-468, Rio de Janeiro, Editora Fiocruz.

Coura JR , Albajar PV 2010. Chagas disease: a new worldwide challenge. Nature Outlook 465: s6-s7

Coura JR, Dias JCP 2009. Epidemiology, control and surveillance of Chagas disease - 100 years after its Discovery. Mem. Inst. Oswaldo Cruz 104 (Suppl. 1): 31-40.

Dias JCP, 1988. Rural resource development and its potential to introduce domestic vectors into new epidemiological situation. Rev. Arg. Microbiol. 20 : 81-85.

Dias JCP, 1995. Aspectos políticos em doença de Chagas. Rev. Soc. Bras. Med. Trop. 28 (Sup. 3):41-45.

Dias JCP, 2001. Prevenção secundária em doença de Chagas. Rev. Soc. Bras. Med. Trop. 34 (Supl. 3): 24-36.

Dias JCP, 2007. Globalização, inequidade e doença de Chagas. CAD. S. Púb. 23 (suppl.1): S13-19

Dias JCP 2009-A. Elimination of Chagas disease transmition: perspectives. Mem. Inst. Oswaldo Cruz 104 (Suppl. 1): 31-40

Dias JCP 2009-B. Longitudinal Studies on Human Chagas Disease in Bambuí, Minas Gerais, Brazil. Rev. Soc. Bras. Med. Trop. 42 (suppl.II): 61-68.

Dias JCP \& Borges Dias R, 1979. Aspectos sociais, econômicos e culturais da doença de Chagas. Ciência e Cultura, 31: 105-124.

Dias JCP, Coura JR, 1997. Epidemiologia. In: Clínica e Terapêutica da Doença de Chagas. Uma abordagem prática para o clínico geral. (J.C.P.Dias \& J.R.Coura, org.), pp. 33-66, Rio de Janeiro, Editora Fiocruz.

Dias JCP , Schofield CJ, 1999. The evolution of Chagas Disease (American Trypanosomiasis) Control after 90 years since Carlos Chagas discovery. Mem. Inst. Oswaldo Cruz 94 (suppl. 1): 103-122.

Dias JCP, Briceño-León R \& Storino R, 1994. Aspectos sociales, económicos, políticos, culturales y psicológicos. In: Enfermedad de Chagas. (R. Storino \& J. Milei, org.) pp. 525-556, Buenos Aires, Doyma Argentina. 
Dias JCP, Prata AR \& Schofield C.J., 2002. Doença de Chagas na Amazônia: esboço da situação atual e perspectivas de prevenção. Rev. Soc. Bras. Med. Trop. 35: 669-678

Dias JCP, Machado, EMM, Fernandes AL \& Vinhaes MC, 2000. Esboço geral e perspectivas da doença de Chagas no Nordeste do Brasil. CAD. S. Públ. 16 (Sup. 2): 13-34.

Dias JCP, Prata AR, Correia D, 2008. Problems and perspectives for Chagas Disease control: in search of a realistic analysis. Rev. Soc. Bras. Med. Trop. 41: 193-196.

Dias JCP, Silveira AC, Schofield CJ 2002. The impacto f Chagas Disease in Latin America; a review. Mem. Inst. Oswaldo Cruz 97: 603-612.

Forattinni OP, 1980. Biogeografia, origem e distribuição da domiciliação de triatomíneos no Brasil. Rev. S. Públ. São Paulo 15: 265-299

Macedo CG, 1997. Notas para uma história recente da Saúde Pública na América Latina. Brasília, OPAS/bra/hrd/005/97, $106 \mathrm{p}$.

Marin Neto JA, Rassi Jr. A, Avezum Jr. A et al, 2009. The BENEFIT trial: teting the hypothesis that trypanocidal therapy is beneficial for patients with chronic Chagas hearth disease. Mem. Inst. Oswaldo Cruz 104 (Suppl. 1): 319-324.

Miles MA, Yeo M, Gaunt MW, 2004. Epidemiology of American Trypanosomiasis. In: Maudlin I, Holmes PH, Miles MA (orgs.) The Trypanosomes. London. CABI Publishing. P. 243-251

Moncayo A, Silveira AC, 2009. Current epidemiological trends for Chagas disease in Latin America and future challenges in epidemiology, surveillance and health policy. Mem. Inst. Oswaldo Cruz 104 (Suppl. 1): 31-40.

Noireau F, 2009. Wild Triatoma infestans, a potential threat to be monitorized. Mem. Inst. Oswaldo Cruz 104 (Suppl. 1): 60-64.

OPS (Organización Panamericana de la Salud) 2006. Estimación cuantitativa de la enfermedad de Chagas en las Américas. OPS/HDM/CD/425-06, Montevideo, 28 p.

Schmunis, GA, 1997. Tripanossomíase americana: seu impacto nas Américas e perspectivas de eliminação. In: Clínica e Terapêutica da Doença de Chagas. Uma abordagem prática para o clínico geral. (J.C.P.Dias \& J.R.Coura, org.), pp. 11-24, Rio de Janeiro, Editora Fiocruz.

Schmunis GA, 2007, Enfermedad de Chagas en un mundo global. In La enfermedad de Chagas a la puerta del conocimiento de una endemia americana ancestral. OPS/CD/426-06, Washington, pp. 251-267.

Schmunis GA. The globalization of Chagas disease. ISBT Science Series. 2007;2(1):6-11.

Schmunis GA, Dias JCP, 2.000. La reforma del sector salud, descentralización prevención y control de enfermedades transmitidas por vectores. Cad. S. Públ. 16 (Sup. 2): 117123.

Schmunis GA, Yadón ZE 2010. Chagas disease: A Latin American health problem becoming a world health problem. Acta Trop., 115(1-2):14-21.

Schofield CJ, Jannin J, Salvatella R, 2006. The future of Chagas disease control. Trends in Parasitology 22: 583-588.

Sosa Estani S 2007. Aspectos asistenciales e inseción de la enfermedad de Chagas en Atención Primaria de la Salud. In La enfermedad de Chagas a la puerta del conocimiento de una endemia americana ancestral. OPS/CD/426-06, Washington, pp. 109-118.

TDR (WHO, UNDP, WB) 1981. Description of the final simulation model, including a listing of the computer program and the data files. Workshop about Mathematical 
Computer Models in the Control of Chagas' Disease, Rabinovich J (Ed.), IVIC, Caracas.

VIEIRA, C., 2002. Globalización, comercio internacional y equidad em materia de salud. Rev. Panam. S. Púb. 11: 425-429.

WHO (World Health Organization), 2002. Control of Chagas Disease. Geneva, WHO Technical Report Series. No. 905, 91 p.

WHO 2007. American Trypanosomiasis and Neglected Diseases. http://www.who.int/neglected_diseases/en/ (accessed in June, 27 2011)

WHO 2010. Control and prevention of Chagas disease in Europe. Report of a WHO informal consultation (jointly organized by WHO headquarters and WHO Regional Office for Europe. WHO/HTM/NTD/IDM/2010,1, Geneva.

WHO 2010. Working to overcome the global impact of neglected tropical diseases. First WHO report on neglected tropical diseases. World Health Organization, Geneva.

WORLD BANK 2005. The World Bank's Economic Growth in the 1990s: Learning from a Decade of Reform. Washington.

Zingales B, Andrade SG, Campbell DA, Chiari E et al 2009.A new consensus for Trypanosoma cruzi intraspecific nomenclature: second revision meeting recommends $\mathrm{TcI}$ to $\mathrm{TC}$ VI. Mem Inst Oswaldo Cruz 104:151-154. 



\section{Edited by Zlatan Delić}

The book "Globalization and Responsibility" consists of 8 chapters. The chapters in the book offer a decentered and dynamic terminology. They show that globalization consists of not only an objective process, but also of a lot of statements that define, describe and analyze the different experiences of the process. The chapters are written by authors and researchers from different academic disciplines, cultures and social contexts, therefore different experiences and scientific analyses on the consequences

of globalization have been unified, starting from the multicultural and social epistemology to ethics of responsibility. Each chapter can be read separately, but in a complex, interconnected global universe of intertextuality of our world.

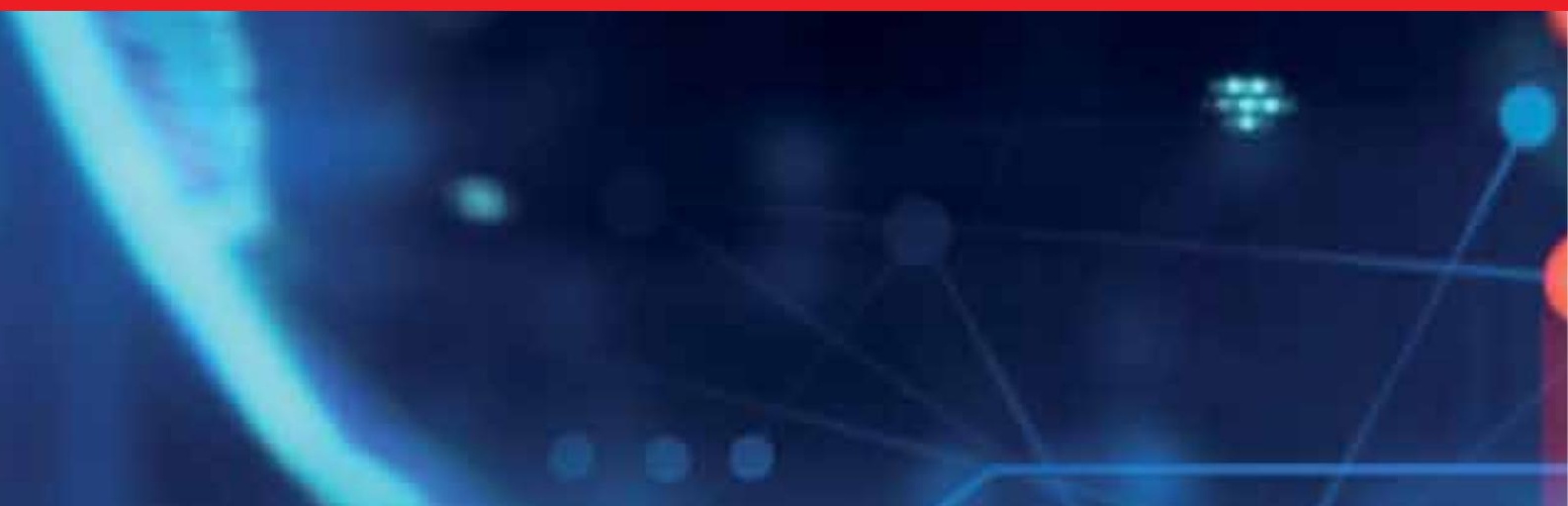

